\title{
The Impact of Mowing and Flooding on the Diversity of Arthropods in Floodplain Grassland Habitats of the Lower Oder Valley National Park, Germany
}

\author{
Dissertation \\ Zur Erlangung des Doktorgrades \\ der Mathematisch-Naturwissenschaftlichen Fakultäten \\ der Georg-August-Universität zu Göttingen
}

vorgelegt von

Judith Rothenbücher

aus Lahnstein

Göttingen, Dezember 2004 
D7

Referent:

Prof. Dr. M. Schaefer

Korreferent:

Prof. Dr. U. Ehlers

Tag der mündlichen Prüfung: $\quad$ 27. Januar 2005 


\section{Contents}

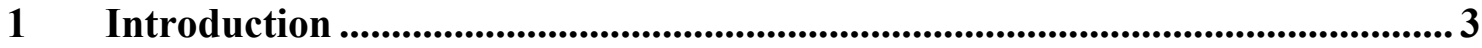

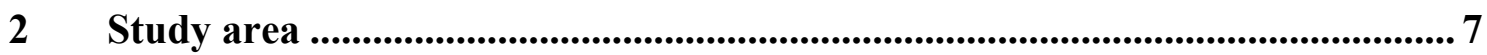

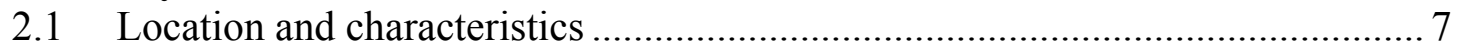

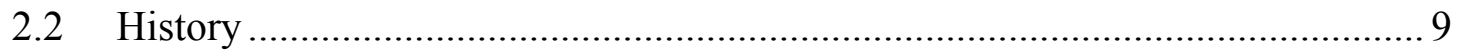

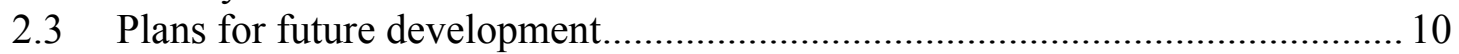

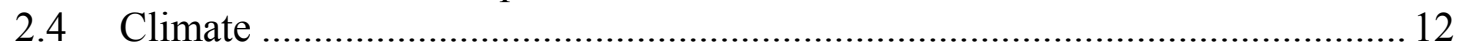

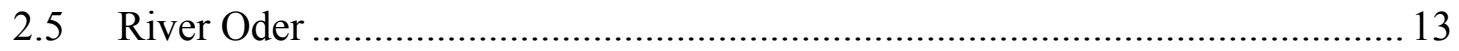

3 Impact of mowing and flooding on the diversity of

plant- and leafhoppers ................................................................................................... 15

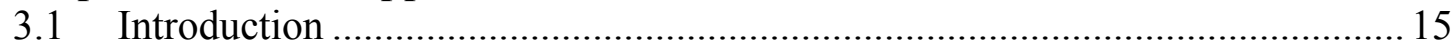

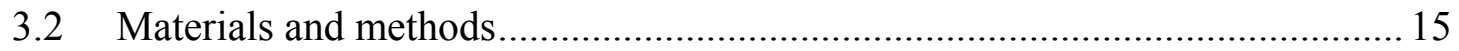

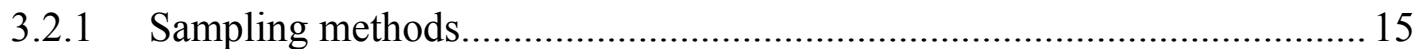

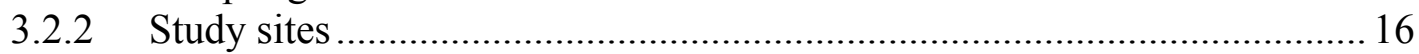

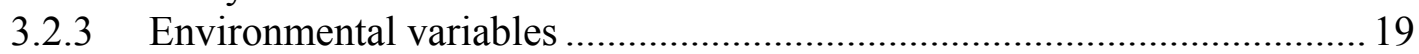

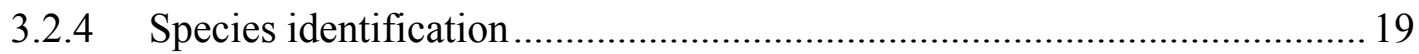

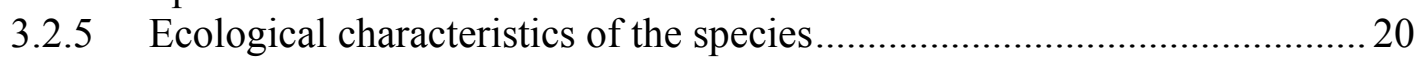

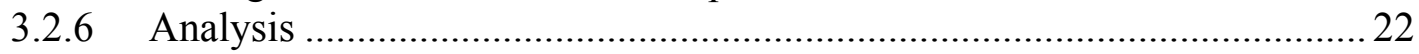

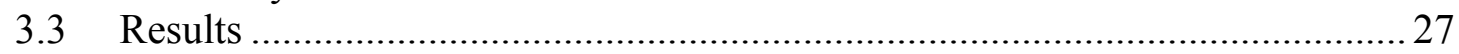

3.3.1 Ecological characteristics of the Auchenorrhyncha community ................ 27

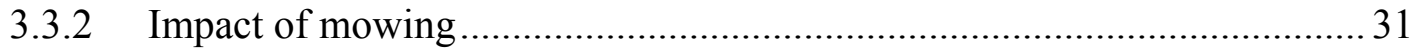

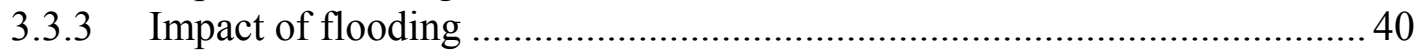

3.3.4 Differences in the impact of flooding on the communities

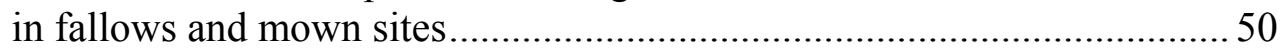

3.3.5 Similarity of species composition between different sites......................... 54

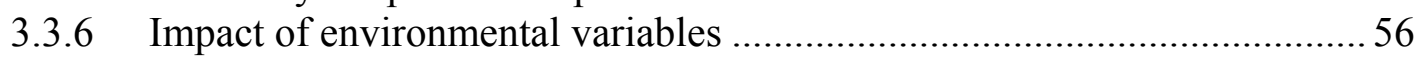

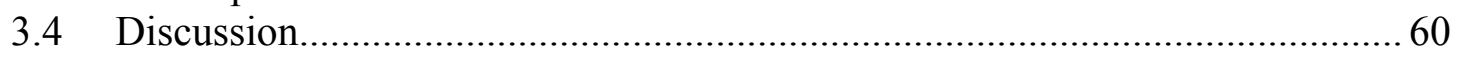

3.4.1 Impact of mowing and flooding on species numbers,

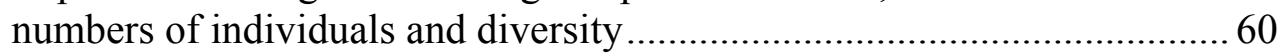

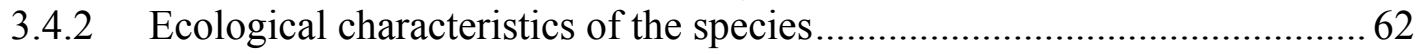

4 Submersion tolerance in floodplain arthropod communities.........................66

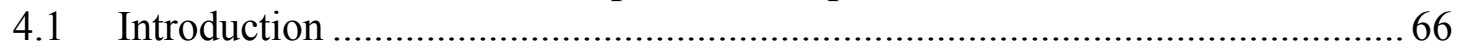

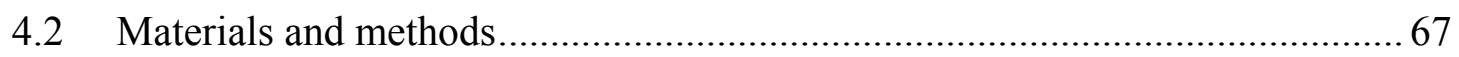

4.2.1 Colonisation experiment and sampling procedure...................................6 67

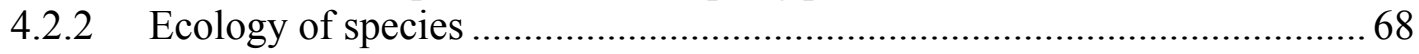

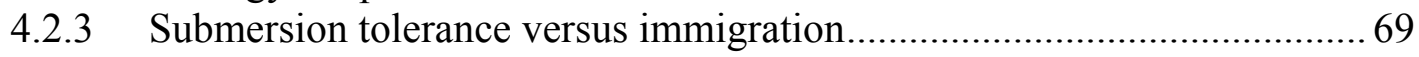

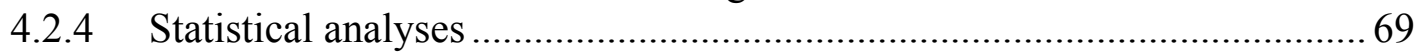

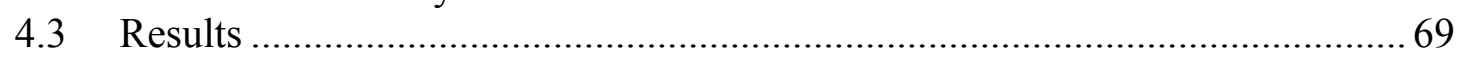

4.3.1 Ecology of species: submersion tolerance versus immigration .................. 70

4.3.2 Impact of flooding on the distribution of submersion tolerant and immigrating species ................................................................ 75

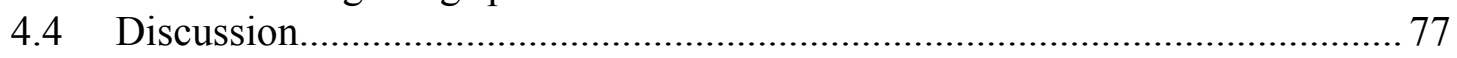

4.4.1 Ecology of species: Submersion tolerance versus immigration ................. 77

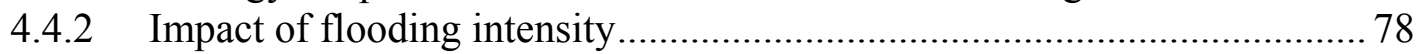


5 Conservation management of target species or conservation of processes - Winners and losers of two different

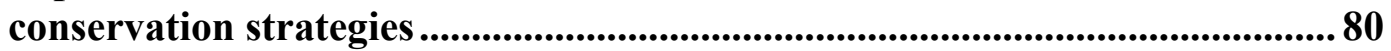

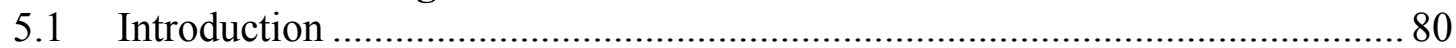

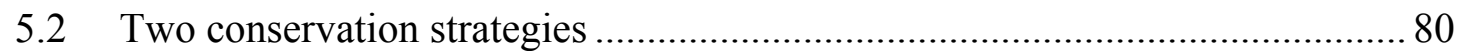

5.3 Three case studies from the Lower Oder Valley National Park, Germany ....... 82

5.3.1 Impact of mowing on the suitability of grassland as habitat of corncrakes (Crex crex) in the Lower Oder Valley National Park.............. 82

5.3.2 Impact of flooding on the amphibian community ................................... 83

5.3.3 Consequences of changes in flooding and land use for the conservation of insects in the Lower Oder Valley National Park .................................... 83

5.4 Discussion: Winners and losers of the two conservation strategies .................. 86

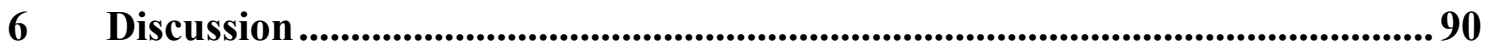

6.1 Impact of mowing and flooding on the diversity of arthropods ....................... 90

6.2 Conclusions for the conservation of arthropods in floodplain grassland .......... 94

6.3 Evaluation of the plans for future national park development ........................ 97

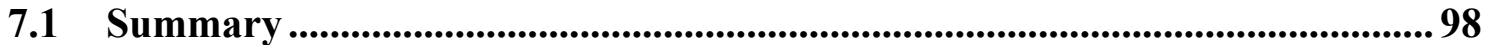

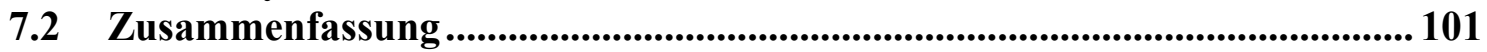

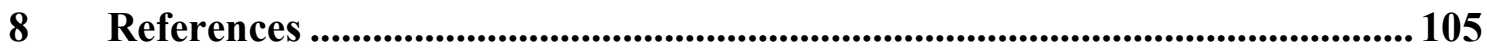

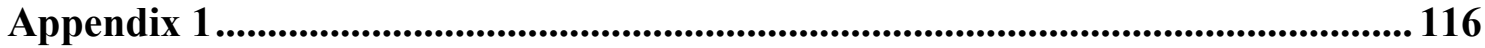

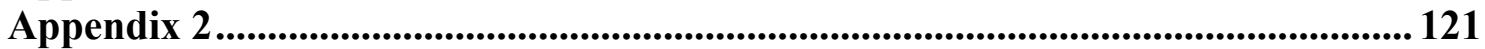

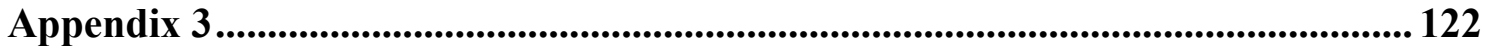

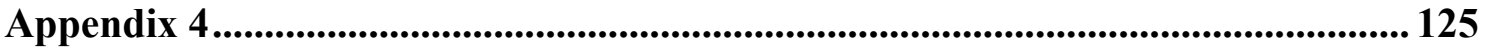

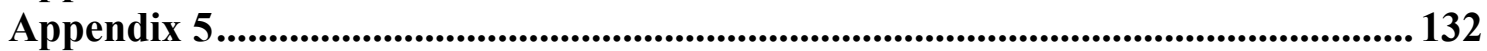

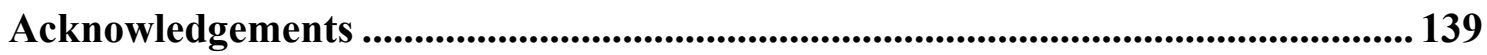

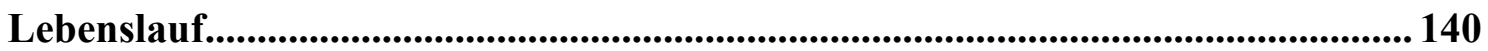




\section{Introduction}

Floodplains are found along streams or rivers and are characterised by regular inundation during periods of flooding. Grassland habitats dominated by reed grass (Phalaris arundinacea), common reed (Phragmites australis) or sedges (Carex spec.) are part of the natural floodplain of lowland rivers in Central Europe (Patt et al. 1998). They occur where floodplains are subjected to a (semi-) natural hydrological regime (RSPB et al. 1997). Natural floodplains are the most species rich habitats in temperate regions (Gerken 1988). Due to the flooding dynamics, they provide high habitat diversity. Plants and animals living in these floodplain habitats have to cope with cycles of wet and dry conditions. Robinson et al. (2002) state that little is known about the ecology of special habitats associated with intact floodplains. In lowland rivers of Central Europe typically long lasting winter floods occur. Terrestrial arthropods living in the floodplains have to cope with these flooding events. Many studies on survival strategies of terrestrial invertebrates inhabiting floodplains have been carried out in the Amazon basin, but much less is known about the situation in Central Europe (Adis \& Junk 2002).

In Europe, large rivers have experienced a long history of modification by man, which often included building of dykes and drainage of floodplains (Petts 1989). Thus, today, only few reaches of natural river remain (Petts 1989). Consequently, riverine floodplains are among the most endangered landscapes world-wide (Olson \& Dinersein 1998, Tockner \& Stanford 2002). In Germany, only about $10 \%$ of the former floodplains are in a near-natural state (see Jungwirth et al. 2002). Tockner \& Stanford (2002) state that there is an urgent need to preserve existing, intact floodplain rivers, in order to avoid dramatic extinction of aquatic and riparian species and of ecosystem services. In Europe, examples of river-floodplain restoration and rehabilitation are few and recent (Buijse et al. 2002).

Wet grassland has been in the centre of interest of conservation biologists for a couple of years (e.g. Achtziger \& Nickel 1997, Achtziger et al. 1999, Klieber et al. 1995, RSPB et al. 1997). In conservation schemes, mowing is a widely used management technique to prevent succession and brushwood encroachment (Cattin et al. 2003). Additionally, it is used to maintain plant diversity (e.g. Cattin et al. 2003, Decleer 1990) or suitable habitats for selected target species (e.g. Decleer 1990, IUS 1998). A lot of studies investigating the impact of land use on various arthropod groups were carried out in different types of grassland habitats (e.g. Andrzejewska 1979, Gerstmeier \& Lang 1996, Morris \& Lakhani 1979, Morris 1981a, Morris 1981b). However, those carried out in temporarily flooded habitats are relatively scarce (e.g. Heller \& Irmler 1997, Nickel \& Hildebrandt 2003). 
Diversity of arthropods is in the centre of interest of this investigation. Since the world summit of Rio de Janeiro in 1992 biological diversity or biodiversity became a popular idea widely referred to by politicians, biologists and conservationists. Although the Convention on Biological Diversity $(\mathrm{CBD})^{1}$ defines biological diversity as the "variability among living organisms ... this includes diversity within species, between species and of ecosystems", in recent years biodiversity became a synonym for quality of life and naturalness of habitats (Ziegler et al. 1997). However, in biological sciences the term diversity has a much longer history. During the 1960s and 70s diversity was understood as species diversity and the use of the term was restricted to the scientific community (Hobohm 2000). Within this study diversity is understood as species diversity, i.e. the number of species within a community (Schaefer 2003).

On a global scale, arthropods comprise more than $60 \%$ of all described living species (Wilson 1992). Thus, when talking about the conservation of biological diversity this group should not be neglected. The phytophagous plant- and leafhoppers (Hemiptera: Auchenorrhyncha) and the predacious spiders (Araneida) and ground beetles (Coleoptera: Carabidae) were chosen as representative groups and studied in detail.

Plant- and leafhoppers occur in nearly all habitats that are inhabited by plants (Remane \& Wachmann 1993). Out of the 620 species known to exist in Germany, many can be found in high abundance within grassland habitats (Nickel \& Hildebrandt 2003). All Auchenorrhyncha are sap-feeding, thus phytophagous. In recent years the knowledge of the ecology of plant- and leafhoppers has increased and summarising papers have been published (Nickel 2003, Nickel \& Remane 2002), making them an interesting focal group for studies in the context of conservation issues.

Spiders can be found in nearly all terrestrial habitats. All 800 species occurring in Germany are predacious generalist feeders (Bellmann 1992). Generally, one can differentiate between wandering spiders and web spinners (Wise 1995). Most spiders are specialised and adapted to specific environmental conditions like temperature, moisture, food availability or occurrence of enemies (Foelix 1992). Wise (1995) regards spiders as "model terrestrial predators".

Like spiders, ground beetles can also be found in nearly all terrestrial habitats. In Germany about 520 species occur, many of these adjacent to stretches of water. Most species are epigeic, whereas only few live under bark, on shrubs, herbs or flowers. Carabids are predominantly predators, some also feeding on carrion or plant material. There exists a lot of knowledge of the ecology of ground beetles, and many species are restricted to a narrow range of environmental conditions (Thiele 1977, Wachmann et al. 1995).

All three taxa occur in high individual and species numbers in grassland habitats. They can easily be collected by established sampling techniques and determination of adults to species level is reliable due to good identification literature. Furthermore, a fair amount of information on the species' ecology can be found in the literature and thus be included in the analysis.

\footnotetext{
${ }^{1}$ Convention on Biological Diversity, 12th June 1992, Bundesgesetzblatt II 1993, p. 1742.
} 
The study was carried out within the scope of the interdisciplinary graduate training program "Valuation and Conservation of Biodiversity" at Göttingen University. Aim of the program was to analyse problems and perspectives that occur when conserving biological diversity within natural habitats (in-situ conservation). The general background of the program was the Convention on Biological Diversity (CBD), especially article 8 dealing with in-situ conservation. In 1993 Germany ratified the CBD and thus committed itself to translating the content of the convention into national legislation. This includes, among other things, the protection of biological diversity within protected areas in Germany.

The "Lower Oder Valley National Park" with its grassland dominated floodplain areas as the most characteristic habitat was chosen as study area. Despite of land use and management of the flooding regime (see chapter 2), the floodplain of the national park is one of the last semi-natural floodplains in Central Europe. Here, it was possible to study the impact of the typical long lasting winter floods of lowland rivers and of land use on the wetland arthropod fauna. The national park being a protected area is supposed to preserve biological diversity. Within article 8 of the Convention on Biological Diversity (CBD) it is stated that "each Contracting Party shall establish a system of protected areas ... to conserve biological diversity". Against this background and based on the findings of this study the national park's plans of the development regarding the conservation of arthropod diversity were analysed.

After a general introduction into the study area, this work is divided into three main parts which are structured as individual papers:

In chapter 3 the impact of land use and flooding on the diversity of plant- and leafhoppers is analysed in detail. It is the aim of this part of the study to investigate the impact of mowing on plant- and leafhopper communities in temporarily flooded habitats, to assess the impact of flooding on plant- and leafhopper communities and to disentangle interactions between both influencing factors.

In chapter 4 survival strategies of Araneida, Auchenorrhyncha and Carabidae during the long lasting winter floods are in the centre of interest. In this part of the study it was analysed which part of the floodplain arthropod fauna overwinters in the inundated floodplain, and which part recolonises the floodplain after each flooding event. Based on these findings, it is analysed whether flooding duration and frequency affects the distribution of submersion tolerant and immigrating arthropods in the floodplain.

Chapter 5 originates from a joint publication with colleagues from the graduate training program (see Rothenbücher et al. 2005). In his diploma thesis, Kai Bentlage investigated the anuran fauna of the Lower Oder Valley National Park (Bentlage 2003). In his dissertation Peter Just carried out a habitat analysis of the corncrake (Crex crex) (Just in prep.). Together with my own results on plant- and leafhoppers (chapter 3) we had the great opportunity to discuss, which impact the national park's plans of conservation management and conservation of processes might have on the corncrake as a chosen target species, on the anuran fauna as a vertebrate group typically found in wetlands and on plant- and leafhoppers as a key insect group in wet grasslands. The 
challenge of this joint approach is the amalgamation of three different conservation methodologies to produce a scenario for the future development of the national park.

In chapter 6 the results discussed in chapter 3 concerning the impact of mowing and flooding on the diversity plant- and leafhoppers are compared to results of studies on spiders and ground beetles that were also carried out within the framework of the graduate training program (Krüger 2004, Rothenbücher et al. in prep. a, Rothenbücher et al. in prep. b, Sellner 2004).

As a consequence of this approach, the following main hypotheses are tested:

(1) Mowing of the vegetation drastically changes the composition of the arthropod community.

(2) Inundation is a key mortality factor for many populations.

(3) Some floodplain populations developed specific adaptations to flooding.

(4) Re-immigration is important for replenishing or re-establishing arthropod floodplain populations.

(5) Winter flooding is a prerequisite for the development of a specialised littoral animal community. 


\section{Study area}

\subsection{Location and characteristics}

The study area - the Lower Oder Valley National Park - is situated about $100 \mathrm{~km}$ northeast of Berlin at the border to Poland (Fig. 1).

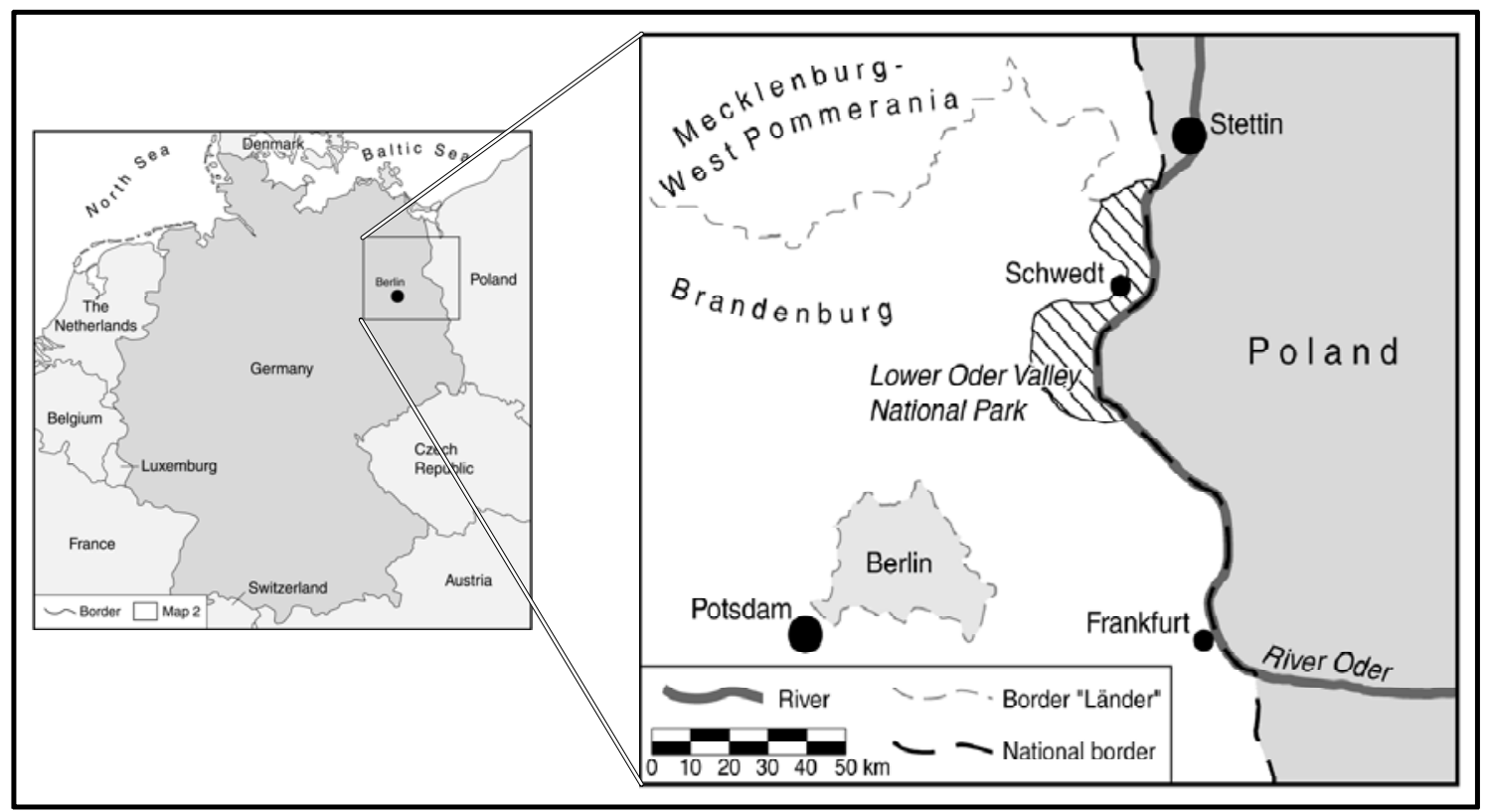

Fig. 1: Location of the Lower Oder Valley National Park (Map design T. Rothenbücher).

The national park is part of a German-Polish network of protected areas. In 1992 it was decided to build an "Inter-National Park" in the Lower Oder Valley that combines German and Polish protected areas located on both sides adjacent to the river Oder (Vössing 1998). In Poland it consists of the two landscape protection areas "Cedynia" and "Dolina Dolneyj Odry". In Germany the "Lower Oder Valley National Park" and the adjacent landscape protection area "Nationalparkregion Unteres Odertal" are part of the "Inter-National Park" (Fig. 2). 


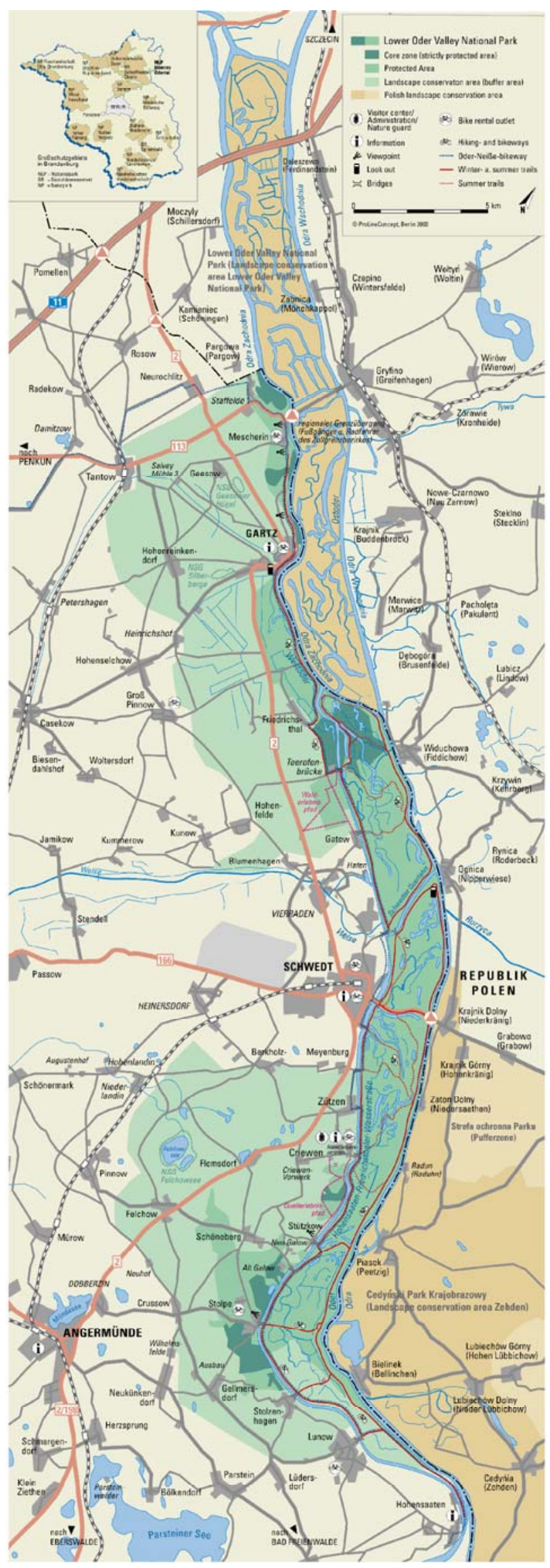

Fig. 2: Map of the Lower Oder Valley National Park and adjacent landscape protection areas in Poland and Germany. (ProLine Concept Berlin, 2003) 
The region's characteristic is a 3 to $4 \mathrm{~km}$ wide floodplain next to the river Oder that is dominated by grassland habitats. This floodplain is the dominant feature of the German national park which comprises an area of 10,500 ha. Its characteristic habitats are wet meadows ("Feuchtgrünland”), sedges ("Seggenriede”), cane brake ("Röhrichte”), oxbow lakes and small patches of alluvial forests. Each year about 4,700 ha of the floodplain are inundated during the typical winter floods (Mönninghof 1997). Despite dyke building and management of the flooding regime since the beginning of the $20^{\text {th }}$ century (see section 2.2), one can still find semi-natural conditions in the floodplain which are unique in Central Europe (Dohle 1999, Mönninghof 1997).

\subsection{History}

Until the middle of the $19^{\text {th }}$ century the present national park area was more or less untouched by man. Afterwards the river Oder became canalised and an artificial waterway was build running parallel to the river Oder. Dykes were built around the area between the two waterways and the former floodplain was drained with the aim to construct a protection against floods, to facilitate navigation on the river Oder and to make effective and profitable land use possible in the floodplain (Vössing 1998). Since 1931 flooding has been regulated in the newly formed polder area. In the so called "dry polder" the dykes prevent inundation throughout the whole year. In contrast, in the "wet polders" flood gates that are integrated into the dykes are opened between $15^{\text {th }}$ November and $1^{\text {st }}$ April each year so the typical winter flood can inundate the polder area. After closing the flood gates to prevent inundation during spring and summer the water is pumped out of the polder area and the level of the groundwater is artificially lowered to make land use possible (Fig. 3) (Dohle et al. 1999).

Within 80 years the natural floodplain had been transformed into pasture land. During the time of the GDR, starting in the 1960s, land use was intensified which included using fertiliser and sowing productive grass species (Gille 1999, Schalitz \& Petrich 1999). During the same time nature conservationists became aware of the importance of the current national park area as resting, breeding and foraging grounds for many birds. The commitment of the local ornithologists for conservation issues finally led to the designation of an area of 5,400 ha as "wetland of international importance" once the GDR acceded to the "Ramsar Convention on Wetlands"2 in 1978. After the political change in 1989 many areas valuable for nature conservation in the GDR were designated as protected areas - among these the Lower Oder Valley (Garrelts et al. 2005). In 1995 the area was designated as national park by the parliament of Brandenburg?

\footnotetext{
2 Ramsar Convention on Wetlands, $2^{\text {nd }}$ February 1971, http://www.ramsar.org/key_conv_e.htm

3 Lower Oder Valley National Park Designation Act (Nationalparkgesetz "Unteres Odertal" - NatPUOG), $27^{\text {th }}$ June 1995, GVB1 I, p. 114.
} 


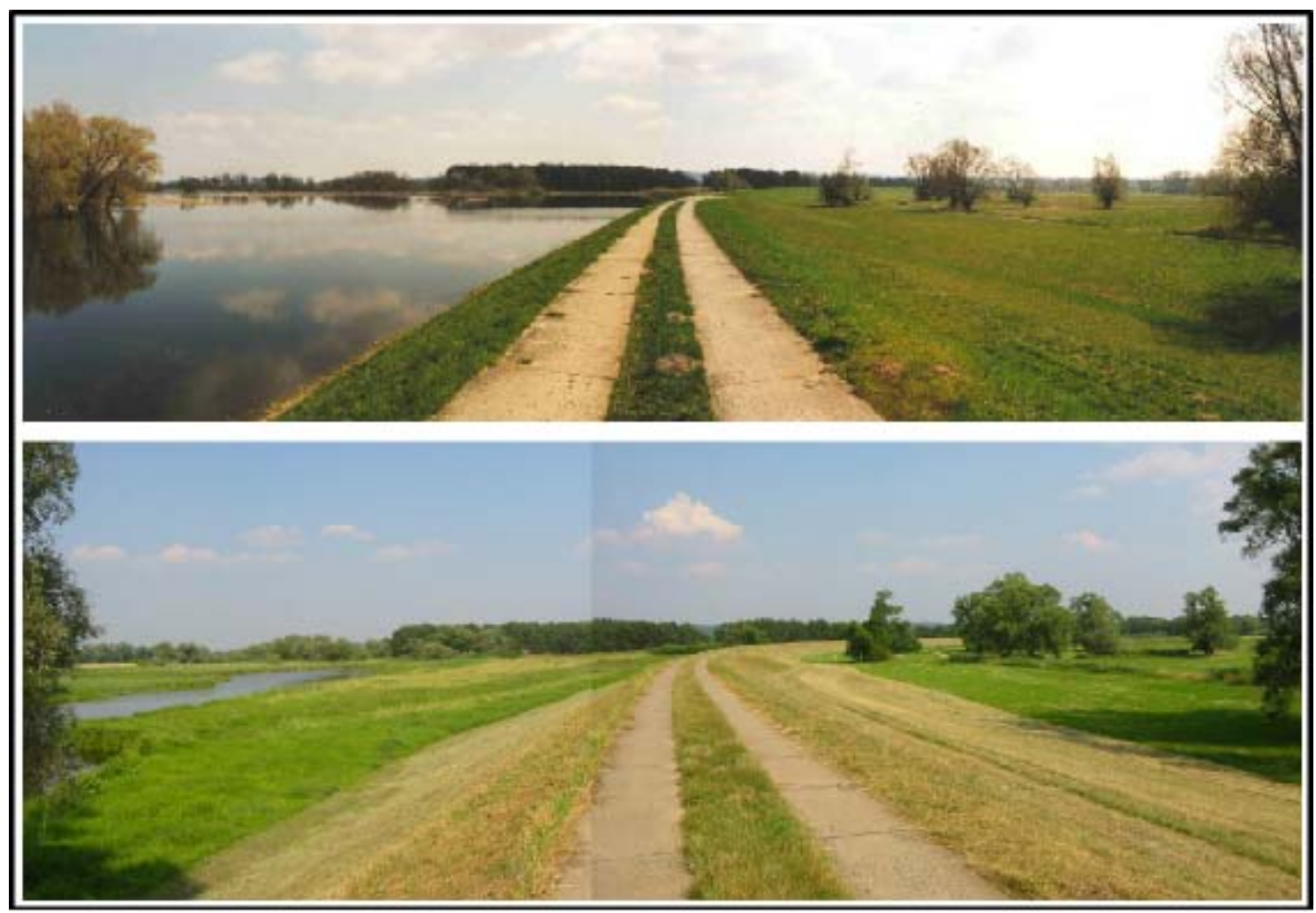

Fig. 3: Management of the flooding regime. "Wet polder" (left) and "dry polder" (right) separated by a dyke. The picture at the top was taken in March, the one at the bottom in July. (Photos: H. Lüssow, J. Rothenbücher)

\subsection{Plans for future development}

At present, the national park is still in the developmental stage as the flooding regime is regulated and a large proportion of the grassland is used for fodder production and grazing. Fodder production by mowing is presently the major land use in the national park. Most meadows are cut twice a year i.e. at the beginning of June and September. Only about $10 \%$ of the national park area are currently declared as core zone. Here the flooding regime is still regulated, but the sites have been abandoned and left for succession since 1995 (Jehle \& Pankoke 1999).

The aims and the purpose of the Lower Oder Valley National Park are outlined in the "National Park Law" that was passed on 22 $2^{\text {nd }}$ June 1995. 
The purpose of the national park is

- to protect, to manage, to preserve and to develop the natural functions of the Lower Oder Valley which includes the floodplain, flora and fauna, wetlands, meadows, alluvial forest and dry grassland,

- to protect and to develop natural processes on a large area undisturbed by anthropogenic impacts,

- to preserve and regenerate the natural flooding regime,

- to allow environmental friendly recreation,

- to develop tourism and

- to conduct environmental education ${ }^{4}$.

Additionally, the national park's area has been federally funded as project area in the context of a program for riparian nature conservation ("Gewässerrandstreifenprojekt") since 1992. In the long run it is planned to restore the floodplain to semi-natural conditions. To accomplish this aim the flooding regime will be altered on a preferably large area as close to a natural flooding dynamic as possible, i.e. longer and more frequent flooding events. Many ideas have been developed to achieve this goal. A very pragmatic approach is to leave the flood gates open during the whole year. More sophisticated ideas include trenching the dykes along the river Oder or connecting oxbow lakes to create an artificial river within the polder area (IUS 1998). Furthermore, it is planned to stop the artificial lowering of the groundwater level in those areas that are no longer used for fodder production. It is planned that by $201050 \%$ of the national park area will be declared as core zone and left for succession whereas in the remaining $50 \%$ resting, breeding and foraging habitats for endangered species (e.g. corncrake) will be optimised by conservation management. Thus current plans for national park development try to realise two conservation strategies side by side, i.e. conservation management for the target species corncrake (Crex crex) and conservation of processes.

4 Lower Oder Valley National Park Designation Act (Nationalparkgesetz "Unteres Odertal" - NatPUOG), $27^{\text {th }}$ June 1995, GVB1 I, p. 114. 


\subsection{Climate}

The Lower Oder Valley is situated in the transition zone between temperate and continental climate. It is characterised by its cold winters and hot summers. On an average, about $530 \mathrm{~mm}$ precipitation and 120 days of frost per year are recorded for the region. These climate data resemble those gathered in continental regions like the Ukraine and differ notably from those observed in the nearer Atlantic region (Vössing 1998).

In figure 4 the mean temperature values for each month of the years 2001 and 2002 in comparison to the monthly average values of the years 1961-1990 are plotted.

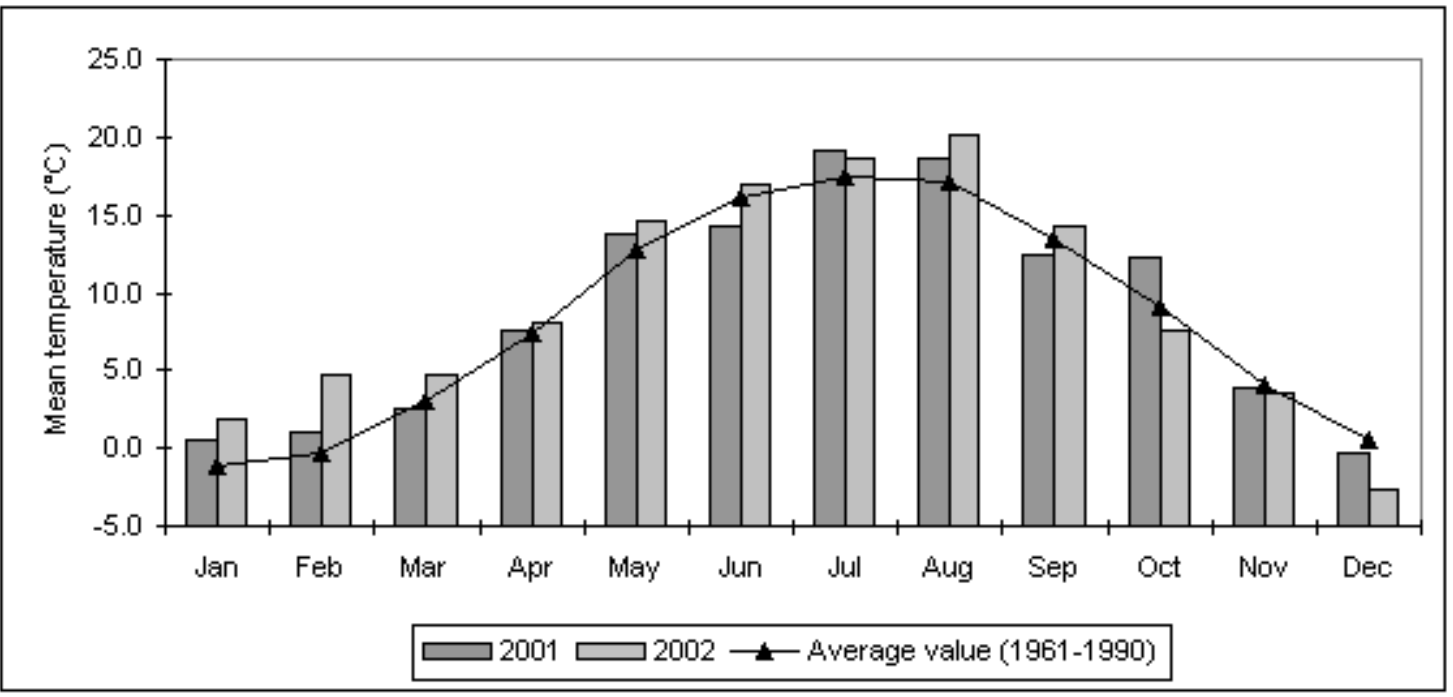

Fig. 4: Mean air temperature values $\left({ }^{\circ} \mathrm{C}\right)$ for each month of the years 2001 and 2002 in comparison to the monthly average value of the years 1961-1990, meteorological station Angermünde (DWD 2002).

In 2001 the mean monthly temperature was below the average value in June and December while in all other months the mean temperature reached at least the average value. From January to September 2002 the mean monthly temperatures were higher than the average values and were lower in October and December. The mean annual temperatures of both years were higher than the average annual temperature of the years $1961-1990\left(8.3^{\circ} \mathrm{C}\right)$, i.e. $8.8^{\circ} \mathrm{C}$ in 2001 and $9.4^{\circ} \mathrm{C}$ in 2002 respectively.

The amounts of precipitation for each month of the years 2001 and 2002 are summed up and compared to the monthly average values (sums) of the years 1961-1990 (Fig. 5). 


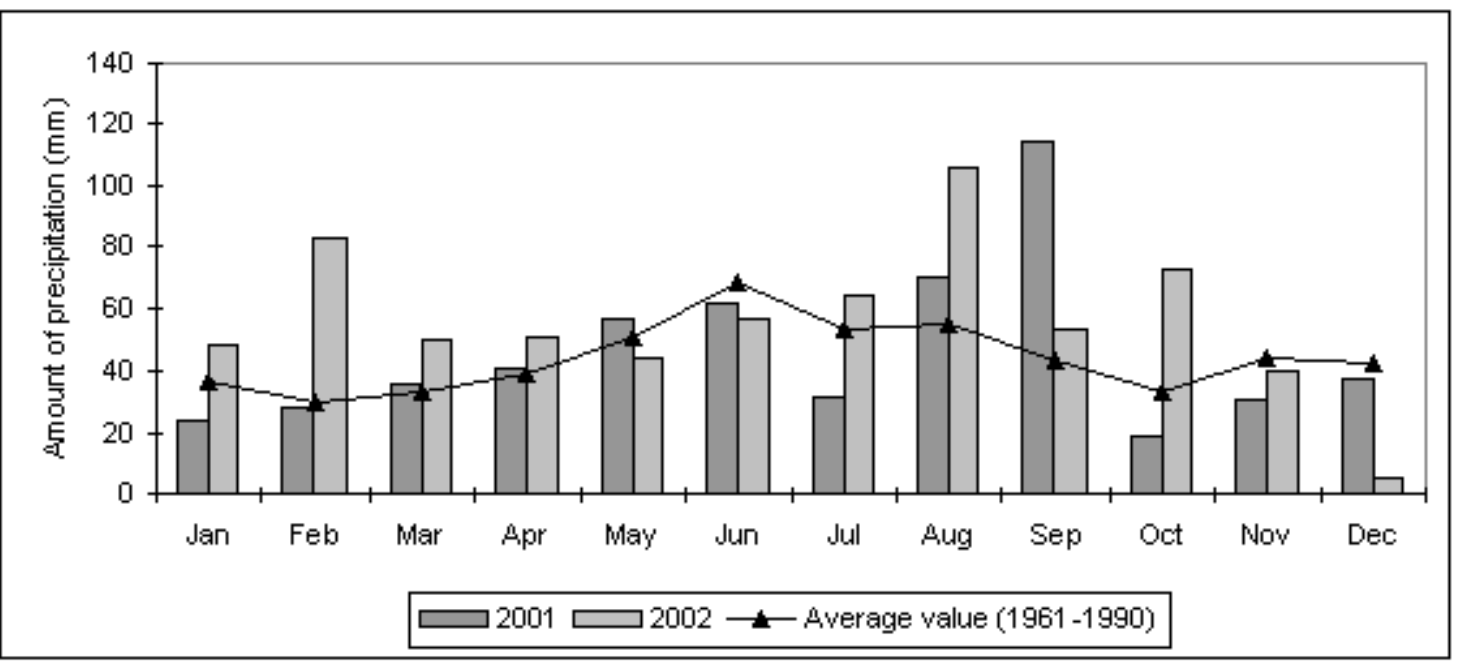

Fig. 5: Precipitation values $(\mathrm{mm})$ are summed up for each month of the years 2001 and 2002 and are compared to the monthly average value of the years 1961-1990, meteorological station Angermünde (DWD 2002).

In August and September 2001 precipitation largely exceeded the average values while in July and October rainfall was comparably low. In 2002 unusually high amounts of precipitation were recorded in February, August and October whereas in December hardly any rainfall was documented. In both years precipitation exceeded the average annual values of the years 1961-1990 (531.9 mm). In $2001552.0 \mathrm{~mm}$ in $2002675.7 \mathrm{~mm}$ rainfall were recorded.

Thus, both years of the study were warmer and wetter than an average year with 2002 exceeding both temperature and precipitation values of 2001 .

\subsection{River Oder}

The headwaters of the river Oder are situated in the Odergebirge in the north-east of the Czech Republic. The river is $854 \mathrm{~km}$ long and flows into the Baltic Sea near Stettin (Poland). The catchment area comprises about $118,861 \mathrm{~km}^{2}$, of these only $5 \%$ are located in Germany. The area between Hohensaaten (Germany) and Stettin (Poland) is called the Lower Oder Valley. Here the river Oder is a typical Central European lowland river where regular floods occur during winter and spring, and high water levels in summer are more rare events (Fig. 6). Floods during winter are mostly due to ice blockage on the river Oder whereas inundation during spring is the result of the snowmelt in the low mountain ranges of the catchment area. However, heavy rainfall in the region of the headwaters can lead to high water levels during summer, but these occur on an average only once in ten years (Vössing 1998). The last severe summer flood leading to a flooding of the "wet polders" occurred in 1997 (Fig. 6). 


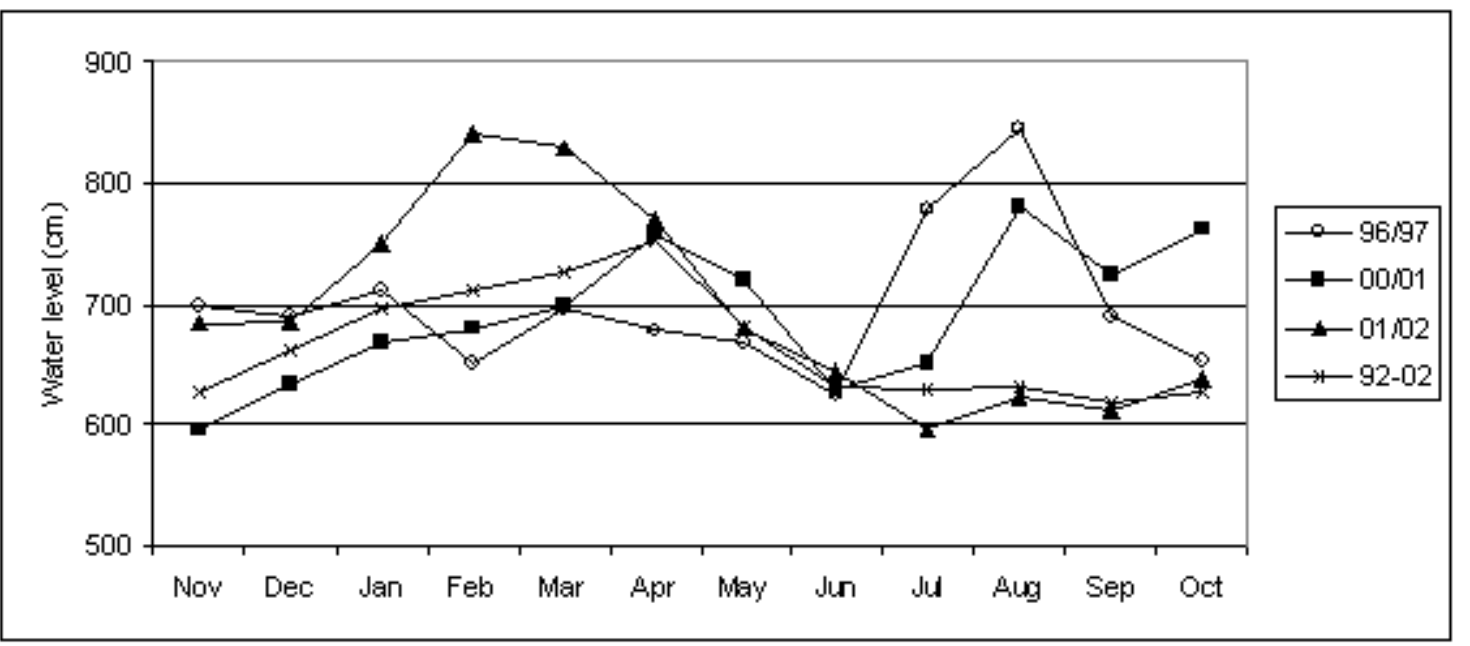

Fig. 6: Mean monthly water level from November to October of the years 1996/97, 2000/01 and 2001/02 compared to the monthly average value of the years 1992-2002, gauging station Stützkow (WSA 2002).

During the winter preceding the growing season 2001 water levels were generally lower than the average value of the last ten years. From the middle of July until the end of October 2001 water levels were unusually high. However, there was no need to open the flood gates but large parts of the river bank were inundated between seven and 80 days during summer. In winter 2001/02 water levels were much higher than the average value, but during summer they stayed mostly below the average levels. 


\section{Impact of mowing and flooding on the diversity of plant- and leafhoppers}

\subsection{Introduction}

A lot of studies investigating the impact of mowing on plant- and leafhoppers were carried out in different types of grassland habitats (see Gerstmeier \& Lang 1996). However, one finds very heterogeneous results concerning the effects of mowing on e.g. species richness, abundance and diversity. Gerstmeier \& Lang (1996) differentiated in their review article on the impact of mowing on arthropods between meadows of different moisture conditions and proposed different management strategies depending on the habitat. Thus, the impact of mowing seems to be dependent on habitat conditions such as soil moisture or flooding impact. Within the large amount of studies that investigate the impact of mowing on plant- and leafhoppers, those carried out in temporarily flooded habitats are scarce (e.g. Heller \& Irmler 1997, Nickel \& Hildebrandt 2003). Furthermore, Nickel \& Hildebrandt (2003) stated that the responses of plant- and leafhoppers to mowing and flooding are principally similar and are difficult to disentangle in field experiments and called for further investigations on the effect of flooding on plant- and leafhoppers. In the Lower Oder Valley National Park mown sites and fallows subject to different flooding conditions can be found site by site. Thus, it was possible to separately assess the impact of mowing and of different flooding regimes on the plant- and leafhopper community as well as the interaction between these two factors.

\subsection{Materials and methods}

\subsubsection{Sampling methods}

Samples were taken by a motor-driven suction apparatus and pitfall traps (Barber 1931) four times between May and September 2001 and 2002, respectively.

On each study site the suction apparatus (STIHL SH 85, diameter of the suction tube: $14 \mathrm{~cm}$ ) was placed onto the ground ten times at random for approximately ten seconds to gather a mixed sample of each study site. Thus, throughout the vegetation period samples were taken in an area of $0.61 \mathrm{~m}^{2}$ per sampling date and plot, respectively. The samples were put in a cold box while in the field and afterwards stored in a deep-freeze compartment for several days. 
Three pitfall traps (diameter of the opening: $5.5 \mathrm{~cm}$, preservative: $50 \%$ ethylene glycol, one drop of detergent) were placed in each study site as indicated in Figure 7.

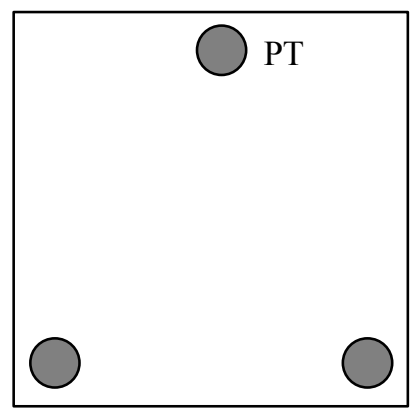

Fig. 7: Arrangement of the pitfall traps (PT) in the study sites.

A cage made out of wire netting was placed above each trap to keep away small mammals. Additionally, the cage was covered by a sheet made of Plexiglas to prevent the trap from filling up with rain water. The traps were open for two weeks in May, June, August and September, respectively.

Invertebrate animals sampled by both methods were sorted and stored in $70 \%$ ethanol. Adult plant- and leafhoppers were determined to species level. The statistical analyses were based on samples taken with the suction apparatus. Plant- and leafhoppers collected in pitfall traps were only considered in the species list (see section 3.3.1).

\subsubsection{Study sites}

The investigation on the effects mowing was carried out during the growing season 2001. It was presumed that flooding duration and frequency affect the communities as well, thus "flooding" was included as a second factor as follows (Fig. 8):

- High flooding impact (HF, HM): These plots are situated on the narrow river bank between the dyke and the river and are inundated not only by the winter floods (winter 2000/01: approximately 50 days; winter 2001/02: approximately 100 days), but also occasionally and unpredictably in summer after heavy rainfall (summer 2001: approximately 20 days; summer 2002: approximately 5 days). Therefore, they are the most heavily disturbed sites and their degree of naturalness is smallest.

- Medium flooding impact (MF, MM): These sites are situated in ditches in the wet polder and are subject to regular flooding for a long time during winter (winter 2000/01 \& 2001/02: approximately 130 days). Flooding conditions in these sites are close to natural flooding conditions.

- Low flooding impact (LF, LM): These sites are situated in more elevated locations in the wet polder and are subject to more unpredictable and short winter floods (winter 2000/01: approximately 80 days; winter 2001/02: approximately 100 days).

- No flooding impact (NF, NM): These plots are situated in the dry polder and are not flooded throughout the whole year. 


\section{Flooding impact:}

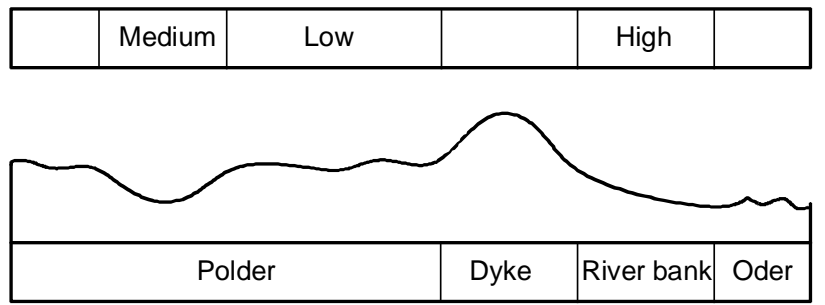

Fig. 8: Schematical cross section of the floodplain which shows the studied habitats (river bank, depressions in the polders, higher elevations in the polders) and the corresponding high, medium and low flooding impact.

In April 2001 three study sites for each pair of influencing factors were selected after the winter flood had receded, each covering an area of approximately $400 \mathrm{~m}^{2}$ (usually $20 \times 20 \mathrm{~m}$ ). Unfortunately, the study design became unbalanced due to changes in land use during the year.

The study design based on the suction samples is specified in Table 1. Species collected with the suction apparatus that were taken between June and September 2001 were summed up for analyses.

Table 1: Study design 2001, suction samples. For each pair of influencing factors the number of study sites sampled between June and September is listed.

\begin{tabular}{|c|c|c|c|c|}
\hline \multirow{2}{*}{$\begin{array}{l}\text { Location } \\
\text { Time of flood }\end{array}$} & \multirow{2}{*}{$\frac{\text { River bank }}{\begin{array}{c}\text { Summer \& } \\
\text { winter }\end{array}}$} & \multicolumn{2}{|c|}{ Wet polder } & \multirow{2}{*}{$\frac{\text { Dry polder }}{\text { No flood }}$} \\
\hline & & Winter (long) & Winter (short) & \\
\hline Flooding impact & High & Medium & Low & None \\
\hline Mown grassland & 1 & 5 & 2 & 2 \\
\hline Fallows & 2 & 2 & 5 & 1 \\
\hline
\end{tabular}

In 2002 the investigations focused on the impact of flooding. In April three fallows per treatment were selected and sampled four times between May and September (Table 2). The four samples collected with the suction apparatus were summed up for analyses.

Table 2: $\quad$ Study design 2002, suction samples \& pitfall traps. For each flooding influence the number of study sites sampled between May and September is listed.

\begin{tabular}{|c|c|c|c|c|}
\hline \multirow{2}{*}{$\begin{array}{l}\text { Location } \\
\text { Time of flood }\end{array}$} & \multirow{2}{*}{$\frac{\text { River bank }}{\begin{array}{c}\text { Summer \& } \\
\text { winter }\end{array}}$} & \multicolumn{2}{|c|}{ Wet polder } & \multirow{2}{*}{$\frac{\text { Dry polder }}{\text { No flood }}$} \\
\hline & & Winter (long) & Winter (short) & \\
\hline Flooding impact & High & Medium & Low & None \\
\hline Fallow & 3 & 3 & 3 & 3 \\
\hline
\end{tabular}

Figure 9 gives an overview of the locations of all study sites that were investigated during the two years of the study. 


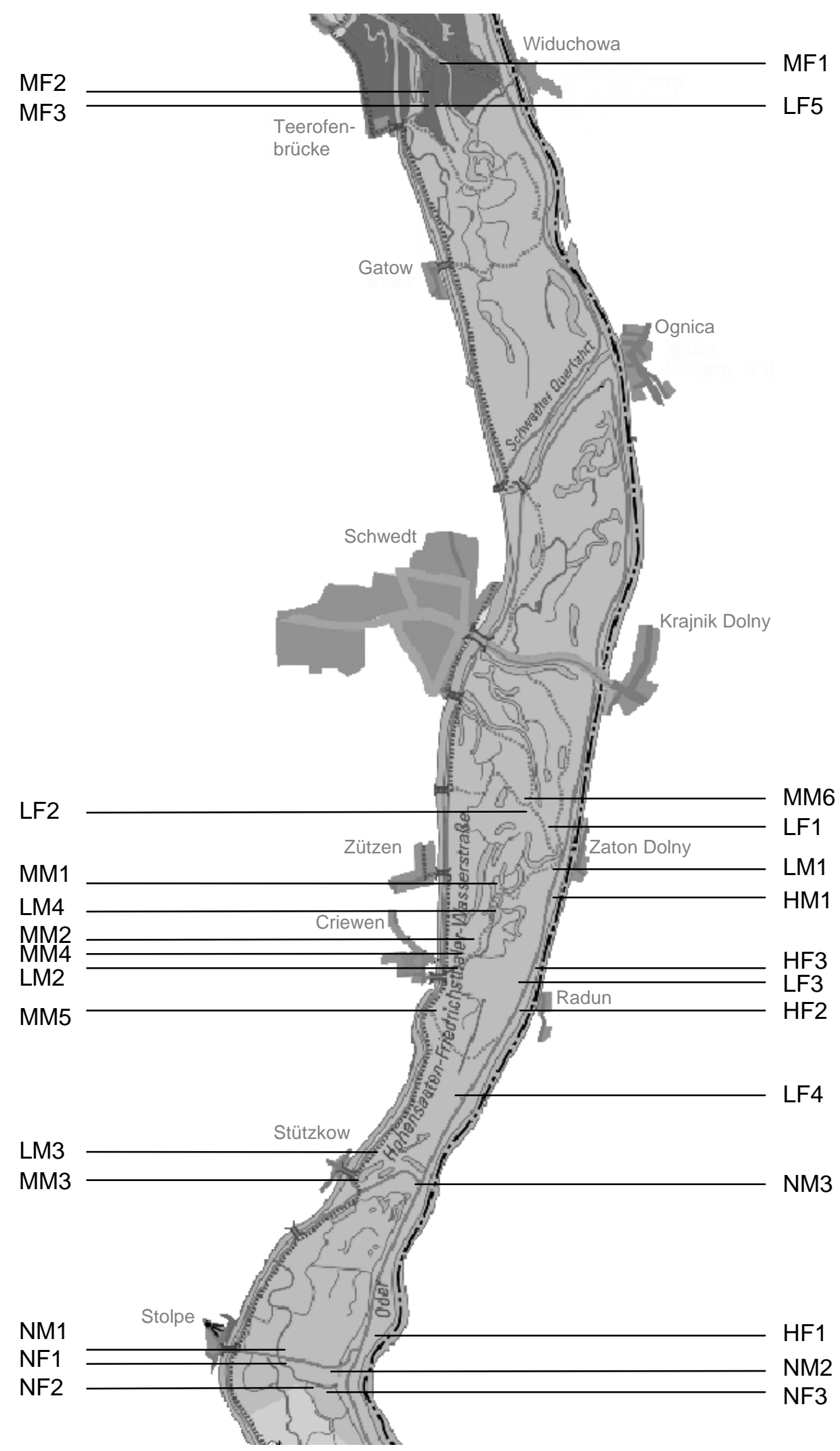

0

\section{$5 \mathrm{~km}$}

Fig. 9: Location of the study sites. The first letter of the abbreviation indicates the impact of flooding: $\mathrm{H}=$ high, $\mathrm{M}=$ medium, $\mathrm{L}=$ low and $\mathrm{N}=$ none; the second letter gives information about land use: $\mathrm{F}=$ fallow, $\mathrm{M}=$ mown site, sites of the same variant are sequentially numbered. 


\subsubsection{Environmental variables}

In addition to the arthropods caught in the study sites, a number of environmental variables were recorded:

- plant species,

- vegetation structure,

- distance to the nearest stretch of water,

- distance to the nearest scrub or tree and

- period of inundation during the winter preceding the investigation.

\section{Plant species}

At the beginning of August 2001 and 2002 a detailed survey on plant species was carried out in each study site, recording all plant species occurring in the respective sites as well as the dominant species (Appendix 1). These lists were completed by additional observations during the whole growing season.

\section{Vegetation structure}

Height of vegetation, density of grasses and herbs as well as the vegetation cover were measured four times between May and September 2001 and 2002, respectively, i.e. once during each sampling period. The height of the vegetation was measured by a ruler. To assess the density of grasses and herbs a stick was put in the ground. All grasses and herbs that came into contact with the stick between 10 and $20 \mathrm{~cm}$ above the ground were counted. The cover of the vegetation was measured by placing a frame ( 25 x $25 \mathrm{~cm}$ ) randomly into the plot and estimating the percentage of vegetation cover inside. All structural parameters were measured ten times per study site and sampling period resulting in 40 measurements per plot and year. For further analyses the average values per site and year were used.

\section{Distance to the nearest stretch of water and the nearest scrub or tree}

The distance to the nearest stretch of water and the nearest scrub or tree of each study site was measured in the field. This information can be used to interpret the occurrence of e.g. hygrophilous or forest species on specific study sites.

\subsubsection{Species identification}

Adult plant- and leafhoppers were identified to species level using a stereomicroscope (Zeiss SV8). For the determination of the species the following books were used:

Ossiannilsson (1978, $1981 \& 1983)$ and Ribaut (1936 \& 1952).

The nomenclature for all Auchenorrhyncha except Cicadellidae follows Holzinger et al. (2003), for Cicadellidae Nickel \& Remane (2002). Species that were difficult to identify were checked by H. Nickel (Göttingen). 


\subsubsection{Ecological characteristics of the species}

For the analyses the following ecological characteristics were taken into account:

- Habitat preferences,

- Mobility, i.e. wing development

- Overwintering stage,

- Numbers of generations per year

- Diet width and

- Habitat specialisation.

\section{Moisture preferences}

The categories of the habitat preferences are based on the classification published by Platen et al. (1991) (Table 3).

Table 3: Definition of moisture preferences.

\begin{tabular}{llll}
\hline Habitat type & Classification & Definition & Abbreviation \\
\hline Open landscape & Hygrophilous & Species occurring preferably in moist to wet habitats & $\mathrm{h}$ \\
& Euryhygric & $\begin{array}{l}\text { Species occurring in nearly all habitats relatively independent of } \\
\text { the degree of moisture }\end{array}$ & \\
& Xerophilous & Species occurring preferably in dry habitats & $\mathrm{x}$ \\
Forest & & Species occurring preferably in forests & $\mathrm{f}$ \\
\hline
\end{tabular}

Firstly, it is differentiated between species occurring predominantly in open habitats as opposed to those of forests. Within species of open landscapes it is distinguished between species differing in their affinity to specific moisture conditions of their habitat. H. Nickel (pers. comm.) provided me with information on the moisture preferences.

\section{Wing development}

In Auchenorrhyncha wing length can be used to determine flight capability. Flight enables species to escape from predators, to reach and colonise new suitable habitats or to find new host plants or suitable hibernation or aestivation sites (Remane \& Wachmann 1993). Most authors distinguish between macropterous, submacropterous and brachypterous species on the one hand and di- or polymorphic species on the other hand. Only macropterous species have fully developed fore and hind wings and are capable of flight. In submacropterous and brachypterous species wings are not completely developed, thus flight is not possible at all or only over short distances.

All arboricolous Auchenorrhyncha and those feeding on tall herbs are monomorphic macropterous, whereas species living in the herbaceous vegetation are predominantly wing dimorphic. However, long-winged individuals are mostly males and mainly occur in low proportions in the populations (Nickel 2003). Beside macropterous and 
dimorphic species, in some taxa brachyptery prevails, e.g. epigeic Delphacidae (Nickel 2003). Within the analyses it is distinguished between monomorphic macropterous and dimorphic species. In the former the flight capability is well developed, whereas in the latter it is restricted. H. Nickel (pers. comm.) provided me with information on the wing length of plant- and leafhoppers.

\section{Overwintering stage}

In temperate regions poikilothermic animals need to adapt to the seasonal variations of climatic conditions. During winter species in the study area have not only to cope with low temperatures and shortage of food resources, but also with the long-lasting winter flood.

Plant- and leafhoppers overwinter either in the egg, nymphal or adult stage. Only few Central European Auchenorrhyncha overwinter in more than one developmental stage (Nickel 2003). A list of all German Auchenorrhyncha with information on their overwintering stage was published by Nickel \& Remane (2002).

\section{Life cycle}

Information on numbers of generations per year were taken from Nickel \& Remane (2002).

\section{Diet width}

A list of all species of German Auchenorrhyncha with information on their diet width can be found in Nickel \& Remane (2002). In this study a wider differentiation based on these categories is applied, using the classes defined in Table 4.

Table 4: $\quad$ Definition of diet width from Schaefer (2003).

\begin{tabular}{lll}
\hline Classification & Definition & Abbreviation \\
\hline Monophagous & Species feed on plants of one host species or genus & mo \\
Oligophagous & Species feed on plants of one host family & ol \\
Polyphagous & Species feed on plants of more than one family & po \\
\hline
\end{tabular}




\section{Habitat specialisation}

Achtziger \& Nickel (1997) divided Auchenorrhyncha of Central European grasslands into four ecological groups based on habitat preference, diet width, wing length and voltinism (Table 5). Later they introduced a specialisation factor ranging from 0 for pioneer species to 3 for stenotopic species (Achtziger et al. 1999).

Table 5: $\quad$ Definition of life strategies (Achtziger \& Nickel 1997, Achtziger et al. 1999).

\begin{tabular}{lllll}
\hline & Pioneer species & Eurytopic species & Oligotopic species & Stenotopic species \\
\hline Habitat preference & $\begin{array}{l}\text { Mainly in early } \\
\text { successional stages }\end{array}$ & $\begin{array}{l}\text { Eurytopic in various } \\
\text { types of grasslands }\end{array}$ & $\begin{array}{l}\text { Associated with } \\
\text { specific abiotic } \\
\text { conditions } \\
\text { Oiet width }\end{array}$ & $\begin{array}{l}\text { Associated with } \\
\text { Polyphocific abiotic } \\
\text { conditions }\end{array}$ \\
Wing length & Macropterous & $\begin{array}{l}\text { Oligophagous on } \\
\text { Poaceae } \\
\text { Macro- and }\end{array}$ & $\begin{array}{l}\text { Macro- and } \\
\text { brachypterous }\end{array}$ & Usually \\
Voltinism & At least bivoltine & Mostly bivoltine & Uni- or bivoltine & Uni- or bivoltine \\
Specialisation factor & 0 & 1 & 2 & 3 \\
\hline
\end{tabular}

The average degree of specialisation of Auchenorrhyncha communities was calculated based on species (a) and individuals (b) using the specialisation factor of each species:

a)

$$
\begin{array}{ll}
\mathrm{DS}_{\mathrm{S}} & =\text { Degree of specialisation based on species } \\
\mathrm{DS}_{S}=\frac{\sum_{\mathrm{i}=1}^{S} S F_{i}}{S} & \mathrm{~S} \quad=\text { Degree of specialisation based on individuals } \\
\mathrm{SF} & =\text { Special number of species } \\
\mathrm{n}_{\mathrm{i}} & =\text { Number of individuals of species } \mathrm{i} \\
\sum_{S} & \mathrm{~N} \quad=\text { Total number of individuals }
\end{array}
$$$$
D S=\frac{\sum_{i=1}^{S} S F_{i}}{S} \quad \mathrm{~S}=\text { Total number of species }
$$

b)

$$
D S_{I}=\frac{\sum_{i=1}^{S} S F_{i} \times n_{i}}{N}
$$

\subsubsection{Analysis}

Data collected during the two years of investigation were analysed separately for each year. All statistical analyses were based on suction samples. For the data collected in 2001 samples that were taken between June and September, for those collected in 2002 samples that were taken between May and September were summed up for analyses.

\section{Species richness estimation}

Although a number of diversity indices have been developed that take into account the number of species and the relative evenness of their abundance (Magurran 1988), species richness continues to be the most frequent measure of biodiversity (Brose et al. 2003). The number of observed species in a restricted area largely depends on the 
number of samples taken (Mühlenberg 1993, Baltanás 1992). The true number of species is underestimated because many rare species do not occur in the samples (Walther \& Morand 1998). A number of methods have been developed to estimate the total species richness from a given set of samples. In the present study species richness of mown sites and fallows as well as of fallows subject to high, medium, low and no flooding influence were estimated using the following seven non-parametric estimators:

- Abundance-based Coverage Estimator (ACE) (Chao et al. 2000),

- Incidence-based Coverage Estimator (ICE) (Chao et al. 2000),

- Chao 1 richness estimator (Chao1) (Chao 1984),

- Chao 2 richness estimator (Chao2) (Chao 1984),

- first order Jackknife richness estimator (Jack1) (Burnham \& Overton 1978),

- second order Jackknife richness estimator (Jack2) (Burnham \& Overton 1978) and

- Bootstrap richness estimator (Bootstrap) (Smith \& van Belle 1984).

Estimations were carried out by using the statistical analysing software "Estimates 7.0" (Colwell 2004).

\section{Ecological indices}

The simplest way to characterise the species community of a selected study site is by listing the abundance of the occurring species. They can be further described by ecological indices such as dominance, diversity and species identity.

Dominance

Dominance gives information on the relative abundance (\%) of a species within a species assemblage (see Mühlenberg 1993). In this study the calculated dominance values are combined to the following categories (Engelmann 1978):

$\begin{array}{lr}\text { Eudominant: } & 32,0-100 \% \\ \text { Dominant: } & 10,0-31,9 \% \\ \text { Subdominant: } & 3,2-9,9 \% \\ \text { Recedent: } & 1,0-3,1 \% \\ \text { Subrecedent: } & 0,32-0,99 \% \\ \text { Sporadic: } & \text { below } 0,32 \%\end{array}$




\section{Diversity}

Diversity measures species richness within a selected habitat taking into account the numbers of species and individuals. A variety of indices have been developed to measure species diversity each having its pros and cons (see Magurran 1988). In this study the Shannon-Wiener-Index $\left(\mathrm{H}_{\mathrm{S}}\right)$ was used (see Schaefer 2003).

High diversity values are either gained with increasing number of species or if species are equally abundant. Thus, for interpretation and comparison of different diversity values the evenness must be taken into account (see Schaefer 2003). Diversity and evenness were calculated separately for each taxon as well as for each study site and year by using the software MVSP (Multi-Variate Statistical Package, Kovach Computing Services).

\section{Similarity in species composition}

Similarities in species composition of different study sites was assessed based on presence-absence data of the species. Sørensen's Coefficient (Mühlenberg 1993) is widely used and was also applied in this study. Similarity was calculated separately for each taxon as well as for each study site and year by using the software MVSP. Based on these similarity values a cluster analysis using the unweighted-pair groups method (UPGMA, Jongman et al. 1995) was carried out.

\section{Centre of distribution in the study area}

For all species found with more than five individuals in the study their centre of distribution was assessed. For each species the proportion of individuals that occurred in each variant was calculated. All species that occurred with at least $70 \%$ of all individuals caught in one variant are assumed to have their centre of distribution in the respective sites.

Species collected during the growing season 2001 were divided into three groups:

I. at least $70 \%$ of all individuals of these species were caught in fallows,

II. species that have no centre of distribution and

III. at least $70 \%$ of all individuals of these species were caught in mown grassland.

Arthropod species found between May and September 2002 were divided into the following four groups:

I. all individuals of these species were caught in just one treatment,

II. all individuals of these species were caught in two treatments,

III. all individuals of these species were caught in three treatments and

IV. all individuals of these species were caught in all four treatments. 


\section{Univariate statistics}

The impact of mowing and flooding on the number of species and individuals as well as on the distribution of species with specific ecological characteristics (see section 3.2.5) was tested by analysis of variance, Mann-Whitney U-Test and Kruskal-Wallis Test (HTest) where appropriate.

\section{Data sampled in 2001}

Based on the data sampled in 2001 the impact of the two factors "mowing" and "flooding" was analysed. Application of a two-factorial analysis of variance, allowed to test not only the effect of the two chosen factors, but also their "interaction", i.e. whether "flooding" affects the species distribution in the same way in sites differing in land use. Analysis of variance being a parametric test statistics, assumes normality of data and homogeneity of variances (Underwood 1997). Normality of data was tested by Shapiro-Wilkes-Test (Shapiro \& Wilk 1965), to analyse the homogeneity of variances F-max Test (Köhler et al. 1996) was carried out. If necessary, data were transformed to fulfil analysis of variance's prerequisites.

Analysis of variance was carried out using the statistical analysing software SAS (Statistical Analysis System, SAS Institute Inc. 1994). Due to the unbalanced study design (see section 3.2.2) the procedure "GLM" combined with Scheffé Test was used. If the assumptions of the parametric test were not fulfilled even after transformation, the effect of mowing was tested by Mann-Whitney U-Test. However, data did not allow a two-factorial non-parametric analysis, hence no identification of "interactions" was possible. Therefore, an analysis of variance was carried out to find out more about possible interactions between the two factors. The results of these tests were interpreted carefully keeping in mind that the assumptions for a parametric analysis were not fulfilled.

Data sampled in 2002

In 2002 the factor "flooding" was in the centre of interest. Due to a balanced study design (see section 3.2.2) the procedure "ANOVA" in combination with the Tukey Test was carried out to identify differences in species distribution in relation to flooding. Prerequisites of analysis of variance were tested and transformation carried out where necessary. If the assumptions of the parametric test were not fulfilled after transformation, the Kruskal-Wallis Test (H-Test) was applied. 


\section{Multivariate statistics}

The impact of the measured environmental variables (see section 3.2.3) on the species communities was assessed by Canonical Correspondence Analysis (CCA) using the software MVSP.

CCA is an ordination technique that arranges sites along axes on the basis of data on species composition and selected environmental factors (Jongman et al. 1995). As a result of the ordination a diagram is gained in which sites and species are represented by dots, environmental variables by arrows. It is the aim of the canonical ordination to detect the main pattern in relations between the species and the observed environmental variables. The eigenvalues of the axes give a measure on how much variation in species data is explained by the respective axis, i.e. by the environmental variables.

To assess whether the measured environmental variables were sufficient to predict the main variation in species composition, eigenvalues gained by CCA were compared to those calculated by a Detrended Correspondence Analysis (DCA). DCA is a technique that constructs a theoretical variable explaining the species data most accurately. Considerably lower eigenvalues of the CCA axes compared to those of the DCA suggest that the measured environmental variables do not predict the main variation in species, but a substantial part of the remaining variation. 


\subsection{Results}

\subsubsection{Ecological characteristics of the Auchenorrhyncha community}

During the growing seasons 2001 and 2002 altogether 3645 individuals belonging to 63 species of Auchenorrhyncha were caught by both collecting methods (Table 6).

Table 6: Species list of Auchenorrhyncha caught in the study area. Individual numbers refer to adults only.

\begin{tabular}{|c|c|c|c|c|c|}
\hline \multirow[b]{2}{*}{ No. } & \multirow[b]{2}{*}{ Species } & \multirow[b]{2}{*}{ Abbreviation } & \multicolumn{2}{|c|}{ Individuals } & \multirow[b]{2}{*}{ Sum } \\
\hline & & & 2001 & 2002 & \\
\hline & Fulgoromorpha & & & & \\
\hline & Delphacidae & & & & \\
\hline 1 & Anakelisia fasciata (Kirschbaum, 1868) & Ana_fas & 1 & 5 & 6 \\
\hline 2 & Stenocranus major (Kirschbaum, 1868) & Ste_maj & 15 & 25 & 40 \\
\hline 3 & Megamelus notula (Germar, 1830) & Meg_not & 8 & 53 & 61 \\
\hline 4 & Eurysula lurida (Fieber, 1866) & Eur_lu & 0 & 2 & 2 \\
\hline 5 & Euconomelus lepidus (Boheman, 1847) & Euc_lep & 1 & 0 & 1 \\
\hline 6 & Megadelphax sordidula (Stal, 1853) & Meg_sor & 0 & 6 & 6 \\
\hline 7 & Laodelphax striatella (Fallén, 1826) & Lao_str & 1 & 6 & 7 \\
\hline 8 & Paraliburnia adela (Flor, 1861) & Par_ad & 4 & 3 & 7 \\
\hline 9 & Mirabella albifrons (Fieber, 1879) & Mir_alb & 3 & 13 & 16 \\
\hline 10 & Muellerianella brevipennis (Boheman, 1847) & Mue_bre & 1 & 42 & 43 \\
\hline 11 & Muellerianella fairmairei (Perris, 1857) & Mue_fai & 0 & 34 & 34 \\
\hline 12 & Acanthodelphax denticauda (Boheman, 1845) & Aca_den & 0 & 1 & 1 \\
\hline 13 & Dicranotropis hamata (Boheman, 1847) & Dic_ham & 10 & 66 & 76 \\
\hline 14 & Xanthodelphax straminea (Stal, 1858) & Xan_sta & 1 & 0 & 1 \\
\hline 15 & Javesella pellucida (Fabricius, 1794) & Jav_pel & 184 & 337 & 521 \\
\hline 16 & Javesella dubia (Kirschbaum, 1868) & Jav_dub & 4 & 51 & 55 \\
\hline \multirow[t]{3}{*}{17} & Ribautodelphax albostriata (Fieber, 1866) & Rib_alb & 8 & 2 & 10 \\
\hline & Cicadomorpha & & & & \\
\hline & Cercopidae & & & & \\
\hline 18 & Neophilaenus lineatus (Linnaeus, 1758) & Neo_lin & 3 & 12 & 15 \\
\hline \multirow[t]{2}{*}{19} & Philaenus spumarius (Linnaeus, 1758) & Phi_spu & 7 & 34 & 41 \\
\hline & Cicadellidae & & & & \\
\hline 20 & Megophthalmus scanicus (Fallén, 1806) & Meg_sca & 3 & 3 & 6 \\
\hline 21 & Anaceratagallia ribauti (Ossiannilsson, 1938) & Ana_rib & 58 & 2 & 60 \\
\hline 22 & Aphrodes bicincta (Schrank, 1776) & Aph_bic & 10 & 4 & 14 \\
\hline 23 & Aphrodes makarovi Zachvatkin, 1948 & Aph_mak & 4 & 0 & 4 \\
\hline 24 & Anoscopus flavostriatus (Donovan, 1799) & Ano_fla & 119 & 173 & 292 \\
\hline 25 & Anoscopus serratulae (Fabricius, 1745) & Ano_ser & 248 & 53 & 301 \\
\hline 26 & Stroggylocephalus agrestis (Fallén, 1806) & Str_agr & 0 & 7 & 7 \\
\hline 27 & Evacanthus acuminatus (Fabricius, 1794) & Eva_acu & 0 & 2 & 2 \\
\hline
\end{tabular}




\begin{tabular}{|c|c|c|c|c|c|}
\hline \multirow[b]{2}{*}{ No. } & \multirow[b]{2}{*}{ Species } & \multicolumn{4}{|c|}{ Individuals } \\
\hline & & Abbreviation & 2001 & 2002 & Sum \\
\hline 28 & Evacanthus interruptus (Linnaeus, 1758) & Eva_int & 0 & 2 & 2 \\
\hline 29 & Cicadella viridis (Linnaeus, 1758) & Cic_vir & 2 & 1 & 3 \\
\hline 30 & Notus flavipennis (Zetterstedt, 1828) & Not_fla & 6 & 7 & 13 \\
\hline 31 & Empoasca pteridis (Dahlbom, 1850) & Emp_pte & 9 & 13 & 22 \\
\hline 32 & Eupteryx atropunctata (Goeze, 1778) & Eup_atr & 1 & 24 & 25 \\
\hline 33 & Eupteryx cyclops Matsumura, 1906 & Eup_cyc & 10 & 22 & 32 \\
\hline 34 & Eupteryx vittata (Linnaeus, 1758) & Eup_vit & 9 & 7 & 16 \\
\hline 35 & Eupteryx notata Curtis, 1837 & Eup_not & 3 & 1 & 4 \\
\hline 36 & Balclutha calamagrostis Ossiannilsson, 1961 & Bal_cal & 3 & 4 & 7 \\
\hline 37 & Balclutha rhenana W.Wagner, 1939 & Bal_rhe & 48 & 18 & 66 \\
\hline 38 & Macrosteles laevis (Ribaut, 1927) & Mac_lae & 22 & 4 & 26 \\
\hline 39 & Macrosteles sexnotatus (Fallén, 1806) & Mac_sex & 89 & 61 & 150 \\
\hline 40 & Macrosteles viridigriseus (Edwards, 1922) & Mac_vir & 4 & 0 & 4 \\
\hline 41 & Deltocephalus pulicaris (Fallén, 1806) & Del_pul & 85 & 2 & 87 \\
\hline 42 & Endria nebulosa (Ball, 1900) & End_neb & 1 & 5 & 6 \\
\hline 43 & Paluda flaveola (Boheman, 1845) & Pal_fla & 7 & 4 & 11 \\
\hline 44 & Rhopalopyx preyssleri (Herrich-Schäffer, 1838) & Rho_pre & 0 & 1 & 1 \\
\hline 45 & Elymana sulphurella (Zetterstedt, 1828) & Ely_sul & 3 & 9 & 12 \\
\hline 46 & Cicadula flori (J. Sahlberg, 1871) & Cic_flo & 5 & 10 & 15 \\
\hline 47 & Cicadula quadrinotata (Fabricius, 1794) & Cic_qua & 3 & 3 & 6 \\
\hline 48 & Cicadula frontalis (Herrich-Schäffer, 1835) & Cic_fro & 3 & 0 & 3 \\
\hline 49 & Mocydia crocea (Herrich-Schäffer, 1837) & Moc_cro & 2 & 16 & 18 \\
\hline 50 & Macustus grisescens (Zetterstedt, 1828) & Mac_gri & 1 & 6 & 7 \\
\hline 51 & Athysanus argentarius Metcalf, 1955 & Ath_arg & 5 & 0 & 5 \\
\hline 52 & Euscelis incisus (Kirschbaum, 1858) & Eus_inc & 3 & 3 & 6 \\
\hline 53 & Streptanus aemulans (Kirschbaum, 1868) & Str_aem & 63 & 82 & 145 \\
\hline 54 & Streptanus sordidus (Zetterstedt, 1828) & Str_sor & 109 & 8 & 117 \\
\hline 55 & Metalimnus formosus (Boheman, 1845) & Met_for & 1 & 24 & 25 \\
\hline 56 & Psammotettix kolosvarensis (Matsumura, 1908) & Psa_kol & 18 & 4 & 22 \\
\hline 57 & Psammotettix alienus (Dahlbom, 1850) & Psa_ali & 10 & 0 & 10 \\
\hline 58 & Psammotettix confinis (Dahlbom, 1850) & Psa_con & 2 & 0 & 2 \\
\hline 59 & Errastunus ocellaris (Fallén, 1806) & Err_oce & 183 & 78 & 261 \\
\hline 60 & Arthaldeus pascuellus (Fallén, 1826) & Art_pas & 386 & 112 & 498 \\
\hline 61 & Cosmotettix costalis (Fallén, 1826) & Cos_cos & 2 & 16 & 18 \\
\hline 62 & Mocuellus collinus (Boheman, 1850) & Moc_col & 4 & 0 & 4 \\
\hline \multirow[t]{2}{*}{63} & Erzaleus metrius (Flor, 1861) & Erz_met & 242 & 125 & 367 \\
\hline & Sum & & 2037 & 1608 & 3645 \\
\hline
\end{tabular}


Out of these, 46 species were found in both years, whereas 9 species were only caught in 2001 and 8 exclusively in 2002. The highest population density with 740 adult individuals per $\mathrm{m}^{2}$ was found in July 2002 in site HF3 (Appendix 2), a fallow subject to high flooding impact. The Auchenorrhyncha assemblage occurring in the grassland of the Lower Oder Valley National Park was dominated by Javesella pellucida, Arthaldeus pascuellus and Erzaleus metrius (Fig. 10).

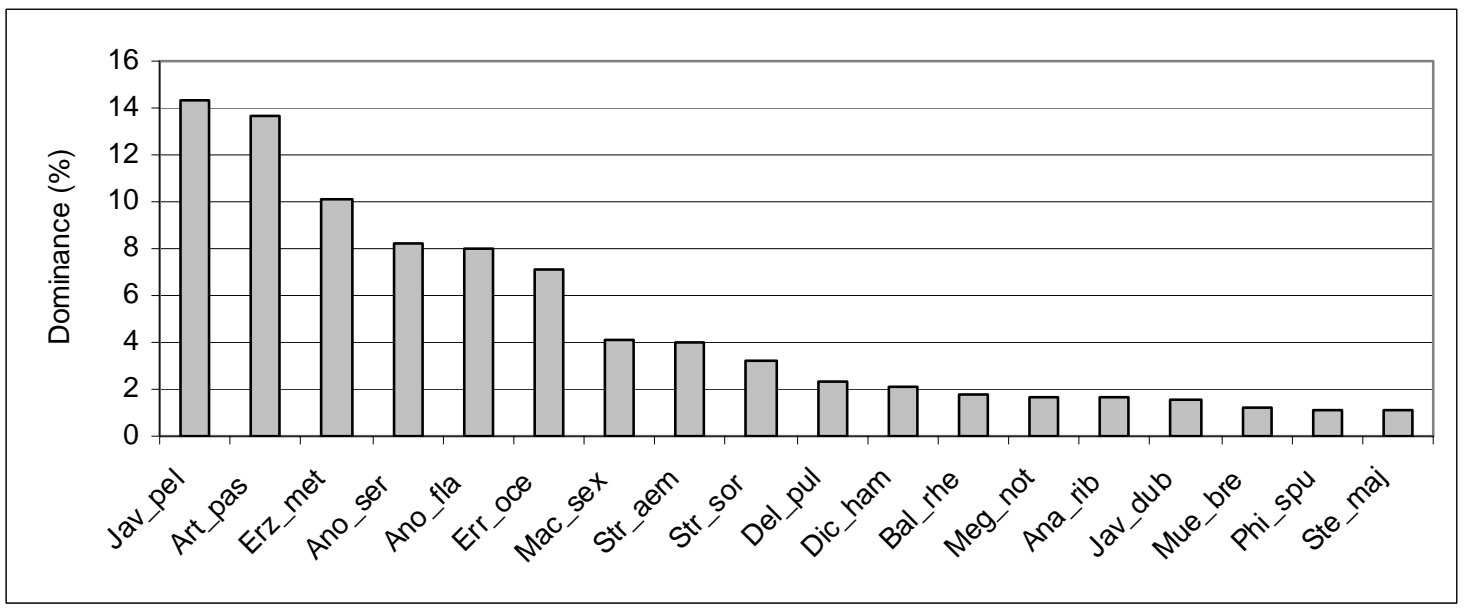

Fig. 10: Dominance of Auchenorrhyncha based on total catches of both study years. Only species found in more than $1 \%$ of the total individual numbers are shown. A list of abbreviations of the species names can be found in Table 6 .

Furthermore, 12 species that were found in the national park's floodplain are listed in the Red Data Book (RDB) of Germany (Remane et al. 1998) (Table 7).

Table 7: Endangered species. RDB categories listed: $\mathrm{V}=$ "Vorwarnliste", 3 = "gefährdet", 2 = "stark gefährdet”

\begin{tabular}{lrr}
\hline Species & RDB category & IUCN category \\
\hline Acanthodelphax denticauda (Boh.) & 3 & vulnerable \\
Anakelisia fasciata (Kbm.) & 3 & vulnerable \\
Cicadula flori (J. Shlb.) & $\mathrm{V}$ & near threatened \\
Cicadula frontalis (H.-S.) & $\mathrm{V}$ & near threatened \\
Cosmotettix costalis (Fall.) & 2 & endangered \\
Euconomelus lepidus (Boh.) & 3 & vulnerable \\
Metalimnus formosus (Boh.) & 2 & endangered \\
Mirabella albifrons (Fieb.) & 3 & vulnerable \\
Paraliburnia adela (Fl.) & 3 & vulnerable \\
Psammotettix kolosvarensis (Mats.) & 3 & vulnerable \\
Stroggylocephalus agrestis (Fall.) & $\mathrm{V}$ & near threatened \\
Xanthodelphax straminea (Stal) & 3 & vulnerable \\
\hline
\end{tabular}

Figure 11 gives an overview of the ecological characteristics of the Auchenorrhyncha community. About $50 \%$ of all species were euryhygric, over $40 \%$ hygrophilous (I). Three quarter of the species showed wing dimorphism (II), thus the populations of these 
species may consist of both brachypterous and macropterous species. Most plant- and leafhoppers found overwinter in the egg stage (III). Furthermore, the proportion of host specialists was high. About $40 \%$ of the species feed on just one host genus, another $40 \%$ were restricted to one host family (IV). This high degree of specialisation was also reflected in the data on life strategy of the species. Nearly $70 \%$ of the plant- and leafhoppers that were found in the national park fall either in the category "oligotopic" or "stenotopic" (V). Most of the Auchenorrhyncha species were monovoltine, about $40 \%$ were bivoltine (VI).
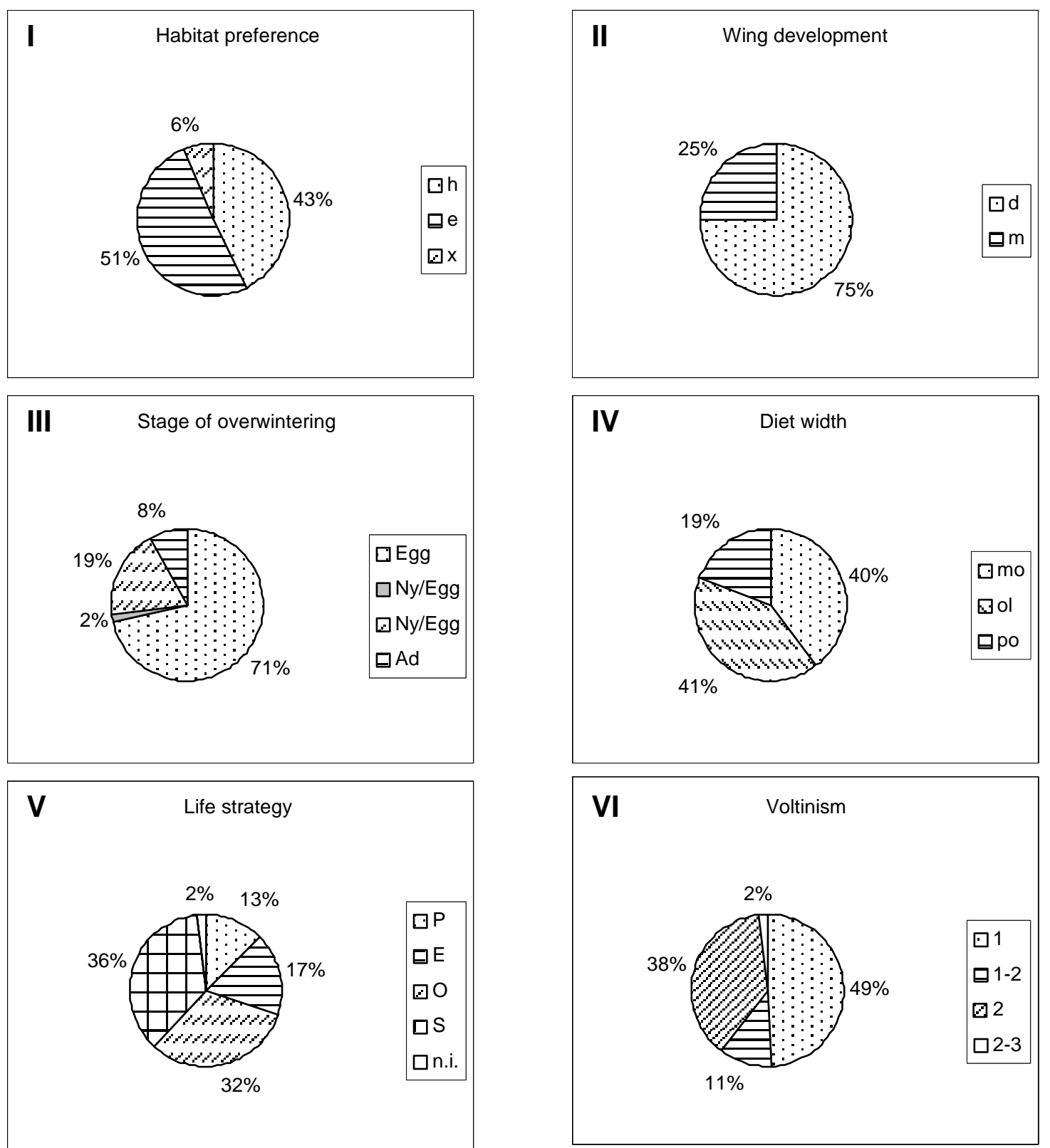

Fig. 11: Ecological characteristics of the Auchenorrhyncha community based on all species caught throughout the growing seasons 2001 and 2002. h: hygrophilous, e: euryhygric, x: xerophilous, d: dimorphic, m: macropterous, Egg: overwintering in the egg stage, Ny/Egg: overwintering as nymph or egg, Ny: overwintering as nymph, Ad: overwintering in the adult stage, mo: monophagous, ol: oligophagous, po: polyphagous, P: pioneer species, E: eurytopic species, O: oligotopic species, S: stenotopic species, n.i.: no information, 1: monovoltine, 1-2: mono- or bivoltine, 2: bivoltine, 2-3: bi- or trivoltine. 


\subsubsection{Impact of mowing}

In this section the impact of mowing on the Auchenorrhyncha communities is analysed in detail. Only adult plant- and leafhoppers are considered. The analyses are all based on data collected by suction sampling between June and September 2001. The samples taken during the different sampling periods were summed up.

\section{Numbers of species, numbers of individuals and diversity}

During the growing season 1553 individuals of plant- and leafhoppers were collected representing 54 species. Altogether more species were caught in fallows than in mown sites (Table 8). A statistical comparison of the data revealed no significant differences in mean numbers of species and individuals as well as in the average diversity values.

Table 8: Numbers of species, numbers of individuals (per $0.45 \mathrm{~m}^{2}$ ) and diversity on fallows and mown study sites.

\begin{tabular}{lrrrr}
\hline Treatment & No. of species & Mean no. of species & Mean no. of individuals & Mean diversity \\
\hline Fallows & 43 & $11.7+/-3.77$ & $76.0+/-39.87$ & $1.63+/-0.53$ \\
Mown sites & 33 & $11.7+/-3.19$ & $78.4+/-34.52$ & $1.82+/-0.29$ \\
\hline
\end{tabular}

The highest species number (20) was collected in a fallow in the dry-polder (NF1), the lowest (5) in a mown study site subject to medium flooding impact (MM1) (Appendix 2a). Going along with these findings the most diverse community was found in site NF1. In this site the community was comparably rich in species and the evenness value was rather high (0.85). The least diverse community was found in a fallow subject to medium flooding impact (MF2), with an evenness of only 0.27 .

Estimated species richness ranged from 49 to 68 species in fallows and from 38 to 54 in mown sites (Table 9). In all estimation methods but Chao 2 species richness was higher in fallows than in mown sites. It seems that this estimator is less accurate for the given set of samples. Also Brose et al. (2003) found in most tested data sets that Chao2 was less accurate than the Jackknife estimators.

Table 9: Estimated species richness by different estimation methods.

\begin{tabular}{lccccccc}
\hline & ACE & ICE & Chao1 & Chao2 & Jack1 & Jack2 & Bootstrap \\
\hline Fallows & 49 & 68 & 55 & 57 & 59 & 66 & 51 \\
Mown sites & 40 & 47 & 39 & 60 & 45 & 54 & 38 \\
\hline
\end{tabular}

Furthermore, they propose to use the community evenness as a measure to choose the appropriate estimator (Brose et al. 2003). In the communities of fallows and mown sites the evenness was high, i.e. 0.65 and 0.68 , respectively. Thus, first- and second-order Jackknife estimators seem to be the appropriate methods. In fallows and mown sites Jack2 calculated one of the highest values of species richness, whereas Jack1 estimated a more moderate value. To compare species richness of fallows and mown sites, the results of the Jack1 estimation are plotted in Figure 12. 


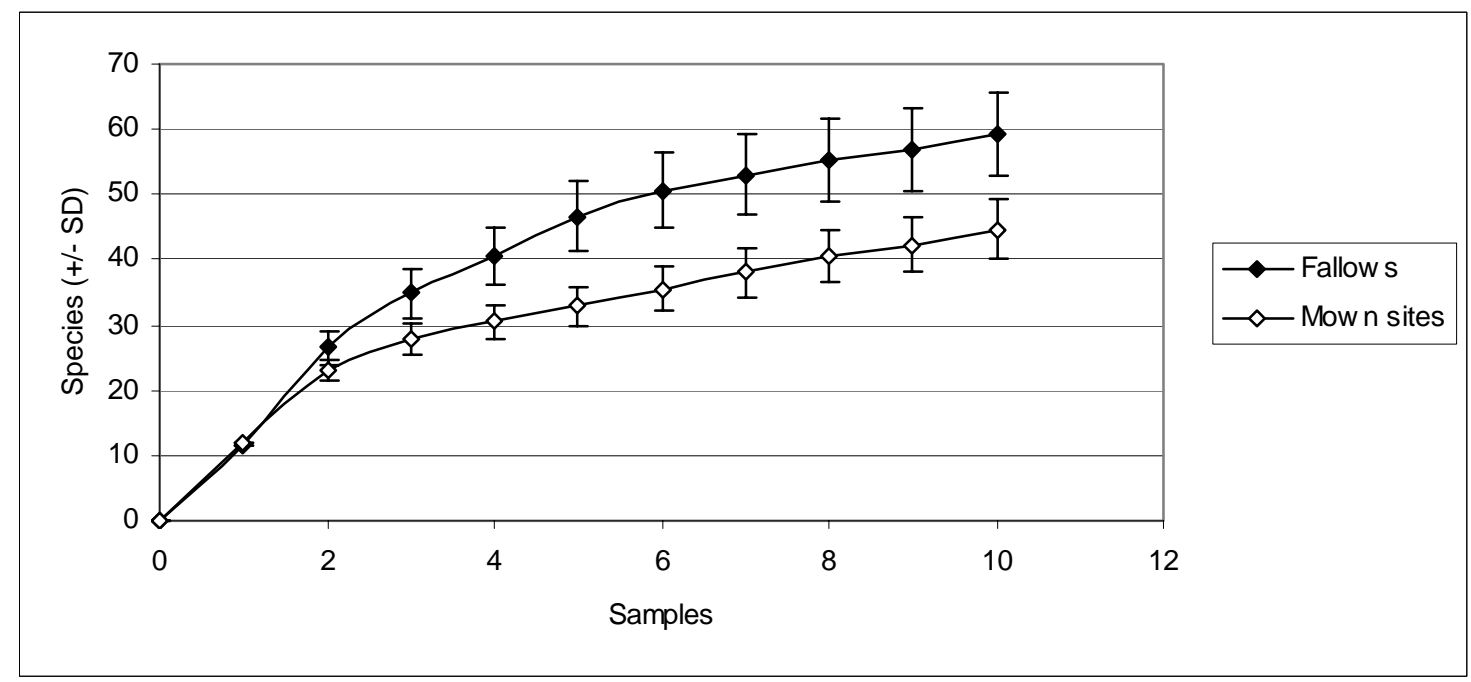

Fig. 12: First-order Jackknife estimation of Auchenorrhyncha species richness in fallows and mown sites.

Regarding the numbers of species and individuals separately for June, August and September, short term effects of mowing become evident (Fig. 13). Whereas no difference between numbers of species were identified in June, i.e. shortly after the first cut (Fig. 13 I), numbers of individuals caught in fallows differed significantly from those in mown sites (Fig. 13 II). In August, no differences were identified, while in September significantly more individuals were found in mown grassland than in fallows.
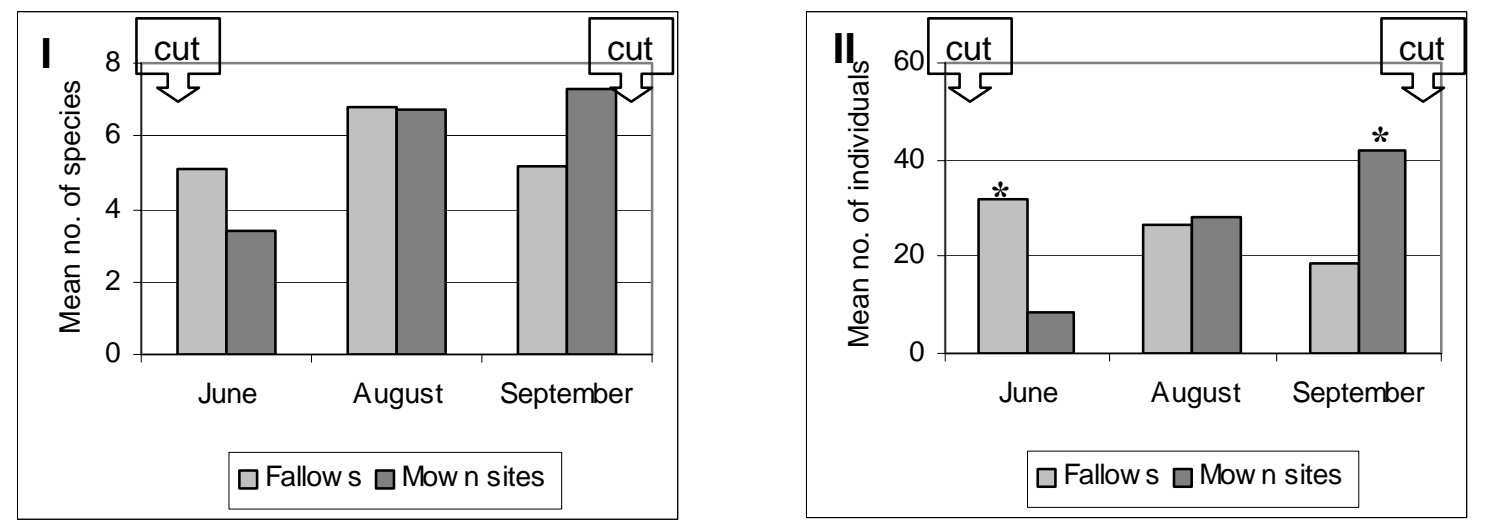

Fig. 13: Mean number of species (I) and individuals per $0.15 \mathrm{~m}^{2}$ (II) in fallows and in mown sites. For each month a Mann-Whitney U-Test was carried out separately. Significant differences are indicated by *, tendencies by (*). Individuals June: $\mathrm{z}=2.31, \mathrm{p}=0.02$; individuals September: $\mathrm{z}=2.23, \mathrm{p}=0.03$. 


\section{Dominance}

Three species fall in the category of "dominant species" (section 3.2.6) in fallows as well as in mown sites, respectively (Fig. 14). In fallows (I) Erzaleus metrius and Errastunus ocellaris prevailed, whereas in mown sites (II) Javesella pellucida and Macrosteles sexnotatus dominated. Further, Arthaldeus pascuellus belonged to the dominant species in both variants.
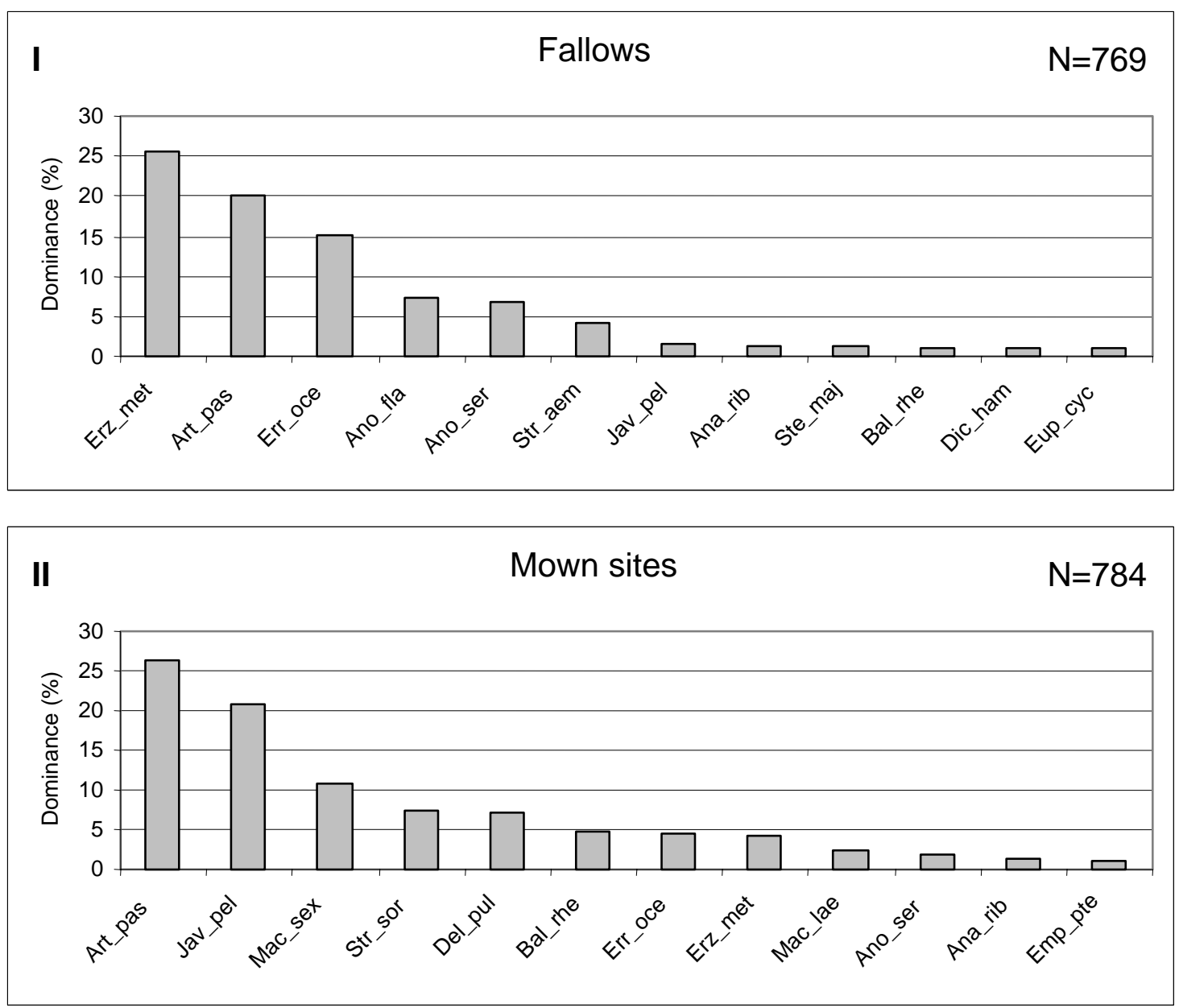

Fig 14: Dominance of Auchenorrhyncha of fallows (I) and mown sites (II) based on suction samples taken in 2001. Only species found in more than $1 \%$ of the total individual numbers $(\mathrm{N})$ are shown. A list of abbreviations of the species names can be found in Table 6 . 


\section{Impact of mowing on common species}

It is analysed whether land use affects the abundance of common plant- and leafhoppers. Anoscopus flavostriatus and Errastunus ocellaris were caught in significantly higher numbers in fallows than in mown sites (Table 10). No differences were identified for Arthaldeus pascuellus, Anoscopus serratulae, Erzaleus metrius, Streptanus aemulans and Balclutha rhenana. All four remaining common species dominated in mown grassland.

Table 10: Impact of mowing on the abundance of common species. For each species that comprises at least four percent of the plant- and leafhopper community of each variant a Mann-Whitney U-Test was carried out separately. If significant differences are found, the higher number of individuals is written in bold.

\begin{tabular}{lllrr}
\hline & \multicolumn{2}{l}{ Mean no. of individuals per $\mathbf{0 . 4 5} \mathbf{~ m}^{\mathbf{2}}$} & & \\
Species & Fallows & Mown sites & Z & p \\
\hline Anoscopus flavostriatus (Don.) & $\mathbf{5 . 7}+/-6.1$ & $0.4+/-0.7$ & 2.70 & 0.007 \\
Errastunus ocellaris (Fall.) & $\mathbf{1 1 . 8}+/-10.1$ & $3.5+/-4.7$ & 1.98 & 0.05 \\
Arthaldeus pascuellus (Fall.) & $15.6+/-21.3$ & $20.7+/-17.2$ & & n.s. \\
Anoscopus serratulae (F.) & $5.3+/-7.1$ & $1.5+/-1.6$ & & n.s. \\
Erzaleus metrius (Fl.) & $19.7+/-40.2$ & $3.4+/-4.7$ & & n.s. \\
Streptanus aemulans (Kbm.) & $3.3+/-4.8$ & $0.6+/-1.3$ & & n.s. \\
Balclutha rhenana W.Wg. & $0.8+/-2.2$ & $3.6+/-6.4$ & & n.s. \\
Deltocephalus pulicaris (Fall.) & $0.3+/-0.67$ & $\mathbf{5 . 5}+/-5.6$ & 3.18 & 0.002 \\
Javesella pellucida (F.) & $1.2+/-1.9$ & $\mathbf{1 5 . 6}+/-10.37$ & 3.78 & 0.0002 \\
Macrosteles sexnotatus (Fall.) & $0.1+/-0.32$ & $\mathbf{8 . 8}+/-17.5$ & 2.44 & 0.01 \\
Streptanus sordidus (Zett.) & $0.3+/-0.48$ & $\mathbf{6 . 0}+/-7.2$ & 2.20 & 0.03 \\
\hline
\end{tabular}




\section{Centre of distribution in the study area}

In Table 11 all species are listed that were caught with at least five individuals in the study area giving information on their centre of distribution. 15 species were found predominantly in fallows, out of these Eupteryx vittata, Paluda flaveola, Philaenus spumarius and Cicadula flori were collected there exclusively. Eight species had their centre of occurrence in mown plots, including Empoasca pteridis and Psammotettix alienus which were found only in mown sites. Five species showed no preference.

Table 11: Centre of distribution in the study area. All species that were caught with at least five individuals in the study area are listed. I: At least $70 \%$ of the individuals of the respective species were caught in fallows. II: Less than $70 \%$ of the individuals occur in one treatment. III: At least $70 \%$ of the individuals of the respective species were caught in mown sites. Species that were only found in one study site are written in italics. Proportions greater than $70 \%$ are written in bold.

\begin{tabular}{|c|c|c|c|c|}
\hline \multirow[b]{2}{*}{ Species } & \multicolumn{2}{|c|}{ Individuals } & \multicolumn{2}{|c|}{ Individuals (\%) } \\
\hline & Fallows & Mown sites & Fallows & Mown sites \\
\hline \multicolumn{5}{|l|}{ I } \\
\hline Eupteryx vittata (L.) & 7 & 0 & 100.0 & 0.0 \\
\hline Paluda flaveola (Boh.) & 7 & 0 & 100.0 & 0.0 \\
\hline Philaenus spumarius (L.) & 7 & 0 & 100.0 & 0.0 \\
\hline Cicadula flori (J. Shlb.) & 5 & 0 & 100.0 & 0.0 \\
\hline Anoscopus flavostriatus (Don.) & 57 & 4 & 93.4 & 6.6 \\
\hline Dicranotropis hamata (Boh.) & 9 & 1 & 90.0 & 10.0 \\
\hline Eupteryx cyclops Mats. & 8 & 1 & 88.9 & 11.1 \\
\hline Megamelus notula (Germ.) & 7 & 1 & 87.5 & 12.5 \\
\hline Ribautodelphax albostriata (Fieb.) & 7 & 1 & 87.5 & 12.5 \\
\hline Erzaleus metrius (Fl.) & 197 & 34 & 85.3 & 14.7 \\
\hline Streptanus aemulans (Kbm.) & 33 & 8 & 80.5 & 19.5 \\
\hline Aphrodes bicincta (Schrk.) & 4 & 1 & 80.0 & 20.0 \\
\hline Athysanus argentarius Metc. & 4 & 1 & 80.0 & 20.0 \\
\hline Anoscopus serratulae (F.) & 53 & 15 & 77.9 & 22.1 \\
\hline Errastunus ocellaris (Fall.) & 118 & 36 & 76.6 & 23.4 \\
\hline \multicolumn{5}{|l|}{ II } \\
\hline Stenocranus major (Kbm.) & 10 & 5 & 66.7 & 33.3 \\
\hline Anaceratagallia ribauti (Oss.) & 10 & 10 & 50.0 & 50.0 \\
\hline Psammotettix kolosvarensis (Mats.) & 7 & 7 & 50.0 & 50.0 \\
\hline Notus flavipennis (Zett.) & 3 & 3 & 50.0 & 50.0 \\
\hline Arthaldeus pascuellus (Fall.) & 156 & 213 & 42.3 & 57.7 \\
\hline \multicolumn{5}{|l|}{ III } \\
\hline Balcluta rhenana W. Wg. & 9 & 39 & 18.8 & 81.2 \\
\hline Javesella pellucida (F.) & 13 & 169 & 7.1 & 92.9 \\
\hline Deltocephalus pulicaris (Fall.) & 3 & 57 & 5.0 & 95.0 \\
\hline Streptanus sordidus (Zett.) & 3 & 60 & 4.8 & 95.2 \\
\hline Macrosteles laevis (Rib.) & 1 & 20 & 4.8 & 95.2 \\
\hline Macrosteles sexnotatus (Fall.) & 1 & 88 & 1.1 & 98.9 \\
\hline Empoasca pteridis (Dhlb.) & 0 & 9 & 0.0 & 100.0 \\
\hline Psammotettix alienus (Dhlb.) & 0 & 7 & 0.0 & 100.0 \\
\hline No. of sites & 10 & 10 & & \\
\hline
\end{tabular}




\section{Ecological characteristics}

In the following section it is analysed whether land use negatively or positively affects plant- and leafhoppers with specific ecological characteristics. Habitat preferences, wing development, voltinism, diet width and specialisation are in the centre of interest.

\section{Moisture preference}

Species of open habitats were classified according to their moisture preference (see 3.2.5). Species assemblages were dominated by euryhygric species in both, fallows and mown sites (Fig. 15). Only few xerophilous species were collected in the study area. In mown study sites, hygrophilous plant- and leafhoppers were caught in higher numbers of species (I) and individuals (II) as opposed to fallows.
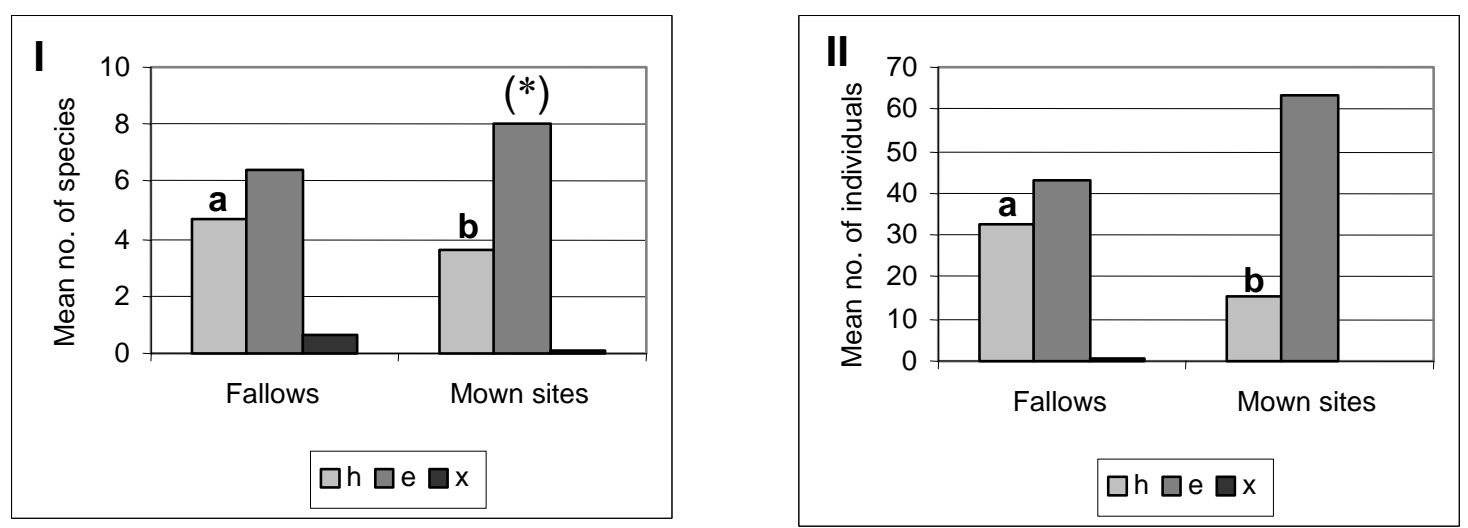

Fig. 15: Moisture preference in the recorded Auchenorrhyncha species. Hygrophilous (h), euryhygric (e) and xerophilous (x) species (I) and individuals per $0.45 \mathrm{~m}^{2}$ (II) in fallows and mown sites. For all three categories a GLM and Scheffé Test were carried out separately. Significant differences are indicated by different letters (Scheffé Test). Hygrophilous species: $\mathrm{F}=5.68, \mathrm{p}=0.03$; hygrophilous individuals: $\mathrm{F}=21.26, \mathrm{p}=0.0006$.

Wing development

Wing dimorphic species dominated in both fallows and mown plots and only few species were monomorphic macropterous (Fig. 16). In mown study sites more macropterous species (I) and individuals (II) were collected than in fallows. However, one should bare in mind that in some dimorphic species typically occurring in mown meadows such as Javesella pellucida macropterous individuals dominate. 

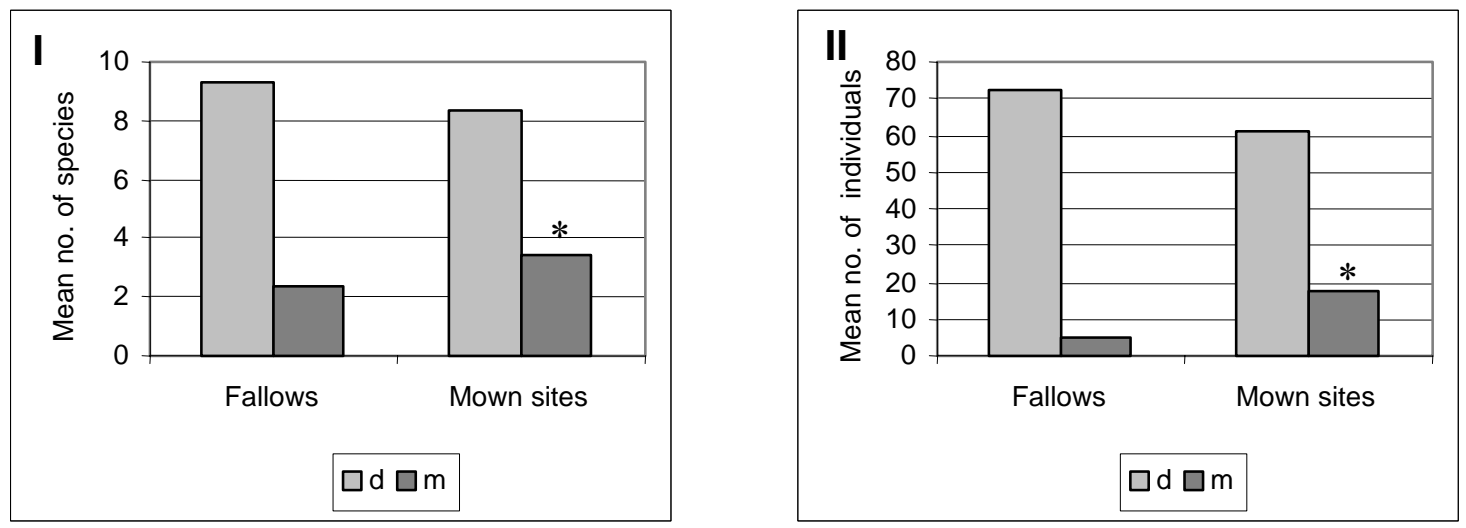

Fig. 16: Wing development in the recorded Auchenorrhyncha species. Dimorphic (d) and monomorphic macropterous (m) species (I) and individuals per $0.45 \mathrm{~m}^{2}$ (II) in fallows and mown sites. For each of the two categories a Mann-Whitney U-Test was carried out separately. Significant differences are indicated by $*$, tendencies by $(*)$. Macropterous species: $z=1.83, p=0.07$; macropterous individuals: $\mathrm{z}=2.62, \mathrm{p}=0.009$.

\section{Voltinism}

In fallows as well as in mown grassland most species were bivoltine (Fig. 17 I). Significantly more monovoltine species were found in fallows than in mown sites. Taking into account the numbers of individuals, the dominance of bivoltine Auchenorrhyncha in both fallows and mown plots became even more evident (Fig. 17 II). Here, significant differences were identified for monovoltine and mono- or bivoltine plant- and leafhoppers.
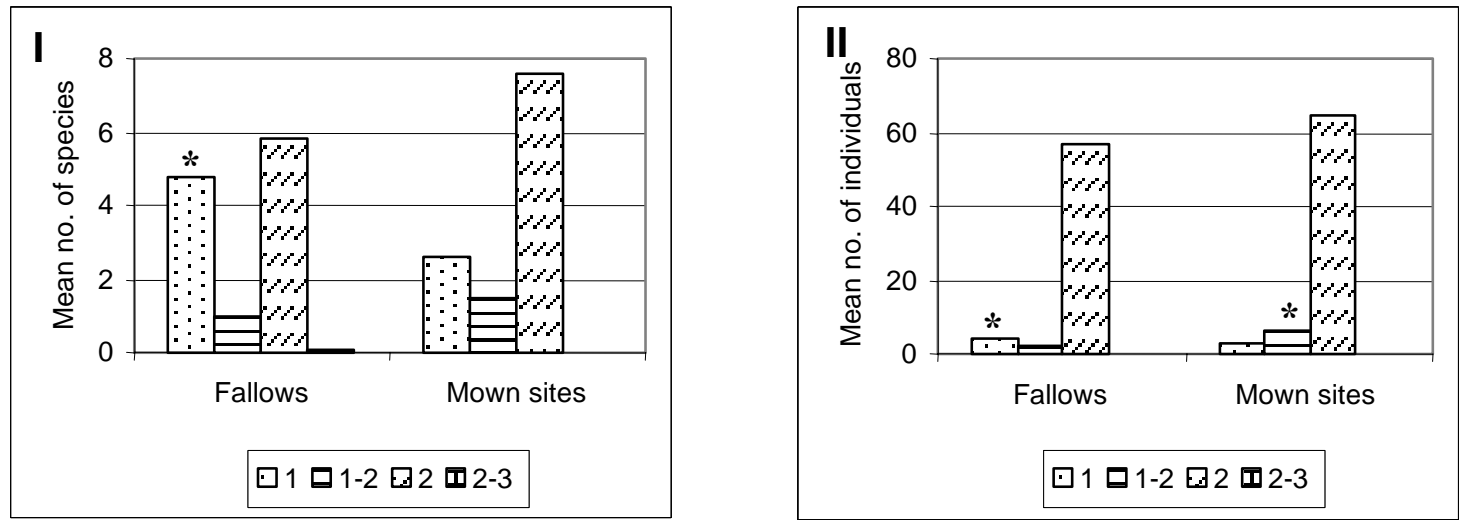

Fig. 17: Annual generation numbers in the recorded Auchenorrhyncha species. Monovoltine (1), monoor bivoltine (1-2), bivoltine (2) and bi- or trivoltine (2-3) species (I) and individuals per $0.45 \mathrm{~m}^{2}$ (II) in fallows and mown sites. For each of the four categories a Mann-Whitney U-Test was carried out separately. Significant differences are indicated by *. Monovoltine species: $\mathrm{z}=2.63$, $\mathrm{p}=0.008$; monovoltine individuals: $\mathrm{z}=2.66, \mathrm{p}=0.008$; mono- or bivoltine individuals: $\mathrm{z}=2.11$, $\mathrm{p}=0.04$. 


\section{Diet width}

In both, fallows and mown grassland, oligophagous species prevailed (Fig. 18). Furthermore, more polyphagous species (I) and individuals (II) were found in mown plots, whereas no differences between monophagous and oligophagous species were identified.
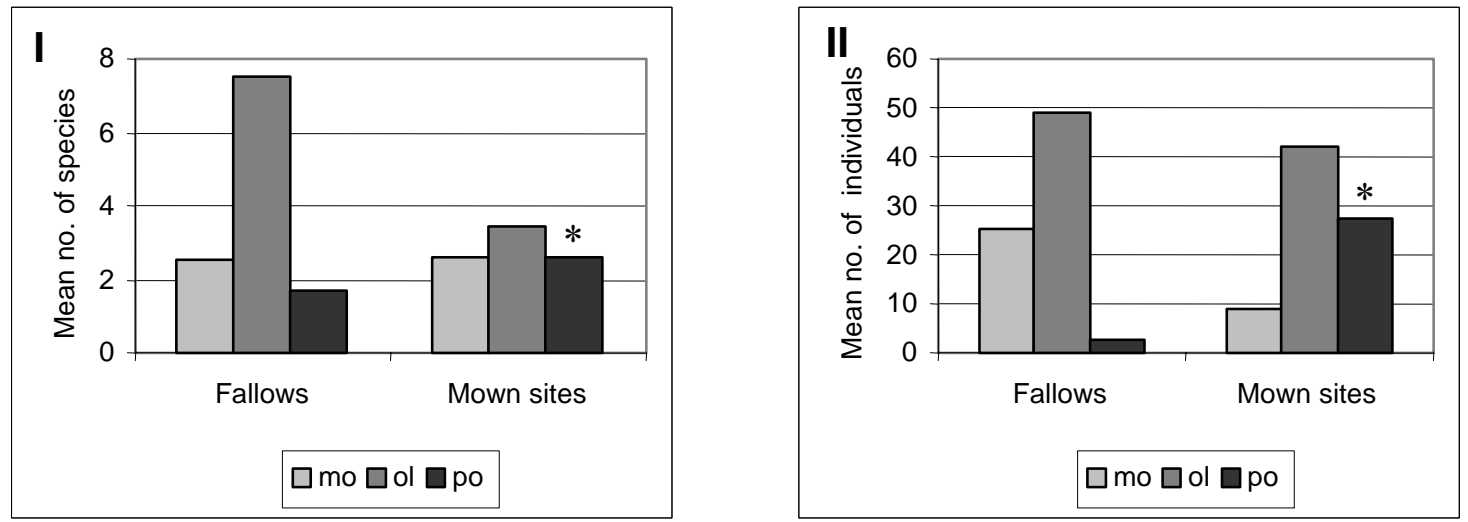

Fig. 18: Diet width in the recorded Auchenorrhyncha species. Monophagous (mo), oligophagous (ol) and polyphagous (po) species (I) and individuals per $0.45 \mathrm{~m}^{2}$ (II) in fallows and mown sites. For each of the three categories a Mann-Whitney U-Test was carried out separately. Significant differences are indicated by $*$, tendencies by $(*)$. Polyphagous species: $z=1.76, p=0.08$; polyphagous individuals: $\mathrm{z}=3.61, \mathrm{p}=0.0003$.

\section{Specialisation}

The degree of specialisation of the plant- and leafhopper communities in fallows was compared to those in mown grassland. The degree of specialisation was higher in fallows than in mown plots (Fig. 19). The difference was evident both in species data (I) and in data based on numbers of individuals (II).
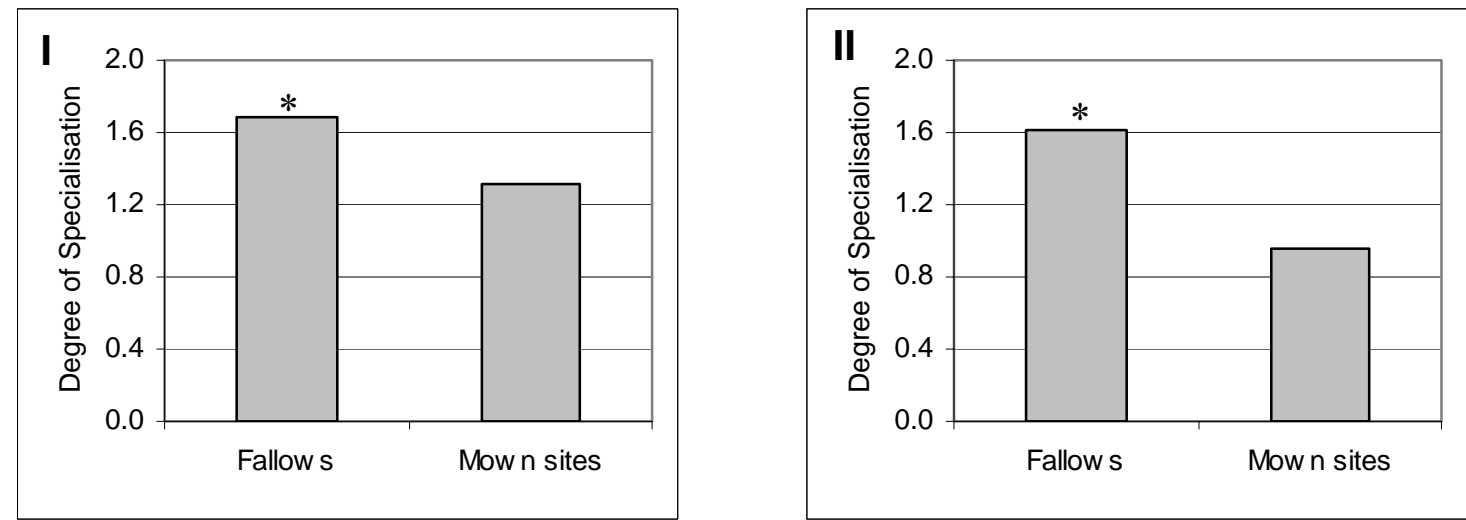

Fig. 19: Degree of specialisation in the recorded Auchenorrhyncha species based on species data (I) and on numbers of individuals (II) in fallows and mown sites. A Mann-Whitney U-Test was carried out. Significant differences are indicated by *. Species: $z=2.27, p=0.02$; Individuals: $z=2.53$, $\mathrm{p}=0.01$. 
A close look at the classes of specialisation reveals, that the Auchenorrhyncha community in fallows was dominated by eurytopic and oligotopic species, whereas in mown sites eurytopic and pioneer species made up the dominant group (Fig. 20 I). In fallows the number of oligotopic species was significantly higher than in mown grassland. Considering individual numbers, stenotopic species were prevalent in fallows, while in mown grassland most individuals were pioneer species (Fig 20 II). Significant differences in the numbers of individuals were identified for both groups.
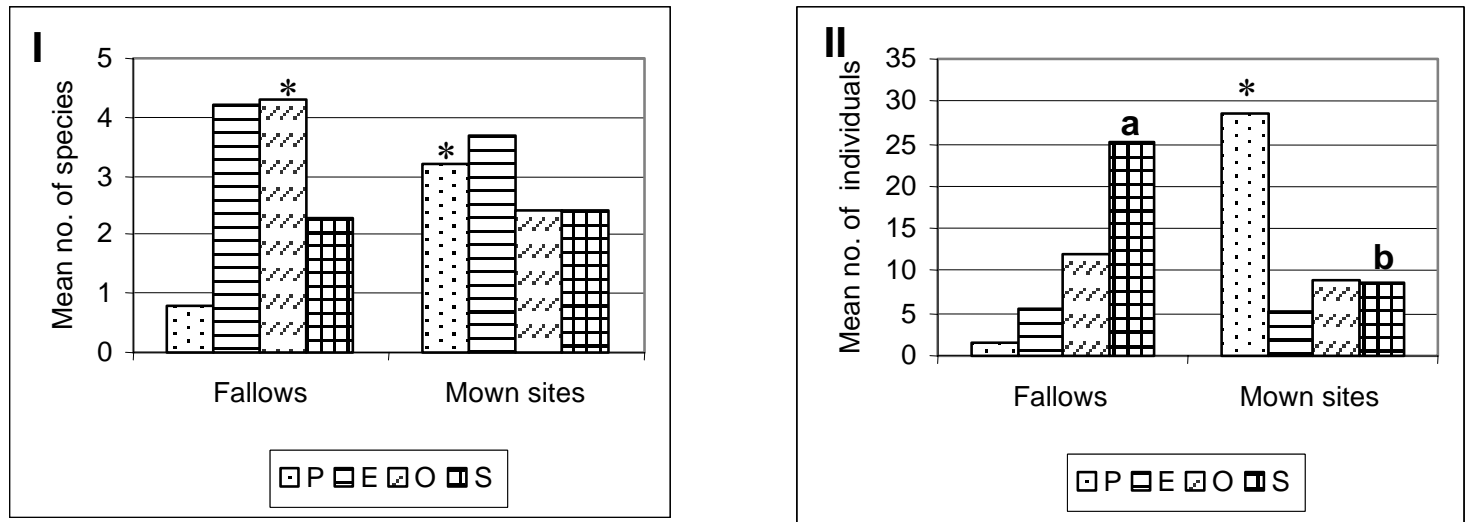

Fig. 20: Life strategy in the recorded Auchenorrhyncha species. Pioneer (P), eurytopic (E), oligotopic (O) and stenotopic (S) species (I) and individuals per $0.45 \mathrm{~m}^{2}$ (II) in fallows and mown sites. For each of the four categories a GLM and Scheffé Test or Mann-Whitney U-Test was carried out separately. Significant differences are indicated by different letters (Scheffé Test) or by * (UTest). Pioneer species (U-test): $\mathrm{z}=3.46, \mathrm{p}=0.0005$; pioneer individuals (U-test): $\mathrm{z}=3.77$, $\mathrm{p}=0.0002$; oligotopic species (U-test): $\mathrm{z}=2.32, \mathrm{p}=0.02$; stenotopic individuals (GLM, transformation: $\left.\mathrm{x}^{-0.5}\right): \mathrm{F}=7.36, \mathrm{p}=0.02$. 


\subsubsection{Impact of flooding}

The influence of flooding on the diversity of Auchenorrhyncha is analysed based on samples taken in fallows between May and September 2002. All samples that were taken with the suction apparatus throughout the growing season were summed up for analyses.

\section{Numbers of species, numbers of individuals and diversity}

Between May and September 20021325 plant- and leafhoppers were collected, which belonged to 53 species. Most species were caught in sites not subject to any flooding impact, the sites the least rich in species were those subject to medium flooding impact (Fig. 21).

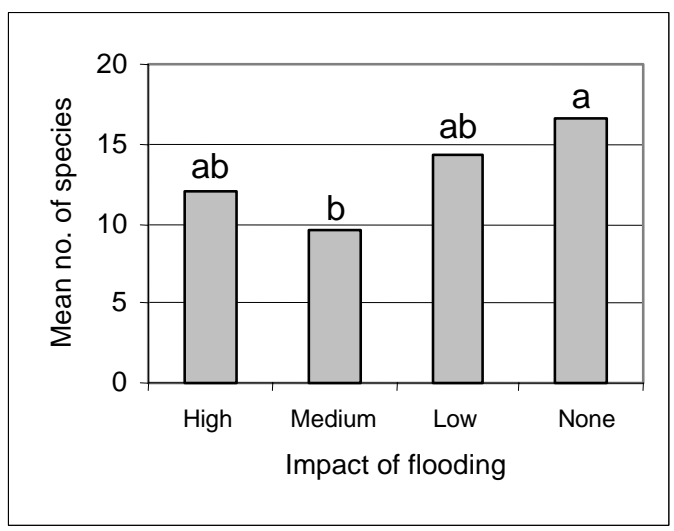

Fig. 21: Effect of flooding on species numbers of Auchenorrhyncha. An ANOVA and Tukey Test was carried out. Bars marked with different letters are significantly different. ANOVA: F=4.95, $\mathrm{p}=0.03$.

The highest average diversity values were found in fallows in the dry-polder, the lowest diversity in sites subject to high and medium flooding impact (Fig. 22).

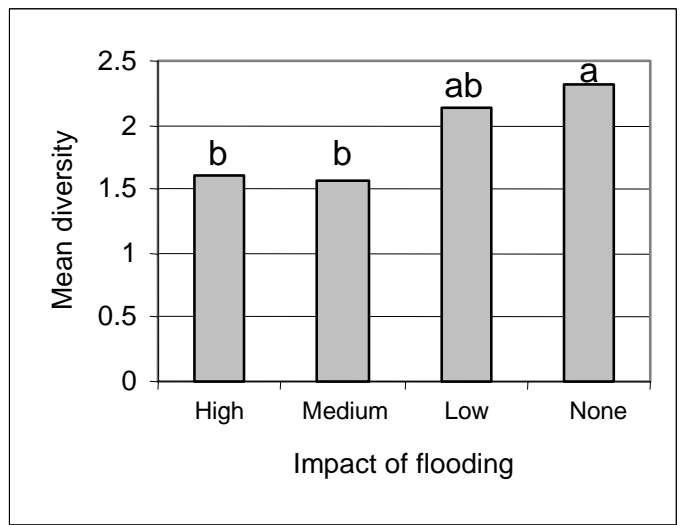

Fig. 22: Diversity in sites subject to different flooding influence. An ANOVA and Tukey Test was carried out. Bars marked with different letters are significantly different. ANOVA: F=5.98, $\mathrm{p}=0.02$.

Numbers of individuals did not differ significantly between sites differing in inundation influence. 
Estimated species richness ranged from 24 to 31 species in fallows subject to high flooding impact, from 18 to 22 in those subject to medium flooding impact, from 32 to 42 in those subject to low flooding impact and from 33 to 41 in those not subject to flooding (Table 12). In all estimation methods except Chao2 (see section 3.3.2) species richness was lowest in fallows subject to medium flooding impact, followed by those subject to high flooding impact. The second most species were calculated for sites not subject to inundation. Most species rich were fallows subject to low flooding impact.

Table 12: Estimated species richness by different estimation methods.

\begin{tabular}{lccccccc}
\hline Flooding regime & ACE & ICE & Chao1 & Chao2 & Jack1 & Jack2 & Bootstrap \\
\hline High & 28 & 27 & 25 & 26 & 27 & 31 & 24 \\
Medium & 21 & 20 & 21 & 19 & 22 & 18 & 21 \\
Low & 38 & 39 & 34 & 35 & 37 & 42 & 32 \\
None & 35 & 35 & 33 & 35 & 36 & 41 & 32 \\
\hline
\end{tabular}

In the communities of fallows differing in flooding regime the evenness was high and ranged from 0.62 to 0.79 . Thus, first- and second-order Jackknife estimators seem to be the appropriate methods. In all variants except in fallows subject to medium flooding impact Jack2 calculated one of the highest species richness values, whereas Jack1 estimated more moderate values. To compare species richness of the fallows differing in flooding regime, the results of the Jack1 estimation are plotted in Figure 23. Sites subject to medium and high flooding impact are less rich in species than sites subject to low or no flooding impact. It seems that in the former sites species richness reached its maximum by 22 and 27 species, respectively. In the latter sites, one might expect to find higher species numbers with increased sampling effort.

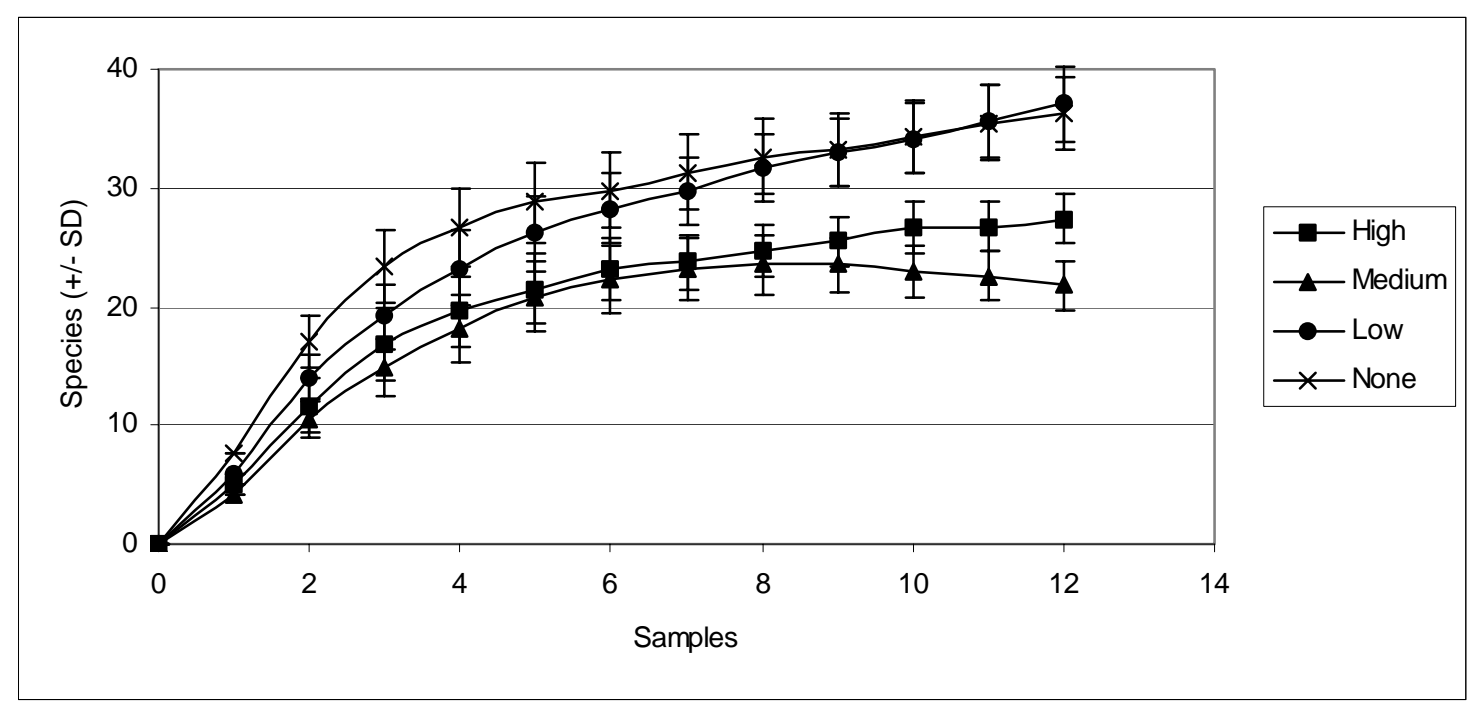

Fig. 23: First-order Jackknife estimation of Auchenorrhyncha species richness in fallows subject to different flooding regimes. 


\section{Dominance}

In sites subject to high (I) and in those subject to medium flooding impact (II) two species dominated (Fig. 24). In fallows subject to low (III) and in those without flooding impact (IV) four species made up more than ten percent of all individuals caught in these plots. Javesella pellucida was the most abundant species in all sites except those subject to medium flooding impact. Arthaldeus pascuellus occurred frequently in sites subject to low or no inundation influence. 
3.3 Impact of mowing and flooding - Results
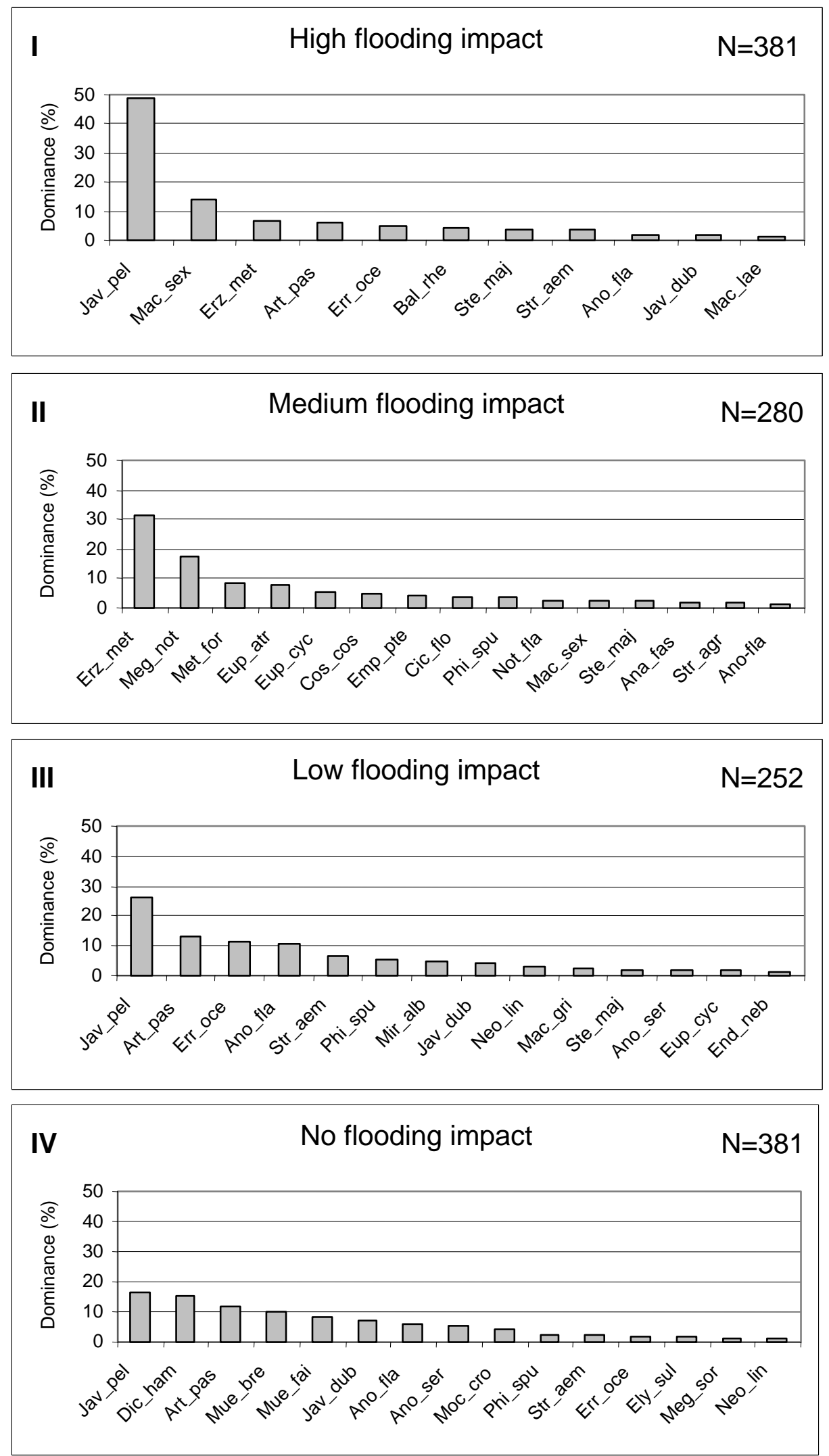

Fig. 24: Dominance of Auchenorrhyncha of fallows subject to high (I), medium (II), low (III) and no (IV) flooding impact based on suction samples taken in 2002. Only species found in more than $1 \%$ of the total individual numbers $(\mathrm{N})$ are shown. A list of abbreviations of the species names can be found in Table 6 .

43 


\section{Impact of flooding on common species}

For three species significant differences correlated with flooding influence were found (Table 13). Anoscopus flavostriatus was most abundant in sites subject to low flooding impact and least abundant in those subject to medium flooding impact. A similar pattern was found for Arthaldeus pascuellus, which was also caught in high numbers in sites in the dry-polder. Javesella pellucida was equally abundant in all sites except in those subject to medium flooding impact.

Table 13: Impact of flooding on the abundance of common species. For each species that comprises at least four percent of the plant- and leafhopper community of each variant an ANOVA and Tukey test was carried out separately. Data was transformed by $\mathrm{x}^{-0.5}$. Different letters indicate significant differences between the variants.

\begin{tabular}{lrrrrrr}
\hline Species & High & Medium & Low & None & F & p \\
\hline Anoscopus flavostriatus & $\mathrm{bc}$ & $\mathrm{c}$ & $\mathrm{a}$ & $\mathrm{ab}$ & 8.68 & 0.007 \\
Arthaldeus pascuellus & $\mathrm{ab}$ & $\mathrm{b}$ & $\mathrm{a}$ & $\mathrm{a}$ & 7.76 & 0.009 \\
Javesella pellucida & $\mathrm{a}$ & $\mathrm{b}$ & $\mathrm{a}$ & $\mathrm{a}$ & 16.17 & 0.0009 \\
\hline
\end{tabular}

Muellerianella brevipennis and M. fairmairei were only found in sites not subject to flooding (Table 14). Additionally, all except one single specimen of Dicranotropis hamata were collected in the dry polder, thus these three species seem to be intolerant of flooding. Apart from a single individual, Mirabella albifrons was exclusively collected in sites subject to low flooding impact. Furthermore, all specimens of Cosmotettix costalis and Metalimnus formosus were found in a single study site subject to medium flooding influence. For all remaining eleven species occurring in high abundance in the study area, no significant differences in regard to flooding influence were identified.

\section{Centre of distribution in the study area}

In table 14 all species are listed that were found with a minimum of five individuals in the study area and information on their centre of distribution is given. Eleven species were most abundant in sites subject to medium flooding impact, with seven ${ }^{5}$ species being restricted to these sites. Out of these, Cicadula flori, Cosmotettix costalis, Metalimnus formosus and Notus flavipennis occurred only in study site MF3. Eight species were only found in the dry-polder, including Megadelphax sordidula which was exclusively collected in site NF2. Balclutha rhenana and Macrosteles sexnotatus were the only species having their centre of distribution in sites subject to high flooding impact, whereas Macustus grisescens and Mirabella albifrons were most abundant in sites subject to low flooding influence.

\footnotetext{
${ }^{5}$ All except one individual of Megamelus notula were collected in sites subject to medium flooding impact. The single specimen probably drifted to the site subject to low flooding impact, where it was found.
} 
Table 14: Center of distribution in the study area. All species that were caught with at least five individuals in the study area are listed. I: All individuals of the respective species were caught in sites of one treatment. II: All individuals of the respective species were caught in sites of two treatments. III: All individuals of the respective species were caught in sites of three treatments. IV: Individuals of these species were collected in sites of all treatments. Species only found in one study site are written in italics. Proportions greater than $70 \%$ are written in bold.

\begin{tabular}{|c|c|c|c|c|c|c|c|c|}
\hline \multirow[b]{2}{*}{ Species } & \multicolumn{4}{|c|}{ Individuals } & \multicolumn{4}{|c|}{ Individuals (\%) } \\
\hline & High & Medium & Low & None & High & Medium & Low & None \\
\hline \multicolumn{9}{|l|}{ I } \\
\hline Anakelisia fasciata (Kbm.) & 0 & 5 & 0 & 0 & 0.0 & 100.0 & 0.0 & 0.0 \\
\hline Stroggylocephalus agrestis (Fall.) & 0 & 5 & 0 & 0 & 0.0 & 100.0 & 0.0 & 0.0 \\
\hline Notus flavipennis (Zett.) & 0 & 7 & 0 & 0 & 0.0 & 100.0 & 0.0 & 0.0 \\
\hline Cicadula flori (J. Shlb.) & 0 & 10 & 0 & 0 & 0.0 & 100.0 & 0.0 & 0.0 \\
\hline Cosmotettix costalis (Fall.) & 0 & 13 & 0 & 0 & 0.0 & 100.0 & 0.0 & 0.0 \\
\hline Metalimnus formosus (Boh.) & 0 & 23 & 0 & 0 & 0.0 & 100.0 & 0.0 & 0.0 \\
\hline Macustus grisescens (Zett.) & 0 & 0 & 6 & 0 & 0.0 & 0.0 & 100.0 & 0.0 \\
\hline Megadelphax sordidula (Stal) & 0 & 0 & 0 & 5 & 0.0 & 0.0 & 0.0 & 100.0 \\
\hline Muellerianella brevipennis (Boh.) & 0 & 0 & 0 & 42 & 0.0 & 0.0 & 0.0 & 100.0 \\
\hline Muellerianella fairmairei (Perr.) & 0 & 0 & 0 & 34 & 0.0 & 0.0 & 0.0 & 100.0 \\
\hline Mocydia crocea (H.-S.) & 0 & 0 & 0 & 16 & 0.0 & 0.0 & 0.0 & 100.0 \\
\hline \multicolumn{9}{|l|}{ II } \\
\hline Balclutha rhenana W. Wg. & 17 & 1 & 0 & 0 & 94.4 & 5.6 & 0.0 & 0.0 \\
\hline Macrosteles sexnotatus (Fall.) & 54 & 6 & 0 & 0 & 90.0 & 10.0 & 0.0 & 0.0 \\
\hline Megamelus notula (Germ.) & 0 & 49 & 1 & 0 & 0.0 & 98.0 & 2.0 & 0.0 \\
\hline Empoasca pteridis (Dhlb.) & 0 & 11 & 2 & 0 & 0.0 & 84.6 & 15.4 & 0.0 \\
\hline Erzaleus metrius (Fl.) & 25 & 88 & 0 & 0 & 22.1 & 77.9 & 0.0 & 0.0 \\
\hline Mirabella albifrons (Fieb.) & 1 & 0 & 12 & 0 & 7.7 & 0.0 & 92.3 & 0.0 \\
\hline Dicranotropis hamata (Boh.) & 0 & 0 & 1 & 62 & 0.0 & 0.0 & 1.6 & 98.4 \\
\hline Elymana sulphurella (Zett.) & 0 & 0 & 1 & 7 & 0.0 & 0.0 & 12.5 & 87.5 \\
\hline Laodelphax striatella (Fall.) & 1 & 0 & 0 & 4 & 20.0 & 0.0 & 0.0 & 80.0 \\
\hline Neophilaenus lineatus (L.) & 0 & 0 & 7 & 5 & 0.0 & 0.0 & 58.3 & 41.7 \\
\hline \multicolumn{9}{|l|}{ III } \\
\hline Eupteryx atropunctata (Goeze) & 0 & 22 & 1 & 1 & 0.0 & 91.6 & 4.2 & 4.2 \\
\hline Eupteryx cyclops Mats. & 1 & 16 & 4 & 0 & 4.8 & 76.2 & 19.0 & 0.0 \\
\hline Anoscopus serratulae (F.) & 1 & 0 & 4 & 22 & 3.7 & 0.0 & 14.8 & 81.5 \\
\hline Stenocranus major (Kbm.) & 14 & 6 & 5 & 0 & 56.0 & 24.0 & 20.0 & 0.0 \\
\hline Streptanus aemulans (Kbm.) & 13 & 0 & 16 & 10 & 33.3 & 0.0 & 41.0 & 25.7 \\
\hline Javesella dubia (Kbm.) & 6 & 0 & 10 & 28 & 13.6 & 0.0 & 22.7 & 63.7 \\
\hline Arthaldeus pascuellus (Fall.) & 23 & 0 & 33 & 10 & 22.1 & 0.0 & 31.7 & 46.2 \\
\hline Philaenus spumarius (L.) & 0 & 10 & 13 & 10 & 0.0 & 30.3 & 39.4 & 30.3 \\
\hline \multicolumn{9}{|l|}{ IV } \\
\hline Javesella pellucida (F.) & 185 & 1 & 66 & 67 & 58.0 & 0.3 & 20.7 & 21.0 \\
\hline Errastunus ocellaris (Fall.) & 18 & 2 & 29 & 8 & 31.6 & 3.5 & 50.9 & 14.0 \\
\hline Anoscopus flavostriatus (Don.) & 7 & 4 & 27 & 25 & 11.1 & 6.3 & 42.9 & 39.7 \\
\hline No. of sites & 3 & 3 & 3 & 3 & & & & \\
\hline
\end{tabular}




\section{Ecological characteristics}

In this section the impact of flooding on the distribution of plant- and leafhoppers regarding their ecological characteristics is analysed, focussing on habitat preference, wing development, voltinism, diet width and specialisation.

\section{Moisture preference}

Euryhygric species prevailed in all sites except in those subject to medium flooding impact (Fig. 25). The latter were dominated by hygrophilous species. Xerophilous species were solely found in sites subject to low or no flooding influence. Significantly more euryhygric plant- and leafhoppers were collected in sites subject to low and no flooding impact as opposed to those sites subject to medium flooding impact.
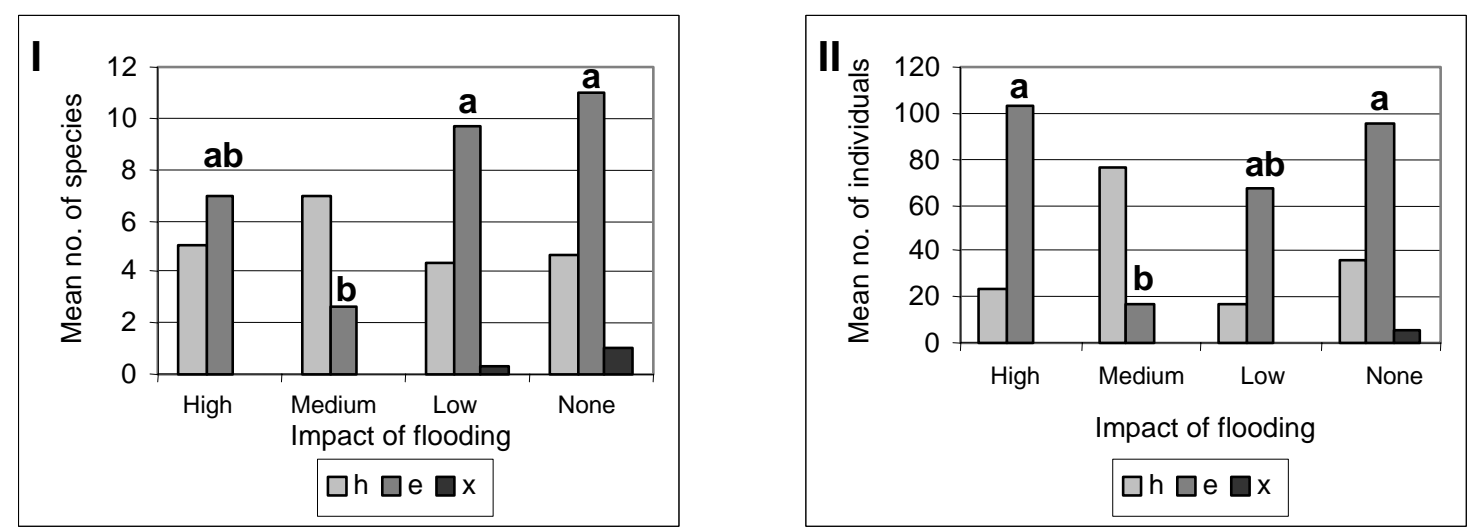

Fig. 25: Moisture preference in the recorded Auchenorrhyncha species. Hygrophilous (h), euryhygric (e) and xerophilous (x) species (I) and individuals (II) in sites differing in flooding influence. For each of the three categories an ANOVA and Tukey Test were carried out separately. Bars marked with different letters are significantly different. Euryhygric species (ANOVA): F=12.8, $\mathrm{p}=0.002$; euryhygric individuals (H-Test): $\mathrm{H}=7.21, \mathrm{p}=0.07$.

Wing development

In all study sites dimorphic species dominated, independent of differences in inundation impact (Fig. 26). Within dimorphic species significant differences in relation to flooding influence were identified: Most species were found in sites not subject to flooding, fewest species in sites subject to medium flooding impact (I). Monomorphic macropterous species and individuals did not differ significantly with regard to flooding influence. 

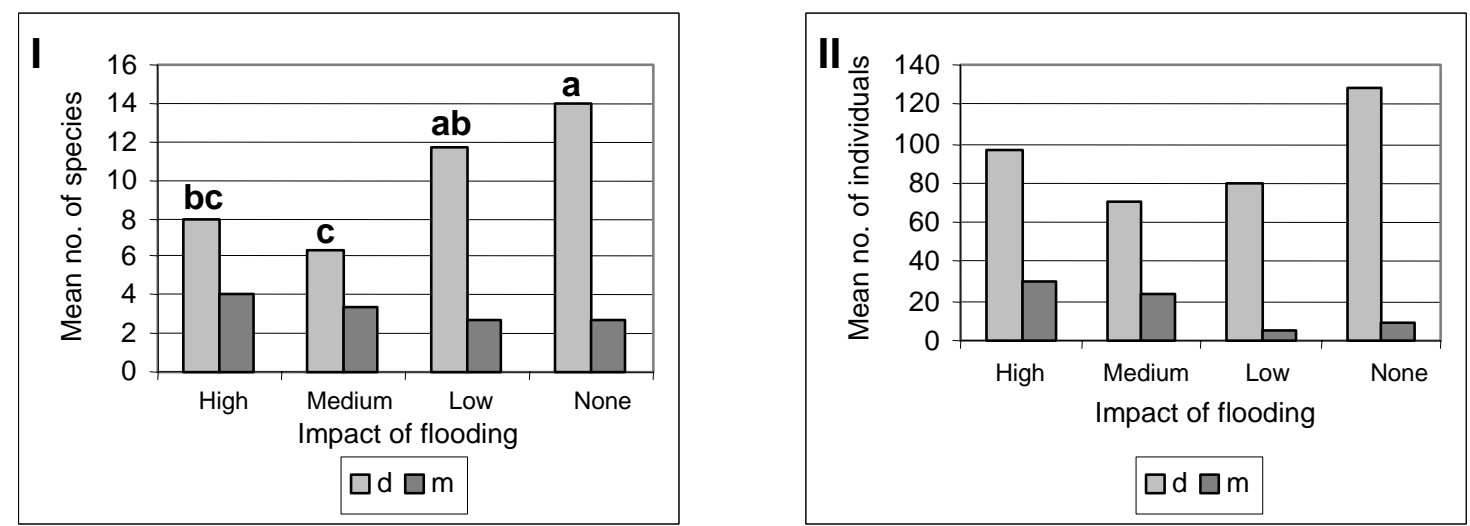

Fig. 26: Wing development in the recorded Auchenorrhyncha species. Dimorphic (d) and monomorphic macropterous (m) species (I) and individuals per $0.6 \mathrm{~m}^{2}$ (II) in sites differing in flooding influence. For each of the two categories an ANOVA and Tukey Test were carried out separately. Bars marked with different letters are significantly different. Dimorphous species (ANOVA): $\mathrm{F}=11.44, \mathrm{p}=0.003$.

\section{Voltinism}

Bivoltine plant- and leafhoppers were very abundant in all study sites irrespective of flooding impact (Fig. 27). Significantly more monovoltine species were collected in sites subject to low and no inundation influence than in those subject to high flooding impact (Fig. 27 I). Furthermore, most mono- or bivoltine species and individuals were caught in sites not subject to any flooding influence (Fig. 27).
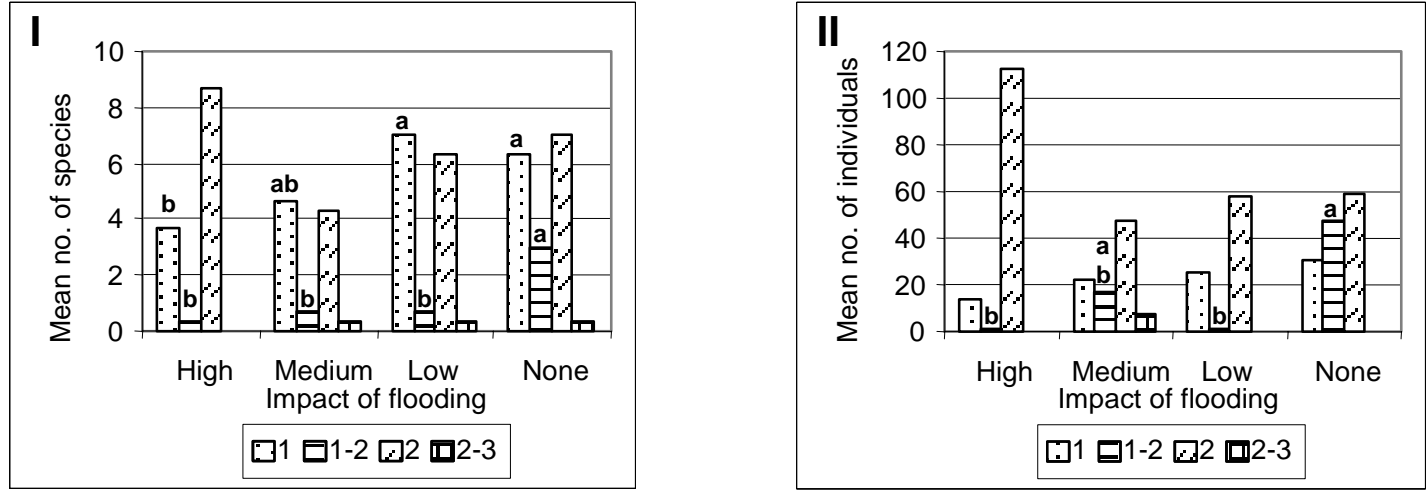

Fig. 27: Annual generation numbers in the recorded Auchenorrhyncha species. Monovoltine (1), monoor bivoltine (1-2), bivoltine (2) and bi- or trivoltine (2-3) species (I) and individuals per $0.6 \mathrm{~m}^{2}$ (II) in fallows and mown sites. For each of the four categories an ANOVA and Tukey Test were carried out separately. Bars marked with different letters are significantly different. Monovoltine species: $F=6.97, p=0.01$; mono- or bivoltine species: $F=18.22, p=0.0006$, mono- or bivoltine individuals (transformation: $\mathrm{x}^{-0.5}$ ): $\mathrm{F}=6.69, \mathrm{p}=0.01$. 
Diet width

All sites except those subject to medium flooding impact were dominated by oligophagous species (Fig. 28 I). Most oligophagous species were caught in sites subject to low or no flooding influence, in sites subject to medium flooding impact monophagous species prevailed. A consideration of the numbers of individuals reveals, that those study sites subject to high flooding impact were dominated by polyphagous plant- and leafhoppers (Fig. 28 II). Most oligophagous individuals were collected in sites not subject to flooding, fewest in sites subject to medium flooding impact.
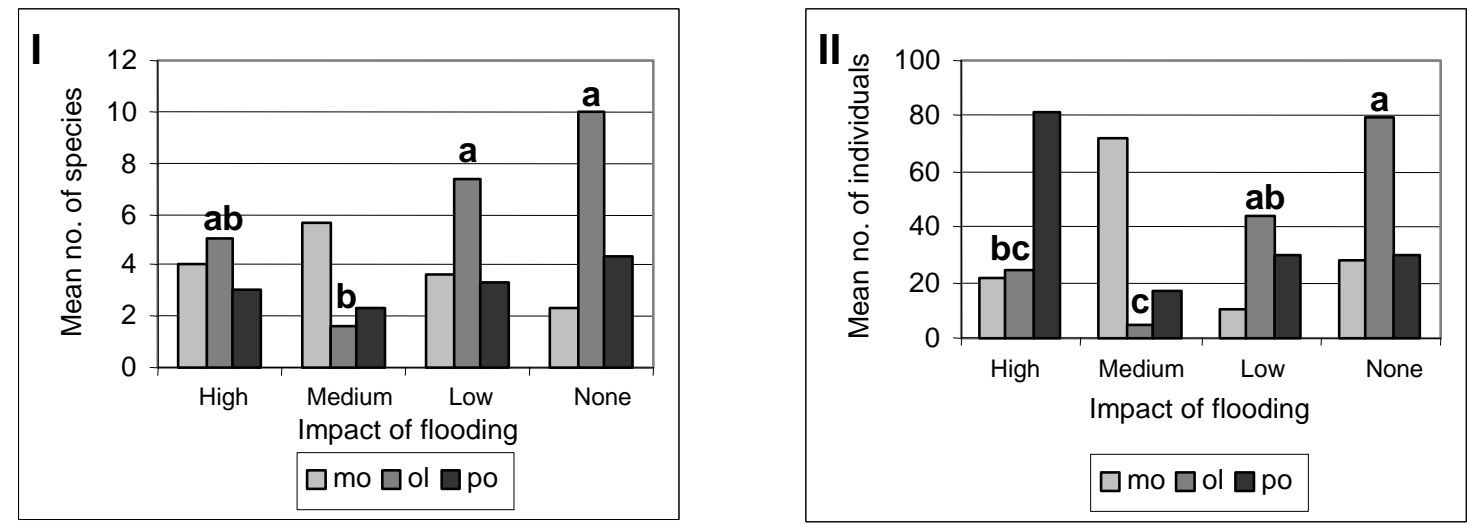

Fig. 28: Diet width in the recorded Auchenorrhyncha species. Monophagous (mo), oligophagous (ol) and polyphagous (po) species (I) and individuals per $0.6 \mathrm{~m}^{2}$ (II) in sites differing in flooding influence. For each of the three categories an ANOVA and Tukey Test were carried out separately. Bars marked with different letters are significantly different. Oligophagous species (ANOVA, transformation: $\mathrm{x}^{-0.5}$ ): $\mathrm{F}=13.59, \mathrm{p}=0.001$; Oligophagous individuals (ANOVA, transformation: $\mathrm{x}^{-0.5}$ ): $\mathrm{F}=15.19, \mathrm{p}=0.001$.

\section{Specialisation}

No significant differences in the degree of specialisation between sites that differ in flooding influence based on species data were identified (Fig. 29 I). However, when taking into account individuals, the most specialised Auchenorrhyncha community was found in sites subject to medium flooding impact (Fig. 29 II). 

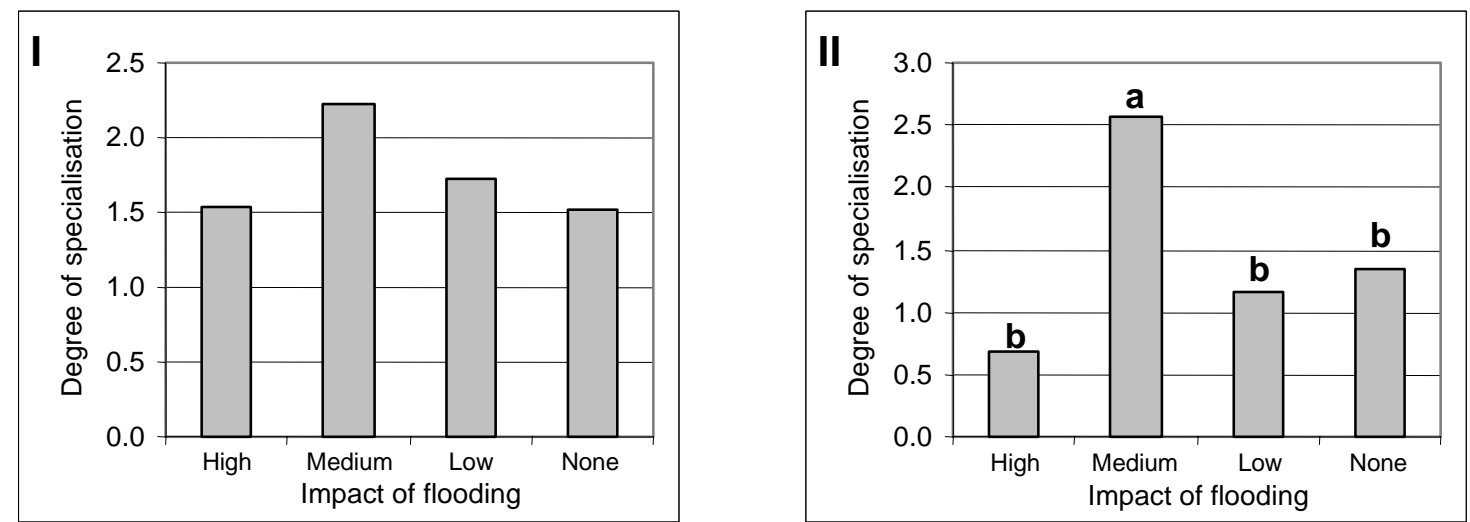

Fig. 29: Degree of specialisation based on species data (I) and on numbers of individuals (II) for sites differing in flooding influence. An ANOVA and Tukey Test were carried out separately. Bars marked with different letters are significantly different. Individuals: $F=14.17, p=0.001$.

Most species that were caught in sites subject to high and medium flooding impact were stenotopic (Fig. 30 I). In contrast, in sites subject to low or no flooding influence eurytopic species prevailed. Within eurytopic and oligotopic species significant differences with regard to flooding influence were identified. Most eurytopic species were found in sites subject to low and no inundation impact, fewest species were collected in sites subject to medium flooding impact. The highest number of oligotopic species were caught in sites not subject to flooding, whereas only few occurred in sites subject to high and medium flooding impact.

In sites subject to high flooding influence a different pattern was found when considering numbers of individuals: Here pioneer species dominated (Fig. 30 II). The number of Auchenorrhyncha classified as "pioneer species" differed significantly from those collected in sites subject to medium flooding impact. Furthermore, most eurytopic plant- and leafhoppers were found in sites located in the dry-polder, fewest in sites subject to medium flooding impact.
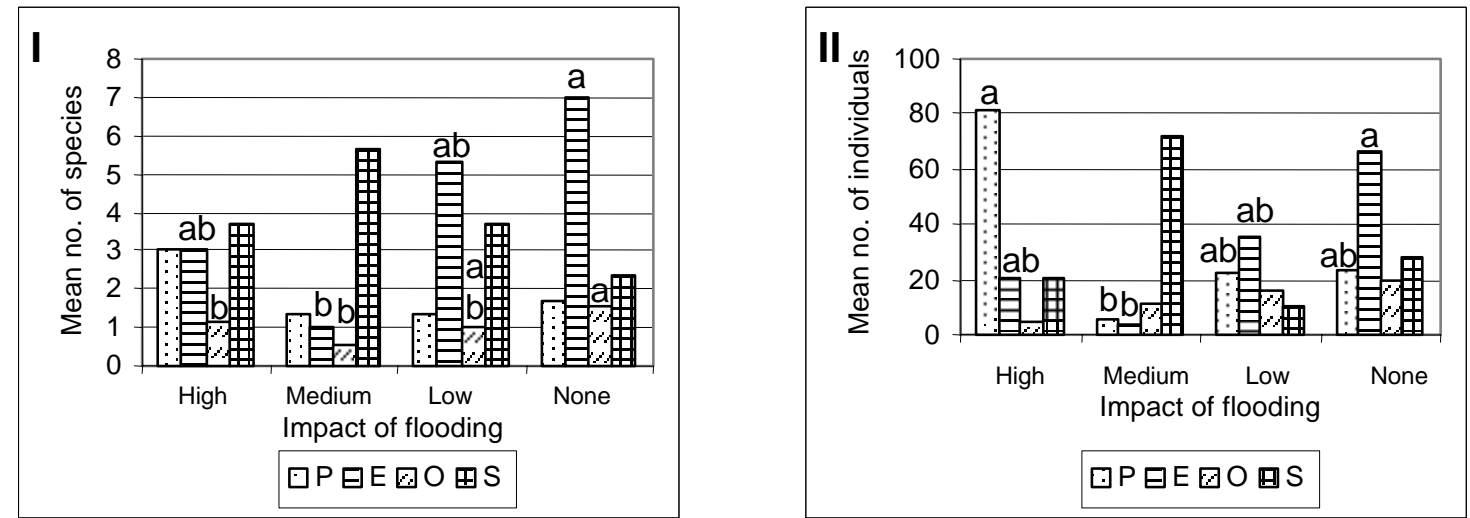

Fig. 30: Life strategy in the recorded Auchenorrhyncha species. Pioneer (P), eurytopic (E), oligotopic (O) and stenotopic (S) species (I) and individuals per $0.6 \mathrm{~m}^{2}$ (II) in sites differing in flooding influence. For each of the four categories an ANOVA and Tukey Test were carried out separately. Bars marked with different letters are significantly different. Eurytopic species (ANOVA): $\mathrm{F}=7.32, \mathrm{p}=0.01$; Oligotopic species (ANOVA): $\mathrm{F}=7.71, \mathrm{p}=0.001$; pioneer individuals (ANOVA, transformation: $\mathrm{x}^{-0.5}$ ): $\mathrm{F}=6.06, \mathrm{p}=0.02$; eurytopic individuals (ANOVA, transformation: $\mathrm{x}^{-0.5}$ ): $\mathrm{F}=8.29, \mathrm{p}=0.008$; stenotopic individuals (ANOVA): $\mathrm{F}=3.88$, $\mathrm{p}=0.06$. 


\subsubsection{Differences in the impact of flooding on the communities in fallows and mown sites}

During the first year of the study not only the impact of mowing on the plant- and leafhopper communities was investigated, but "flooding" was integrated as a second factor. To identify differences in the impact of flooding on the communities in fallows and in mown sites a two-factorial analysis of variance was carried out. In some cases flooding affected Auchenorrhyncha communities in fallows and mown plots differently, i.e. significant "interactions" between the two factors "mowing" and "flooding" were identified.

\section{Common species}

In all fallows except in those subject to medium flooding impact more individuals of Anoscopus serratulae were collected than in mown sites (Fig. 31). Furthermore, this cicadellid leafhopper was found in high numbers of individuals only in fallows in the dry-polder.

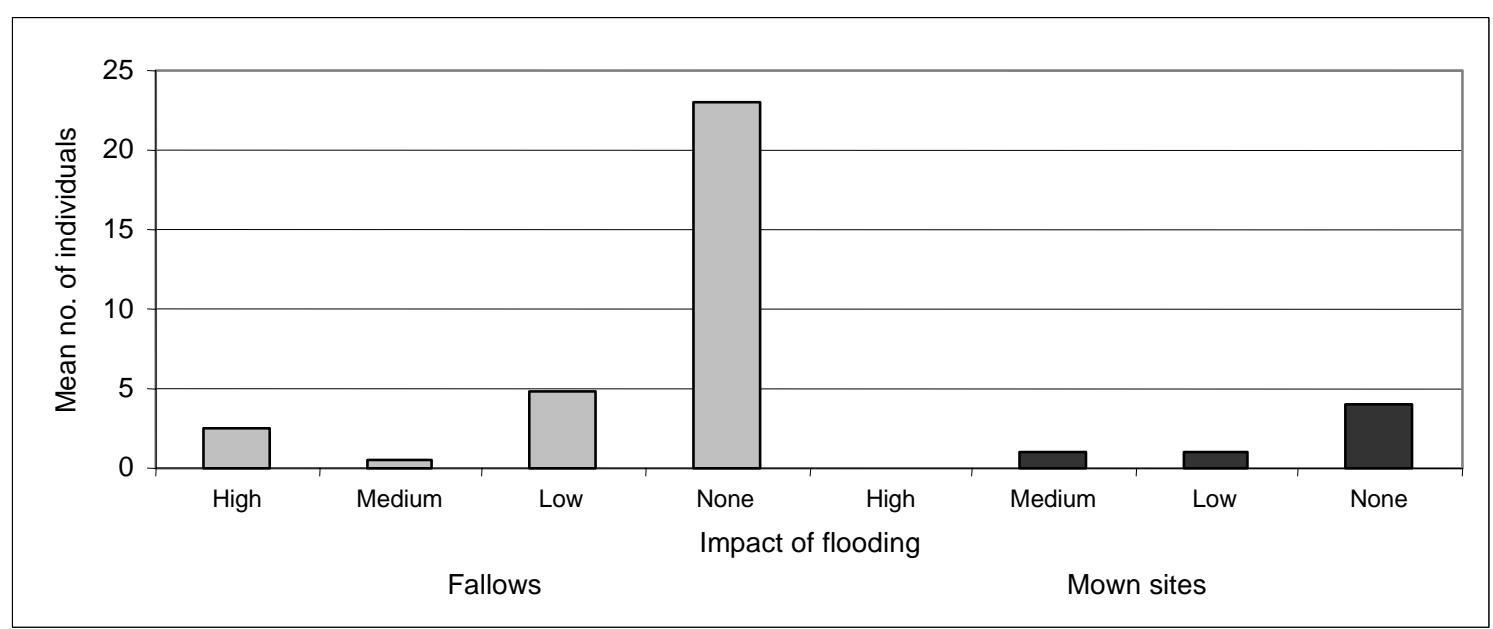

Fig. 31: Mean numbers of individuals of Anoscopus serratulae in fallows and mown sites subject to different flooding impact. GLM "interaction": $\mathrm{F}=8.56, \mathrm{p}=0.003$. 
More individuals of Erzaleus metrius were collected in fallows subject to medium flooding impact than in all other treatments (Fig. 32). Comparing fallows to mown sites reveals, that more individuals of Erzaleus metrius were found in fallows subject to medium and no flooding impact than in mown sites subject to similar flooding conditions. In contrast, in the remaining fallows fewer individuals of the species were collected than in the corresponding mown plots.

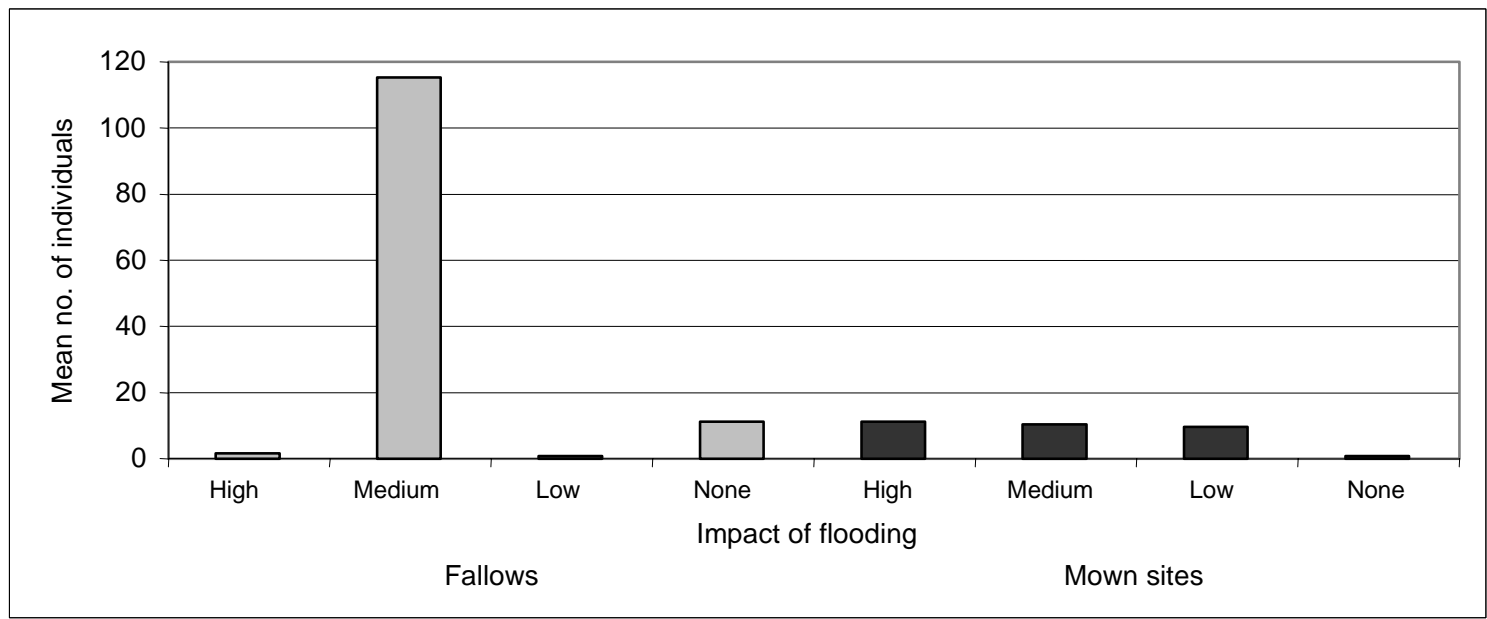

Fig. 32: Mean numbers of individuals of Erzaleus metrius in fallows and mown sites subject to different flooding impact. GLM “interaction" (transformation: $\mathrm{x}^{-0.5}$ ): $\mathrm{F}=30.18, \mathrm{p}<0.0001$.

Most individuals of Streptanus sordidus were caught in mown sites subject to medium flooding impact (Fig. 33). More individuals were collected in fallows than in mown sites subject to high and no flooding impact, respectively. In contrast, Streptanus sordidus was more abundant in mown grassland than in fallows subject to medium and low flooding impact.

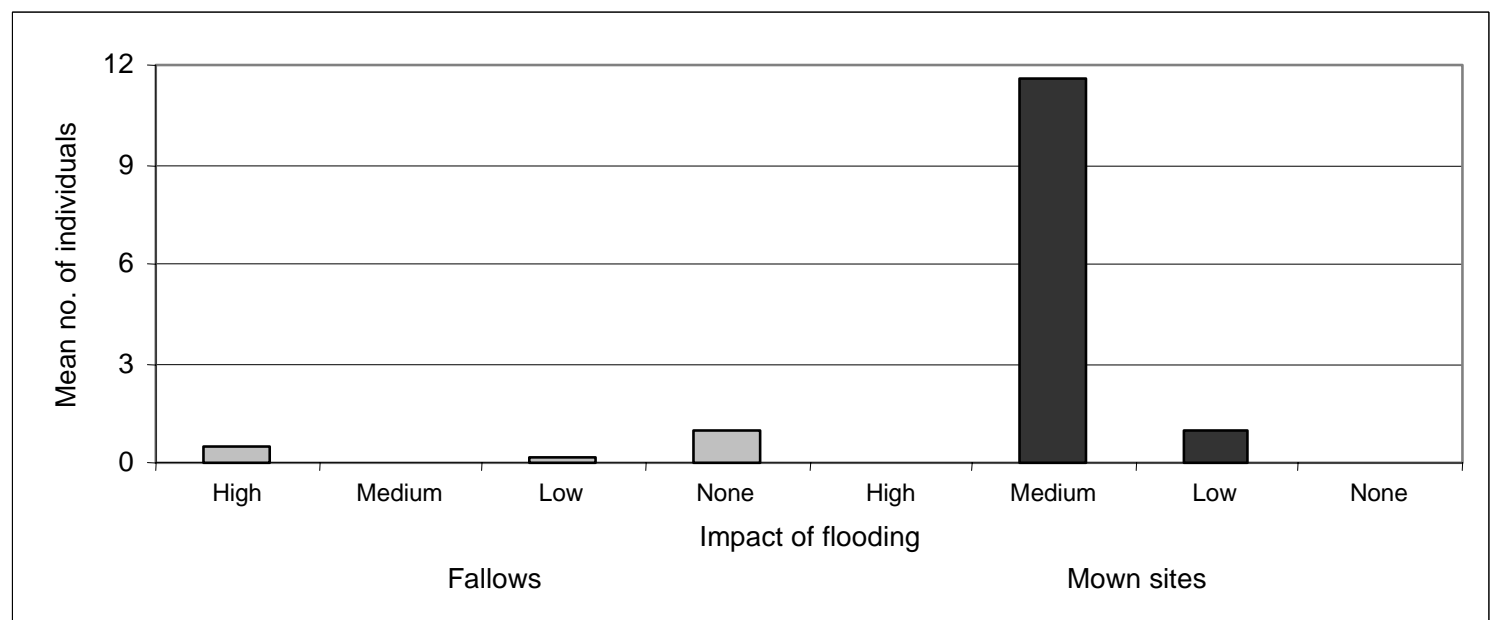

Fig. 33: Mean numbers of individuals of Streptanus sordidus in fallows and mown sites subject to different flooding impact. GLM “interaction" (transformation: $\mathrm{x}^{-0.5}$ ): $\mathrm{F}=7.51, \mathrm{p}=0.004$. 


\section{Hygrophilous species}

In all fallows except in those subject to high flooding impact more hygrophilous plantand leafhoppers were caught than in mown study sites subject to the same flooding impact (Fig. 34). The difference between numbers of hygrophilous individuals collected in fallows and mown plots both subject to medium flooding impact was high compared to the difference assessed in areas with less or more flooding influence.

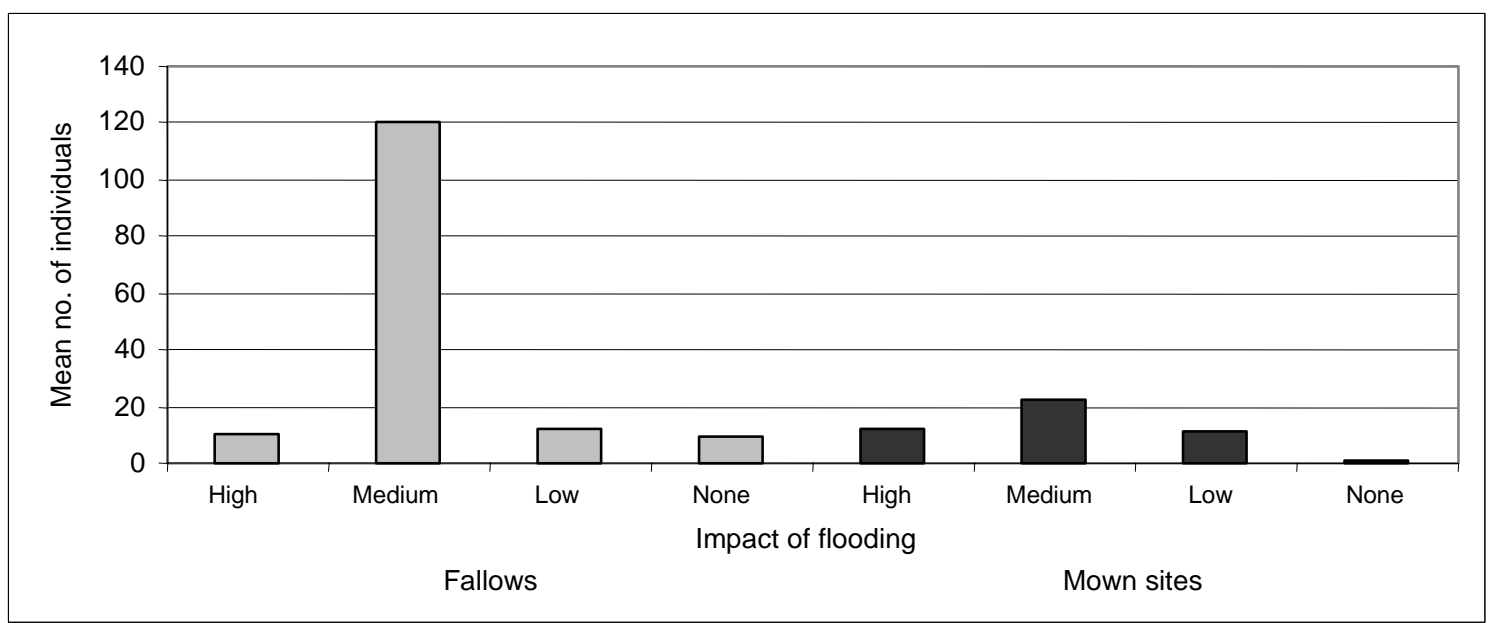

Fig. 34: Mean individual numbers of hygrophilous species in fallows and mown sites subject to different flooding impact. GLM "interaction": $F=25.16, p<0.0001$.

\section{Specialisation}

The degree of specialisation based on numbers of individuals was generally higher in fallows than in mown plots with similar inundation impact (Fig. 35). However, the degree of specialisation of Auchenorrhyncha communities was extremely high in fallows subject to medium flooding impact, almost reaching the possible maximum of three.

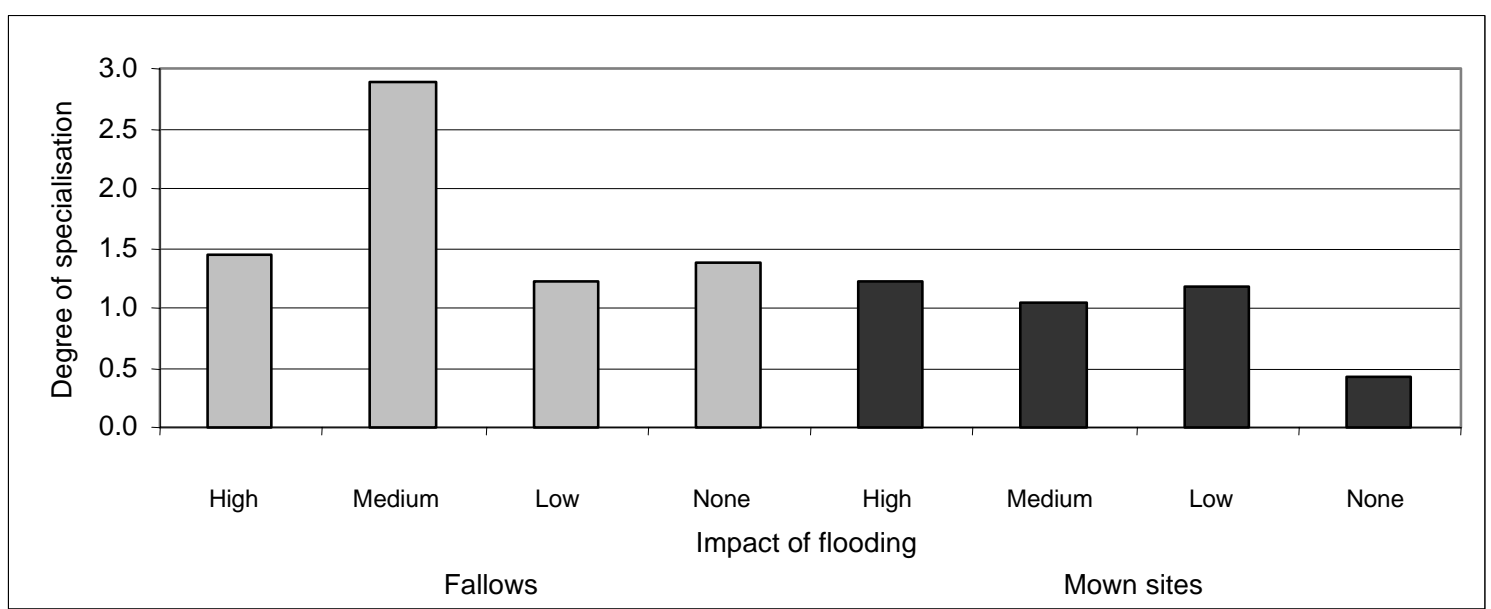

Fig. 35: Degree of specialisation based on numbers of individuals species in fallows and mown sites subject to different flooding impact. GLM “interaction": F=15.82, p=0.0002. 
More stenotopic species were found in fallows subject to medium and no flooding impact (Fig. 36). In contrast, higher numbers of stenotopic Auchenorrhyncha were caught in mown plots than in fallows subject to low and high flooding impact. Furthermore, in fallows subject to medium flooding impact nearly 120 individuals of stenotopic plant- and leafhoppers were collected, whereas in all other variants less than 20 stenotopic individuals were caught.

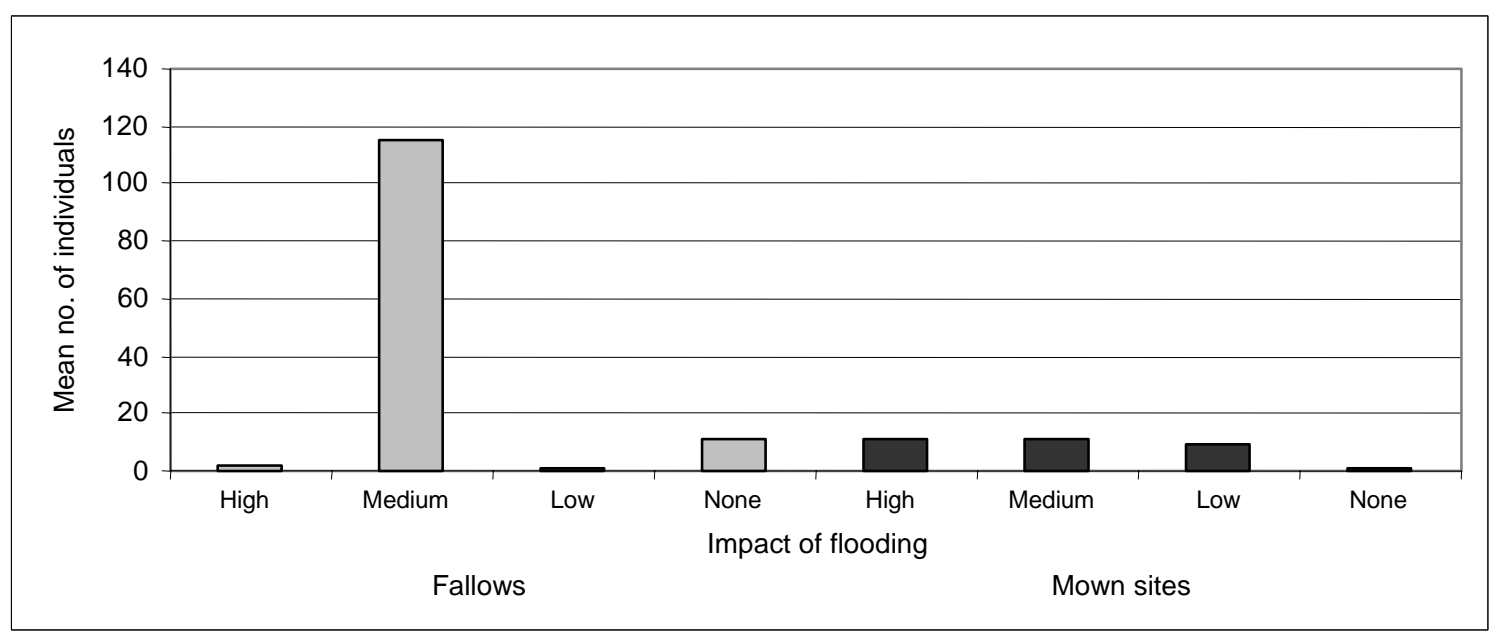

Fig. 36: Mean number of stenotopic individuals in fallows and mown sites subject to different flooding impact. GLM "interaction" (transformation: $\mathrm{x}^{-0.5}$ ): $\mathrm{F}=20.07, \mathrm{p}<0.0001$. 


\subsubsection{Similarity of species composition between different sites}

Similarities in presence and absence of species was assessed using Sørensen's Coefficient. During the first year of the study data were collected in sites differing in land use and flooding, whereas in the second year the investigation was concentrated on fallows subject to different flooding impact.

\section{Similarity of species in sites differing in land use and flooding influence}

Study sites MF2 and LF2 differed in species composition from all other study sites. These other areas were classified forming three main groups: (i) sites without any inundation impact, (ii) mown study sites differing in flooding influence and (iii) fallows differing in flooding influence (Fig. 37).

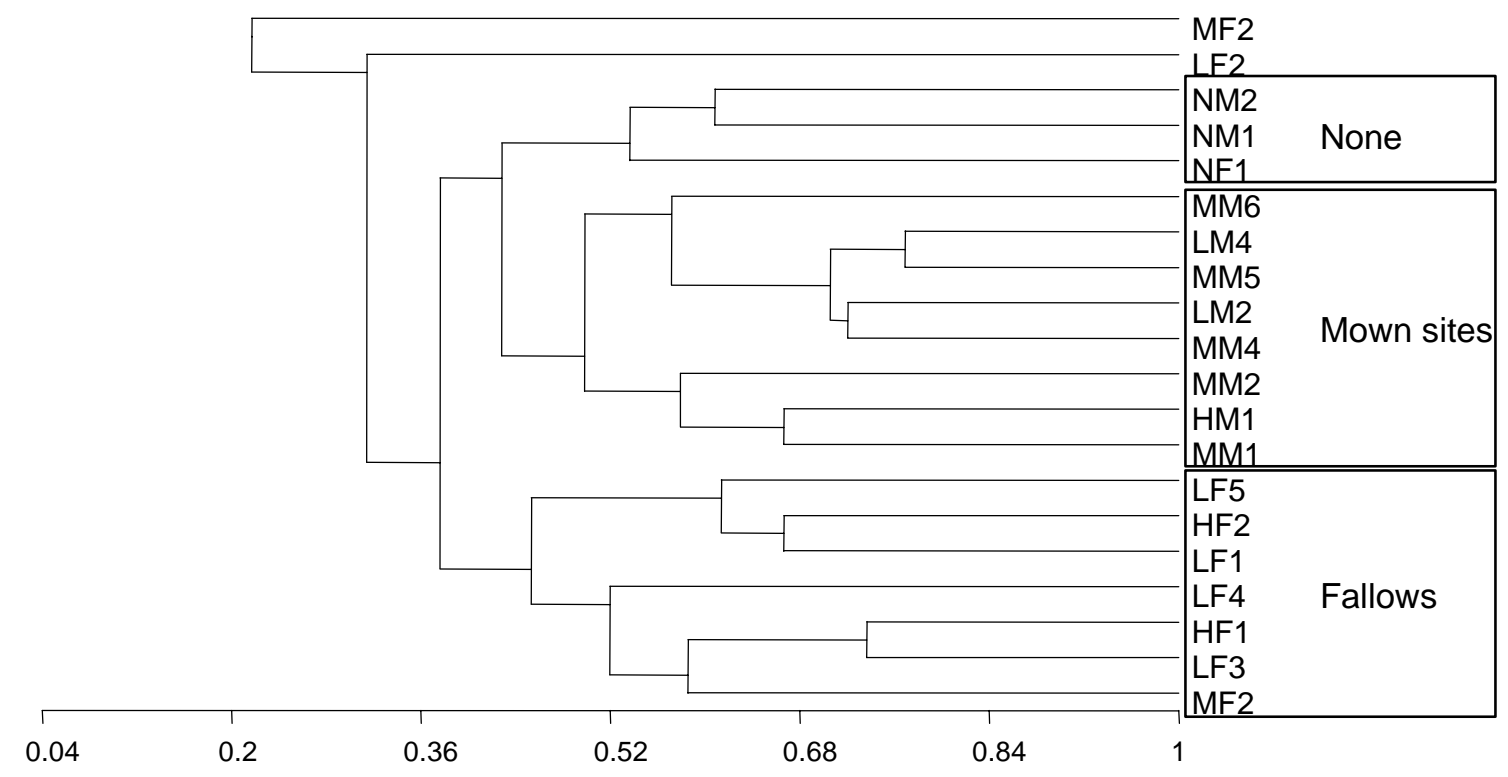

Fig. 37: Similarity of species composition in sites differing in land use and flooding impact (Sørensen's Coefficient, UPMAG). The first letter of the abbreviation indicates the impact of flooding: $\mathrm{H}=$ high, $\mathrm{M}=$ medium, $\mathrm{L}=$ low and $\mathrm{N}=$ none; the second letter gives information about land use: $\mathrm{F}=$ fallow, $\mathrm{M}=$ mown site, None $=$ no flooding impact. Sites of the same variant are sequentially numbered. 


\section{Similarity of species in fallows differing in flooding influence}

Three main groups were identified: sites subject to medium flooding impact, those not subject to flooding and the third group contained all other study sites (Fig. 38). However, site LF2 was more similar in species composition to sites not subject to flooding than to other study sites subject to low flooding impact. Furthermore, plot MF1 more resembled site HF1 which was subject to high flooding impact than other sites subject to medium flooding impact.

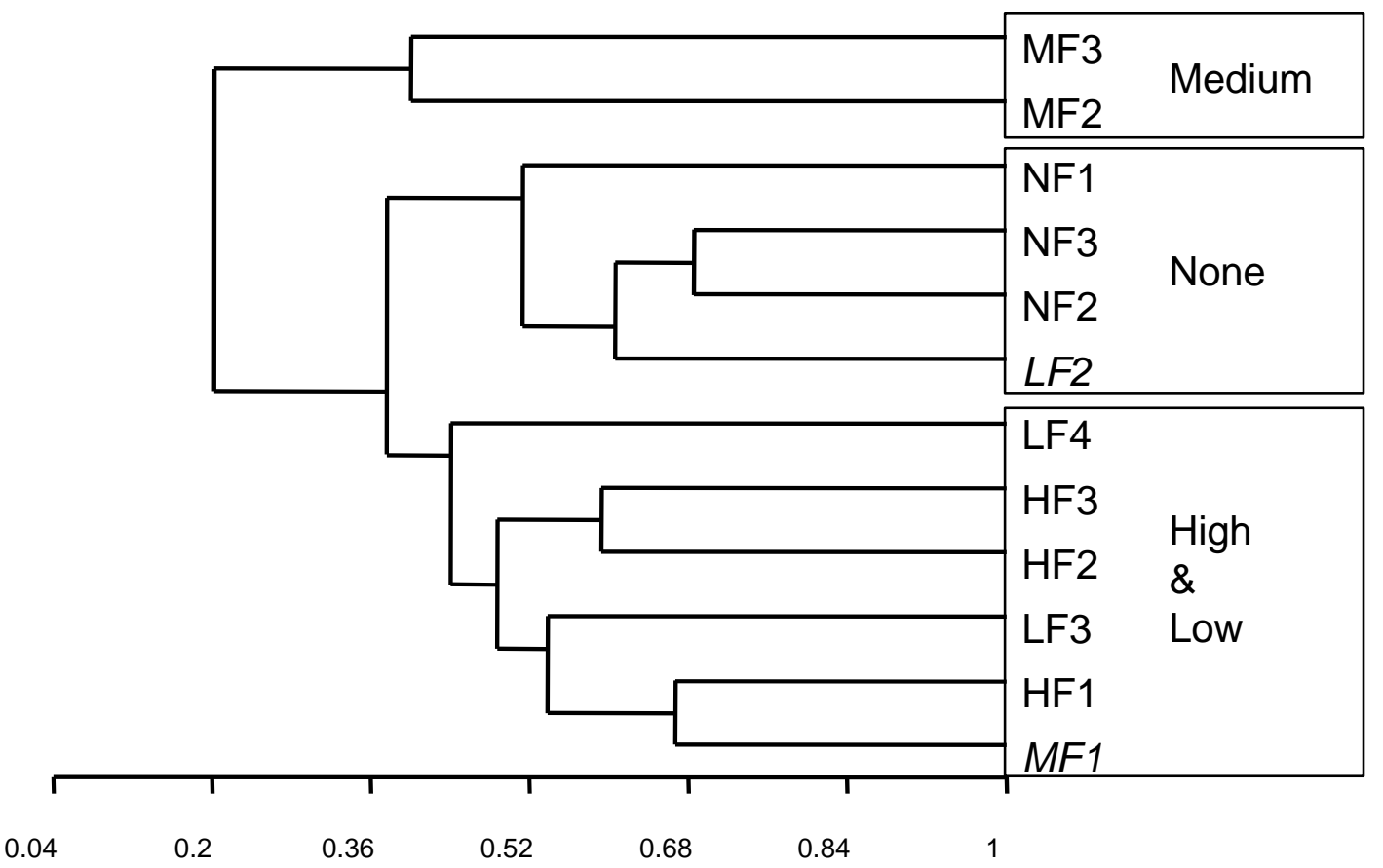

Fig. 38: Similarity of species composition in fallows differing in flooding impact (Sørensen's Coefficient, UPGMA). Sites written in italics differ in flooding influence from all other study sites within the respective group. The first letter of the abbreviation indicates the impact of flooding: $\mathrm{H}=$ high, $\mathrm{M}=$ medium, $\mathrm{L}=$ low and $\mathrm{N}=$ none; the second letter gives information about land use: $\mathrm{F}=$ fallow. Sites of the same variant are sequentially numbered. 


\subsubsection{Impact of environmental variables}

In this section it is analysed which of the measured environmental variables (see section 3.2.3) had the strongest influence on the Auchenorrhyncha assemblage. For this purpose Canonical Correspondence Analyses (CCA) were carried out separately for the data collected in 2001 and 2002.

\section{CCA based on the data collected in 2001}

A CCA revealed three different groups of study sites (Fig. 39 I):

i. fallows subject to medium flooding impact,

ii. fallows differing in flooding influence and

iii. all mown study sites.

For each group of study sites a set of characteristic plant- and leafhoppers can be identified from Figure 39 II and Table 15.

Table 15: Characteristic plant- and leafhoppers occurring in a specific group of study sites.

\begin{tabular}{ll}
\hline Group & Characteristic plant- and leafhoppers \\
\hline i & Cicadula flori, Erzaleus metrius, Eupteryx cyclops, Megamelus notula, Paraliburnia adela \\
ii & Anoscopus flavostriatus, A. serratulae, Aphrodes bicincta, Athysanus argentarius, \\
& $\begin{array}{l}\text { Dicranotropis hamata, Errastunus ocellaris, Eupteryx vittata, Mocuellus collinus, Paluda } \\
\text { flaveola, Philaenus spumarius, Ribautodelphax albostriatus, Streptanus aemulans }\end{array}$ \\
& Deltocephalus pulicaris, Empoasca pteridis, Javesella dubia, J. pellucida, Macrosteles laevis, \\
& M. sexnotatus, Psammottetix alienus, Streptanus sordidus \\
\hline
\end{tabular}

The first axis largely correlates with the environmental variable "height of vegetation" and to a lesser extend with "flooding", whereas the second axis correlates with the factor "mowing". The plant- and leafhoppers found in group i occurred in sites with high vegetation and long flooding influence. Those of group ii were negatively correlated with mowing, and thus, typical for fallows. Furthermore, the occurrence of these species seems to depend on vegetation height and/or flooding influence. The third group of species (iii) was associated with mown plots.

Comparing the eigenvalues of the axes gained by CCA to those of a Detrended Correspondence Analysis (DCA) reveals, that the chosen environmental variables predict the main variation in species sufficiently well (Table 16).

Table 16: Comparison of eigenvalues and of the variance of species data explained by the first two axes of the DCA and the CCA.

\begin{tabular}{lccl}
\hline Analysis & Axis 1 & Axis 2 & $\begin{array}{l}\text { Variance } \\
\text { explained }\end{array}$ \\
\hline DCA & 0.747 & 0.390 & $43.54 \%$ \\
CCA & 0.661 & 0.413 & $39.06 \%$ \\
\hline
\end{tabular}




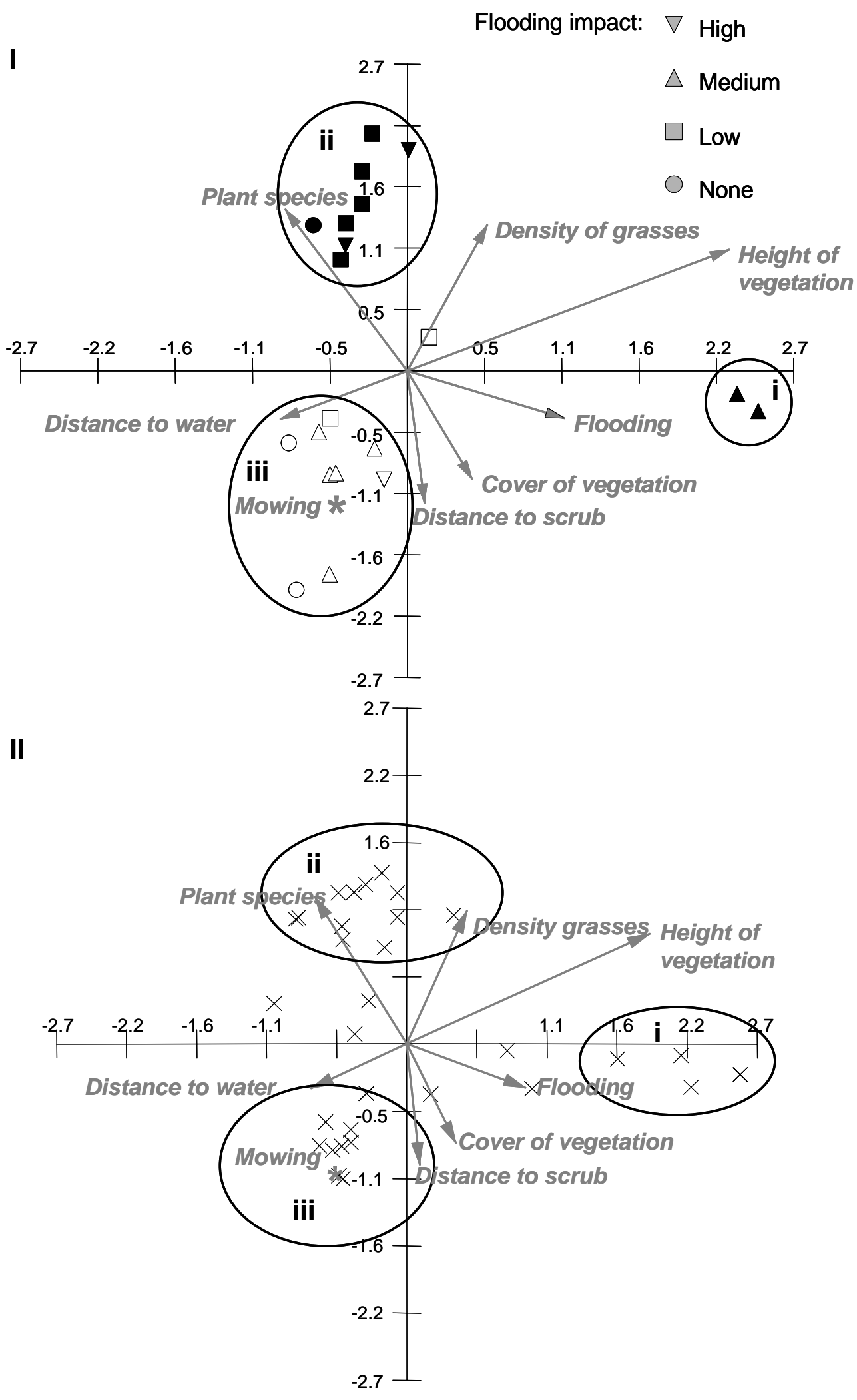

Fig. 39: CCA ordination diagram based on Auchenorrhyncha species abundance and selected environmental variables. I: study sites; II: species. All environmental variables except "mowing" are plotted as arrows, "mowing" being a class of a nominal variable as a centroid. Open markers represent mown plots, solid markers fallows. 


\section{CCA based on the data collected in 2002}

In fallows four different groups of study sites could be distinguished (Fig. 40 I):

i. Site MF3, that was subject to medium flooding impact,

ii. two study sites subject to medium flooding impact,

iii. two fallows not subject to flooding and

iv. all other study sites.

Interestingly, the species assemblage of site NF1, which was located in the dry-polder, was more similar to those of sites subject to low flooding impact than to the communities of the other plots not subject to flooding. The first axis of the diagram strongly correlates with the variable "height of vegetation", the second axis with the factor "flooding". Figure 40 II and Table 17 show the Auchenorrhyncha species that were characteristic for the respective group of study sites.

Table 17: Characteristic plant- and leafhoppers occurring in a specific group of study sites.

\begin{tabular}{ll}
\hline Group & Characteristic plant- and leafhoppers \\
\hline i & Cicadula flori, Cosmottetix costalis, Metalimnus formosus, Notus flavipennis \\
ii & Empoasca pteridis, Erzaleus metrius, Eupteryx atropunctata, E. cyclops \\
iii & Elymana sulphurella, Megadelphax sordidula, Mocydia crocea, Muellerianella brevipennis, \\
& M. fairmairei \\
iv & Anoscopus flavostriatus, A. serratulae, Arthaldeus pascuellus, Balclutha rhenana, Errastunus \\
& $\begin{array}{l}\text { ocellaris, Javesella pellucida, Macrosteles sexnotatus, Macustus grisescens, Mirabella } \\
\text { albifrons, Neophilaenus lineatus, Philaenus spumarius, Stenocranus major, Streptanus } \\
\text { aemulans }\end{array}$
\end{tabular}

Species of group i occurred predominantly in sites with high vegetation and subject to high flooding influence, whereas those of group ii were associated to lower vegetation but the same level of inundation impact. Most of the remaining plant- and leafhoppers were grouped along an inundation gradient. At the one end species of group iii were typical for sites in the dry-polder, whereas Balclutha rhenana and Macrosteles sexnotatus were characteristic for sites subject to higher flooding influence. Comparing the eigenvalues of the axes gained by CCA to those of a DCA reveals, that the chosen environmental variables predict the main variation in species sufficiently well (Table 18).

Table 18: Comparison of eigenvalues and of the variance of species data explained by the first two axes of the DCA and the CCA.

\begin{tabular}{lccl}
\hline Analysis & Axis 1 & Axis 2 & $\begin{array}{l}\text { Variance } \\
\text { explained }\end{array}$ \\
\hline DCA & 0.925 & 0.295 & $37.23 \%$ \\
CCA & 0.847 & 0.514 & $41.56 \%$ \\
\hline
\end{tabular}




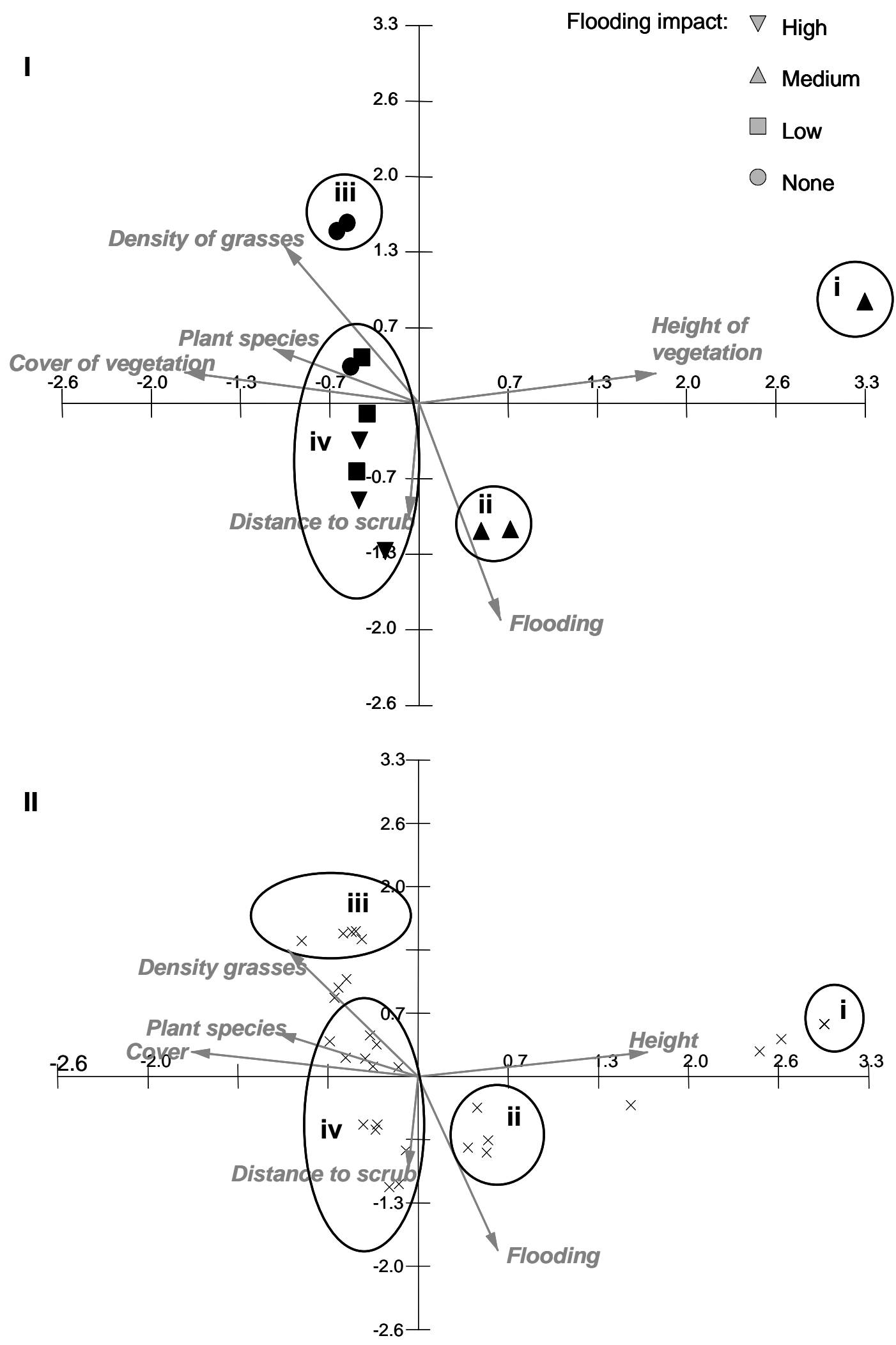

Fig. 40: CCA ordination diagram based on Auchenorrhyncha species abundance and selected environmental variables. I: study sites; II: species. All environmental variables are plotted as arrows. 


\subsection{Discussion}

Mowing and flooding are both catastrophic events for arthropods. Mowing abruptly and drastically reduces the size and complexity of the aboveground habitat leading to dramatic changes of microclimatic conditions in the meadow. During submersion terrestrial arthropods have to face low oxygen concentrations in the water, passive drift with high water and danger of cell destruction due to swelling (Hildebrandt 1997). Furthermore, in the geologically young river floodplains of Central Europe flooding duration and frequency vary from year to year. Both, mowing and flooding have shortterm and long-term effects on the species communities. Short-term effects are directly related to the events of "cutting" or "flooding"; long-term effects are based on changes in the habitat which are the results of regular mowing and/or flooding events. The following discussion focuses on long-term effects of both factors.

\subsubsection{Impact of mowing and flooding on species numbers, numbers of individuals and diversity}

Altogether more species were collected in fallows than in mown sites. Estimates of species numbers based on my samples revealed the same pattern. However, no effect on the mean number of species was identified. A lot of studies analysing the effect of mowing on plant- and leafhoppers have been carried out in a variety of grassland habitats and the results concerning the impact of mowing on species richness are very heterogeneous. On the one hand, more species were found in fallows than in mown meadows in temporarily flooded grassland (Nickel \& Hildebrandt 2003) as well as in moist grassland (Klieber et al. 1995). On the other hand, Achtziger et al. (1999) found fewer species in fallows than in extensively used moist grassland. All these studies were carried out in areas differing in flooding impact, soil moisture and mowing intensity. Morris \& Lakhani (1979) and Gerstmeier \& Lang (1996) came to the conclusion that the response of Auchenorrhyncha is dependent on mowing frequency and, above all, on the cutting date. Mowing in July affected the plant- and leafhopper community more severely than in May (Morris \& Lakhani 1979). Gerstmeier \& Lang (1996) concluded, that in moist meadows cutting once a year or once in two years will lead to a maximum number of species. Furthermore, Klieber et al. (1995) state that species richness of Auchenorrhyncha is not only dependent on mowing intensity but also on soil moisture: They found an increase in species richness with decreasing mowing intensity and increasing soil moisture. These findings suggest that also flooding might affect species richness. Unfortunately, none of the studies took into account "flooding" as a separate factor, even though some were carried out in temporarily inundated grassland.

In the present study a comparison of the species assemblages based on Sørensen's Coefficient as well as the results of the Canonical Correspondence Analysis showed that mowing had a stronger impact on the plant- and leafhopper community than flooding. The impact of flooding was mostly overridden by the impact of mowing and could only be identified in fallows. In the latter, the most species-rich community was found in 
sites not subject to any flooding impact, whereas the fewest species were collected in sites subject to medium flooding impact. These patterns were also found comparing total, estimated, and mean numbers of species. Thus, species numbers varied a lot in fallows due to flooding impact leading to a mean number of species which is comparable to the one of mown meadows. But nevertheless, it seems that in temporarily flooded grassland which is partially mown twice a year overall more species occur in fallows than in mown sites.

Just like for species numbers, no differences were found in mean $\boldsymbol{\alpha}$-diversity values between fallows and mown sites. However, in fallows differences correlated with flooding. The patterns are basically consistent with those found for species numbers. In the literature only few studies take the measure " $\alpha$-diversity" into account. Gerstmeier \& Lang (1996) concluded within their review article that in moist meadows cutting once a year or once in two years will not only positively affect species richness but will also often lead to high values of diversity and evenness.

In the present study no long-term effects of mowing and flooding on mean numbers of individuals were identified. However, at least for mowing such effects are reported in the literature. Like for species numbers, one finds very heterogeneous results: On the one hand, Klieber et al. (1995) found more individuals in fallows than in mown moist grassland in floodplains of the "Alte Sorge" river. In calcareous grassland significantly more individuals were recorded in uncut control plots than in mown plots (Morris \& Lakhani 1979). Klieber et al. (1995) found an increase in species abundance with decreasing mowing intensity and increasing soil moisture. On the other hand, Andrzejewska (1979) stated that over the year the average density of phytophagous insects is higher in mown meadows than in unexploited ones.

Furthermore, a more detailed analysis revealed different responses to mowing and flooding on the species level. In the Lower Oder Valley 15 plant- and leafhopper species predominantly occurred in fallows, whereas eight species favoured mown grassland. In the present study negative effects of mowing were found for Anoscopus flavostriatus, Aphrodes bicincta, Eupteryx vittata, Paluda flaveola and Philaenus spumarius. Positive effects were identified for Macrosteles laevis and M. sexnotatus. These findings were affirmed by Morris (1981a, 1981b). Furthermore, our findings go along with those of Nickel \& Achtziger (1999) revealing that Deltocephalus pulicaris, Javesella pellucida, Macrosteles laevis, M. sexnotatus, Psammotettix alienus and Streptanus sordidus occur predominantly in mown sites. These authors also discovered a positive response to land use of Arthaldeus pascuellus and Errastunus ocellaris. In the Lower Oder Valley the former species both dominant in mown sites and fallows. The latter species even occurred predominantly in fallows. For Streptanus aemulans results are also very heterogeneous. The results of the present study confirm the findings of Morris (1981a) revealing that the species is negatively affected by mowing twice a year, whereas Nickel \& Achtziger (1999) did find the species predominantly occurring in meadows that were cut twice a year. Gerstmeier \& Lang (1996), on the other hand, found that cutting neither positively nor negatively affected the occurrence of this species. 
These heterogeneous results suggest that the occurrence of these species is not only affected by mowing. Therefore, it was tested in what respect the combination of the factors "mowing" and "flooding" affect their occurrence, but none of the species in question was favoured by a specific combination of influencing factors. However, Anoscopus serratulae was identified to occur predominantly in fallows not subject to flooding, Erzaleus metrius in fallows subject to medium flooding impact and Streptanus sordidus in mown sites subject to medium flooding impact. Taking Erzaleus metrius as an example, it seems that abiotic factors such as moisture conditions or flooding impact are responsible for the presence or absence of the Auchenorrhyncha species. The leafhopper lives monophagously on Phalaris arundinacea, which is the dominant grass in most parts of the study area. Nonetheless, the leafhopper occurs predominantly in sites subject to medium flooding impact. In fallows I also found groups of species that occurred predominantly in sites subject to a specific flooding impact. For eight species flooding impact or moisture conditions seem to be influential factors, whereas for 15 species the restricted presence is correlated with the limited occurrence of their respective host plants. Thus two different explanations for the restricted occurrence of the plant- and leafhoppers can be found: (i) host plants occur only in parts of the study area, (ii) abiotic conditions are responsible for the presence or absence of the species. Furthermore, Macrosteles sexnotatus which was identified to be favoured by mowing, occurs within fallows predominantly in sites subject to high flooding impact. These sites are also dominated by Javesella pellucida.

Similar observations were made after the catastrophic summer flood at the river Elbe in 2002 (W. Witsack pers. comm.). Additional flooding during summer favours plant- and leafhopper communities that are similar to those occurring in mown meadows. Thus, it seems that disturbance by flooding during summer has a similar effect on Auchenorrhyncha communities as disturbance by mowing.

\subsubsection{Ecological characteristics of the species}

Despite the very heterogeneous results found when analysing the impact of mowing on numbers of species, numbers of individuals and $\alpha$-diversity, homogeneous patterns were found in different studies concerning the ecological characteristics of the species: In the Lower Oder Valley more pioneer species, being mostly macropterous and polyphagous, were found in mown sites rather than in fallows, whereas in the latter a more specialised community occurred. Andrzejewska (1979) found an increase in the proportion of invasive species in managed meadows in Poland, Achtziger et al. (1999) identified an increase in stenotopic species with decreasing land use in moist grassland and Nickel \& Hildebrandt (2003) collected more specialists in fallows than in mown temporarily flooded grassland along the river Elbe. A prevalence of macropterous, bivoltine and polyphagous Auchenorrhyncha was reported for ephemeral habitats (e.g. Novotný 1994a, 1995).

The differences between the ecological characteristics of the species occurring in mown sites and those of fallows can be seen as a direct consequence of the disturbance caused by cutting. Additionally, they are based on changes in plant species composition, 
habitat complexity and microclimate in the aftermath of the cut. Nickel (2003) states that habitat disturbance favours macropterous, bi- and polyvoltine as well as polyphagous species. Novotný (1995) terms this combination of ecological characteristics "colonisation syndrome". A dominance of bivoltine and polyphagous species was also found in fallows situated on the river bank where additional flooding events can occur in summer. These findings support our earlier assumption that disturbance by flooding during summer has a similar effect on Auchenorrhyncha communities as disturbance by mowing. Like mown meadows these sites were dominated by pioneer species. Contrarily, the most specialised community was found in fallows subject to medium flooding impact. These sites were dominated by hygrophilous and monophagous plant- and leafhoppers.

In the following paragraphs a number of ecological characteristics are discussed in detail:

\section{Wing length}

In the Lower Oder Valley, macroptery was found to be common in species of mown grassland. More monomorphic macropterous plant- and leafhoppers occurred in mown sites than in fallows. In dimorphic species wing length was not measured, thus the number of macropterous Auchenorrhyncha might be even underestimated. This was certainly the case in fallows subject to high flooding impact. 50\% of the individuals collected in these sites belonged to Javesella pellucida. Most individuals of this dimorphic planthopper that were caught in the study area were macropterous (Rothenbücher unpublished data). Several authors found a dominance of macropterous forms in ephemeral habitats, while with increasing persistence of the habitats the proportion of macropters decreased (Denno et al. 1991, Novotný 1995). In ephemeral and disturbed habitats the high mobility of the macropterous species enables them to emigrate when habitat conditions are bad and to quickly (re)colonise suitable habitats. These advantages are obtained at the cost of a reduced rate of reproduction (Denno et al. 1991, Roff 1994). Roff (1994) identified the factors "persistence of the habitat" and "cost of being macropterous" as most important in determining the frequency of macroptery in a population. It seems that immigration plays an important role for Auchenorrhyncha communities in mown meadows as well as in fallows subject to high flooding impact, but so far studies have been carried out to assess the actual proportion of species which survive the disturbance and which colonise the grassland afterwards. However, Nickel \& Hildebrandt (2003) speculate, that mown meadows may be large population sinks for surrounding habitats. The results of the present study indicate that this might also be the case for grassland that is subject to regular summer floods.

\section{Voltinism}

In the study area bivoltine species dominated in both, mown sites and in fallows. One might have expected to find bivoltine species to play a minor role in near-natural habitats (Novotný 1994a, 1994b, 1995, Nickel \& Achtziger 1999). However, the comparative high number of bivoltine species collected in fallows may be correlated 
with disturbance by flooding. Especially fallows subject to high flooding impact were dominated by bivoltine Auchenorrhyncha. However, fewer monovoltine Auchenorrhyncha occurred in mown sites than in fallows, which can be interpreted as a consequence of cutting. Klieber et al. (1995) found a reduction in the abundance of the monovoltine leafhopper Streptanus sordidus because mowing occurred during reproduction period. Contrarily, reproduction periods of the bivoltine planthopper Javesella pellucida fit in between the two mowing dates resulting in an increased abundance of the planthopper in the mown meadows. This increase might additionally be based on the better food quality of the freshly grown grass. Andrzejewska (1979) relates the rapid increase in numbers of individuals between two cutting events (which was found likewise in the present study) to the high growth rate and the slowing down of the processes of maturing and dying of plants in the mown meadows resulting in a higher nitrogen content of the plants. She found out that invertebrate phytophages supplied with food rich in nitrogen compounds have a shorter period of larval development, larger body weight and increased fecundity. Furthermore, she stated that the highest numbers and biomass of young developmental stages of phytophages coincide with the period of rapid plant growth, i.e., with the period of the grass's physiological youth and high nutritive value.

Diet width

Despite a dominance of oligophagous plant- and leafhoppers in the two land use variants, more polyphagous Auchenorrhyncha occurred in mown sites. On the one hand food availability is very variable in mown sites, but more persistent in fallows. On the other hand, throughout the growing season host plant quality is higher in mown sites than in fallows (see previous section). Nickel (2003) states that Auchenorrhyncha communities of disturbed habitats show similar characteristics to those of early successional stages. Novotný (1994b) found specialised leafhoppers predominating in permanent habitats, while polyphagous species dominated on plants typical of ephemeral habitats. He also states that polyphagous leafhoppers occur on ruderal plants in the initial phase of secondary succession e.g. in managed meadows (Novotný 1994b). Furthermore, in the study area polyphagous plant- and leafhoppers dominated in fallows subject to high flooding impact, which might be also a consequence of unpredictable disturbance by summer floods. However, beside these typical polyphagous, macropterous pioneer species the monophagous, macropterous specialist Balclutha rhenana occurred predominantly in these sites. As stated earlier, it seems that in these sites mobility is a very important characteristic. It seems that in contrast to mown meadows the dominance of polyphagous plant- and leafhoppers in fallows subject to high flooding impact are rather due to the joined occurrence of macroptery and polyphagy than due to limits in food plant availability. 


\section{Moisture preference}

Many euryhygric, but only few of the typical hygrophilous wetland species were found in the mown meadows. Euryhygric plant- and leafhoppers can cope with a wide range of moisture conditions and thus seem to be able to tolerate changes in microclimate due to mowing. More hygrophilous Auchenorrhyncha occurred in fallows - especially in those subject to medium flooding impact. In these sites regular and long lasting winter floods occur. The sites were dominated by a variety of moisture indicating plants. Here, moist microclimatic conditions remain relatively stable throughout the growing season, thus favour the occurrence of hygrophilous plant- and leafhoppers. 


\section{Submersion tolerance in floodplain arthropod communities}

\subsection{Introduction}

Floodplains of natural rivers are shaped and characterised by the flooding dynamics of the adjacent river. Thus, all species living in floodplains have to cope with a more or less regular cycle of wet and dry conditions throughout the year. The main problems terrestrial arthropods have to face during submersion are low oxygen concentrations in the water, danger of cell destruction due to swelling and passive drift with high water (Hildebrandt 1997). The occurrence of terrestrial invertebrates in periodically submerged habitats suggests that there are special adaptations that help species to survive these unfavourable conditions (Adis 1992). Principally, two types of adaptations can be distinguished: migration activity before and after the flooding period, and submersion tolerance. Hildebrandt (1997) defined submersion tolerance as resistance to inundation, which is based on physiological or morphological adaptations that enable the species to survive in their inundated habitat. For example, ground beetles of the genus Dicheirotrichus reduce oxygen consumption by lowering their metabolic rates during submersion (Foster \& Treherne 1976). Furthermore, survival by means of floodresistant eggs is a common (pre)adaptation in the phenology of terrestrial floodplain invertebrates (Adis \& Junk 2002). In this study, species overwintering in the egg stage are included in the class of "submersion tolerant species" in contrast to "immigrating species". Many studies on survival strategies of terrestrial invertebrates inhabiting floodplains have been carried out in the Amazon basin, but much less is known about the situation in Central Europe (Adis \& Junk 2002).

The aim of this study is to analyse which part of the typical wetland fauna overwinters in the inundated floodplain of the Lower Oder Valley National Park, and which part recolonises the floodplain after each flood. Based on this classification, it is tested whether flooding duration and frequency affects the distribution of submersion tolerant and immigrating species in the floodplain of the national park.

The analysis focuses on adult arthropods. Planthoppers and leafhoppers (Hemiptera: Auchenorrhyncha), spiders (Araneida) and ground beetles (Coleoptera: Carabidae) typically occur in high numbers in wet grassland, hence they were chosen as representative groups. 


\subsection{Materials and methods}

\subsubsection{Colonisation experiment and sampling procedure}

With receding water level in May 2002, nine gauze-covered exclosure tents (mesh size: $250 \mu \mathrm{m})$ (Fig. 41), each covering an area of $1 \mathrm{~m}^{2}$, were placed into the floodplain to prevent colonisation of the space underneath, but still allowing the plants to grow. The base of the tents was placed about $10 \mathrm{~cm}$ deep into the earth and all further openings were sealed with sticky tape to prevent arthropods from crawling into the tents.

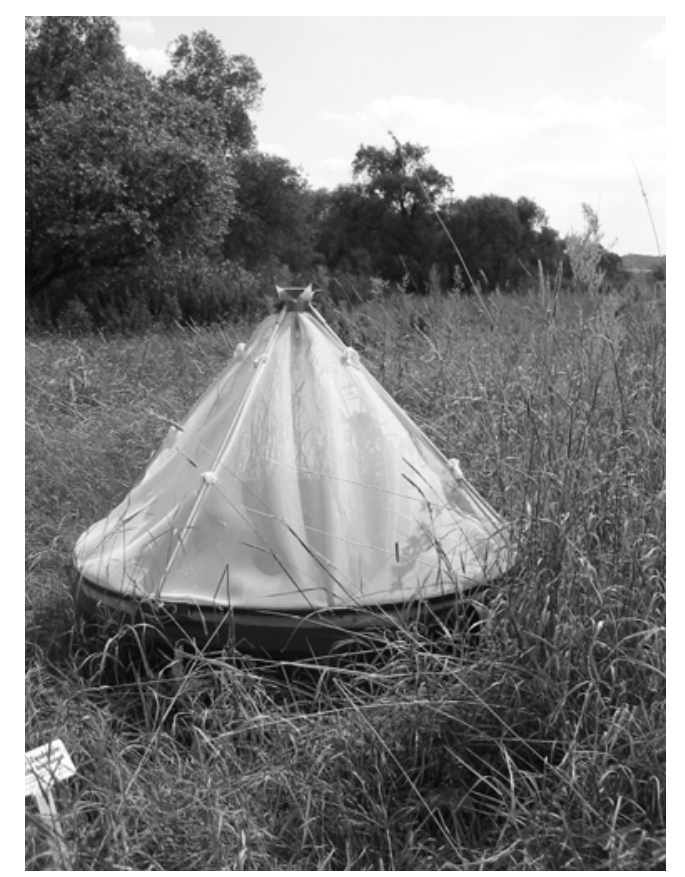

Fig. 41: Gauze-covered exclosure tent.

At the same time as setting up the tents, samples were taken in adjacent uncovered control plots and in "nearby sites" to record those species that were already active in the floodplain at the beginning of the experiment, because early immigration events of some species could not be entirely excluded. In July 2002 samples were taken from underneath the exclosure tents as well as from the control plots by a motor-driven suction apparatus (STIHL SH 85, diameter of suction tube $14 \mathrm{~cm}$ ) and one pitfall trap per tent and control plot (diameter of the trap opening: $5.5 \mathrm{~cm}$, preservative: $50 \%$ ethylene glycol), respectively (Table 19). After sampling, the exclosure tents were removed. Additionally, samples were taken from nearby sites using the same methods during the whole growing season (Table 19). 
Table 19: Sampling design.

\begin{tabular}{lllll}
\hline & \multicolumn{2}{c}{ Suction samples } & \multicolumn{2}{c}{ Pitfall traps } \\
& Time & Area & Time & Traps per site \\
\hline Experimental plots & May (Co) & $1 \mathrm{~m}^{2}$ & 3 days & 1 \\
& July (Co \& Ex) & $1 \mathrm{~m}^{2}$ & 14 days & 1 \\
Nearby sites & May, June, August; September & $0.15 \mathrm{~m}^{2}$ & 14 days & 3 \\
\hline
\end{tabular}

$\mathrm{Co}=$ control plot, $\mathrm{Ex}=$ exclosure tent

Nine groups, each consisting of an exclosure tent, a control plot and a "nearby site", were placed in an area that was $20 \mathrm{~km}$ by $3 \mathrm{~km}$. The tents and their respective control plots were no more than $1 \mathrm{~m}$ apart; the distance to the relevant "nearby sites" was no larger than $5 \mathrm{~m}$. The shortest distance between two groups was at least $100 \mathrm{~m}$.

In order to study the effect of inundation intensity, samples were taken in the "nearby sites" subject to different flooding conditions: (i) to high flooding impact (river bank, summer and winter flooding), (ii) to medium flooding impact (depressions in the polder, long winter flooding) and (iii) to low flooding impact (higher elevations in the polder, short winter flooding) (Fig. 8). Each treatment was replicated three times.

All adult planthoppers, leafhoppers, spiders and ground beetles, occurring in the samples were determined to species level. For all three taxa, analyses of species numbers were based on both suction and pitfall samples. For plant- and leafhoppers all analyses of individual numbers only considered samples taken with the suction apparatus; for spiders and ground beetles only samples taken with pitfall traps were taken into account.

\subsubsection{Ecology of species}

Information on the ecology of plant- and leafhoppers were taken from Nickel (2003), for spiders from Lang \& Pütz (1999), Locket \& Millidge. (1951, 1953), Locket et al. (1974), Schaefer (1976) and Platen et al. (1991) and for ground beetles from Barndt et al. (1991), Lang \& Pütz (1999) and Turin (2000). H. Nickel (pers. comm.) provided further information on flight capability and habitat preferences of plant- and leafhoppers.

Categories of habitat preferences are based on the classification by Platen et al. (1991) and Barndt et al. (1991). I distinguished species from open habitats as being either hygrophilous (hy; occurring preferably in moist to wet habitats), euryhygric (eu; occurring in different habitats independent of moisture conditions) or xerophilous (xe; occurring preferably in dry habitats). Furthermore, species occurring preferably in wooded habitats or on trees or shrubs were treated as forest species (fo).

The nomenclature for all plant- and leafhoppers, except Cicadellidae follows Holzinger et al. (2003), for Cicadellidae Nickel \& Remane (2002), for spiders Heimer \& Nentwig (1991) and for ground beetles Freude et al. (1976). 


\subsubsection{Submersion tolerance versus immigration}

As emphasised above, two general strategies can be distinguished that help species to cope with the annual long winter flood:

- overwintering in the floodplain in a flood-resistant egg, juvenile (larval) or adult stage (submersion tolerance)

- dying during winter or emigrating out of the floodplain in autumn and (re)colonising it with receding water levels (immigration)

Those species that were found as adults underneath the exclosure tents in July, but were not recorded in May were classified as potential submersion tolerant species. Furthermore, species that were caught as adults in the control plots in July but not in May and not underneath the exclosure tents were identified as potential immigrating species. Those species recorded as adults already at the beginning of the experiment could be either submersion tolerant, immigrating or both. For all occurring species I tried to distinguish between immigration and submersion tolerance by considering both, own results and published ecological data. Based on literature information, I also tried to assign species that were found in the floodplain after the end of the experiment to one of the two strategies. However, some species seem to follow both strategies. Thus, I differentiated between three categories: "submersion tolerance", "immigration" and "submersion tolerance and immigration".

\subsubsection{Statistical analyses}

The impact of flooding intensity [high, medium, low] on the distribution of "submersion tolerant", "immigrating" and "submersion tolerant and immigrating" species and individuals sampled in the "nearby sites" were tested using analysis of variance (ANOVA, Tukey test). Normality of data was tested using the Shapiro-Wilk Test (Shapiro \& Wilk 1965); homogeneity of variances using the Fmax Test (Köhler et al. 1995). If necessary, data were transformed to approximate normality and homogeneity of variances.

\subsection{Results}

Between May and July, 30 species of plant- and leafhoppers (1079 individuals), 69 species of spiders (1694 individuals) and 63 species of ground beetles (2006 individuals) were collected as adults. In plant- and leafhoppers these species represented about $60 \%$ and in spiders and carabids over $80 \%$ of the total species numbers recorded throughout the growing season (Table 20). The abundance of the most common plantand leafhoppers, spiders as well as ground beetles and information on their ecological characteristics are given in Appendix 3. 
Table 20: Species numbers of planthoppers, leafhoppers, spiders and ground beetles sampled in the floodplain during the periods May to July (i.e. the period covered by the colonisation experiment) and May to September.

\begin{tabular}{lccc}
\hline & Plant- and leafhoppers & Spiders & Ground beetles \\
\hline May - July & 30 & 69 & 63 \\
May - September & 47 & 83 & 74 \\
Percent species recorded from May to July & $63 \%$ & $83 \%$ & $85 \%$ \\
\hline
\end{tabular}

\subsubsection{Ecology of species: submersion tolerance versus immigration}

\section{Species group $\mathbf{A}$}

In July 21 species of plant- and leafhoppers but only five species of spiders and one carabid species that were not recorded in May, were found underneath the exclosure tents (Table 21, Appendix 3). The most abundant species of plant- and leafhoppers were Arthaldeus pascuellus, Streptanus aemulans and Megamelus notula (Appendix 3).

Table 21: Numbers of species (S) and adult individuals $(\mathrm{N})$ of planthoppers, leafhoppers, spiders and ground beetles sampled in the exclosure tents, control plots and adjacent plots.

\begin{tabular}{|c|c|c|c|c|c|c|}
\hline & \multicolumn{2}{|c|}{ Plant- and leafhoppers } & \multicolumn{2}{|c|}{ Spiders } & \multicolumn{2}{|c|}{ Ground beetles } \\
\hline & $\mathbf{S}$ & $\mathbf{N}$ & $\mathbf{S}$ & $\mathbf{N}$ & $\mathbf{S}$ & $\mathbf{N}$ \\
\hline $\begin{array}{l}\text { Exclosure tents July } \\
\text { (but not May) }\end{array}$ & 21 & 273 & 5 & 9 & 1 & 6 \\
\hline $\begin{array}{l}\text { Control plots July } \\
\text { (but not May nor exclosure tents July) }\end{array}$ & 3 & 3 & 11 & 17 & 2 & 8 \\
\hline Control plots and nearby sites May & 6 & 37 & 53 & 1310 & 60 & 1318 \\
\hline $\begin{array}{l}\text { Nearby sites after July } \\
\text { (but not May nor exclosure tents or } \\
\text { control plots July) }\end{array}$ & 17 & 116 & 14 & 440 & 11 & 61 \\
\hline
\end{tabular}

Among plant- and leafhoppers all of the species collected underneath the exclosure tents overwinter in the egg stage (Fig. $42 \mathrm{~A}$ ), and almost all show reduced capability to fly (Fig. 42 A). Hygrophilous and euryhygric species each comprise about $40 \%$ of the species recorded (Fig. $42 \mathrm{~A}$ ). 


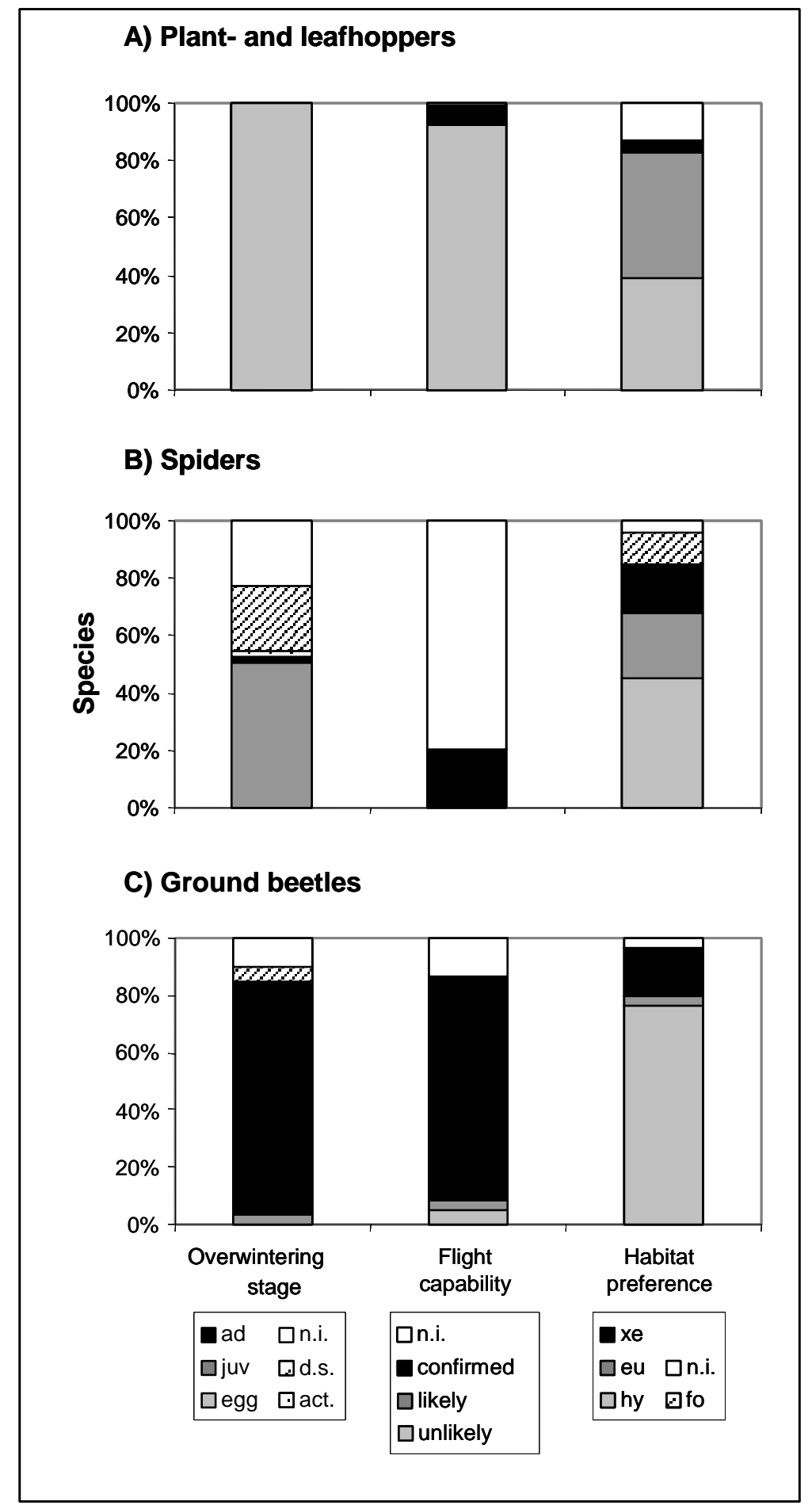

Fig. 42: Ecological characteristics of plant- and leafhoppers $(S=21)$ that were found underneath the exclosure tents in July but not in May (A), of spiders $(S=53)(B)$ and ground beetles $(S=60)$ (C) that were recorded in May. Proportion of species overwintering in the egg stage (egg), as juveniles (juv), adults (ad), adults active in winter (act.) or in different developmental stages (d.s.). Proportion of species, where flight capability is unlikely (unlikely), likely (likely) and those where flight is confirmed (confirmed). Proportion of hygrophilous (hy), euryhygric (eu), xerophilous (xe) and forest (fo) species. n.i.: no information 
The spider Microlinyphia impigra typically occurs in moist to wet habitats. In the study area it was caught in sites subject to medium and low flooding impact. All the plantand leafhoppers of species group A and the spider Microlinyphia impigra overwinter in the floodplain and thus tolerate submersion. According to our own results the spider Oedothorax apicatus tolerated submersion and overwintered in the floodplain. However, Lang \& Pütz (1999) observed the spider Oedothorax apicatus immigrating into the floodplain in spring. Accordingly, this spider seem to follow both strategies, i.e. submersion tolerance and immigration. The remaining species of spiders and the ground beetle were collected in only one study site subject to low flooding impact. Unfortunately, there is no evidence that this study site was inundated during the winter preceding the experiment. Thus, for these species data were not sufficient to assign them to either of the three categories. In summary, 22 species tolerated submersion, one species followed both strategies and for four species the strategy remains unclear.

\section{Species group B}

Three species of plant- and leafhoppers, 11 species of spiders and two species of ground beetles that were found in the control plots in July, were neither found in May nor underneath the exclosure tents in July (Table 21). These species appear to have immigrated into the floodplain after the exclosure tents were set up. Most of these are hygrophilous, three overwinter in the egg stage, and four are capable of flight or ballooning (Appendix 3). All species except Bathyphantes approximatus, Theridion hemerobius, Walckenaeria atrotibialis, Anakelisia fasciata and Metalimnus formosus occur in sites that are situated either close to the dyke or close to trees and shrubs. The planthopper Anakelisia fasciata and the leafhopper Metalimnus formosus as well as the spider Argiope bruennichi were classified as submersion tolerant, although they were collected in the control plots in July and not underneath the exclosure tents. The two plant- and leafhopper species overwinter in the flood-resistant egg stage and typically occur in temporary flooded sites (Nickel 2003). Their distribution in the study area is patchy as they are monophagous on sedges, notably Carex acuta, C. riparia and C. elata. These plant species were not present underneath the exclosure tents, which explains the absence of the specialised phytophages in these samples. The juveniles of the spider A. bruennichi overwinter in the cocoons (Köhler \& Schäller 1987). The spider had been observed in high numbers in the study area, but was rarely collected during two years of investigation. Thus, the failure of recording this species underneath the exclosure tents might be due to the use of inappropriate sampling methods. To summarise, three submersion tolerant and 13 immigrating species were identified. 


\section{Species group C}

Only six plant- and leafhopper species but 53 spider and 60 carabid species were present in the floodplain before the start of the experiment in May (Table 21). Individuals of these species either hibernated in the inundated site or immigrated early. All spiders found in May overwinter in the juvenile or adult stage (Fig. 42 B). For about $20 \%$ of them ballooning activity is reported, and more than $40 \%$ of the species are hygrophilous (Fig. $42 \mathrm{~B}$ ). $58 \%$ are smaller than $5 \mathrm{~mm}$, thus ballooning is likely. The most abundant spiders were Pardosa prativaga, P.palustris and Erigone atra (Appendix 3). For carabids, about $80 \%$ of the species overwinter as adults (Fig. 42 C). Only Poecilus lepidus and Pseudoophonus rufipes overwinter in the larval stage. For approximately $80 \%$ of the species flight activity is reported (Fig. 42 C). Only Carabus granulatus, Dyschirius globulosus and Harpalus autumnalis are not able to fly. In May the ground beetle community was clearly dominated by hygrophilous species (Fig. 42 C), the most abundant species were Agonum afrum, Poecilus versicolor and Carabus granulatus (Appendix 3). Most of the species of species group C immigrated into the floodplain with receding water level. In contrast, the planthopper Paraliburnia adela and the spider Hypomma fulvum (see Wohlgemuth-von Reiche et al. 1997) tolerated submersion. The planthopper was caught in sites subject to medium flooding impact, it typically occurs in temporarily flooded sites (Nickel 2003) and flight activity is unlikely. Furthermore, four species were identified to follow both strategies, i.e. submersion tolerance and overwintering: Wohlgemut-von Reiche et al. (1997) assume that the spider Porrhomma pygmaeum hibernates in the inundated floodplain, whereas Lang \& Pütz (1999) observed the spider immigrating into the floodplain during spring. Furthermore, Fuellhaas (1997) observed that Poecilus versicolor, Pterostichus melanarius and Pt. nigrita survived long periods of submersion, and that these species immigrated into a fen in spring. For Carabus granulatus and Dyschirius globulosus, no flight activity has been observed (Turin 2000). In the Lower Oder Valley these species occurred in several study sites independent of flooding influence. For both ground beetles, migration activity from shrubs and trees into grassland was found during spring, and in autumn migration into potential overwintering sites was observed (Lang \& Pütz 1999). Moreover, in Carabus granulatus submersion tolerance was found (Fuellhaas 1997). Additionally, Wohlgemut-von Reiche \& Grube (1999) observed Clivina fossor to combine both strategies.

In summary, two species were submersion tolerant, 59 immigrated into the floodplain, seven followed both strategies and for 51 species data was not sufficient for classification. 


\section{Species group D}

As previously mentioned, not all species present in the floodplain were sampled during the experiment. Those that were caught with more than four individuals in "nearby sites" after the end of the experiment are listed in Appendix 3 (species group D). Out of the species of group D, seven plant- and leafhopper species and two spider species overwinter in the egg stage, for nine species flight activity is reported, and all except the spider Marpissa radiata and the ground beetle Amara plebeja are adult from summer until autumn. All seven plant- and leafhoppers, two species of spiders and the ground beetle Patrobus atrorufus were classified as submersion tolerant. The plant- and leafhoppers and spiders overwinter in the egg stage (Appendix 3) and do not reach maturity before the end of July, therefore it was not possible to find adults of these species underneath the exclosure tents which were removed in July. The spiders Allomengea scopigera and A. vidua typically occur in wet habitats. The ground beetle Patrobus atrorufus hibernates as adult and is not capable of flight. It was exclusively found in sites subject to medium flooding impact, and possible dry overwintering sites were further away. Lang \& Pütz (1999) did not record any directional emigration activity of this species prior to inundation. Furthermore, the planthopper Stenocranus major, the spider Kaestneria pullata and five carabid species were classified as immigrating species. Out of these, five species are capable of flight. Although for Kaestneria pullata no ballooning activity has been observed, flying by the help of its thread is assumed to be likely as the spider is smaller than $5 \mathrm{~mm}$. The ground beetle Calathus fuscipes is not capable of flight (Turin 2000), but was exclusively collected in study sites close to the dyke. Thus, it might have overwintered in these sheltered areas and then immigrated into the floodplain with receding water levels. Hence, in the "nearby sites" 10 submersion tolerant and seven immigrating species were identified, while for 25 species data were not sufficient for classification.

Summarising the findings of all four species groups, 37 submersion tolerant and 79 immigrating species were identified. Furthermore, eight species follow both strategies and for 80 species no classification was possible (for details see Table 22)

Table 22: Species numbers of sampled arthropods with indication to their adaptation to submersion.

\begin{tabular}{lcccccc}
\hline & \multicolumn{2}{c}{ Plant- and leafhoppers } & \multicolumn{2}{c}{ Spiders } & \multicolumn{2}{c}{ Ground beetles } \\
& S & \% & S & \% & S & \% \\
\hline Submersion tolerant & 31 & 66 & 5 & 6 & 1 & 1 \\
Immigrating & 7 & 15 & 32 & 39 & 40 & 54 \\
Immigrating and submersion tolerant & 0 & 0 & 2 & 2 & 6 & 8 \\
Uncertain & 9 & 19 & 44 & 53 & 27 & 37 \\
Sum & 47 & 100 & 83 & 100 & 74 & 100 \\
\hline
\end{tabular}




\subsubsection{Impact of flooding on the distribution of submersion tolerant and immigrating species}

Most recorded species of plant- and leafhoppers tolerated winter submersion (Fig. $43 \mathrm{~A}$ ). No differences in the proportions of immigrating or submersion tolerant species due to flooding impact were found. The relative proportion of the number of individuals indicates that the few immigrating species clearly dominated in sites subject to high flooding impact (ANOVA: $\mathrm{F}=7.5, \mathrm{p}<0.05$, transformation: $\arcsin \left[\mathrm{x}^{0.5}\right]$ ), whereas submersion tolerant species dominated in sites subject to medium flooding impact (ANOVA: $\mathrm{F}=12.7, \mathrm{p}<0.05$, transformation: $\arcsin \left[\mathrm{x}^{0.5}\right]$ ) (Fig. $43 \mathrm{~A}$ ).

Flooding intensity had no effect on the occurrence of submersion tolerant and immigrating species of spiders (Fig. 43 B). All study sites were dominated by immigrating species. Regarding the proportion of individuals, submersion tolerant species significantly dominated in sites subject to medium flooding impact (ANOVA: $\mathrm{F}=63.8, \mathrm{p}<0.001)$ (Fig. $43 \mathrm{~B})$.

Immigrating carabid species dominated in all study sites. However, the proportion of immigrating species was significantly lower in sites subject to low flooding impact than in those subject to high flooding impact (ANOVA: F=5.9, p<0.05) (Fig. $43 \mathrm{C}$ ). Pseudoophonus rufipes was exclusively sampled in sites subject to medium flooding impact. Considering the proportion of individuals, the dominance of immigrating species is still evident in sites subject to high and medium inundation impact (Fig. 43 C). Furthermore, in sites subject to low flooding influence, higher proportions of species were found that follow both strategies, i.e. immigrating and submersion tolerance, as compared to all other study sites (ANOVA: F=23.3, p<0.001) (Fig. 43 C). 


\section{A) Plant- and leafhoppers}

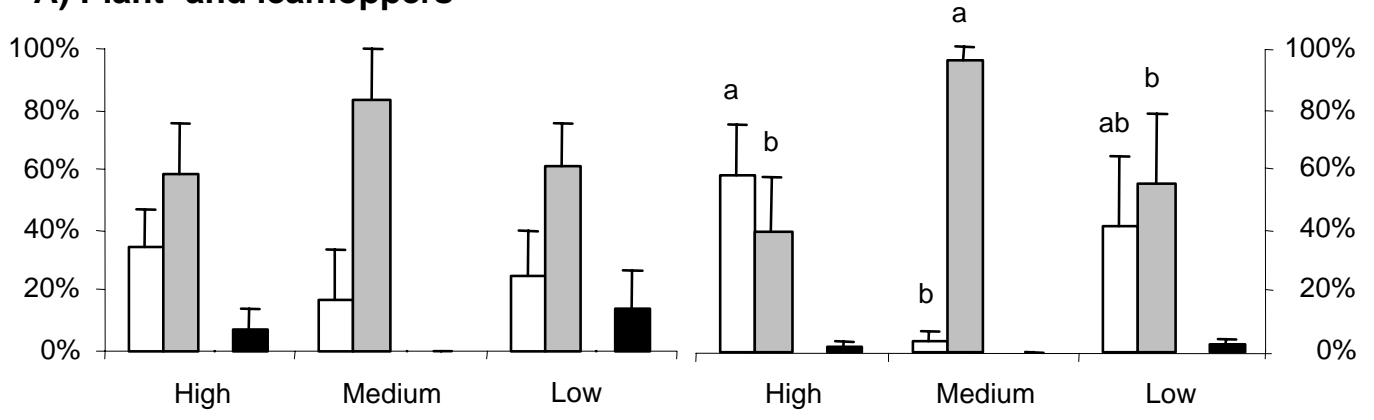

\section{B) Spiders}

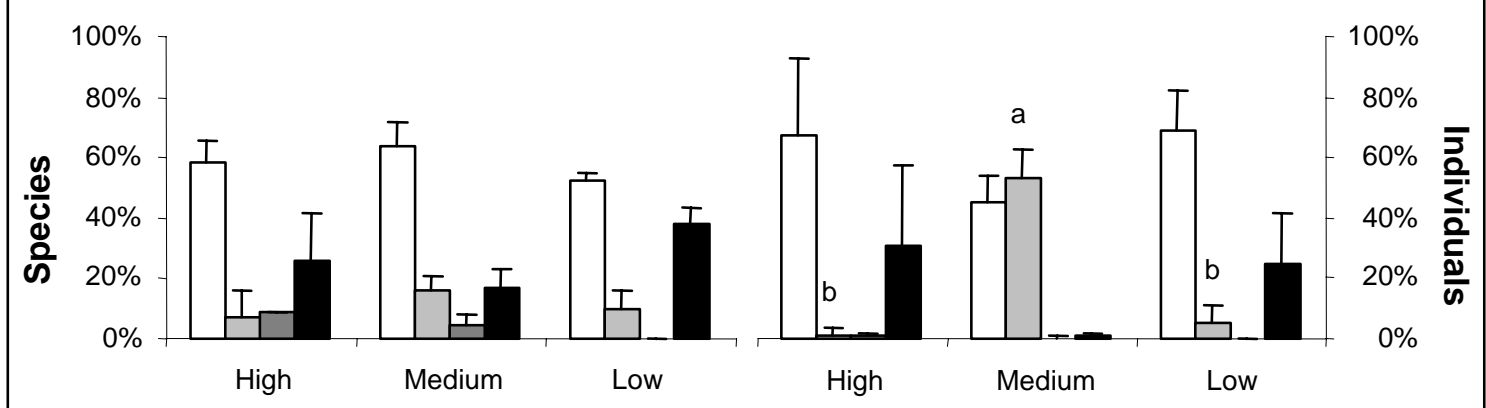

\section{C) Ground beetles}

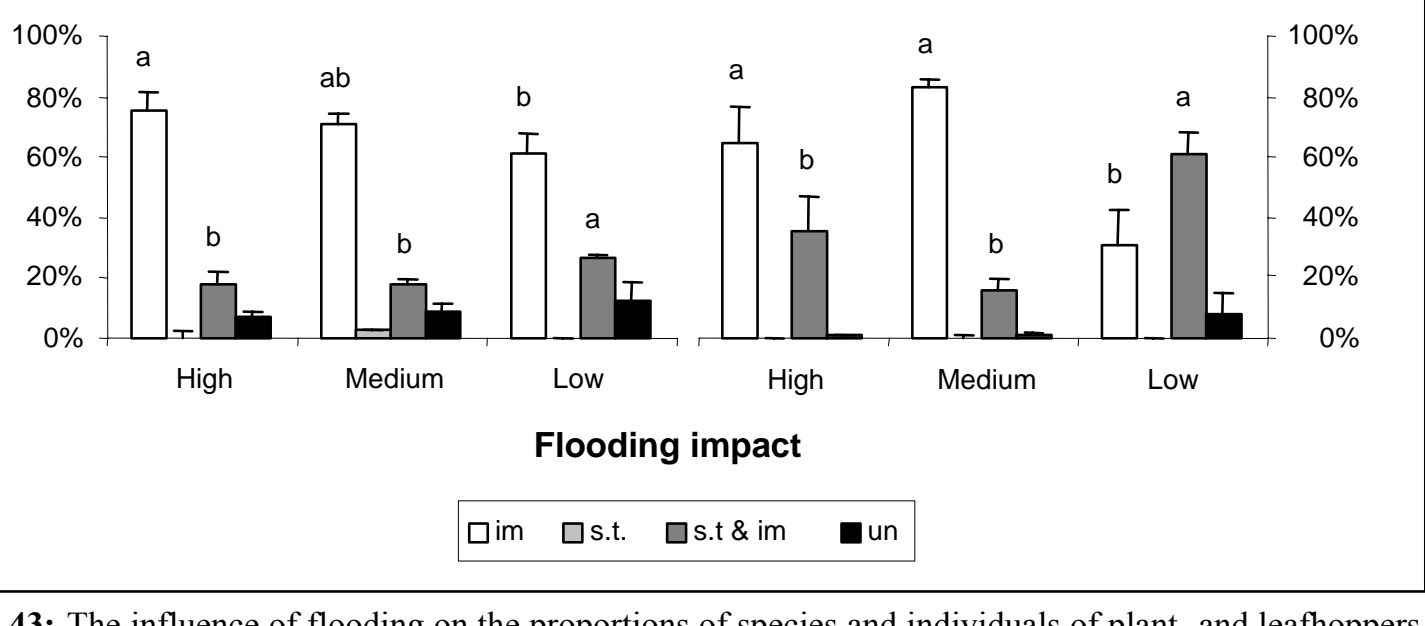

Fig. 43: The influence of flooding on the proportions of species and individuals of plant- and leafhoppers ( $\mathrm{S}=40, \mathrm{~N}=920$ ) (A), spiders $(\mathrm{S}=52, \mathrm{~N}=2056)(\mathrm{B})$ and ground beetles $(\mathrm{S}=66, \mathrm{~N}=4003)(\mathrm{C})$, with the following strategies: immigration (im), submersion tolerance (s.t.), submersion tolerance and immigration (s.t. \& im) and uncertain (un). The letters in the diagram indicate the Tukey groupings. Bars with different letters are significantly different. 


\subsection{Discussion}

\subsubsection{Ecology of species: Submersion tolerance versus immigration}

The present study revealed, that the typical floodplain arthropod fauna consists of submersion tolerant and immigrating species as well as of species that follow both strategies.

Most species of plant- and leafhoppers tolerate submersion during winter. All but one species overwinter in the egg stage, that is considered as rather flood resistant (see Tamm 1986, Schöpke 1996). According to Weigmann \& Wohlgemuth-von Reiche (1999) it is unlikely that Central European arthropods evolved special adaptations to cope with the flooding as it has been found in e.g. Central Amazonian arthropods (see Adis \& Junk 2002). In temperate regions river floodplain systems are comparatively young and flooding events are less predictable than those of Central Amazonia (see Adis \& Junk 2002). Thus, most adaptations that help Central European arthropods to survive the winter flood are considered as "predispositions", i.e. they evolved before the species populated floodplain ecosystems as an adaptation to other environmental conditions than flooding. In Germany more than $60 \%$ of all plant- and leafhoppers overwinter in the egg stage (Nickel 2003), which can be interpreted as an adaptation to avoid unfavourable conditions such as cold and lack of food resources during winter. Thus, this phenological predisposition allows many plant- and leafhopper species to become established in floodplain habitats. In the study area submersion tolerance in the egg stage was also found for the spiders Allomengea scopigera and A.vidua. Furthermore, this adaptation was also identified in springtails (Isotoma spp.), the centipede Lamyctes emarginatus and some caeliferan grasshoppers (Weigmann \& Wohlgemut-von Reiche 1999, Zerm 1999). Obviously, flood-resistance of eggs is a common (pre-)adaptation of terrestrial arthropods to survive longer periods of submersion (Tamm 1986, Adis \& Junk 2002).

In contrast, most species of spiders and ground beetles but only few plant- and leafhopper species did not hibernate in the floodplain but (re-)colonised the habitat with receding water levels either from shelters within the floodplain or from outside. All these species overwinter in the juvenile or adult stages. In general, most spiders overwinter in the juvenile or adult stages, only $7 \%$ overwinter in the egg stage (Schaefer 1976). Ground beetles hibernate either as larvae or as adults and only for very few species overwintering in the egg stage is considered (Thiele 1977). Thus, my findings are in accordance with the theory of Weigmann \& Wohlgemuth-von Reiche (1999) explained above. The juvenile or adult stages of terrestrial arthropods are less flood resistant than the eggs, and the evolution of adaptations to survive long periods of submersion are unlikely. Furthermore, all of these immigrating species are characterised by high mobility. Immigration in spring and emigration in autumn of many species of spiders and ground beetles was found by Lang \& Pütz (1999) at the river Oder. High flight activity of ground beetles was also recorded at the river Elbe (Germany) and the 
Morava river (Austria) (Bonn et al. 1997, Zulka 1994). Thus, species that overwinter in the juvenile or adult stages are not able to tolerate winter submersion, but avoid the unfavourable conditions during winter by migration into sheltered areas. However, some contradicting results were found as well. The planthopper Paraliburnia adela, the spiders Microlinyphia impigra, Oedothorax apicatus and Porrhomma pygmaeum as well as a number of ground beetles were found to tolerate winter submersion in the juvenile or adult stages. At present, possible physiological or morphological adaptations are still unknown and further research is necessary.

Furthermore, some species of spiders and ground beetles followed both strategies to cope with the annual winter flood. For three species of ground beetles Fuellhaas (1997) found that the viability of their populations was dependent on immigrating species. Possibly, some of the species classified as submersion tolerant in the present study might also be dependent on immigrating individuals to maintain a viable population. Thus, future investigations should focus on the question, in what respect immigrating individuals of submersion tolerant species are crucial for the survival of the populations.

\subsubsection{Impact of flooding intensity}

Sites subject to high flooding impact, i.e. to summer and winter flooding, were dominated by immigrating species of all three arthropod groups that were studied in detail. In these sites, flooding is unpredictable and can occur at nearly any time of the year. Especially during summer, inundation has a severe impact on the arthropod communities. Shortly after the catastrophic summer flood at the river Elbe (Germany) in 2002, only few pioneer species such as the planthopper Javesella pellucida were found in the floodplain (W. Witsack pers. comm.). In these sites, species that are characterised by high mobility and high fecundity are favoured. They can emigrate during the time of flooding and quickly recolonise the sites with receding water levels. Furthermore, increased mortality is compensated by a high reproductive rate.

In contrast, immigrating species of plant- and leafhoppers and spiders were less successful in sites subject to medium flooding impact, i.e. sites that are regularly flooded for a long time during winter. This might be due to the low competitive ability of the immigrating populations. In these sites, submersion tolerant species of plant- and leafhoppers dominated in terms of numbers of species and individuals. In spiders I found a similar pattern. Although most of the spiders that occurred in the Lower Oder Valley were identified as immigrating species, the submersion tolerant species Allomengea scopigera and A. vidua accounted for $50 \%$ of the total number of individuals in sites subject to medium flooding impact. Most of the species tolerate submersion in the egg stage. Only the ground beetle Patrobus atrorufus and the planthopper Paraliburnia adela survived long winter flooding as larvae. Furthermore, many of the submersion tolerant plant- and leafhopper species of sites subject to medium flooding impact are specialists (see chapter 3), most of which are monophagous, monovoltine, brachypterous and restricted to a narrow range of habitats (Achtziger et al. 1999). Also, both submersion tolerant spider species typically occur in moist to wet habitats. Heller \& Irmler (1997) found at the "Alte Sorge Schleife" 
(Germany) specialised species of spiders and ground beetles being favoured by long lasting winter floods. Thus, it seems that overwintering in the egg stage is a good preadaptation to regularly occurring and long lasting winter floods. This might also explain the low number of submersion tolerant ground beetles, as overwintering in the egg stage is rarely found in this group. Furthermore, in these sites, specialised arthropods are favoured, which seem to have a higher competitive ability than many immigrating species.

In sites subject to low flooding impact I found a high proportion of ground beetles following both strategies. For three species of ground beetles, Fuellhaas (1997) showed that they were not able to maintain large populations only based on overwintering individuals when the habitat was regularly flooded for a long period of time. Here, the survival of the population depended on immigrating individuals. In the Lower Oder Valley the sites subject to low flooding impact were mostly situated close to potential shelter areas, such as the dykes or groups of trees and shrubs. Recolonisation out of these areas was possible. Furthermore, some adult ground beetles seem to be able to tolerate submersion for a short period of time. Zulka (1994) found that the ground beetle Bembidion dentellum survived in cold, aerated water for 40 days. However, under conditions simulating spring inundation at a river bank, all beetles emerged within two days. The chance of adult ground beetles to survive the annual winter flood is dependent on the period of submersion and thus is much higher in sites subject to low flooding impact than in sites subject to high or medium inundation influence. 


\section{Conservation management of target species or conservation of processes - Winners and losers of two different conservation strategies}

\subsection{Introduction}

In 1993 Germany ratified the Convention on Biological Diversity (CBD) and thus committed to translating the content of the convention into national legislation. This includes, among other things, the protection of biological diversity within protected areas in Germany i.e. the conservation of ecosystems and natural habitats as well as the maintenance and recovery of viable populations of species in their natural surroundings. More than ten years after the world summit of Rio de Janeiro in 1992, it is interesting to investigate whether conservation of biological diversity is successful within protected areas in Germany.

In the context of the graduate training programme "Conservation and Valuation of Biodiversity", three case studies were carried out in the Lower Oder Valley National Park. Peter Just analysed the habitat parameters that are crucial for the successful establishment of breeding corncrakes (Crex crex) in the national park. In the second study Kai Bentlage investigated the impact of flooding on the amphibian community, whereas in the third study carried out by myself the impact of land use and flooding on the diversity of insects was the centre of interest. In the national park conservation management for target species and conservation of processes are realised side by side which provides the opportunity to discuss and compare the effects of the two conservation strategies on the selected taxa within the context of the protection of biological diversity.

\subsection{Two conservation strategies}

Conservation management for selected target species and conservation of processes are two strategies in nature conservation that have been largely discussed (Jedicke 1995, 1998, Mühlenberg and Hovestadt 1992, Vogel et al. 1996, Scherzinger 2002, Schneider 1998).

It is the aim of the target-species approach to preserve and - if necessary - manage the habitat of the selected target species in such a way that it can maintain at least a minimum viable population (MVP) of the species. The target-species approach is not restricted to just one selected habitat. By choosing several target species as representatives for different sites in a habitat mosaic, a larger area can be managed. For the successful use of this approach in nature conservation it is crucial to select the appropriate target species. Vogel et al. (1996) name four criteria for the selection of target species: degree of vulnerability, chance of survival, "windfall gain" ("Mitnahmeeffekt") and popularity. Taking into account the degree of vulnerability, emphasis should be laid on species that have their centre of distribution in Central Europe and that are threatened on a nationwide, regional or local level. Furthermore, the particular species should have a reason- 
able chance of survival in the selected area. To reach a good windfall gain preferably umbrella species, key-stone species or species with a large home range should be chosen as it is assumed that quite a number of other species will profit from conservation efforts (Mühlenberg and Hovestadt 1992, Vogel et al. 1996). Beside these biological criteria, popularity is important too, although it is more a political criterion. Public support for a conservation programme is gained more easily if charismatic species are chosen as target species. An advantage of this approach is that by choosing a target species the conservation aim is more clearly defined. This easily allows evaluation of the conservation efforts and optimisation of the conservation strategy if necessary. Disadvantages of this strategy are that it can be time consuming and expensive. One crucial point of this approach is the assessment of the target species' chance of survival in the selected area. The suitable scientific approach is a population viability analysis (PVA). For this analysis, information on long term dynamics and habitat factors are needed. To gain a meaningful PVA, data of at least three years field work should be analysed (Vogel et al. 1996). For some species permanent habitat management e.g. regular cutting might be necessary to maintain suitable habitats which might include long term costs. Furthermore, there is a lack of investigation on the postulated windfall gain.

It is the aim of the "conservation of processes" strategy that the functions and processes in communities and ecosystems are preserved under preferably natural conditions for a long period of time (Schaefer 2003). Thus, a habitat is chosen to become a protected area and from this moment on the area is left for succession. Anthropogenic impacts are restricted to a single measure with the aim of initiating a favoured stage of succession ("Initialmaßnahmen") e.g. planting willows to initialise the development of an alluvial forest. Whereas most authors restrict the concept of process conservation to the conservation of anthropogenically uncontrolled dynamics, Jedicke (1998) includes man made dynamics e.g. land use in the concept. The former is known as a segregative, the latter as an integrative strategy (Jedicke 1998). In this chapter process conservation alludes solely to the segregative concept. Jedicke (1998) names two prerequisites for a successful integration of the strategy into nature conservation programmes. Firstly, the protected area must comprise an area of sufficient size. To assess the appropriate size population dynamics must be taken into account which might include among others, the application of the concept of MVP and the theory of island biogeography. The ideal case would be that the area should be able to host all seral stages side by side if possible. Secondly, any anthropogenic impact must be forbidden in the area which includes accepting unwelcome and unexpected developments e.g. a large outbreak of pest species as happened in the Bavarian Forest National Park (Pongratz 1995). The advantages and risk of this conservation strategy is that it is comparably cheap to realise. Thus, it must be carefully assessed whether the approach is appropriate for the protected area in question depending mainly on the size of the area. The assessment of the appropriate size is the sore point of the strategy. In contrast to the target-species approach no "target" is defined which can be used to assess the needs to host a MVP successfully. Furthermore, evaluation of the conservation aim is more difficult than in the target-species approach. Nevertheless, the 
strategy of conserving processes seems at present the only approach that includes the preservation of habitat dynamics into nature conservation hence being a chance to preserve naturalness in a largely man-made landscape.

In a nutshell, the target species approach aims at preserving a habitat for a selected species whereas process conservation aims at preserving a habitat and its dynamics.

\subsection{Three case studies from the Lower Oder Valley National Park, Germany}

\subsubsection{Impact of mowing on the suitability of grassland as habitat of corncrakes (Crex crex) in the Lower Oder Valley National Park}

The main results of Peter Just's study on the impact of mowing on the suitability of grassland as habitat for corncrakes are outlined in the following section. More detailed information can be found in Appendix 4.

In the Lower Oder Valley National Park the corncrake has been chosen as a target species for conservation. The bird typically occurs in grassland, meadows and fields. Overwintering in Africa, corncrakes return to Central Europe in spring and start breeding in May. Mowing meadows in spring and early summer and loss of habitats due to intensified agriculture resulted in a decline in corncrake populations. The corncrake is under threat of global extinction. In Germany the largest population can be found in the Lower Oder Valley National Park.

It was the aim of this case study to investigate the consequences of changes in land use on habitats and their suitability for corncrakes. Local ornithologists provided information on the places where singing corncrakes occur in the study area. Additionally, a variety of variables characterising the vegetation structure were measured. Data were analysed by stepwise multiple regression.

After the returning of the birds in May, "height" and "cover" of the vegetation were identified as the main structural variables responsible for the habitat selection of the corncrake. The probability of occurrence of the birds increased with increasing vegetation height. Suitable habitats for the corncrake must provide sufficient cover. In the study area, no difference in the key variables were found between fallows and mown sites, because the meadows are usually not cut before June. Thus, in May both land use variants seem to be suitable habitats for the birds.

In June, "cover of dead phytomass" was identified as key variable. With decreasing cover of dead phytomass, the probability of occurrence of the birds increased. A number of investigations revealed that corncrakes are not capable of walking through very dense vegetation. In the study area a dense cover of dead phytomass was found in fallows. In June, corncrakes occurred predominantly in mown meadows. Mowing not before the end of July was proposed as a suitable management to reduce the cover of dead phytomass in the meadows, and thus maintain suitable habitats for the corncrake. 


\subsubsection{Impact of flooding on the amphibian community}

In the floodplain of the Lower Oder Valley National Park a variety of waterbodies provide suitable habitats for many amphibian species. It was the aim of the study carried out by Kai Bentlage to investigate the impact of flooding on the amphibian communities. More detailed information can be found in Appendix 5. Between May and September 2002 he recorded the occurrence of tadpoles, juvenile and adult amphibians around and in different waterbodies in the wet and in the dry polder.

Altogether eight species were found in the study area. In the dry polder the majority of species occurred, whereas in the wet polder only two species of the so-called "water frog complex" were found. Inundation of the wet polder until the middle of April seem to prevent many amphibian species from establishing populations. Most amphibians migrate to their breeding places and mate relatively early in the year, whereas only species of the water frog complex hibernate under water. They have no need to migrate to their breeding places. Furthermore, mating takes place between May and July.

The future plans of the national park to restore a more natural flooding regime will probably lead to longer periods of submersion in spring. These changes seem to neither positively nor negatively affect species of the water frog complex. However, the occurrence of the majority of the amphibian species will still be restricted to the dry polder.

\subsubsection{Consequences of changes in flooding and land use for the conservation of insects in the Lower Oder Valley National Park}

As outlined in chapter 2, land use and flooding are currently the two major factors affecting species living in the floodplain of the Lower Oder Valley National Park. Both factors are planned to be altered in the future. Based on the data analysed in chapter 3, the consequences of changes in land use and flooding for the conservation of plant- and leafhoppers in the national park are discussed.

It was obvious from ordination that mowing appeared to be the most important variable affecting the distribution of species assemblages. No significant differences in mean numbers of species and individuals, as well as in diversity, were found between fallows and mown grassland. Taking the habitat preferences of the plant- and leafhoppers into account revealed that significantly more hygrophilous species were found in fallows than in mown grassland. Furthermore, more polyphagous Auchenorrhyncha were collected in mown plots than in fallows.

The conclusions drawn from these findings depend on the conservation objectives. A national park is a protected area sensu CBD. Thus, one aim is the conservation of biological diversity. This might be understood as preserving high numbers of species and high diversity. Against this background it seems to make no difference whether the grassland is cut twice a year or left for succession as no differences in mean numbers of species and diversity between fallows and mown study sites were found. However, altogether more species were caught in fallows than in mown meadows. Many studies revealed that with decreasing land use intensity the numbers of species and individuals increase (Morris and Lakhani 1979, Klieber et al. 1995, Nickel and Achtziger 1999), but 
decrease again with longer fallow period (Nickel and Achtziger 1999). Thus, for increasing the numbers of species in the area one might think about reducing mowing e.g. to one cut a year or every two years but abandoning grassland would be out of the question.

In the declaration act of the Lower Oder Valley National Park, the aims and purpose of the national park are outlined. Among other things, it is stated that the purpose of the national park is to protect and to develop natural processes on a large area which is undisturbed by anthropogenic impacts. This leads to a different conservation aim i.e. a development towards more naturalness which includes abandoning the grassland and leaving it for succession. The number of hygrophilous species can be used as a measure of the degree of specialisation of the communities to floodplain habitats. More hygrophilous plant- and leafhoppers were caught in fallows than in mown study sites. Fallows seem to host the species assemblages more typical for floodplain grassland than mown plots. Hence, giving up mowing activity will favour the typical Auchenorrhyncha floodplain fauna.

Apart from the reduction of land use, the plan for future national park development includes a change in flooding regime towards more natural flooding conditions, i.e. longer and more frequent flooding events. To assess the impact of these changes on the plantand leafhopper communities, fallows that were subject to different flooding influence were chosen as study sites. The river bank seems at first sight to be the habitat in the national park closest to natural conditions. But the areas between the dyke and the river Oder are very narrow, thus the water level rises and falls rapidly and the grassland and the Auchenorrhyncha species are subjected to very variable water levels and high currents. The former natural floodplain was much wider thus inundation was a slower process with slower currents. The long lasting floods occur in the Lower Oder Valley typically during winter. Summer flooding is a more rare event and high water levels that are comparable to winter flooding occur on average only once in 10 years (Vössing 1998). Thus, the sites subject to long lasting and regularly occurring winter floods, i.e. subject to medium flooding impact, seem to be closest to natural conditions.

Analysis of the data revealed that fallows without any flooding influence host species rich and diverse communities, whereas in sites subject to medium flooding impact the lowest number of species and the lowest diversity value were found. Additionally, flooding duration and frequency affected the occurrence of hygrophilous species. In fallows subject to medium flooding influence $80 \%$ of the plant- and leafhoppers were hygrophilous. In contrast, less than $20 \%$ of the individuals caught on the river bank were hygrophilous species, the habitat was dominated by euryhygric species. Like the fallows on the river bank, sites subject to low flooding impact were dominated by euryhygric species. Comparing the species in regard to their food plant specialisation gives further information on the effect of flooding on the Auchenorrhyncha communities. Monophagous species dominated in fallows subject to medium inundation impact. Oligophagous species dominated in sites subject to no or low flooding impact.

The analysis revealed that fallows host more specialised communities in terms of moisture and food plant specialisation than mown plots. Within fallows, ordination 
showed that the species assemblages differed in regard to flooding influence. Sites subject to high and low flooding impact have in common that the flooding influence is not very predictable. Sites on the river bank are subject to regular winter flooding while summer floods are less predictable events. Sites subject to low flooding influence are situated on more elevated locations in the wet polder, hence they might not be inundated every winter. On the other hand, sites subject to medium flooding influence are inundated regularly every winter. Thus, it seems that regularity and predictability of flooding are important factors influencing species assemblages. Furthermore, the most specialised communities were found in sites subject to medium flooding influence. Plans including the reduction of land use and a change towards more natural flooding conditions seem to favour specialised plant- and leafhoppers but reduce species diversity. Furthermore, as all endangered species found in the national park are specialists (Fig. 44), the plans for future national park development can be approved as positive from a nature conservation point of view.

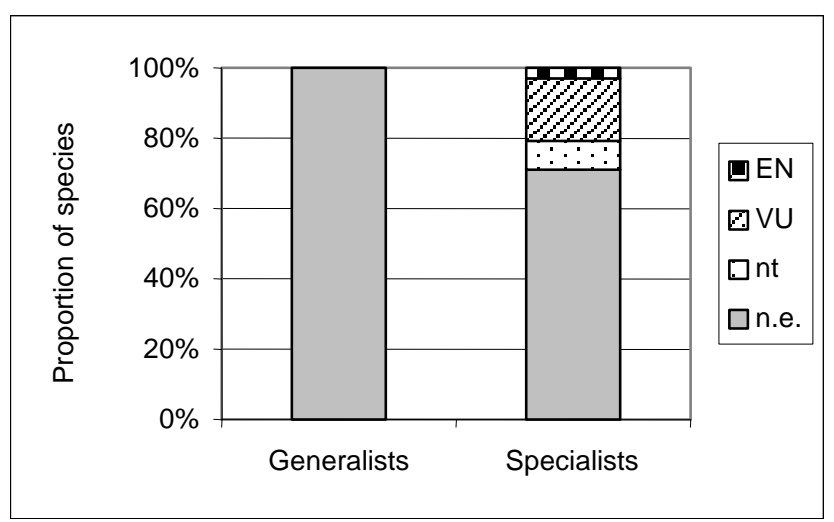

Fig. 44: The percentage of species listed in the Red Data Book for generalist and specialist plant- and leafhopper species caught in the study area. EN: endangered; VU: vulnerable; nt: near threatened; n.e.: not endangered. 


\subsection{Discussion: Winners and losers of the two conservation strategies}

Combining the results of the three case studies makes it possible to assess on one hand the effect of conservation management for the target species corncrake on the diversity of plant- and leafhoppers. On the other hand, the consequences of process conservation on the corncrake population as well as on the Anura and Auchenorrhyncha communities can be assessed.

Currently, conservation management for the corncrake follows a very pragmatic approach. No management plan officially regulating the mowing activity in the national park is in use. Nesting sites of the corncrake are mapped every year by voluntary local ornithologists. Based on this survey, instructions for mowing are given to the farmers because the present mowing practice, i.e. first cut at the beginning of June, would lead to the destruction of eggs or the death of freshly hatched chicks. Thus, small areas around the identified nesting sites are left uncut. In the long run it is intended to alter the mowing practice. The first cut is planned to be not before $15^{\text {th }}$ August and larger patches of grassland will be left uncut each year within the mown meadows (IUS 1998).

The comparison of the vegetation structure in meadows and fallows revealed that "cover of dead phytomass" was the most correlating variable for the differentiation between suitable and unsuitable nesting sites for corncrakes. By mowing, phytomass is taken out of the meadows, thereby reducing its accumulation. Thus, mowing seems to be an appropriate management practice to preserve suitable habitats for corncrakes. Green et al. (1997) states that the amount of dead phytomass in grassland is also reduced by winter floods. These findings could not be confirmed by the study of corncrakes as both fallows and mown grassland are regularly subjected to long winter floods, but clearly differed in suitability for corncrakes.

The study on Anura did not take the factor mowing into account but Blab (1996) and Beebee (1996) state that reducing land use has a positive effect on amphibian communities.

The study on plant- and leafhoppers showed that the current mowing practice does not affect numbers of species and individuals but significantly reduces the number of specialists. As many specialists are listed in the Red Data Book (Nickel and Remane 2002), mowing has a negative effect on the Auchenorrhyncha species assemblage from the point of view of nature conservation. One might argue that the planned change in mowing practice might have a positive effect on Auchenorrhyncha because Achtziger et al. (1999) showed that with decreasing land use intensity the number of species, individuals and specialists increased. However, not only the number of mowing events but also the timing plays an important role. It seems that mowing in autumn or early in spring leads to species rich and specialised Auchenorrhyncha communities (Achtziger et al. 1999, Morris and Lakhani 1979). Mowing early in spring is not debatable when talking about conservation management for the benefit of the corncrake as the birds need sufficient cover when establishing their mating territories. If both corncrake and plant- and leafhoppers should profit from the conservation management, it seems that mowing should take place in autumn. But current data is not sufficient to answer this 
question satisfactorily. An experimental approach would be necessary to investigate the impact of mowing at different times in the year on the diversity of plant- and leafhoppers as well as on other insect groups. In addition, a socio-economic study would be necessary to assess the costs for compensating the farmers for the loss in fodder quality due to later mowing activity i.e. for conservation management. It seems that by changing the mowing practice, plant- and leafhoppers will not necessarily be the "losers". It is more a question of whether the farmers or the plant- and leafhoppers will be the "winners".

Against these results, one can call the selection of the corncrake as target-species into question. Corncrakes, having a large home range, are considered to be an umbrella species and thus it is supposed that a large number of smaller species will profit from the conservation efforts made for the corncrake. However, the results presented above do not support this assumption. At least Auchenorrhyncha and Anura, being typical species of wet grassland habitats, do not profit from the conservation management. On the contrary, conservation measures even negatively affect the selected taxa.

Besides conservation management for target species conservation of processes will be realised in the national park. It is planned that until $201050 \%$ of the national park's area will be declared as core zone. These areas will be set aside and left for succession. Furthermore, process conservation includes that flooding will be altered towards a more natural flooding regime i.e. longer and more frequent flooding events. The artificial lowering of the ground water level is planned to be stopped as soon as the area of the respective polder is completely set aside.

For the corncrake, the results show that regular mowing events are essential to maintain suitable breeding habitats. Thus setting aside grassland will surely make grassland unsuitable to be used by corncrakes' population after a few years. As the case study of the amphibian community presented above focused on the impact of the long winter flooding on the Anura, it is not possible to assess the impact of reduced mowing activity on the amphibians. However, the reduction of land use might even have a positive effect on the amphibian community (Blab 1986, Beebee 1996). For Auchenorrhyncha, it was previously stated that stopping mowing activity will lead to a community consisting of only a few, but specialised species.

At present it is not clear how long the floodplain would be inundated without regulations as the flooding regime is still managed and ideas of how to realise the change in flooding regime are still under discussion. Independent of how the changes will be realised they will lead to longer flooding time in spring.

A study on Anurans revealed that the current flooding regime already negatively affects amphibian diversity. In the "wet polder" two species of the water frog complex were found whereas in the "dry polder" seven species were caught. But even longer flooding periods might not negatively affect the water frog complex. Although their mating time starts in May, it can continue until July. Furthermore, in contrast to the frogs occurring in the "dry polder", species of the water frog complex are able to hibernate under water which makes overwintering in the "wet polder" possible (Günther 1996a, 1996b). Thus, they do not have the problem of long distance migration and can 
find suitable waterbodies for breeding in the "wet polder" during their mating period (Blab 1986, Günther 1996a, 1996b). A reduction of the artificial lowering of the ground water level throughout the "dry polder" might have a positive effect on the amphibians. Besides other species, the fire-bellied toad and the moor frog which are bound to high levels of ground water, will find more waterbodies suitable for breeding and thus have the possibility to spread (Günther and Nabrowsky 1996, Schneeweiß 1996). Unfortunately, the "dry polder" is the area where conservation management for corncrakes is planned, thus mowing must still be possible and this includes maintaining the regulation of the ground water level.

For Auchenorrhyncha, the study revealed that the species assemblages on fallows differ in regard to flooding period and frequency. Significant differences in specialisation of the species to moisture conditions and diet width were identified. Communities in sites that are subject to long winter floods are dominated by specialised plant- and leafhoppers, while sites that are subject to short winter floods or to summer and winter floods host more generalists. Ideally, the change in flooding regime will lead to a patchy environment that is subject to dynamic changes due to flooding influence. High summer floods are a more rare event in the study area. High water levels similar to those of the winter floods occur on average only once in ten years (Vössing 1998). Changes towards longer flooding in combination with higher ground water levels throughout the whole year will therefore increase the number of patches in the wet polder, similar to the areas subject to long winter flooding. Additionally, areas subject to winter and summer floods that are comparable to the study sites on the river bank will increase as the more regularly occurring smaller summer floods will no longer be restricted to the river bank. The more elevated areas are comparable to those study sites subject to low flooding impact. The changes will favour on the one hand specialised plant- and leafhoppers, but will host on the other hand a number of generalists that can cope with the more unpredictable flooding conditions. Thus, besides the preservation of specialists and endangered species, process conservation might lead to a high $\beta$-diversity.

To summarise, conservation management for the target species corncrake will certainly have a positive effect on the corncrake population. Its effect on the anuran community is not assessable by this study because the impact of mowing on amphibians was not investigated. For the plant- and leafhoppers, as an example of typical grassland insects, benefit and loss seems to be dependent on the date of mowing which is in turn, dependent on the money that can be spent for conservation management. However, current plans concerning the conservation management for the target species corncrake seem to have negative effects on Auchenorrhyncha. The studies reveal that the corncrake seems an unsuitable umbrella species for wet grassland habitats. Process conservation, on the other hand will clearly have negative effects on the corncrake population. The anuran community in the "wet polder" seems to be neither positively nor negatively affected by a change towards more natural flooding conditions. In the "dry polder" a change towards a higher ground water level might be beneficial for many anurans. The changes in the Auchenorrhyncha community due to an altered flooding regime seems to be positive for both preservation of specialists and diversity. 
With these results, it seems that the idea of realising the two conservation strategies side by side can be a successful approach to combine conservation of rare endangered species as well as of biological diversity. But for the Lower Oder Valley National Park as well as for other protected areas following a similar approach, some open questions still remain. Is the protected area big enough to host (in just a part of its area at least), a MVP of the selected target species? Is the remaining area sufficient to host all seral stages created by natural dynamics side by side? Are the revitalised dynamics sufficient to create a patchy environment comparable to natural conditions? How can e.g. farmers currently using large parts of the floodplain be integrated into the conservation plans? The answers to these questions are out of the scope of the studies presented above and thus further investigations are necessary. 


\section{Discussion}

\subsection{Impact of mowing and flooding on the diversity of arthropods}

In chapter 3 the impact of mowing and flooding on the diversity of plant- and leafhoppers was analysed and discussed in detail.

In chapter 4 it was investigated whether the typical wetland fauna recolonises the floodplain after each flooding event or survives winter submersion in the habitat. Based on these findings, it was analysed whether flooding duration and frequency affect the distribution of arthropods. In this chapter not only plant- and leafhoppers but also spiders and ground beetles were in the centre of interest. On the one hand, the study revealed differences in the patterns found for the different arthropod taxa: Most species of plant- and leafhoppers tolerated submersion and overwintered in the floodplain, whereas in spiders and in carabids most species immigrated into the floodplain with a receding water level. On the other hand, the distribution of immigrating and submersion tolerant species was dependent on the frequency and duration of flooding. Although phytophagous and zoophagous arthropods cope with the annual winter floods in different ways, similar patterns in the distribution of immigrating and submersion tolerant species in respect to flooding influence were found. Submersion tolerant species of Auchenorrhyncha and Araneida dominated in sites that were regularly flooded for a long time during winter. Immigrating species of all three groups dominated in sites subject to summer and winter floods as well as in sites subject to short winter flooding. These findings provoke the question, whether in spider and ground beetle communities the impact of mowing and flooding will lead to patterns similar to those found in plant- and leafhoppers.

The data analysed in chapter 3 were based on samples taken with pitfall traps and a motor driven suction apparatus (see 3.2.1). By these sampling methods - especially by pitfall traps - a large number of spiders and ground beetles were collected along with the plant- and leafhoppers. These species were identified by Klaus Dornieden, Uwe Krüger, Michael Sellner and myself and the impact of mowing and flooding on the diversity of spiders and ground beetles was analysed (Krüger 2004, Rothenbücher et al. in prep. a, Rothenbücher et al. in prep. b, Sellner 2004). A comparison of the results of these studies with those presented in chapter 3, allows to explore patterns common for plant- and leafhoppers and the other arthropod groups.

\section{Short term effect of mowing on numbers of individuals}

Short term effects on numbers of individuals were different in all three taxa:

In June, i.e. shortly after the cutting event, more individuals of plant- and leafhoppers were collected in fallows than in mown sites. In the following months individual numbers increased again in mown sites, resulting in significantly higher individual numbers in mown sites than in fallows in September. No difference in numbers of individuals of spiders was found in June, whereas about six weeks after the cutting 
event significantly less individuals were collected in fallows than in mown meadows (Krüger 2004). In September, only few spiders were caught and no differences were found between the two land use variants. Just as in plant- and leafhoppers, in June more individuals of ground beetles were collected in fallows than in mown sites and no difference was found for August (Sellner 2004). However, like in spiders only few ground beetles were caught in September and individual numbers did not differ between the two treatments.

The decrease in numbers of individuals of Auchenorrhyncha and Carabidae directly after the cutting event is a result of emigration activity and increased mortality (Andrzejewska 1979, Gerstmeier \& Lang 1996). Increased mortality is due to the cutting itself but also due to changes in microclimate and higher vulnerability to predators in the short vegetation.

For plant- and leafhoppers the decline in numbers is also a result of reduced food plant availability in the mown meadow. Andrzejewska (1979) relates the rapid increase in numbers of individuals of plant- and leafhoppers between two cutting events to the high growth rate and the slowing down of the processes of maturing and dying of plants in the mown meadows resulting in a higher nitrogen content of the plants (see chapter 3 ). At the same time as an increase in Auchenorrhyncha abundance was recorded in mown sites, a decrease was observed in fallows. In both fallows and mown sites bivoltine plant- and leafhoppers dominated. Probably, the higher nutritive value of the plants in the mown sites favours the development of the nymphs of the second generation, resulting in higher numbers of individuals in the mown sites. Additionally, in comparison to fallows more monomorphous macropterous Auchenorrhyncha occurred in mown sites, showing immigration activity into the mown sites. These immigrating species also contribute to the higher abundance of plant- and leafhoppers in mown plots in September.

The further decrease in numbers of individuals of ground beetles in summer and autumn can be explained by the life cycle of the species and the sampling by pitfall traps. About $80 \%$ of the carabids caught in the study area reproduce in spring (Sellner 2004). Ground beetles are most active during time of reproduction and the numbers of individuals caught by pitfall traps correlates with activity of the species. Thus, the number of individuals caught in pitfall traps decreases with decreasing activity of the species.

In contrast to the plant- and leafhoppers' and ground beetles' reaction to mowing, more spiders were found in mown meadows than in fallows about six weeks after the cutting event. This increase can be explained by the reduced spatial resistance in the meadows due to cutting. Reduced spatial resistance leads to a higher activity of the spiders resulting in higher capture rates in the pitfall traps. One might argue that the reduced spatial resistance should equally affect the activity of ground beetles. However, differences in the life cycle of the taxa provide a plausible explanation. While most carabids caught in the study area reproduce and are most active in spring (Sellner 2004), most spiders are stenochronous with reproduction periods in spring and summer (Krüger 2004). Thus, the high numbers of spiders collected by pitfall traps in mown 
meadows seem to be a result of reduced spatial resistance during time of high activity. The findings of Klieber et al. (1995) support this assumption. By pitfall traps they caught significantly more individuals of spiders in mown sites than in fallows, whereas in photo-eclectors - which measure the real densities of spiders - significantly more individuals were caught in fallows.

\section{Long term effects of mowing and flooding on the arthropod communities}

As outlined in chapter 3, mowing had a stronger impact on the Auchenorrhyncha communities than flooding. The same pattern was found for spiders (Krüger 2004). In contrast, in ground beetles flooding had a stronger impact than mowing (Sellner 2004). Similar results were found by Bonn et al. (2002): In the floodplains of the rivers Elbe, Weser and Oder the ground beetle communities were primarily determined by differences in the flooding regime, whereas in spiders the factor "habitat structure" was identified as key factor. Mowing changes the plant species composition, habitat complexity and microclimate of the meadow. Flooding impact determines the moisture conditions in the grassland, although they are also affected by mowing. Surely, the availability of food plants largely determines Auchenorrhyncha communities. Duffey (1966), Uetz (1990) and Gibson et al. (1992) showed that spiders use the three dimensional properties of their habitat much more than ground beetles (McCracken 1994, Sanderson et al. 1995). Thus, it seems that it is the change of habitat complexity in mown meadows that largely affects the spider community. A number of studies revealed a sensitive reaction of ground beetles to different moisture conditions (Andersen 1985, Luff et al. 1989, Sanderson et al. 1995). Therefore, for ground beetles moisture conditions in the meadow seem to be a key factor.

\section{Impact of mowing}

Comparing numbers of species occurring in mown sites and fallows revealed that more Auchenorrhyncha species were found in fallows.

For spiders collected by suction sampling a similar result was found, i.e. 40 species were collected in fallows, whereas only 22 were found in mown meadows (Rothenbücher et al. in prep.b). In contrast, six weeks after the cutting event significantly more species were collected by pitfall traps in mown sites than in fallows (Krüger 2004). As explained above also the high number of spider species collected by pitfall traps in mown meadows are a result of reduced spatial resistance during time of high activity. In photo-eclectors significantly more species of spiders were caught in fallows than in mown meadows (Klieber et al. 1995). Curry (1994) states that mown meadows support far fewer species of spiders than unmanaged grassland because cutting simplifies the habitat. Thus, web-spinning spiders characteristic for the vegetation layer are largely eliminated. Furthermore, just as in plant- and leafhoppers (see chapter 3) the impact of mowing is dependent on cutting frequency and date (Baines et al. 1998).

In the direct aftermath of the cutting event, significantly more species of ground beetles were collected in fallows than in mown sites. In the following months the same 
pattern was observed, however, no significant differences between the respective areas were identified (Sellner 2004). Likewise, in a number of earlier studies, more species were caught in fallows than in mown sites (Menke 2000, Vowinkel 1997, Wohlgemutvon Reiche \& Grube 1999). In contrast, Klieber et al. (1995) did not find any differences in numbers of species and individuals due to mowing. Furthermore, in contrast to Auchenorrhyncha and Araneida, the date of mowing did not affect numbers of carabid species (Klieber et al. 1995).

These findings reveal that mowing twice a year, i.e. in late spring and late summer, leads to a decrease in arthropod species living in the mown meadows with some taxa reacting stronger than others.

In both, mown sites and fallows, quite specific plant- and leafhopper assemblages were found. In mown sites species were characterised by high mobility and low degrees of specialisation (see chapter 3). Similar patterns were found in spiders and ground beetles: More euryhygric spiders and more of those capable of ballooning were collected in mown sites rather than in fallows (Krüger 2004, Rothenbücher et al. in prep. b). Cattin et al. (2003) found fewer mobile spiders in wet meadows, and they state that species linked to litter and dead reeds were reduced by mowing. Decleer (1990) recorded an increase in ubiquists in cut areas, most of them with pioneering abilities, and only a few wetland spiders. Bell et al. (2001) concluded in their review article that in intensely managed meadows spider communities are not very diverse and are dominated by r-selected species.

In the Lower Oder Valley National Park less stenotopic hygrophilous and more macropterous individuals of ground beetles were collected in mown sites than in fallows (Sellner 2004). Furthermore, more brachypterous carabids were found in fallows. High numbers of eurytopic carabids in mown meadows and high numbers of stenotopic species in fallows were also recorded by Dülge et al. (1994) and Handke \& Menke (1995). Additionally, numbers of hygrophilous ground beetles decrease with increasing cutting intensity and are replaced by species which occur in a wide range of habitats differing in moisture conditions (Klieber et al. 1995). Capability to fly is a common trait in species occurring in habitats that are repeatedly recolonised such as fields (Klieber et al. 1995) or which are disturbed like for example floodplain habitats (Handke 1996, Bonn \& Helling 1997, Rothenbücher 2000) and mown meadows.

Thus, high mobility and a low degree of specialisation is not only a common characteristic for plant- and leafhoppers occurring in mown meadows, but is also typical for spiders and ground beetles.

\section{Impact of flooding}

All three arthropod groups show differences in their species distribution with respect to flooding. In fallows that were subject to summer and winter floods, species communities of Auchenorrhyncha and Araneida were - like in mown meadows characterised by mobile and less specialised species (see chapter 3, Rothenbücher et al. in prep. b). In ground beetles also many individuals capable of flight were collected, 
but the sites were dominated by more specialised, i.e. hygrophilous species. Furthermore, species richness was comparably high. The same patterns in spiders and ground beetles were also found by Grube \& Beyer (1997) and Wohlgemut-von Reiche \& Grube (1999).

The river bank consists of a variety of small habitat patches as a result of the flooding dynamics. Due to high mobility, a number of specialised ground beetles can successfully colonise these habitats (Grube \& Beyer 1997). In contrast, stenotopic hygrophilous spiders were only found near sheltered areas such as higher elevations or shrubs (Grube \& Beyer 1997). These results support the hypothesis evolved on Auchenorrhyncha data (see chapter 3.4) which states that mobility is the most important characteristic of arthropods living in grassland subject to summer and winter flooding. The results of the study on submersion tolerance (see chapter 4) support this hypothesis and reveal that these sites were dominated by immigrating species of all three taxa. The low degree of specialisation in the plant- and leafhopper community seems to be a result of the fact that many macropterous species are not very specialised. However, the occurrence of the monophagous, macropterous specialist Balclutha rhenana suggests that also in mobile species of plant- and leafhoppers specialisation is possible. In ground beetles, it seems that particularly those species specialised to temporarily flooded habitats are very mobile (e.g. Bonn \& Helling 1997, Handke 1996, Rothenbücher 2000). In fallows that were flooded for a long time during winter similar patterns were found for plant- and leafhoppers and spiders, i.e. very specialised species communities were found which were not very rich in species (see chapter 3, Rothenbücher et al. in prep. b). In ground beetles, on the one hand, many typical wetland species occurred. On the other hand, the community was very species rich and many of the carabids were capable of flight (Rothenbücher et al. in prep. a). These findings fit into the patterns found for immigrating and submersion tolerant arthropods (see chapter 4). Submersion tolerant Auchenorrhyncha and spiders dominated in sites that were regularly flooded for a long time during winter, whereas immigrating ground beetles dominated in these sites. As outlined in chapter 4.4, it seems that overwintering in the egg stage is a good preadaptation to regular and long lasting winter floods. This might also explain the occurrence of high numbers of very mobile ground beetles in temporarily flooded habitats. Overwintering in the egg stage is rarely found in this group, which makes submersion tolerance very unlikely. Thus, flight is a crucial characteristic of carabids to successfully populate floodplain habitats.

\subsection{Conclusions for the conservation of arthropods in floodplain grassland}

As outlined in the introduction, conservation schemes of wet grassland often include management by mowing and changes of the flooding regime. The present study revealed that in temporarily flooded grassland mowing twice a year, i.e. in late spring and late summer, led to a decrease of species numbers and favoured pioneer species which are well adapted to disturbed habitats. Flooding in summer affected the Auchenorrhyncha and Araneida communities in a similar way. Regular flooding for a 
long time during winter led to plant- and leafhopper and spider communities not very rich in species but consisting of many specialists. In contrast, in both areas of the floodplain a lot of carabid species occurred, many of which were specialists.

The present results suggest that mowing should be stopped if it is the aim to preserve typical floodplain arthropod communities. The question remains how to maintain open grassland habitats, i.e. how to prevent the growth of shrubs and trees. For plant- and leafhoppers Achtziger et al. (1999) suggest a more extensive mowing regime. In moist grassland mowing parts of the area in autumn resulted in an even more species rich Auchenorrhyncha community as compared to fallows (Achtziger et al. 1999). Furthermore, many of these species were specialists (Achtziger et al. 1999). For moist grassland it was found that a decrease in mowing intensity favoured hygrophilous carabids, i.e. typical wetland species (Klieber et al. 1995). Decleer (1990) states that cutting in summer was more severe for spider communities than cutting in winter. But can we apply these results to temporarily flooded habitats?

In chapter 4 it was outlined that many of the specialist plant- and leafhoppers and two typical wetland spiders overwinter and tolerate winter submersion in the egg stage. But currently we have no knowledge about mortality rates during the time of submersion. It is known from ground beetles that a species being capable of surviving submersion, needs immigrating individuals to maintain a viable population (Fuellhaas 1997). This might also be the case for a number of other arthropods. Mowing in autumn might further increase mortality rates in the egg stage and hence lower the populations' chances of survival during winter submersion.

Grazing is a second common management to maintain open grassland. The impact of grazing on arthropods was out of the scope of the present study but was investigated in a number of earlier studies: Such as for mown sites, Morris (1973) identified a number of Auchenorrhyncha species responding differently to the impact of grazing. Nickel \& Hildebrandt (2003) found that moderate grazing had less severe effects than mowing twice a year when regarding species numbers and specialists. Spiders might benefit from a mosaic of short and longer swards which results from grazing, but at present there is no clear evidence whether grazing is preferable to cutting in relation to spiders (Bell et al. 2001). Reducing grazing intensity seems to have no effect on numbers of carabid species, however changes in species assemblage were found (Irmler \& Heydemann 1985).

Mowing and grazing are both common management measures in a variety of grassland habitats. However, in temporarily flooded grassland one might ask the question whether mowing or grazing is really necessary to keep shrubs and trees out. In the Polish parts of the Lower Oder Valley there are areas that belonged to the polder system until World War II. During the war, dykes were damaged and not rebuilt afterwards and the area has since been left for succession. The climax vegetation in the area mainly consists of alder and to a lesser extent of willow forests, but at present large areas are still devoid of trees. This might be caused by the frequent flooding (Jasnowska et al. 1999). Especially the catastrophic summer flood in 1997 had a severe impact on the plant communities 
(Jasnowska et al. 1999). These findings suggest that restoring natural flooding dynamics in floodplains might as well contribute to preserve open grassland habitats.

The results of the present study help to understand in what respect natural flooding will affect arthropod communities. Natural flooding dynamics of the lower river Oder, as an example of a typical lowland river of Central Europe, are characterised by regular and long lasting winter floods. Summer floods are more rare events and high water levels that are comparable to winter floods occur only once in ten years in average (Vössing 1998).

At first sight, study sites subject to high flooding impact, i.e. to winter and summer floods, seem to be subject to a near-natural flooding regime. As outlined above, this flooding influence favours arthropod communities which are similar to those found in mown meadows. But in contrast to the relatively wide floodplain of lowland rivers, these study sites were situated on a very narrow stretch of the river bank. Here, the water level rises and falls rapidly and the grassland as well as the arthropods are subject to very variable water levels and high currents. The former natural floodplain was much wider, consequently summer floods had a less severe impact on the arthropod communities. The water flooded a larger area thus inundation was slower and less severe or changes in the water level were even just detectable by a rise in the ground water level.

Restoring natural flooding dynamics seems to favour areas which are comparable to some of our study sites subject to medium flooding impact. Here, long lasting floods occur regularly in winter and even during summer ground water levels remain relatively high. In these study sites we found very specialised communities which, however, were not rich in Auchenorrhyncha and Araneida species. Conversely, in the latter two groups significantly more species were only collected in sites not subject to flooding at all. Thus, it seems that there is a trade-off between diversity and naturalness when it is the aim to conserve plant- and leafhoppers and spiders in floodplain grassland. Ground beetles, on the other hand, occur in high species numbers especially in sites subject to long winter floods and in those subject to summer and winter floods. Differences in the relief and in the distance to the river will - under natural flooding dynamics - lead to a number of habitat patches differing in flooding influence. Some might be comparable to those of our study sites subject to high, medium and low flooding impact. The present results (see chapter 3) and those of Krüger (2004) and Sellner (2004) demonstrate that species similarity between these sites was $20-60 \%$. Furthermore, in sites subject to medium flooding impact already at present a variety of patches can be found that are dominated by different plant species such as sedges (Carex spec.), sweet-grass (Glyceria spec.), reed grass (Phalaris arundinacea) and common reed (Phragmites australis). These differences might be due to different moisture conditions. For the present study we selected only sites dominated by sedges (Carex spec.) and reed grass (Phalaris arundinacea). In habitat patches dominated by other plant species one can expect to find a number of additional Auchenorrhyncha species due to the availability of different food plants. Furthermore, additional species of spiders and ground beetles might be found due to conditions such as specific moisture or differences in vegetation 
structure. Consequently, in a floodplain which is characterised by a lot of different habitat patches due to natural flooding dynamics one does not only find very specialised communities but also a high $\beta$-diversity.

Additionally, the findings of chapter 4 revealed, that both submersion tolerant and immigrating arthropods were abundant in temporarily flooded grassland. Many of the submersion tolerant species seem to have a low dispersal capacity. It is important to investigate the dispersal range of these species to assess whether they are capable to colonise new suitable habitats such as those created by restoration of wetlands within a specific conservation scheme. Furthermore, the assemblage of immigrating species is dependent of the regional species pool. They need suitable non-flooded overwintering sites inside as well as in the surroundings of the floodplain, from which they can recolonise it with receding water levels each spring. Thus, in conservation projects that have the aim to preserve typical floodplain arthropod communities not only land use should be stopped and a more natural flooding regime should be restored, but also the surrounding landscape of the sites in question should be taken in account.

\subsection{Evaluation of the plans for future national park development}

As outlined in chapter 5, it is planned to realise conservation management - for the benefit of the target species corncrake - and conservation of processes side by side in the Lower Oder Valley National Park. Regular mowing of the meadows was found to be an important procedure to maintain suitable habitats for the corncrake. This management, however, negatively affects plant- and leafhopper communities. As discussed in sections 6.1 and 6.2 mowing has also a negative effect on spider and ground beetle communities. These results support my earlier assumption that the corncrake is an unsuitable umbrella species for wet natural grassland habitats. Conservation of processes, i.e. leaving the area in question for succession and restore more natural flooding dynamics, was identified to create a mosaic of different habitat patches, each hosting specialised and endangered plant- and leafhoppers. Similar patterns were found for spiders and ground beetles. Thus, those areas of the Lower Oder Valley National Park that are left for natural succession contribute to the conservation of arthropods. Process conservation seems to be the better strategy for the conservation of the typical arthropod fauna of floodplains. 


\subsection{Summary}

It was the aim of this study to analyse the impact of land use and flooding on the diversity of arthropods living in temporarily flooded grassland habitats.

The "Lower Oder Valley National Park" was chosen as study area. The Lower Oder is a typical lowland river in Central Europe, where flooding events are frequent in winter but exceptional in summer. The floodplain mainly consists of grassland habitats. Parts of the grassland are extensively used for farming, whereas other parts were taken out of use in 1995. Currently, dykes bordering the river Oder prevent natural inundation of the floodplain during the summer months. During winter, floodgates integrated into the dykes stay open. Thus, the typical winter flooding can reach the floodplain.

The phytophagous plant- and leafhoppers (Hemiptera: Auchenorrhyncha) and the predacious spiders (Araneida) and ground beetles (Coleoptera: Carabidae) were chosen as representative groups.

In a descriptive field study, the impact of mowing and flooding on the diversity of plant- and leafhoppers was analysed (1).

Based on an experimental approach, it was investigated whether the typical wetland fauna repopulates the floodplain after each flooding event or overwinters in the habitats (2).

It was discussed, which impact the national park's plans of conservation management and conservation of processes might have on the corncrake as a chosen target species, on the anuran fauna as a vertebrate group typically found in wetlands and on plant- and leafhoppers as a key insect group in wet grasslands (3).

The results of the study on the impact of mowing and flooding on the diversity of plantand leafhoppers were compared to those of studies on spiders and ground beetles, that were also carried out in the study area. Patterns common for plant- and leafhoppers and the other arthropod groups were explored. Based on these findings conclusions for the conservation of floodplain arthropods were drawn (4).

(1) The impacts of mowing and of flooding on the diversity of plant- and leafhoppers were investigated. Samples were taken by a motor-driven suction apparatus and pitfall traps four times between May and September 2001 and 2002, respectively. In 2001 plant- and leafhoppers were collected in a variety of sites differing in land use (fallows, mown sites) and in flooding impact (high, medium, low, none). In 2002 samples were only taken in fallows subject to different flooding regimes.

In fallows more species (43) were collected than in mown sites (33). The impact of flooding was only found in fallows, because mowing had a stronger impact on the plantand leafhopper communities than flooding. In fallows the most species rich (29) communities occurred in sites not subject to flooding, whereas fewest species (21) were found in sites subject to regularly occurring long lasting winter floods. Flooding conditions in the latter sites resemble the natural flooding conditions most. 
In both, mown sites and fallows, quite specific species assemblages were found. 15 species occurred predominantly in fallows, while eight species favoured mown grassland. In fallows two species were found to occur predominantly in sites subject to summer and winter flooding, 11 species in sites subject to long and regularly occurring winter floods, two in sites subject to short winter flooding and eight in sites not subject to inundation. For a number of species, the distribution was either limited by food plant availability or by abiotic conditions.

In mown sites species were characterised by high mobility and a low degree of specialisation, whereas in fallows the communities differed in respect to flooding impact. In fallows that were subject to summer and winter floods, species communities were - like in mown meadows - characterised by mobile and less specialised species. Contrarily, in fallows that were flooded a long time during winter, very specialised species communities were found which were, however, not very species rich.

(2) Arthropods living in river floodplains have to cope with a more or less regular cycle of wet and dry conditions. It was investigated whether the typical wetland fauna recolonises the floodplain after each flooding event or survives winter submersion in the habitat. Based on these findings, it was analysed whether flooding duration and frequency affect the distribution of arthropod species in the floodplain.

With receding water levels in May 2002, nine gauze-covered tents were placed into the floodplain to prevent colonisation of the space underneath. In July 2002 samples were taken from underneath the tents as well as from adjacent uncovered control plots with pitfall traps and a motor-driven suction apparatus. Additionally, samples were taken from nearby sites during the whole vegetation period. Planthoppers, leafhoppers, spiders and ground beetles were studied in detail.

Most species of plant- and leafhoppers (68\%) tolerated submersion and overwintered in the floodplain, whereas in spiders $(60 \%)$ and carabids $(70 \%)$ most species immigrated into the floodplain with a receding water level. Some carabids followed both strategies. Furthermore, the distribution of immigrating and submersion tolerant species was dependent on the frequency and duration of flooding. Submersion tolerant plant- and leafhoppers as well as spiders dominated in sites that were regularly flooded for a long time during winter. Among these many were specialised and endangered species. Immigrating species of all three groups dominated in sites subject to summer and winter floods as well as in sites subject to short winter flooding. To create and maintain a maximum diversity of habitats and specialists a semi-natural flooding regime needs to be achieved.

(3) Studies on insect and amphibian communities as well as on selected meadow bird species were carried out in the floodplain of the Lower Oder Valley National Park. The aim of these three studies was to analyse the effects of the present land use and management of the flooding regime on the selected species.

The national park is still in the developmental stage. In plans for the future development of the national park, two main conservation strategies were discussed. On the one hand, 
conservation management is proposed with the aim to preserve and generate suitable habitats for the selected target species, corncrake (Crex crex). On the other hand, process conservation is suggested intending to create habitats suitable for the typical wetland fauna and flora by leaving some areas to natural processes and succession.

On the basis of the three case studies the effects of the two conservation strategies on the selected taxa were discussed. On the one hand, Auchenorrhyncha and Anura will not necessarily benefit from conservation effort carried out for the benefit of the target species corncrake. These results cast doubt on the selection of the corncrake as umbrella species. On the other hand, conservation of processes negatively affects corncrake populations while the anuran community is neither positively nor negatively affected and insect communities benefit from the conservation strategy.

(4) Mowing and flooding were identified as main factors determining the distribution of plant- and leafhoppers in the floodplain. Patterns common for plant- and leafhoppers were compared to those found for spiders and ground beetles.

Short term effects of mowing on numbers of individuals were different in all three taxa. Numbers of individuals of plant- and leafhoppers and ground beetles decreased directly after the cutting event as a result of emigration activity, increased mortality and in Auchenorrhyncha additionally due to reduced food plant availability. Until September, individual numbers of plant- and leafhoppers increased again as a result of the higher nutritive value of the freshly grown plants. Individual numbers of ground beetles decreased further, which correlated with the decreasing activity of the species during times of non-reproduction. Numbers of spiders were higher in mown sites than in fallows six weeks after the cutting due to reduced spatial resistance in the meadow. The latter led to a higher activity of the spiders resulting in higher capture rates in the pitfall traps.

Mowing had a stronger impact on Auchenorrhyncha and Araneida communities, whereas flooding had a stronger impact on the carabid communities. Nevertheless, mowing negatively affected numbers of species in all three taxa. Furthermore, species of all three taxa occurring in mown sites were characterised by high mobility and a low degree of specialisation.

In fallows that were subject to summer and winter floods, species communities of Auchenorrhyncha and Araneida were found to be characterised by mobile and less specialised species. In ground beetles, also a mobile but very specialised community was found. The mobile specialists can successfully colonise a variety of small habitat patches on the river bank. These sites were dominated by immigrating species of all three taxa. Thus, mobility is the most important characteristic of species occurring in these sites.

In fallows that were flooded for a long time during winter, very specialised communities of plant- and leafhoppers and spiders were found, which were not very rich in species. In these sites submersion tolerant species of both taxa dominated, which overwinter in the egg stage. In contrast, the typical wetland communities of ground beetles were dominated by immigrating and very mobile species. As ground beetles 
rarely overwinter in the egg stage, submersion tolerance is unlikely, thus flight is crucial to successfully populate floodplain habitats.

Concerning the conservation of typical floodplain arthropod communities, the results of this study reveal that it is crucial to stop land use and start restoring a more natural flooding regime. Additionally, the surrounding landscape of the conservation sites in question should be taken in account, as all immigrating species are dependent on nonflooded overwintering sites within as well as in the surroundings of the floodplain.

Furthermore, this study reveals that the Lower Oder Valley National Park conservation management is beneficial for the target species corncrake, but will negatively affect arthropod communities. In contrast, those areas left for succession contribute to the conservation of floodplain arthropods.

\subsection{Zusammenfassung}

Im Rahmen dieser Arbeit wurden die Auswirkungen der anthropogenen Einflussfaktoren - Landnutzung und Überflutungsmanagement - auf die Diversität der Arthropodenfauna in der Grünlandaue des Nationalparks „Unteres Odertal“ untersucht. Die untere Oder ist ein typischer mitteleuropäischer Tieflandfluss. Ihre Aue ist im Winter und Frühjahr regelmäßig für mehrere Monate überflutet. Sommerhochwasser sind seltener, kürzer und überfluten nicht die komplette Aue. Ein Teil der Grünlandaue wird extensiv bewirtschaftet, kleinere Bereiche wurden schon 1995 aus der Nutzung genommen. Die Aue ist von Deichen umgeben, die die natürliche Überflutung während der Sommermonate verhindern. In den Deich integrierte Wehrtore sind im Winter geöffnet und das Winterhochwasser kann die Aue überfluten.

Als Beispielorganismen wurden Zikaden (Hemiptera: Auchenorrhyncha), als Vertreter einer phytophagen Tiergruppe, sowie Spinnen (Araneida) und Laufkäfer (Coleoptera: Carabidae) als prädatorische Gruppen gewählt.

In einer deskriptiv angelegten Freilanduntersuchung wurde der Einfluss von Mahd und Überflutung auf die Diversität von Zikaden untersucht (1).

In einem Freilandexperiment wurde untersucht, welcher Teil der typischen Flussauenfauna (Zikaden, Spinnen und Laufkäfer) im überfluteten Gebiet überwintert, und welcher Teil die Aue nach jedem Hochwasser wieder neu besiedelt (2).

Die Entwicklungspläne des Nationalparks sehen vor, Zielartenschutz und Prozessschutz jeweils in unterschiedlichen Bereichen des Schutzgebiets zu realisieren. Es wurden die Auswirkungen dieser beiden Schutzstrategien auf die Zielart Wachtelkönig (Crex crex), auf die Amphibienfauna, als typische Vertebratenguppe in Feuchtgebieten und auf die Zikaden, als eine Schlüsselgruppe der Insekten im Feuchtgrünland diskutiert (3).

Die Ergebnisse der Arbeit über den Einfluss von Mahd und Überflutung auf die Diversität der Zikaden wurde mit den Ergebnissen aus Arbeiten über Spinnen und Laufkäfer verglichen, die auch im Nationalpark durchgeführt wurden. Unterschiede und Gemeinsamkeiten in den Mustern wurden herausgearbeitet und diskutiert. Auf der 
Grundlage dieser Ergebnisse wurden Schlussfolgerungen für den Schutz der typischen Arthropodenfauna der Flussauen gezogen (4).

(1) Es wurde der Einfluss von Mahd und Überflutung auf die Diversität der Zikaden untersucht. Zwischen Mai und September der Jahre 2001 und 2002 wurden jeweils in vier Untersuchungszeiträumen mit Hilfe eines umgebauten Laubsaugers und mit Bodenfallen Proben genommen. 2001 erfolgte die Probenahme auf Flächen, die sich in Nutzung (Brache, Mähwiesen) und Überflutungseinfluss (stark, mittel, schwach, kein) unterschieden. 2002 wurden ausschließlich Brachen untersucht, die unterschiedlicher Überflutung ausgesetzt waren.

Auf Brachen wurden mehr Arten (43) nachgewiesen als auf gemähten Wiesen (33). Der Einfluss der Überflutung wurde nur auf Brachen deutlich, da die Mahd einen stärkeren Einfluss auf die Zikadenzönose hatte als die Überflutung. Innerhalb der Brachen wurden die meisten Arten (29) auf Flächen gefangen, die ganzjährig nicht überflutet werden. Die wenigsten Arten (21) wurden auf Flächen nachgewiesen, die einer relativ naturnahen Überflutung ausgesetzt sind, d.h. diese werden im Winter regelmäßig und über einen längeren Zeitraum überflutet.

Brachen und Mähwiesen zeichneten sich jeweils durch eine charakteristische Artengemeinschaft aus. 15 Zikadenarten wurden überwiegend auf Brachen gefangen, acht hingegen überwiegend auf Mähwiesen. Für Brachen, die sowohl im Winter als auch im Sommer überflutet werden, wurden zwei charakteristische Arten identifiziert. Elf Arten wurden überwiegend auf Brachen nachgewiesen, die im Winter regelmäßig und über einen längeren Zeitraum überflutet werden, zwei Arten auf Brachen, die nur kurz im Winter überflutet werden und acht Arten kamen überwiegend auf Flächen vor, die ganzjährig nicht überflutet werden.

Unabhängig vom Überflutungseinfluss wurden auf gemähten Flächen vor allem mobile und wenig spezialisierte Arten nachgewiesen. Innerhalb der Brachen prägt der Überflutungseinfluss die Artengemeinschaft. Die Zikadenzönose der Brachen, die sowohl im Winter als auch im Sommer überflutet werden, war - wie die der Mähwiesen - von mobilen und wenig spezialisierten Arten dominiert. Auf den Brachen, die im Winter regelmäßig und über einen längeren Zeitraum überflutet werden, dominierten Spezialisten. Allerdings wurden hier insgesamt nur recht wenige Arten nachgewiesen.

(2) Flussauen sind durch den regelmäßigen Wechsel von überfluteten und trockenen Perioden geprägt. Arthropoden, die diesen Lebensraum besiedeln, müssen an diese Bedingungen angepasst sein. Es wurde untersucht, welche Arten der typischen Flussauenfauna im überfluteten Gebiet überwintern und welche die Aue nach jedem Hochwasser wieder neu besiedeln.

Kurz nach Rückgang des Winterhochwassers im Mai 2002 wurden Gazezelte in der Flussaue aufgestellt, um die Wiederbesiedlung der darunter liegenden Flächen zu verhindern. Im Juli 2002 wurde die Besiedlung der mit Gaze abgedeckten Untersuchungsflächen sowie von daneben liegenden Kontrollflächen durch Zikaden, Spinnen und Laufkäfer mit Hilfe eines umgebauten Laubsaugers und mit Bodenfallen 
beprobt. Während der gesamten Vegetationsperiode wurden auf angrenzenden Flächen zusätzlich Proben genommen, um zu untersuchen, welcher Anteil der typischen Flussauenfauna mit Hilfe des Experiments erfasst wurde.

Die meisten Zikadenarten (68\%) tolerierten die Überflutung und überwinterten in der Flussaue, während die meisten Spinnen $(60 \%)$ und Laufkäfer $(70 \%)$ die Flussaue in jedem Frühjahr neu besiedelten. Zusätzlich beeinflussten Dauer und Häufigkeit der Überflutung die Verteilung von einwandernden und überwinternden Arten in der Flussaue. Die überflutungstoleranten Spinnen- und Zikadenarten wurden in hohen Individuenzahlen vor allem auf Flächen nachgewiesen, die im Winter lange überflutet werden. Viele dieser Arten haben einen hohen Spezialisierungsgrad und werden als gefährdet eingestuft. Einwandernde Arten aller drei Taxa wurden vor allem auf Flächen mit geringem Überflutungseinfluss und auf Flächen, die im Winter und im Sommer überflutet werden, gefunden. Weiterhin hat die Untersuchung gezeigt, dass für einige seltene Auenarthropoden besonders regelmäßige und lange andauernde Überflutungsereignisse von besonderer Bedeutung sind.

(3) In der Überflutungsaue des Nationalparks wurden der Einfluss von Mahd und Überflutung auf Insekten, Amphibien und Wiesenbrüter untersucht. Der Nationalpark befindet sich zur Zeit in der Entwicklungsphase. In Zukunft ist geplant, zwei unterschiedliche Schutzkonzepte nebeneinander im Nationalpark zu realisieren. Auf der einen Seite sollen geeignete Habitate für ausgewählte Zielarten, wie z.B. den Wachtelkönig (Crex crex), durch gezielte Pflegemaßnahmen erhalten und ggf. neu geschaffen werden. Auf der anderen Seite sollen Gebiete der natürlichen Sukzession überlassen werden, was dem Konzept des Prozessschutzes entspricht.

Am Beispiel von drei Fallstudien wurden die Auswirkungen der unterschiedlichen Schutzstrategien auf drei verschiedene Tiergruppen diskutiert. Einerseits profitieren Zikaden und Amphibien nicht per se von den Pflegemaßnahmen, die für die Erhaltung der Zielart Wachtelkönig notwendig sind. Diese Ergebnisse stellen den Wachtelkönig als Zielart in Frage. Andererseits wirken sich die Veränderungen in der Aue im Verlauf der Sukzession negativ auf die Wachtelkönigpopulationen aus. Amphibien reagieren weder positiv noch negativ auf die Veränderungen, während Insekten von diesen profitieren.

(4) Mahd und Überflutung wurden als die Haupteinflussfaktoren identifiziert, die die Zikadengemeinschaften der Grünlandaue prägen. Die für Zikaden gefundenen Muster wurden mit Mustern, die für Spinnen- und Laufkäferzönosen gefunden wurden verglichen.

Mahd beeinflusste direkt und kurzfristig die Individuenzahlen der drei Arthropodentaxa, allerdings wurden in allen drei Gruppen unterschiedliche Muster gefunden. Direkt nach der Mahd nahmen die Individuenzahlen von Zikaden und Laufkäfern aufgrund von Abwanderung, erhöhter Mortalität und - im Fall der Zikaden - einem reduzierten Nährpflanzenangebot ab. In den folgenden Monaten stiegen die Individuenzahlen bei Zikaden wieder an, was in einem erhöhten Nährstoffgehalt in den frisch 
nachwachsenden Pflanzen begründet sein kann. Die Individuenzahlen der Laufkäfer nahmen hingegen in den Folgemonaten weiter $a b$, was auf eine geringe Aktivität außerhalb ihrer Reproduktionsphase zurückzuführen ist. Sechs Wochen nach der Mahd wurden auf gemähten Wiesen bei Spinnen höhere Individuenzahlen nachgewiesen als auf Brachen. Durch die Mahd wird der Raumwiderstand auf den Flächen reduziert, dies führt zu erhöhter Aktivität der Spinnen und somit zu hohen Fangzahlen in den Bodenfallen.

Die Mahd prägte die Zikaden- und Spinnenzönosen stärker als die Überflutung, bei Laufkäfern wurde ein stärkerer Einfluss der Überflutung festgestellt. Bei allen drei Arthropodengruppen hatte die Mahd einen negativen Einfluss auf die Artenzahlen. Auf Mähwiesen zeichneten sich die Artengemeinschaften aller drei Taxa durch hohe Mobilität und geringe Spezialisierung aus.

Auf Brachen, die sowohl im Sommer als auch im Winter überflutet werden, wurden vor allem mobile und wenig spezialisierte Zikaden- und Spinnenarten nachgewiesen. Die Laufkäferzönose zeichnete sich ebenfalls durch hohe Mobilität, aber durch einen hohen Spezialisierungsgrad aus. Spezialisierte Laufkäfer besiedeln erfolgreich eine Reihe typischer, von der Flussdynamik geprägter, Uferhabitate. Bei allen drei Arthropodengruppen dominierten einwandernde Arten. Somit scheint Mobilität eine wichtige Eigenschaft von Flussufer bewohnenden Arthropoden zu sein.

Auf Brachen, die im Winter regelmäßig und über einen längeren Zeitraum überflutet werden, wurden sehr spezialisierte Zikaden- und Spinnenzönosen nachgewiesen. Allerdings waren diese nicht sehr artenreich. Es dominierten überflutungstolerante Arten, die im Eistadium überwintern. Bei Laufkäfern dominierten hingegen einwandernde Arten. Überwinterung im Eistadium ist bei Laufkäfern relativ selten, und somit ist Überflutungstoleranz eine recht unwahrscheinliche Anpassung an das Leben in den Auen. Bei Laufkäfern wurde Flugfähigkeit als wichtige Eigenschaft identifiziert, um eine erfolgreiche Besiedlung der Auen zu gewährleisten.

Die Ergebnisse dieser Untersuchungen lassen im Hinblick auf den Schutz typischer Arthropodenzönosen der Auen folgende Schlussfolgerungen zu:

Landnutzung sollte in den Auenwiesen eingestellt und ein möglichst naturnahes Überflutungsregime hergestellt werden. Die Umgebung von Schutzgebieten sollte mit in die Planung einbezogen werden, da viele einwandernde Arten trockene Überwinterungshabitate nicht nur innerhalb sondern auch in der Umgebung der Aue benötigen.

Die im Nationalpark „Unteres Odertal“ eingesetzten Pflegemaßnahmen zur Erhaltung des Wachtelkönigs haben negative Auswirkungen auf die Arthropodenfauna. Im Gegensatz dazu leisten die der Sukzession überlassenen Gebiete einen wichtigen Beitrag zur Erhaltung der für Flussauen typischen Arthropodenfauna. 


\section{References}

Achtziger R, Nickel H (1997) Zikaden als Bioindikatoren für naturschutzfachliche Erfolgskontrollen im Feuchtgrünland. Beiträge zur Zikadenkunde 1: 3-16.

Achtziger R, Nickel H, Schreiber R (1999) Auswirkungen von Extensivierungsmaßnahmen auf Zikaden, Wanzen, Heuschrecken und Tagfalter im Feuchtgrünland. Schriftenreihe des Bayrischen Landesamtes für Umweltschutz 150: 109-131.

Adis J (1992) Überlebensstrategien terrestrischer Invertebraten in Überschwemmungswäldern Zentralamazoniens. Verhandlungen des naturwissenschaftlichen Vereins Hamburg 33: 21-114.

Adis J, Junk WJ (2002) Terrestrial invertebrates inhabiting lowland river floodplains of Central Amazonia and Central Europe: a review. Freshwater Biology 47: 711731.

Andersen J (1985) Humidity responses and water balance of riparian species of Bembidiini (Coleoptera, Carabidae). Ecology and Entomology 63: 363-376.

Andrzejewska L (1979) Herbivorous fauna and its role in the economy of grassland ecosystems I. Herbivores in natural and managed meadows. Polish ecological studies 5: 5-44.

Baines M, Hambler C, Johnson PJ, Macdonald DW, Smith H (1998) The effects of arable field margin management on the abundance of species richness of the Araneae (spiders). Ecography 21: 74-86.

Baltanás A (1992) On the use of some methods for the estimation of species richness. Oikos 65: 484-492.

Barber H (1931) Traps for cave-inhabiting insects. Journal of the Elisha Mitchell Scientific Society 46: 259-265.

Barndt D, Brase H, Glauche H, Gruttke B, Kegel B, Platen R, Winkelmann H (1991) Die Laufkäferfauna von Berlin(West) - mit Kennzeichnung und Auswertung der verschollenen und gefährdeten Arten (Rote Liste, 3. Fassung. In: Auhagen A, Platen R, Sukopp H (eds) Rote Liste der gefährdeten Pflanzen und Tiere in Berlin. Landschaftsentwicklung und Umweltforschung, Special issue 6: 243275.

Beebee TJC (1996) Ecology and Conservation of Amphibians. Chapman \& Hall, London.

Bell JR, Wheater CP, Cullen WR (2001) The implictaions of grassland and heathland management for the conservation of spider communities: a review. Journal of Zoology 255: 377-387.

Bellmann H (1992) Spinnen: beobachten - bestimmen. Naturbuch, Augsburg.

Bentlage K (2003) Amphibiendiversität und Gewässerstrukturen im Nationalpark Unteres Odertal. Diploma thesis, Universität Göttingen

Berger L (1967) Embryonal and larval development of F1 Generation of green frogs different combinations. Acta Zoolgica Cracoviensia 12 (7): 123-160. 
Blab J (1986) Biologie, Ökologie und Schutz von Amphibien. Schriftenreihe für Landschaftspflege und Naturschutz 18. KILDA, Bonn - Bad Godesberg.

Bonn A, Hagen K, Helling B (1997) Einfluß des Überschwemmungsregimes auf die Laufkäfer- und Spinnengemeinschaften in Uferbereichen der Mittleren Elbe und Weser. In: Handke K, Hildebrandt J (eds) Einfluß von Vernässung und Überstauung auf Wirbellose. Institut für Landschaftsökologie der Westfälischen Wilhelms-Universität, Münster, pp 177-191.

Bonn A, Hagen K, Wohlgemut-von Reiche D (2002) The significance of flood regimes for carabid beetle and spider communities in riparian habitats - a comparison of three major rivers in Germany. River Research and Application 18: 43-64.

Bonn A, Helling B (1997) Einfluß von schwankenden Wasserständen auf die Flugaktivität von Laufkäfern. Mitteilungen der Deutschen Gesellschaft für allgemeine und angewandte Entomologie 11: 439-442.

Borgula A (1995) Langjährige Bestandsentwicklung einer kleinen Metapopulation des Laubfrosches (Hyla aborea L.) in der Schweiz. In: Geiger A (ed) Der Laubfrosch (Hyla aborea) - Ökologie und Artenschutz. DGHT, Bonn, 8-26.

Brose U, Martinez ND, Williams RJ (2003) Estimating species richness: Sensitivity to sample coverage and insensitivity to spatial patterns. Ecology 84: 2364-2377.

Buijse AD, Coops H, Staras M, Jans L, Van Geest GJ, Grift RE, Ibelings BW, Oosterberg W, Roozen FCJM (2002) Restoration strategies for river floodplains along large lowland rivers in Europe. Freshwater Biology 47: 889-907.

Burnham KP, Overton WS (1978) Estimation of the size of a closed population when capture probabilities vary among animals. Biometrika 65: 623-633.

Cadbury CJ (1980) The status and habitats of the corncrake in Britain. Bird Study 27: 203-218.

Cattin M, Blandenier G, Banasek-Richter C, Bersier L (2003) The impact of mowing as a management strategy for wet meadows on spider (Araneae) communities. Biological Conservation 113: 179-188.

Chao A (1984) Non-parametric estimation of the number of classes in a population. Scandinavian Journal of Statistics 11: 265-270.

Chao A, Hwang W, Chen Y, Kuo C (2000) Estimating the number of shared species in two communities. Statistica Sinica 10: 227-246.

Colwell R (2004) EstimateS: Statistical estimation of species richness and shared species from samples. Version 7. http://purl.oclc.org/estimates.

Curry J (1994) Grassland Invertebrates. Ecology, influence on soil fertility and effects on plant growth. Chapman \& Hall, London.

Decleer K (1990) Experimental cutting of reedmarsh vegetation and its influence on the spider (Araneae) fauna in the Blankaart nature reserve, Belgium. Biological Conservation 52: 161-185.

Denno RF, Roderick GK, Olmstead KL, Döbel HG (1991) Density-related migration in planthoppers (Homoptera: Delphacidae): The role of habitat persistence. The American Naturalist 138: 1513-1541. 
Dohle W (1999) Die Auen des Unteren Odertals - Möglichkeiten und Chancen der Erforschung und Rekonstruktion einer Flußauenlandschaft. In: Dohle W, Bornkamm R, Weigmann G (eds) Das Untere Odertal. Auswirkungen der periodischen Überschwemmungen auf Biozönosen und Arten. E. Schweizerbart, Stuttgart, pp 1-22.

Duffey E (1966) Spider ecology and habitat structure. Senckenbergiana Biologica 47: 45-49.

Dülge R, Andretzke H, Handke K, Hellbernd-Tienemann L, Rode M (1994) Beurteilung nordwestdeutscher Feuchtgrünlandstandorte mit Hilfe von Laufkäfergesellschaften (Coleoptera: Carabidae). Natur und Landschaft 69: 148-156.

Dürr T, Mädlow W, Ryslavy T, Sohns G (1997) Rote Liste und Liste der Brutvögel des Landes Brandenburg. In: Landesumweltamt Brandenburg (ed) Naturschutz und Landespflege in Brandenburg 6 (2): insert.

DWD (2002) Data measured at the meteorological station Angermünde provided by the German Meteorological Service. Written notification.

Eikhorst R (1984) Untersuchungen zur Verwandtschaft der Grünfrösche. Dissertation, Universität Bremen.

Eikhorst R, Rahmel UAP (1986) Zur Verbreitung des Kleinen Teichfrosches Rana lessonae und des Seefrosches Rana ridibunda in Niedersachsen. Salamandra 22 (1): 79-92.

Engelmann H (1978) Zur Dominanzklassifizierung von Bodenarthropoden. Pedobiologia 378-380.

Fischer S, Dittberner W, Helmecke A, Sadlik A, Bellebaum J (1999, unpublished) Bewertung des Beitrages nationaler und internationaler Naturschutzvorhaben in Deutschland zur Erhaltung stark gefährdeter Vogelarten auf landwirtschaftlich extensiv genutzten Flächen. Projektbericht im Auftrag des Bundesamtes für Naturschutz (BfN).

Foelix RF (1992) Biologie der Spinnen. Thieme, Stuttgart, New York.

Foster WA, Treherne JE (1976) Insects of marine saltmarshes: problems and adaptations. In: Cheng L (ed) Marine insects. North-Holland, Amsterdam, pp 542.

Freude H, Harde KW, Lohse GA (1976) Die Käfer Mitteleuropas. 2. Adephaga 1. Goecke \& Evers, Krefeld.

Fuellhaas U (1997) Der Einfluß von Vernässung und Überstauungsmaßnahmen in degeneriertem Niedermoorgrünland auf ausgewählte Laufkäferarten (Cileoptera: Carabidae). In: Handke K, Hildebrandt J (eds) Einfluß von Vernässung und Überstauung auf Wirbellose. Institut für Landschaftsökologie der Westfälischen Wilhelms-Universität, Münster, pp 133-146. 
Garrelts H, Birner R, Wittmer Heidi (2005) Policy-Windows for the Declaration of Protected Areas - A Comparative Case Study of Germany and Guatemala. In: Markussen M, Buse R, Garrelts H, Mánez Costa MA, Menzel S, Marggraf R (eds) Conservation and Valuation of Biodiversity - Interdisciplinary Perspectives on the Convention on Biological Diversity. Springer Verlag, Berlin, Heidelberg, pp 65-83.

Gerken B (1988) Auen - verborgene Lebensadern der Natur. Rombach Verlag, Freiburg.

Gerstmeier R, Lang C (1996) Beitrag zu Auswirkungen der Mahd auf Arthropoden. Zeitschrift für Ökologie und Naturschutz 5: 1-14.

Gibson CWD, Hambler C, Brown VK (1992) Changes in spider (Araneae) assemblages in relation to succession and grazing management. Journal of Applied Ecology 29: 132-142.

Gille H (1999) Geschichte und Stand des Naturschutzes im Unteren Odertal. In: Dohle W, Bornkamm R, Weigmann G (eds) Das Untere Odertal. Auswirkungen der periodischen Überschwemmungen auf Biozönosen und Arten. E. Schweizerbart, Stuttgart, pp 39-44.

Glutz von Blotzheim U, Bauer KM, Bezzel E (1973) Handbuch der Vögel Mitteleuropas 5, Galliformes und Gruiformes. Aula, Frankfurt am Main.

Green R (1996) Factors affecting the population density of the corncrake in Britain and Ireland. Journal of Applied Ecology 33: 237-248.

Green R, Rocamora G, Schäffer N (1997) Populations, ecology and threats to the Corncrake in Europe. Vogelwelt 118: 117-134.

Green R, Stowe TJ (1993) The decline of the corncrake in Britain and Ireland in relation to habitat change. Journal of Applied Ecology 30, 689-695.

Groombridge B (1994) IUCN Red List of Threatened Animal. World Conservation Monitoring Centre, Cambridge.

Grosse WR (1994) Der Laubfrosch. Die Neue Brehmbücherei Nr. 615. Westarp Wissenschaften, Magdeburg.

Grube R, Beyer W (1997) Einfluß eines naturnahen Überflutungsregimes auf die räumlich-zeitliche Dynamik der Spinnen- und Laufkäferfauna am Beispiel des Deichvorlandes der Unteren Oder. In: Handke K, Hildebrandt J (eds) Einfluß von Vernässung und Überstauung auf Wirbellose. Institut für Landschaftsökologie der Westfälischen Wilhelms-Universität, Münster, pp 209226.

Günther R (1990) Die Wasserfrösche Europas. Ziemsen Verlag, Wittenberg.

Günther R (1996a) Teichfrosch - Rana kl. esculenta LINNAEUS, 1758. In: Günther R (ed) Die Amphibien und Reptilien Deutschlands. Gustav Fischer, Jena, 455-474.

Günther R (1996b) Seefrosch - Rana ridibunda PALLAS, 1771. In: Günther R (ed) Die Amphibien und Reptilien Deutschlands. Gustav Fischer, Jena, 490-507.

Günther R, Nabrowsky H (1996) Moorfrosch - Rana arvalis NILSSON, 1842. In: Günther R (ed) Die Amphibien und Reptilien Deutschlands. Gustav Fischer, Jena, 364-388. 
Handke K (1996) Die Laufkäferfauna des Naturschutzgebietes Lampertheimer Altrhein in der südhessischen Oberrheinebene (Kreis Bergstraße). Decheniana 149: 139160 .

Handke K, Menke K (1995) Laufkäferfauna von Röhrichten und Grünlandbrachen Naturschutz-Bedeutung feuchter Brachflächen in der Bremer Flußmarsch. Naturschutz und Landschaftsplanung 27: 107-114.

Heimer S, Nentwig W (1991) Spinnen Mitteleuropas. Paul Parey, Berlin, Hamburg.

Heller K, Irmler U (1997) Auswirkungen der Wiedervernässung auf die Wirbellosengemeinschaften in Grünlandsystemen des NSG "Alte SorgeSchleife". In: Handke K, Hildebrandt J (eds) Einfluß von Vernässung und Überstauung auf Wirbellose. Institut für Landschaftsökologie der Westfälischen Wilhelms-Universität Münster, Münster, pp 63-76.

Helmecke A (2000, unpublished) Raum- und Habitatnutzung des Wachtelkönigs (Crex crex , L.) im Unteren Odertal. Diploma thesis, Humboldt Universität Berlin.

Hildebrandt J (1997) Wie sind terrestrische Wirbellose an Überflutung angepaßt? In: Handke K, Hildebrandt J (eds) Einfluß von Vernässung und Überstauung auf Wirbellose. Institut für Landschaftsökologie der Westfälischen WilhelmsUniversität Münster, Münster, pp 15-25.

Hobohm C (2000) Biodiversität. Quelle \& Meyer, Wiebelsheim.

Holzinger WE, Kammerlander I, Nickel H (2003) The Auchenorrhyncha of Central Europe - Die Zikaden Mitteleuropas. Volume 1: Fulgoromorpha, Cicadomorpha excl. Cicadellidae. Brill, Leiden.

Hosmer DW, Lemeshow S (2000) Applied logistic regression. Wiley, New York.

Irmler U, Heydemann B (1985) Der Einfluß von Rinderbeweidungauf die Struktur der Salzwiesenzönose. Verhandlungen der Gesellschaft für Ökologie 13: 71-76.

IUS Weisser und Ness (1998, unpublished) Pflege- und Entwicklungsplan Unteres Odertal, Ziele und Maßnahmen im Kerngebiet. IUS Weisser und Ness, Heidelberg, Potsdam, Kandel.

Jasnowska J, Friedrich S, Kowalski W, Markowski S (1999) Gliederung und Dynamik der Pflanzengesellschaften im Unteren Odertal untersucht auf der Basis eines Transekts aus Dauerflächen. In: Dohle W, Bornkamm R, Weigmann G (eds) Das Untere Odertal. Auswirkungen der periodischen Überschwemmungen auf die Biozönosen und Arten. E. Schweizerbart, Stuttgart, pp 45-62.

Jedicke E (1995) Ressourcenschutz und Prozeßschutz - Diskussion notwendiger Ansätze zu einem ganzheitlichen Naturschutz. Naturschutz und Landschaftsplanung 27: $125-133$.

Jedicke E (1998) Raum-Zeit-Dynamik in Ökosystemen und Landschaften. Kenntnisstand der Landschaftsökologie und Formulierung einer Prozeßschutzdefinition. Naturschutz und Landschaftsplanung 30: 229-236.

Jehle P, Pankoke K (1999) Die Pflanzengesellschaften ausgewählter Totalreservatsflächen im Nationalpark Unteres Odertal. In: Dohle W, Bornkamm R, Weigmann G (eds) Das Untere Odertal Auswirkungen der periodischen Überschwemmungen auf Biozönosen und Arten. E. Schweizerbart, Stuttgart, pp 123-146. 
Jongman RHG, Ter Braak CJF, Van Tongeren OFR (1995) Data analysis in community and landscape ecology. Cambridge University Press, Cambridge.

Jungwirth M, Muhar S, Schultz S (2002) Re-establishing and assessing ecological integrity in riverine landscapes. Freshwater Biology 47: 867-887.

Just P (in prep.) Vegetationsstruktur in Habitaten des Wachtelkönigs (Crex crex) zur flächenhaften Prognose der Habitateignung im Nationalpark „Unteres Odertal““. Dissertation, Universität Göttingen.

Kleyer M, Kratz R, Lutze G, Schröder B (1999/2000) Habitatmodelle für Tierarten: Entwicklung, Methoden und Perspektiven für die Anwendung. Zeitschrift für Ökologie und Naturschutz 8: 177-194.

Klieber A, Schröder U, Irmler U (1995) Der Einfluß der Mahd auf die Arthropoden des Feuchtgrünlandes. Zeitschrift für Ökologie und Naturschutz 4: 227-237.

Köhler G, Schäller G (1987) Untersuchungen zur Phänologie und Dormanz der Wespenspinne Argiope bruennichi (Scopoli) (Araneae: Araneidae). Zoologische Jahrbücher Abteilung für Systematik, Ökologie und Geographie der Tiere 114: 65-82.

Köhler W, Schachtel G, Voleske P (1996) Biostatistik: Einführung in die Biometrie für Biologen und Agrarwissenschaftler. Springer, Berlin.

Krüger U (2004, unpublished) Einfluss von Mahd und Überflutung auf die Diversität der Spinnen im Nationalpark „Unteres Odertal“. Diploma thesis, Universität Göttingen.

Lang O, Pütz S (1999) Frühjahrsbesiedlung eines im Winter überfluteten Naßpolders durch Laufkäfer und Spinnen im Nationalpark Unteres Odertal. In: Dohle W, Bornkamm R, Weigmann G (eds) Das Untere Odertal. Auswirkungen der periodischen Überschwemmungen auf Biozönosen und Arten. E. Schweizerbart, Stuttgart, pp 171-196.

Lindeiner von A (1994) Die Amphibienlaichgewässer des Naturparks Schönbuch. Zeitschrift für Feldherpetologie 1: 135-152.

Locket G, Millidge A, Merrett P (1974) British Spiders. Volume III. Ray Society, London.

Locket M, Millidge A (1951, 1953) British Spiders. Volumes I \& II. Ray Society, London.

Luff ML, Eyre MD, Rushton SP (1989) Classification and ordination of habitats of ground beetles (Coleoptera, Carabidae) in north-east England. Journal of Biogeography 16: 121-130.

Mädlow W, Adam S (1998, unpublished) Pflege- und Entwicklungsplan Unteres Odertal. Erfassungsbericht Amphibien. Weisser \& Ness, Heidelberg.

Magurran AE (1988) Ecological Diversity and Its Measurement. Croom Helm, Sydney, London.

McCracken D (1994) A fuzzy classification of moorland ground beetle (Coleoptera: Carabidae) and plant communities. Pedobiologia 38: 12-27.

Menke K (2000) Die Laufkäferfauna von Röhrichten, Grünland und Grünlandbrachen im Werderbergland bei Bremen. Angewandte Carabidologie 2/3:19-36. 
Mönninghof W (1997) Nationalpark Unteres Odertal. VEBU, Berlin.

Morris MG (1973) The effect of seasonal grazing on the Heteroptera and Auchenorrhyncha (Hemiptera) of chalk grassland. Journal of Applied Ecology 10: 761-780.

Morris MG (1981a) Responses of Grassland Invertebrates to Management by Cutting III. Adverse Effects on Auchenorrhyncha. Journal of Applied Ecology 18: 107123.

Morris MG (1981b) Responses of Grassland Invertebrates to Management by Cutting IV. Positive Responses of Auchenorrhyncha. Journal of Applied Ecology 18: 763-771.

Morris MG, Lakhani K (1979) Responses of grassland invertebrates to management by cutting. I. Species diversity of Hemiptera. Journal of Applied Ecology 16: 77-98.

Mühlenberg M (1993) Freilandökologie. Quelle und Meyer, Wiesbaden.

Mühlenberg M, Hovestadt T (1992) Das Zielartenkonzept. NNA-Berichte 5: 36-41.

Nickel H (2003) The leafhoppers and planthoppers of Germany (Hemiptera, Auchenorrhyncha): patterns and strategies in a highly diverse group of phytophagous insects. Pensoft, Sofia, Moscow.

Nickel H, Achtziger R (1999) Wiesen bewohnende Zikaden (Auchenorrhyncha) im Gradienten von Nutzungsintensität und Feuchte. Beiträge zur Zikadenkunde 3: $65-75$

Nickel H, Hildebrandt J (2003) Auchenorrhyncha communities as indicators of disturbance in grasslands (Insecta, Hemiptera) - a case study from the Elbe flood plains (northern Germany). Agriculture, Ecosystems and Environment 98: 183199.

Nickel H, Remane R (2002) Artenliste der Zikaden Deutschlands, mit Angabe von Nährpflanzen, Nahrungsbreite, Lebenszyklus, Areal und Gefährdung (Hemiptera, Fulgoromorpha et Cicadomorpha). Beiträge zur Zikadenkunde 5: 27-64.

Nöllert A, Nöllert C (1992) Die Amphibien Europas: Bestimmung, Gefährdung, Schutz. Kosmos, Stuttgart.

Novotný V (1994a) Relation between temporal persistence of host plants and wing length in leafhoppers (Hemiptera: Auchenorrhyncha). Ecological Entomology 19: 168-176.

Novotný V (1994b) Association of polyphagy in leafhoppers (Auchenorrhyncha, Hemiptera) with unpredictable environments. Oikos 70: 223-232.

Novotný V (1995) Relationships between life history of leafhoppers (Auchenorrhyncha - Hemiptera) and their host plants (Juncaceae, Cyperaceae, Poaceae). Oikos 73: $33-42$.

Olson DM, Dinersein E (1998) The global 200: a representation approach to conserving the earth's most biologically valuable ecosystems. Conservation Biology 12: 502-515. 
Ossiannilsson F (1978) The Auchenorrhyncha (Homoptera) of Fennoscandia and Denmark. Part 1: Introduction, infraorder Fulgoromorpha. Scandinavian Science Press, Kopenhagen.

Ossiannilsson F (1981) The Auchenorrhyncha (Homoptera) of Fennoscandia and Denmark. Part 2: The Families Cicadidae, Cercopidae, Membracidae, and Cicadellidae (excl. Deltocephalinae). Scandinavian Science Press, Kopenhagen.

Ossiannilsson F (1983) The Auchenorrhyncha (Homoptera) of Fennoscandia and Denmark. Part 3: The Family Cicadellidae: Deltocephalinae, Catalogue, Literature and Index. 594-979.

Patt H, Jürging P, Kraus W (1998) Naturnaher Wasserbau: Entwicklung und Gestaltung von Fließgewässern. Springer, Berlin, Heidelberg.

Peeters E, Gardeniers J (1998) Logistic regression as a tool for defining habitat requirements of two common gammarids. Freshwater Biology 39: 605-615.

Petts G (1989) Historical Analysis of Fluvial Hydrosystems. In: Petts GE, Möller H, Roux AL (eds) Historical change of large alluvial rivers: Western Europe. Wiley, Chichester, New York.

Platen R, Moritz M, v. Broen B, Bothmann I, Bruhn K, Simon U (1991) Liste der Webspinnen- und Weberknechtarten (Arach.: Araneida, Opilionida) des Berliner Raumes und ihre Auswertung für Naturschutzzwecke (Rote Liste). In: Auhagen A, Platen R, Sukopp H (eds) Rote Liste der gefährdeten Pflanzen und Tiere in Berlin. Landschaftsentwicklung und Umweltforschung, Sonderheft 6: 169-205.

Plötner J (2001) Struktur und Dynamik einer Seefrosch/Teichfrosch-MännchenPopulation (Rana ridibunda, Rana esculenta) in der Oderaue bei Frankfurt/Oder. Zeitschrift für Feldherpetologie 8: 253-264.

Pongratz E (1995) Eine Jahrhundert-Tragödie? Die Erweiterung des Nationalparks Bayerischer Wald. Nationalpark 3/95: 6-9.

Remane R, Achtziger R, Fröhlich W, Nickel H, Witsack W (1998) Rote Liste der Zikaden (Homoptera, Auchenorrhyncha). In: Binot M, Bless R, Boye P, Gruttke $\mathrm{H}$, Pretscher P (eds) Rote Liste gefährdeter Tiere Deutschlands. Bundesamt für Naturschutz, Bonn Bad Godesberg, pp 243-249.

Remane R, Wachmann E (1993) Zikaden: kennenlernen - beobachten. Naturbuch, Augsburg.

Ribaut H (1936) Homoptères Auchenorhynques (I. Typhlocybidae). Faune de France 31, Paris.

Ribaut H (1952) Homoptères Auchenorhynques (II. Jassidae). Faune de France 57, Paris.

Robinson CT, Tockner K, Ward JV (2002) The fauna of dynamic riverine landscapes. Freshwater Biology 47: 661-677.

Roff DA (1994) Habitat persistence and the evolution of wing dimorphism in insects. The American Naturalist 144: 772-798.

Rothenbücher J (2000, unpublished) Vergleichende Untersuchung der Carabidenfauna auf vegetationsarmen Insel- und Uferflächen am Mittelrhein. Diploma thesis, Universität Bonn. 
Rothenbücher J, Bentlage K, Just P (2005) Conservation Management of Target Species or Conservation of Processes - Winners and Losers of Two Different Conservation Strategies. In: Markussen M, Buse R, Garrelts H, Mánez Costa MA, Menzel S, Marggraf R (eds) Conservation and Valuation of Biodiversity Interdisciplinary Perspectives on the Convention on Biological Diversity. Springer, Berlin, Heidelberg, pp 155-192.

Rothenbücher J, Dornieden K, Sellner M, Schaefer M (in prep. a) The impact of mowing and flooding on the diversity of ground beetles.

Rothenbücher J, Krüger U, Schaefer Matthias (in prep. b) The impact of mowing and flooding on the diversity of spiders.

RSPB (The Royal Society for the Protection of Birds), English Nature (EN), Institute of Terrestrial Ecology (ITE) (1997) The Wet Grassland Guide: Managing floodplain and coastal wet grassland for wildlife. RSPB.

Sanderson R, Rushton S, Cherrill A, Byrne B (1995) Soil, vegetation and space: an analysis of their effects on the invertebrate communities of a moorland in northeast England. Journal of Applied Ecology 32: 506-518.

Schaefer M (1976) Experimentelle Untersuchungen zum Jahreszyklus und zur Überwinterung von Spinnen (Araneida). Zoologische Jahrbücher Abteilung für Systematik, Ökologie und Geographie der Tiere 103: 127-289.

Schaefer M (2003) Wörterbuch der Ökologie. Spektrum, Heidelberg Berlin.

Schäffer N (1997) Habitatwahl und Partnerschaftssystem von Tüpfelralle (Porzana porzan) und Wachtelkönig (Crex crex). Dissertation, Universität Würzburg.

Schäffer N, Münch S (1993) Untersuchungen zur Habitatwahl und Brutbiologe des Wachtelkönigs Crex crex im Murnauer Moos/Oberbayern. Vogelwelt 114: 5572.

Schalitz G, Petrich G (1999) Möglichkeiten der Renaturierung intensivierter Grünlandflächen an der unteren Oder unter den Bedingungen verlängerter Überflutung. In: Dohle W, Bornkamm R, Weigmann G (eds) Das Untere Odertal Auswirkungen der periodischen Überschwemmungen auf Biozönosen und Arten. E. Schweizerbart, Stuttgart, pp 79-98.

Scherzinger W (2002) Stehen Biotop- und Artenschutz in Widerspruch zur Idee des Prozess-Schutzes? Artenschutzreport 12: 1-5.

Schlüpmann M, Günther R (1996) Grasfrosch - Rana temporaria LINNAEUS, 1758. In: Günther R (eds) Die Amphibien und Reptilien Deutschlands. Gustav Fischer, Jena, 412-453.

Schmidtler JF, Gruber U (1980) Die Lurchfauna Münchens. Schriftenreihe Naturschutz und Landschaftspflege 12: 105-139.

Schneeweiß N (1996) Zur Verbreitung und Bestandentwicklung der Rotbauchunke in Brandenburg. In: Krone A, Kühnel KD (eds) RANA Sonderheft 1: Die Rotbauchunke (Bombina bombina) Ökologie und Bestandssituation. Natur \& Text, Rangsdorf, 87-103.

Schneider R (1998) Das Zielartenkonzept aus verhaltensbiologischer Sicht. Artenschutzreport 8: 26-30. 
Schöpke H (1996) Untersuchungen zur Autökologie von Zikaden (Homoptera: Auchenorrhyncha) unter besonderer Berücksichtigung des Wasserangebots im Verlauf der Embryogenese. Dissertation, Universität Halle / Saale.

Schröder B (2000) Zwischen Naturschutz und Theoretischer Ökologie: Modelle zur Habitateignung und räumlichen Populationsdynamik für Heuschrecken im Niedermoor. Selbstverlag, Dissertation, Universität Braunschweig.

Sellner M (2004, unpublished) Einfluss von Mahd und Überflutung auf die Carabidenfauna im Nationalpark „Unteres Odertal“. Diploma thesis, Universität Göttingen.

Shapiro SS, Wilk MB (1965) An analysis of variance test for normality (complete samples). Biometrika 52: 591-611.

Smith EP, van Belle G (1984) Nonparametric estimation of species richness. Biometrics 40: 119-129.

Stowe TJ, Hudson VA (1991) Radio telemetry studies of Corncrakes in Great Britain. Vogelwelt 112: 10-16.

Tamm JC (1986) Eine Überlebensstrategie terrestrischer Kleinarthropoden in Überschwemmungsgebieten und einige Konsequenzen für die Funktion semiterrestrischer Uferökosysteme. Verhandlungen der Deutschen Zoologischen Gesellschaft 79: 32 .

Thiele H (1977) Carabid beetles in their environment - A study on habitat selection by adaptations in physiology and behaviour. Springer, Berlin, Heidelberg.

Tockner K, Stanford JA (2002) Riverine flood plains: present state and future trends. Environmental Conservation 29: 308-330.

Turin H (2000) De Nederlandse loopkevers, verspreiding en oecologie (Coleoptera: Carabidae). KNNV Uitgeverij \& EIS-Nederland, Leiden.

Tyler GA (1996) The ecology of the Corncrake, with special reference of the effect of mowing on breeding production. Dissertation, University College Cork.

Uetz GW (1990) Habitat structure and spider foraging. In: Bell SS, McCoy ED, Mushinsky HR (eds) Habitat Structure: The Physical Arrangements of Objects in Space. Chapman \& Hall, London, pp 348-525.

Underwood AJ (1997) Experiments in ecology. Their logical design and interpretation using analysis of variance. Cambridge University Press, Cambridge.

Vössing A (1998) Der Internationalpark Unteres Odertal Ein Werk und Wanderbuch. Stapp, Berlin.

Vogel K, Vogel B, Rothaupt G, Gottschalk E (1996) Einsatz von Zielarten im Naturschutz - Auswahl der Arten, Methode von Populationsgefährdungsanalyse und Schnellprognose, Umsetzung in der Praxis. Naturschutz und Landschaftsplanung 28: 179-184.

Vowinkel K (1997) Auswirkungen von Nutzungsintensivierung und Verbrachung auf die epigäische Arthropodenfauna im Mittelgebirgsgrünland des Westharzes bei St. Andreasberg. Artenschutzreport 7: 43-48.

Wachmann E, Platen R, Barndt D (1995) Laufkäfer: Beobachtung, Lebensweise. Naturbuch, Augsburg. 
Walther BA, Morand S (1998) Comparative performance of species richness estimation methods. Parasitology 116: 395-405.

Weigmann G, Wohlgemuth-von Reiche D (1999) Vergleichende Betrachtung zu den Überlebensstrategien von Bodentieren im Überflutungsbereich von Tieflandauen. In: Dohle W, Bornkamm R, Weigmann G (eds) Das Untere Odertal. Auswirkungen der periodischen Überschwemmungen auf die Biozönosen und Arten. E. Schweizerbart, Stuttgart, pp 229-240.

Wilke HJ (1995) Frösche, Kröten, Unken, Molche. Schwedter Jahresblätter 19: 19-29.

Wilson E (1992) Der gegenwärtige stand der biologischen Vielfalt. In: Wilson E (eds) Ende der biologiscehn Vielfalt? Der Verlust an Arten, Genen und Lebensräumen und die Chancen für eine Umkehr. Spektrum, Heidelberg, Berlin, pp 19-36.

Wise DH (1995) Spiders in Ecological Webs. Cambridge University Press, Cambridge.

Witt K, Bauer HG, Berthold P, Boye P, Hüppop O, Knief W (1998) Rote Liste der Brutvögel (Aves). In: Bundesamt für Naturschutz (ed) Rote Liste gefährdeter Tiere Deutschlands. Schriftenreihe für Landschaftspflege und Naturschutz, 55: 40-47.

Wohlgemuth-von Reiche D, Griegel A, Weigmann G (1997) Reaktion terrestrischer Arthropodengruppen auf Überflutung der Aue im Nationalpark Unteres Odertal. In: Handke K, Hildebrandt J (eds) Einfluß von Vernässung und Überstauung auf Wirbellose. Institut für Landschaftsökologie der Westfälischen WilhelmsUniversität, Münster, 18: 193-207.

Wohlgemut-von Reiche D, Grube R (1999) Zur Lebensraumbindung der Laufkäfer und Webspinnen (Coleoptera, Carabidae; Araneae) im Überflutungsbereich der Odertal-Auen. In: Dohle W, Bornkamm R, Weigmann G (eds) Das Untere Odertal. Auswirkungen der periodischen Überschwemmungen auf die Biozönosen und Arten. E. Schweizerbart, Stuttgart, pp 147-170.

WSA (2002) Data measured at the gauging station "Stützkow" provided by the Water and Shipping Authority Eberswalde. Written notification.

Zerm M (1999) Vorkommen und Verteilung von Tausendfüßern, Hundertfüßern, Zwergfüßern (Myriapoda: Diplopoda, Chilopoda, Symphyla) und Landasseln (Isopoda: Oniscidae) in den Auen des Unteren Odertals. In: Dohle W, Bornkamm R, Weigmann G (eds) Das Untere Odertal. Auswirkungen der periodischen Überschwemmungen auf die Biozönosen und Arten. E. Schweizerbart, Stuttgart, pp 197-210.

Ziegler W, Bode H, Mollenhauer D, Peters DS, Schminke HK, Trepel L, Türkay M, Zizka G, Zwölfer H (1997) Biodiversitätsforschung: Ihre Bedeutung für Wissenschaft, Anwendung und Ausbildung; Fakten Argumente und Perspektiven. Waldemar Kramer, Frankfurt.

Zulka K (1994) Carabids in a Central European floodplain: species distribution and survival during inundations. In: Desender K, Dufrêne M, Loreau M, Luff M, Maelfait J-P (eds) Carabid Beetles: Ecology and Evolution. Kluwer, Netherlands, pp 399-405. 


\section{Appendix 1}

Appendix 1: Plant species occurring in the study sites. X: dominance of the species, $x$ : occurrence of the species.

\begin{tabular}{|c|c|c|c|c|c|c|c|c|c|c|c|c|c|c|c|c|c|c|c|c|c|c|c|c|c|c|c|}
\hline Scientific name / Site & HF1 & HF2 & HF3 & HM1 & MF1 & MF2 & MF3 & MM1 & MM2 & MM3 & MM4 & MM5 & MM6 & LF1 & LF2 & LF3 & LF4 & LF5 & LM1 & LM2 & LM3 & NF1 & $\mathrm{NF2}$ & NF3 & NM1 & NM2 & NM3 \\
\hline Achillea ptarmica & . & $\mathrm{x}$ & . & . & . & . & . & $\mathrm{x}$ & $\mathrm{x}$ & - & . & 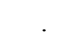 & $\mathrm{x}$ & . & . & $\mathrm{x}$ & . & $\mathrm{x}$ & . & . & $\mathrm{X}$ & . & . & . & . & . & . \\
\hline Achillea spec. & . & . & . & . & . & . & . & . & . & . & $\mathrm{x}$ & . & . & $\mathrm{x}$ & . & . & $\mathrm{x}$ & . & . & . & . & $\mathrm{x}$ & . & . & $\mathrm{x}$ & . & $\mathrm{x}$ \\
\hline Agropyron repens & $\mathrm{X}$ & $\mathrm{x}$ & . & $\mathrm{x}$ & . & . & . & . & . & . & $\mathrm{x}$ & . & $\mathrm{X}$ & $\mathrm{X}$ & $\mathrm{X}$ & $\mathrm{x}$ & $\mathrm{x}$ & . & . & . & . & $\mathrm{x}$ & $\mathrm{x}$ & . & $\mathrm{x}$ & . & . \\
\hline Agrostis stolonifera & . & $\mathrm{x}$ & $\mathrm{x}$ & . & . & . & . & $\mathrm{x}$ & $\mathrm{x}$ & . & $\mathrm{x}$ & $\mathrm{x}$ & $\mathrm{x}$ & . & $\mathrm{x}$ & . & $\mathrm{x}$ & $\mathrm{x}$ & $\mathrm{x}$ & . & $\mathrm{x}$ & . & $\mathrm{x}$ & $\mathrm{x}$ & . & . & . \\
\hline Alisma spec. & . & . & . & . & . & . & $\mathrm{x}$ & . & . & . & . & . & 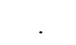 & . & . & . & . & . & . & . & . & . & . & . & . & . & . \\
\hline Allium spec. & . & . & . & . & . & . & . & . & . & . & . & . & & . & . & $\mathrm{x}$ & . & . & . & . & . & . & . & . & . & 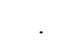 & . \\
\hline Alopecurus geniculatus & . & . & . & . & . & . & 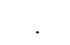 & $\mathrm{X}$ & . & . & $\mathrm{x}$ & $\mathrm{X}$ & $\mathrm{x}$ & . & . & . & . & . & . & . & . & . & . & . & . & . & . \\
\hline Alopecurus pratensis & . & . & . & $\mathrm{X}$ & . & . & . & . & $\mathrm{x}$ & . & $\mathrm{x}$ & . & . & $\mathrm{X}$ & $\mathrm{X}$ & $\mathrm{x}$ & $\mathrm{x}$ & $\mathrm{x}$ & . & . & . & $\mathrm{x}$ & . & . & $\mathrm{x}$ & . & $\mathrm{x}$ \\
\hline Anchusa officinalis & . & . & . & . & . & . & . & . & . & . & . & . & . & . & . & . & . & . & . & . & . & $\mathrm{x}$ & . & . & . & . & . \\
\hline Anthemis spec. & . & . & . & . & . & . & . & . & . & . & . & . & . & $\mathrm{x}$ & . & . & . & . & $\mathrm{x}$ & . & . & $\mathrm{x}$ & . & . & . & . & $\mathrm{x}$ \\
\hline Apera spica-venti & . & . & . & . & . & . & . & . & . & . & . & . & . & $\mathrm{x}$ & . & . & & . & & . & . & . & . & . & . & . & . \\
\hline Arctium spec. & . & . & . & . & . & . & . & . & . & . & . & . & . & . & . & . & . & . & . & . & . & $\mathrm{x}$ & . & . & $\mathrm{x}$ & $\mathrm{x}$ & . \\
\hline Arrhenatherum elatius & . & . & . & . & . & . & . & . & . & . & . & . & . & . & . & . & . & . & . & . & . & . & $\mathrm{x}$ & . & $\mathrm{x}$ & $\mathrm{x}$ & $\mathrm{X}$ \\
\hline Artemisia vulgaris & . & . & . & . & . & . & . & . & . & . & . & . & . & . & . & . & . & . & . & . & . & $\mathrm{x}$ & . & . & . & . & . \\
\hline Bidens tripartita & . & . & . & . & . & . & . & $\mathrm{x}$ & . & . & . & . & & . & . & . & . & . & . & . & $\mathrm{x}$ & . & . & . & . & . & . \\
\hline Calamagrostis epigeios & . & $\mathrm{x}$ & . & . & . & $\mathrm{x}$ & . & . & . & . & . & . & $\mathrm{x}$ & $\mathrm{x}$ & $\mathrm{x}$ & $\mathrm{X}$ & $\mathrm{X}$ & $\mathrm{x}$ & . & . & . & . & $\mathrm{x}$ & $\mathrm{x}$ & . & . & . \\
\hline Calystegia sepium & . & . & . & . & . & $\mathrm{x}$ & . & . & . & . & . & . & $\mathrm{x}$ & . & . & . & . & . & . & . & . & . & . & . & . & . & . \\
\hline Capsella bursa-pastoris & . & . & . & . & . & . & . & . & . & . & . & $\mathrm{x}$ & . & . & . & . & . & . & . & . & . & . & . & . & . & . & . \\
\hline Carduus crispus & . & . & . & . & . & . & . & . & . & . & . & . & . & $\mathrm{x}$ & . & . & . & . & . & . & . & . & $\mathrm{x}$ & . & . & . & . \\
\hline Carex acuta & . & . & . & . & $\mathrm{X}$ & $\mathrm{X}$ & $\mathrm{X}$ & $\mathrm{x}$ & . & . & . & . & . & . & . & . & . & . & . & . & . & . & . & . & . & . & . \\
\hline Carex riparia & & & . & & & $\mathrm{x}$ & $\mathrm{x}$ & . & & & . & $\mathrm{x}$ & & . & . & . & . & $\mathrm{x}$ & . & . & . & . & . & . & . & & \\
\hline
\end{tabular}




\section{Carex spec.}

Carex vulpina

Cerastium spec.

Chenopodium album

Chenopodium spec.

Chrysanthemum vulgare

Cichorium intybus

Cirsium arvense

Cirsium vulgare

Convolvulus arvensis

Crepis biennis

Cuscuta europaea

Dactylis glomerata

Daucus carota

Deschampsia cespitosa

Eleocharis spec.

Epilobium hirsutum

Epilobium spec.

Equisetum arvense

Erigeron canadensis

Erysimum cheiranthoides

Euphorbia cyparissias

Festuca pratensis

Filipendula ulmaria

Galeopsis spec. 


\begin{tabular}{|c|c|c|c|c|c|c|c|c|c|c|c|c|c|c|c|c|c|c|c|c|c|c|c|c|c|c|c|}
\hline Scientific name / Site & HF1 & HF2 & HF3 & HM1 & MF1 & MF2 & MF3 & MM1 & MM2 & MM3 & MM4 & MM5 & MM6 & LF1 & LF2 & LF3 & LF4 & LF5 & LM1 & LM2 & LM3 & NF1 & NF2 & NF3 & NM1 & NM2 & NM3 \\
\hline Galeopsis tetrahit & . & . & . & . & . & . & . & 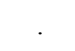 & . & . & . & . & . & . & . & $\mathrm{x}$ & . & . & . & . & . & . & . & . & . & . & . \\
\hline Galium mollugo & . & . & . & . & . & . & . & . & . & . & . & . & . & . & . & . & . & . & . & . & . & $\mathrm{x}$ & . & . & $\mathrm{x}$ & . & . \\
\hline Galium palustre & . & . & . & $\mathrm{x}$ & . & . & . & $\mathrm{x}$ & $\mathrm{x}$ & . & $\mathrm{x}$ & . & $\mathrm{x}$ & . & $\mathrm{x}$ & . & . & . & $\mathrm{x}$ & . & . & . & . & . & . & . & . \\
\hline Galium spec. & . & . & . & . & . & . & . & . & . & . & . & . & . & . & . & . & . & . & . & . & . & . & $\mathrm{x}$ & $\mathrm{x}$ & . & . & $\mathrm{X}$ \\
\hline Glechoma hederacea & . & . & . & . & . & . & . & . & . & . & . & $\mathrm{x}$ & . & $\mathrm{x}$ & $\mathrm{x}$ & $\mathrm{x}$ & $\mathrm{x}$ & $\mathrm{x}$ & $\mathrm{x}$ & . & . & . & . & $\mathrm{x}$ & . & . & . \\
\hline Glyceria тахіта & . & . & . & . & . & $\mathrm{x}$ & . & $\mathrm{x}$ & . & . & . & . & . & . & . & . & . & . & . & . & . & . & . & . & . & . & . \\
\hline Heracleum sphondylium & . & . & . & . & . & . & . & . & . & . & . & . & . & . & . & . & . & . & . & . & . & . & . & . & $\mathrm{x}$ & $\mathrm{x}$ & $\mathrm{X}$ \\
\hline Holcus lanatus & . & . & . & . & . & . & . & . & . & . & . & . & . & $\mathrm{x}$ & . & . & . & . & . & . & . & $\mathrm{x}$ & $\mathrm{x}$ & $\mathrm{x}$ & . & . & $\mathrm{X}$ \\
\hline Humulus lupulus & . & . & & & . & $\mathrm{x}$ & . & . & . & . & . & . & . & . & . & . & . & . & . & . & . & . & & . & . & . & . \\
\hline Hypericum perforatum & . & $\mathrm{x}$ & . & . & . & . & . & . & . & . & . & . & . & . & . & $\mathrm{x}$ & $\mathrm{x}$ & . & . & . & . & $\mathrm{x}$ & . & . & . & . & . \\
\hline Inula britannica & . & . & . & . & . & . & . & . & . & . & . & . & . & . & . & . & . & . & $\mathrm{x}$ & . & . & . & . & . & . & . & . \\
\hline Iris pseudacorus & . & . & . & . & $\mathrm{x}$ & $\mathrm{x}$ & . & . & . & . & . & . & . & . & . & . & . & . & . & . & . & . & . & . & . & . & . \\
\hline Juncus effusus & . & . & . & . & . & . & . & . & . & . & . & . & . & . & . & . & $\mathrm{x}$ & . & . & . & . & $\mathrm{x}$ & . & . & . & . & . \\
\hline Leontodon autumnalis & . & . & . & . & . & . & . & $\mathrm{X}$ & $\mathrm{x}$ & . & $\mathrm{x}$ & . & $\mathrm{x}$ & . & . & . & . & . & $\mathrm{X}$ & . & $\mathrm{x}$ & $\mathrm{x}$ & . & . & $\mathrm{x}$ & . & . \\
\hline Leonurus marrubiastrum & . & . & . & . & . & . & . & . & . & . & . & . & . & $\mathrm{x}$ & $\mathrm{X}$ & . & . & . & . & . & . & . & . & . & . & . & . \\
\hline Linaria vulgaris & . & . & . & . & . & . & . & . & . & . & . & . & . & . & $\mathrm{x}$ & . & $\mathrm{x}$ & $\mathrm{x}$ & . & . & . & . & . & . & . & . & . \\
\hline Lolium perenne & . & . & . & . & . & . & . & . & . & . & . & . & . & . & . & . & . & . & . & . & . & . & . & . & $\mathrm{x}$ & $\mathrm{X}$ & . \\
\hline Lotus spec. & . & . & & . & . & . & . & . & . & . & . & . & . & . & . & . & $\mathrm{x}$ & . & . & . & . & . & . & . & . & . & . \\
\hline Lychnis flos-cuculi & . & . & . & $\mathrm{x}$ & . & . & . & . & . & . & . & . & . & . & . & . & . & . & . & . & . & . & . & . & . & . & . \\
\hline Lyсориs europaeus & . & & . & . & . & $\mathrm{x}$ & . & . & . & . & . & . & . & . & . & . & . & $\mathrm{x}$ & . & . & . & . & . & . & . & . & . \\
\hline Lythrum salicaria & . & . & . & . & $\mathrm{x}$ & $\mathrm{x}$ & . & . & . & . & . & . & $\mathrm{x}$ & . & $\mathrm{x}$ & . & . & . & . & . & . & $\mathrm{x}$ & . & . & . & . & . \\
\hline Lythrum vulgaris & . & . & . & . & . & $\mathrm{x}$ & . & $\mathrm{x}$ & . & . & . & . & . & . & . & . & . & $\mathrm{x}$ & . & . & . & . & . & . & . & . & . \\
\hline Mentha arvensis & . & . & . & . & . & . & . & . & $\mathrm{x}$ & . & . & $\mathrm{x}$ & . & . & . & . & . & . & . & . & . & . & . & . & . & . & . \\
\hline Pastinaca sativa & . & . & . & . & . & . & . & . & . & . & . & . & . & . & . & . & . & . & . & . & . & . & . & . & $\mathrm{X}$ & . & . \\
\hline Phalaris arundinacea & $\mathrm{x}$ & $\mathrm{X}$ & $\mathrm{X}$ & $\mathrm{X}$ & $\mathrm{X}$ & $\mathrm{x}$ & . & $\mathrm{x}$ & $\mathrm{X}$ & . & $\mathrm{X}$ & $\mathrm{X}$ & $\mathrm{X}$ & $\mathrm{x}$ & $\mathrm{x}$ & $\mathrm{X}$ & . & $\mathrm{x}$ & $\mathrm{x}$ & $\mathrm{X}$ & $\mathrm{X}$ & $\mathrm{x}$ & $\mathrm{x}$ & $\mathrm{x}$ & . & . & . \\
\hline
\end{tabular}


Phleum pratense

Phragmites australis

Plantago lanceolata

Plantago major

Poa palustris

Poa pratensis

Poa spec.

Poa trivialis

Polygonum amphibium

Potentilla anserina

Potentilla argentea

Potentilla reptans

Ranunculus repens

Rorippa palustris

Rubus spec.

Rumex acetosa

Rubus caesius

Salix alba

Senecio jacobaea

Silene vulgaris

Silene latifolia

Sium latifolium

Solanum dulcamara

Sonchus asper

Stachys palustris 
Stellaria palustris

Symphytum officinale

Taraxacum officinale

Thalictrum flavum

Thalictrum minus

Trifolium avense

Trifolium dubium

Trifolium pratense

Trifolium repens

Urtica dioica

Veronica longifolia

Vicia cracca

$\mathrm{x} \quad \cdot \quad \cdot \quad \cdot \quad \cdot \quad \cdot \quad \mathrm{x} \quad \mathrm{x} \quad \mathrm{x}$

Vicia spec.

\begin{tabular}{ccccc}
$\cdot \mathrm{x}$ & $\mathrm{x}$ & $\cdot$ & $\mathrm{x}$ & $\cdot$ \\
$\cdot$ & $\cdot$ & $\cdot$ & $\cdot$ & $\mathrm{x}$ \\
$\cdot$ & $\cdot$ & $\cdot$ & $\cdot$ & $\cdot$ \\
$\cdot$ & $\cdot$ & $\cdot$ & $\cdot$ & $\cdot$ \\
$\cdot$ & $\cdot$ & $\cdot$ & $\cdot$ & $\cdot$ \\
$\cdot$ & $\cdot$ & $\cdot$ & $\cdot$ & $\cdot$ \\
$\cdot$ & $\cdot$ & $\cdot$ & $\cdot$ & $\cdot$ \\
$\cdot$ & $\cdot$ & $\cdot$ & $\cdot$ & $\cdot$ \\
$\mathrm{x}$ & $\mathrm{x}$ & $\cdot$ & $\cdot$ & $\cdot$ \\
$\cdot$ & $\cdot$ & $\cdot$ & $\cdot$ & $\cdot$ \\
\hline
\end{tabular}

$\mathrm{x}$

$\mathrm{x}$.




\section{Appendix 2}

Appendix 2a: $\quad$ For each study site investigated in 2001 numbers of species, numbers of individuals, $\alpha$-diversity, evenness and numbers of individuals per $\mathrm{m}^{2}$ and month are listed.

\begin{tabular}{lccccccc}
\hline Site & Species & Individuals & Diversity & Evenness & \multicolumn{3}{c}{ Individuals per m } \\
& & & & & June & July & September \\
\hline HF1 & 9 & 24 & 1.62 & 0.74 & 0 & 153 & 7 \\
HF2 & 13 & 38 & 1.97 & 0.77 & 180 & 60 & 13 \\
HM1 & 10 & 35 & 1.83 & 0.79 & 13 & 193 & 27 \\
MF1 & 11 & 127 & 0.65 & 0.27 & 533 & 180 & 133 \\
MF2 & 14 & 119 & 1.45 & 0.55 & 313 & 333 & 147 \\
MM1 & 11 & 95 & 1.71 & 0.71 & 93 & 147 & 393 \\
MM2 & 5 & 23 & 1.37 & 0.85 & 47 & 107 & 0 \\
MM4 & 14 & 115 & 1.81 & 0.69 & 53 & 93 & 620 \\
MM5 & 14 & 103 & 1.97 & 0.75 & 153 & 247 & 287 \\
MM6 & 17 & 119 & 2.24 & 0.79 & 147 & 453 & 193 \\
LF1 & 14 & 61 & 2.18 & 0.83 & 127 & 73 & 207 \\
LF2 & 7 & 32 & 1.45 & 0.74 & 40 & 60 & 113 \\
LF3 & 10 & 72 & 1.69 & 0.74 & 207 & 187 & 87 \\
LF4 & 8 & 73 & 1.17 & 0.56 & 220 & 40 & 227 \\
LF5 & 11 & 134 & 1.65 & 0.69 & 407 & 360 & 127 \\
LM2 & 11 & 54 & 1.81 & 0.75 & 27 & 73 & 260 \\
LM4 & 12 & 70 & 1.96 & 0.79 & 0 & 180 & 287 \\
NF1 & 20 & 89 & 2.54 & 0.85 & 93 & 327 & 173 \\
NM1 & 13 & 61 & 2.23 & 0.87 & 0 & 140 & 267 \\
NM2 & 10 & 109 & 1.39 & 0.61 & 40 & 240 & 447 \\
\hline
\end{tabular}

Appendix 2b: $\quad$ For each study site investigated in 2002 numbers of species, numbers of individuals, $\alpha$-diversity, evenness and numbers of individuals per $\mathrm{m}^{2}$ and month are listed.

\begin{tabular}{lcccccccc}
\hline Site & Species & Individuals & Diversity & Evenness & \multicolumn{4}{c}{ Individuals per $\mathbf{m}^{2}$} \\
& \multicolumn{1}{l}{} & & & & May & June & July & September \\
\hline HF1 & 9 & 77 & 1.761 & 0.802 & 13 & 27 & 200 & 273 \\
HF2 & 13 & 98 & 1.343 & 0.523 & 0 & 13 & 553 & 87 \\
HF3 & 14 & 206 & 1.697 & 0.643 & 93 & 80 & 740 & 460 \\
MF1 & 9 & 93 & 1.105 & 0.503 & 0 & 240 & 200 & 180 \\
MF2 & 12 & 83 & 1.975 & 0.795 & 7 & 127 & 180 & 240 \\
MF3 & 8 & 104 & 1.61 & 0.774 & 0 & 240 & 267 & 187 \\
LF2 & 14 & 84 & 2.213 & 0.838 & 7 & 187 & 287 & 80 \\
LF3 & 17 & 92 & 2.165 & 0.764 & 0 & 140 & 313 & 160 \\
LF4 & 12 & 76 & 2.045 & 0.823 & 53 & 80 & 340 & 33 \\
NF1 & 15 & 114 & 2.079 & 0.768 & 20 & 220 & 373 & 147 \\
NF2 & 19 & 170 & 2.487 & 0.845 & 47 & 140 & 653 & 293 \\
NF3 & 16 & 128 & 2.415 & 0.871 & 40 & 147 & 340 & 327 \\
\hline
\end{tabular}




\section{Appendix 3}

Appendix 3: $\quad$ Abundance of species of planthoppers, leafhoppers, spiders and ground beetles collected in the floodplain at sites differing in flooding impact. Furthermore, information on the type of spatiotemporal distribution, ecology and adaptation to inundation is given (for abbreviations: see below). The ten most abundant species of each group that occurred with at least five individuals are listed for each type of spatiotemporal distribution. If less than ten species were found per type of spatiotemporal distribution, all species are listed. Numbers of individuals were calculated per three pitfall traps and one $\mathrm{m}^{2}$ suction sample. Numbers of individuals collected by both methods were summed.

\begin{tabular}{|c|c|c|c|c|c|c|c|c|c|c|c|c|c|c|c|c|c|}
\hline \multirow[b]{2}{*}{ Flooding impact } & \multicolumn{3}{|c|}{ Co \& N. S. May } & \multicolumn{2}{|c|}{ Ex July } & \multicolumn{4}{|c|}{ Co July } & \multicolumn{3}{|c|}{ N. S. after July } & \multirow{2}{*}{$\begin{array}{l}\text { Type } \\
\text { of } \\
\text { spatio- } \\
\text { tem- } \\
\text { poral } \\
\text { distri- } \\
\text { bution }\end{array}$} & \multicolumn{3}{|c|}{$\begin{array}{l}\text { Ecological } \\
\text { characteristics }\end{array}$} & \multirow{2}{*}{$\begin{array}{l}\text { Adapta- } \\
\text { tion to } \\
\text { inun- } \\
\text { dation }\end{array}$} \\
\hline & $\mathrm{H}$ & M & $\mathrm{L}$ & $\mathrm{H}$ & M & L & $\mathrm{H}$ & M & $\mathrm{L}$ & $\mathrm{H}$ & M & $\mathrm{L}$ & & Ow & $\mathrm{Fl}$ & Hp & \\
\hline
\end{tabular}

\begin{tabular}{|c|c|c|c|c|c|c|c|c|c|c|c|c|c|c|c|c|c|}
\hline \multicolumn{18}{|c|}{ Plant- and leafhoppers } \\
\hline Anoscopus & & & & & & & & & & & & & & & & & \\
\hline $\begin{array}{l}\text { serratulae } \\
\text { Arthaldeus }\end{array}$ & 0 & 0 & 0 & 0.3 & 0 & 11 & 0.7 & 0 & 6 & 20 & 0 & 33 & $\mathbf{A}$ & egg & unli & eu & 1 \\
\hline pascuellus & 0 & 0 & 0 & 4 & 0 & 20 & 0.7 & 0.3 & 7 & 83 & 0 & 80 & $\mathbf{A}$ & egg & unli & eu & 1 \\
\hline Athysanus & 0 & 0 & 0 & 07 & 0 & 1 & & & & & & & 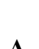 & & Noli & en & 1 \\
\hline Cosmotettix & 0 & 0 & 0 & 0.1 & 0 & 1 & 0 & 0 & 0 & 0 & 0 & 0 & A & egg & unli & $\mathrm{eu}$ & 1 \\
\hline $\begin{array}{l}\text { caudatus } \\
\text { Cosmotettix }\end{array}$ & 0 & 0 & 0 & 4 & 0 & 0 & 0 & 0 & 0 & 0 & 0 & 0 & $\mathbf{A}$ & egg & unli & unce & 1 \\
\hline $\begin{array}{l}\text { costalis } \\
\text { Errastunus }\end{array}$ & 0 & 0 & 0 & 0 & 5 & 0 & 0 & 4 & 0 & 0 & 20 & 0 & $\mathbf{A}$ & egg & unli & hy & 1 \\
\hline $\begin{array}{l}\text { ocellaris } \\
\text { Erzaleus }\end{array}$ & 0 & 0 & 0 & 0.7 & 4 & 2 & 1 & 9 & 1 & 67 & 3 & 57 & $\mathbf{A}$ & egg & unli & eu & 1 \\
\hline $\begin{array}{l}\text { metrius } \\
\text { Megamelus }\end{array}$ & 0 & 0 & 0 & 0.7 & 4 & 4 & 1 & 11 & 0 & 57 & 167 & 0 & $\mathbf{A}$ & egg & unli & hy & 1 \\
\hline notula & 0 & 0 & 0 & 0 & 12 & 3 & 0 & 7 & 0 & 0 & 117 & 0 & $\mathbf{A}$ & egg & unli & hy & 1 \\
\hline $\begin{array}{l}\text { Streptanus } \\
\text { aemulans } \\
\text { Anakelisia }\end{array}$ & 0 & 0 & 0 & 1 & 0 & 12 & 0.3 & 0 & 11 & 97 & 3 & 60 & $\mathbf{A}$ & egg & unli & eu & 1 \\
\hline $\begin{array}{l}\text { fasciata } \\
\text { Laodelphax }\end{array}$ & 0 & 0 & 0 & 0 & 0 & 0 & 0 & 0.3 & 0 & 0 & 17 & 0 & B & egg & unli & hy & 1 \\
\hline $\begin{array}{l}\text { Laodelphax } \\
\text { striatella } \\
\text { Metalimnus }\end{array}$ & 0 & 0 & 0 & 0 & 0 & 0 & 0.3 & 0 & 0 & 7 & 0 & 0 & B & juv & unli & eu & 2 \\
\hline $\begin{array}{l}\text { formosus } \\
\text { Balclutha }\end{array}$ & 0 & 0 & 0 & 0 & 0 & 0 & 0 & 0.3 & 0 & 0 & 43 & 0 & B & egg & unli & hy & 1 \\
\hline $\begin{array}{l}\text { rhenana } \\
\text { Javesella }\end{array}$ & 60 & 0 & 0 & 3 & 0 & 0 & 82 & 0.3 & 1 & 63 & 3 & 7 & C & $\mathrm{ad}$ & conf & hy & 2 \\
\hline $\begin{array}{l}\text { dubia } \\
\text { Javesella }\end{array}$ & 0 & 0 & 7 & 0 & 0 & 0 & 0 & 0 & 0 & 20 & 0 & 27 & C & juv & unli & eu & 2 \\
\hline $\begin{array}{l}\text { pellucida } \\
\text { Macustus }\end{array}$ & 133 & 0 & 0 & 13 & 0 & 1 & 77 & 1 & 33 & 613 & 3 & 227 & C & juv & conf & eu & 2 \\
\hline $\begin{array}{l}\text { grisescens } \\
\text { Mirabella }\end{array}$ & 0 & 0 & 40 & 0 & 0 & 0 & 0 & 0 & 0 & 0 & 0 & 0 & C & juv & unli & hy & 2 \\
\hline $\begin{array}{l}\text { albifrons } \\
\text { Paraliburnia }\end{array}$ & 0 & 0 & 19 & 0 & 0 & 0 & 0 & 0 & 7 & 3 & 0 & 30 & C & juv & unli & eu & 2 \\
\hline $\begin{array}{l}\text { adela } \\
\text { Cicadula }\end{array}$ & 7 & 0 & 0 & 0 & 0 & 0 & 0 & 0 & 0 & 7 & 0 & 0 & C & juv & unli & hy & 1 \\
\hline $\begin{array}{l}\text { flori } \\
\text { Empoasca }\end{array}$ & 0 & 0 & 0 & 0 & 0 & 0 & 0 & 0 & 0 & 0 & 23 & 0 & D & egg & unli & hy & 1 \\
\hline $\begin{array}{l}\text { pteridis } \\
\text { Endria }\end{array}$ & 0 & 0 & 0 & 0 & 0 & 0 & 0 & 0 & 0 & 0 & 23 & 3 & D & egg & conf & eu & 1 \\
\hline $\begin{array}{l}\text { nebulosa } \\
\text { Eupteryx }\end{array}$ & 0 & 0 & 0 & 0 & 0 & 0 & 0 & 0 & 0 & 0 & 0 & 17 & D & egg & unli & hy & 1 \\
\hline $\begin{array}{l}\text { atropunctata } \\
\text { Eupteryx }\end{array}$ & 0 & 0 & 0 & 0 & 0 & 0 & 0 & 0 & 0 & 0 & 73 & 3 & D & egg & conf & eu & 1 \\
\hline $\begin{array}{l}\text { cyclops } \\
\text { Macrosteles }\end{array}$ & 0 & 0 & 0 & 0 & 0 & 0 & 0 & 0 & 0 & 3 & 3 & 207 & D & egg & conf & hy & 1 \\
\hline $\begin{array}{l}\text { laevis } \\
\text { Stenocranus }\end{array}$ & 0 & 0 & 0 & 0 & 0 & 0 & 0 & 0 & 0 & 20 & 0 & 0 & D & egg & conf & eu & 1 \\
\hline $\begin{array}{l}\text { major } \\
\text { Stroggyloce- }\end{array}$ & 0 & 0 & 0 & 0 & 0 & 0 & 0 & 0 & 0 & 47 & 20 & 17 & D & $\mathrm{ad}$ & conf & hy & 2 \\
\hline phalus agrestis & 0 & 0 & 0 & 0 & 0 & 0 & 0 & 0 & 0 & 0 & 23 & 0 & D & egg & unli & hy & 1 \\
\hline $\begin{array}{l}\text { Spiders } \\
\text { Meioneta } \\
\text { rurestris }\end{array}$ & 0 & 0 & 0 & 0 & 0 & 0.3 & 0.3 & 0 & 0 & 0 & 0 & 0 & $\mathbf{A}$ & d.s. & conf & xe & unce \\
\hline $\begin{array}{l}\text { Microlinyphia } \\
\text { impigra } \\
\text { Oedothorax }\end{array}$ & 0 & 0 & 0 & 0 & 0.3 & 1 & 1 & 0 & 0 & 0 & 0 & 0 & $\mathbf{A}$ & juv & unce & hy & 1 \\
\hline apicatus & 0 & 0 & 0 & 0 & 0.3 & 0 & 8 & 0 & 0 & 0.3 & 0 & 0 & $\mathbf{A}$ & d.s. & unce & $\mathrm{xe}$ & $1 \& 2$ \\
\hline
\end{tabular}




\begin{tabular}{|c|c|c|c|c|c|c|c|c|c|c|c|c|c|c|c|c|c|}
\hline \multirow[b]{2}{*}{ Flooding impact } & \multicolumn{3}{|c|}{ Co \& N. S. May } & \multicolumn{3}{|c|}{ Ex July } & \multicolumn{3}{|c|}{ Co July } & \multicolumn{3}{|c|}{ N. S. after July } & \multirow{2}{*}{$\begin{array}{l}\text { Type } \\
\text { of } \\
\text { spatio- } \\
\text { tem- } \\
\text { poral } \\
\text { distri- } \\
\text { bution }\end{array}$} & \multicolumn{3}{|c|}{$\begin{array}{l}\text { Ecological } \\
\text { characteristics }\end{array}$} & \multirow{2}{*}{$\begin{array}{l}\text { Adapta- } \\
\text { tion to } \\
\text { inunda- } \\
\text { tion }\end{array}$} \\
\hline & $\mathrm{H}$ & $\mathrm{M}$ & $\mathrm{L}$ & $\mathrm{H}$ & M & $\mathrm{L}$ & $\mathrm{H}$ & M & $\mathrm{L}$ & $\mathrm{H}$ & M & $\mathrm{L}$ & & Ow & $\mathrm{Fl}$ & Нp & \\
\hline $\begin{array}{l}\text { Pachygnatha } \\
\text { listeri } \\
\text { Xerolycosa }\end{array}$ & 0 & 0 & 0 & 0 & 0 & 0.3 & 0 & 0 & 0 & 0 & 0 & 0 & $\mathbf{A}$ & d.s. & unce & fo & unce \\
\hline $\begin{array}{l}\text { miniata } \\
\text { Argiope }\end{array}$ & 0 & 0 & 0 & 0 & 0 & 0.3 & 0 & 0 & 0 & 0 & 0 & 0 & $\mathbf{A}$ & juv & unce & xe & unce \\
\hline $\begin{array}{l}\text { bruennichi } \\
\text { Bathyphantes }\end{array}$ & 0 & 0 & 0 & 0 & 0 & 0 & 0 & 0 & 0.3 & 0 & 0 & 0 & B & juv & unce & eu & 1 \\
\hline $\begin{array}{l}\text { approximatus } \\
\text { Diplostyla }\end{array}$ & 0 & 0 & 0 & 0 & 0 & 0 & 0 & 1 & 0 & 0 & 20 & 0 & B & d.s. & unce & hy & 2 \\
\hline $\begin{array}{l}\text { concolor } \\
\text { Lepthyphantes }\end{array}$ & 0 & 0 & 0 & 0 & 0 & 0 & 0 & 0 & 1 & 0 & 0 & 0.2 & B & d.s. & unce & hy & 2 \\
\hline $\begin{array}{l}\text { mengei } \\
\text { Microlinyphia }\end{array}$ & 0 & 0 & 0 & 0 & 0 & 0 & 0 & 0 & 0.3 & 0 & 0 & 0 & B & d.s. & conf & hy & 2 \\
\hline $\begin{array}{l}\text { pusilla } \\
\text { Oedothorax }\end{array}$ & 0 & 0 & 0 & 0 & 0 & 0 & 0.3 & 0 & 0.3 & 0 & 0 & 0 & B & juv & unce & eu & 2 \\
\hline $\begin{array}{l}\text { agrestis } \\
\text { Robertus }\end{array}$ & 0 & 0 & 0 & 0 & 0 & 0 & 3 & 0 & 0 & 0 & 0 & 0 & B & unce & conf & hy & 2 \\
\hline $\begin{array}{l}\text { lividus } \\
\text { Theridion }\end{array}$ & 0 & 0 & 0 & 0 & 0 & 0 & 0 & 0 & 1 & 0 & 0 & 0 & B & d.s. & unce & fo & 2 \\
\hline $\begin{array}{l}\text { hemerobius } \\
\text { Theridion }\end{array}$ & 0 & 0 & 0 & 0 & 0 & 0 & 0 & 0.3 & 0 & 0 & 0 & 0 & B & juv & unce & hy & 2 \\
\hline $\begin{array}{l}\text { pictum } \\
\text { Tibellus }\end{array}$ & 0 & 0 & 0 & 0 & 0 & 0 & 0 & 0 & 0.3 & 0 & 0 & 0 & B & unce & unce & fo & 2 \\
\hline $\begin{array}{l}\text { maritimus } \\
\text { Walckenaeria }\end{array}$ & 0 & 0 & 0 & 0 & 0 & 0 & 0 & 0 & 0.7 & 0 & 0 & 0 & B & juv & unce & hy & 2 \\
\hline $\begin{array}{l}\text { atrotibialis } \\
\text { Bathyphantes }\end{array}$ & 0 & 0 & 0 & 0 & 0 & 0 & 0 & 1 & 2 & 0 & 0 & 0 & B & juv & unce & fo & 2 \\
\hline $\begin{array}{l}\text { gracilis } \\
\text { Erigone }\end{array}$ & 29 & 1 & 7 & 0 & 0.3 & 0.3 & 7 & 0.3 & 1 & 24 & 34 & 14 & C & d.s. & conf & $\mathrm{eu}$ & 2 \\
\hline $\begin{array}{l}\text { atra } \\
\text { Hypomma }\end{array}$ & 18 & 0 & 1 & 10 & 1 & 1 & 44 & 6 & 2 & 27 & 7 & 0 & C & d.s. & conf & eu & 2 \\
\hline $\begin{array}{l}\text { bituberculatum } \\
\text { Lepthyphantes }\end{array}$ & 1 & 70 & 0 & 0 & 1 & 0 & 0 & 0.3 & 0 & 0 & 0 & 0 & C & juv & unce & hy & 2 \\
\hline $\begin{array}{l}\text { tenuis } \\
\text { Meionet }\end{array}$ & 7 & 0 & 40 & 0 & 0 & 0 & 0.3 & 0 & 0 & 14 & 0 & 13 & C & d.s. & conf & $\mathrm{xe}$ & 2 \\
\hline $\begin{array}{l}\text { beata } \\
\text { Pardosa }\end{array}$ & 7 & 0 & 23 & 1 & 0 & 1 & 0 & 0 & 0.3 & 3 & 0 & 3 & C & unce & unce & xe & 2 \\
\hline $\begin{array}{l}\text { palustris } \\
\text { Pardosa }\end{array}$ & 74 & 0 & 5 & 0 & 0 & 0 & 0 & 0 & 0 & 0.2 & 0 & 0.2 & C & juv & conf & eu & 2 \\
\hline $\begin{array}{l}\text { prativaga } \\
\text { Pirata }\end{array}$ & 139 & 44 & 74 & 0 & 2 & 2 & 24 & 19 & 5 & 9 & 10 & 1 & C & juv & conf & eu & 2 \\
\hline $\begin{array}{l}\text { piraticus } \\
\text { Porrhomma }\end{array}$ & 8 & 10 & 0 & 1 & 10 & 0 & 2 & 30 & 0 & 0 & 1 & 0 & C & juv & conf & hy & 2 \\
\hline $\begin{array}{l}\text { pygmaeum } \\
\text { Savygnia }\end{array}$ & 31 & 15 & 12 & 3 & 0 & 0 & 3 & 0 & 0 & 50 & 77 & 3 & C & juv & conf & hy & $1 \& 2$ \\
\hline $\begin{array}{l}\text { frontata } \\
\text { Allomengea }\end{array}$ & 31 & 21 & 42 & 4 & 0 & 0 & 2 & 2 & 0 & 17 & 27 & 3 & C & d.s. & conf & hy & 2 \\
\hline $\begin{array}{l}\text { scopigera } \\
\text { Allomengea }\end{array}$ & 0 & 0 & 0 & 0 & 0 & 0 & 0 & 0 & 0 & 0.8 & 45 & 2 & D & egg & unce & hy & 1 \\
\hline $\begin{array}{l}\text { vidua } \\
\text { Kaestneria }\end{array}$ & 0 & 0 & 0 & 0 & 0 & 0 & 0 & 0 & 0 & 0.3 & 53 & 6 & D & egg & unce & hy & 1 \\
\hline $\begin{array}{l}\text { pullata } \\
\text { Marpissa }\end{array}$ & 0 & 0 & 0 & 0 & 0 & 0 & 0 & 0 & 0 & 20 & 0 & 13 & D & unce & unce & hy & 2 \\
\hline radiata & 0 & 0 & 0 & 0 & 0 & 0 & 0 & 0 & 0 & 0 & 17 & 0 & D & unce & unce & hy & unce \\
\hline
\end{tabular}

Ground beetles

Epaphius

secalis

Amara

lunicollis

Chlaenius

tristis

Acupalpu

dubius

Acupalpu

exiguus

Agonum

afrum

Bembidion

biguttatum

Carabus

granulatus

Dyschirius

globosus

Philorhizus

sigma

Poecilus

cupreus

\begin{tabular}{|c|c|c|c|c|c|c|c|c|c|c|c|c|c|c|c|c|}
\hline 0 & 0 & 0 & 0 & 0 & 6 & 0 & 0 & 2 & 0 & 1 & 1 & $\mathbf{A}$ & juv & unli & fo & unce \\
\hline 0 & 0 & 0 & 0 & 0 & 0 & 0 & 0 & 7 & 0 & 0 & 0.2 & B & ad & conf & xe & 2 \\
\hline 0 & 0 & 0 & 0 & 0 & 0 & 1 & 0 & 0 & 0 & 0.7 & 0 & B & ad & conf & hy & 2 \\
\hline 51 & 8 & 0 & 0 & 0 & 0 & 0 & 0 & 0 & 0 & 0 & 0 & C & ad & conf & hy & 2 \\
\hline 1 & 13 & 6 & 0 & 0 & 0 & 0 & 2 & 0 & 0 & 0 & 3 & C & ad & conf & hy & 2 \\
\hline 8 & 57 & 20 & 7 & 10 & 0 & 5 & 64 & 5 & 6 & 99 & 5 & C & ad & conf & hy & 2 \\
\hline 11 & 9 & 3 & 1 & 1 & 0 & 10 & 10 & 0 & 0.7 & 24 & 28 & C & ad & conf & hy & 2 \\
\hline 10 & 23 & 13 & 2 & 0 & 0 & 12 & 16 & 6 & 17 & 4 & 10 & C & ad & unli & hy & $1 \& 2$ \\
\hline 58 & 4 & 89 & 1 & 3 & 4 & 9 & 23 & 6 & 42 & 23 & 35 & C & ad & unli & hy & $1 \& 2$ \\
\hline 0 & 13 & 14 & 0 & 0 & 0.3 & 0 & 0 & 1 & 0 & 10 & 13 & C & ad & unce & hy & 2 \\
\hline 17 & 1 & 5 & 0 & 0 & 0 & 4 & 4 & 8 & 9 & 0.2 & 0.7 & C & ad & conf & hy & 2 \\
\hline
\end{tabular}




\begin{tabular}{|c|c|c|c|c|c|c|c|c|c|c|c|c|c|c|c|c|c|}
\hline \multirow[b]{2}{*}{ Flooding impact } & \multicolumn{3}{|c|}{ Co \& N. S. May } & \multicolumn{3}{|c|}{ Ex July } & \multicolumn{3}{|c|}{ Co July } & \multicolumn{3}{|c|}{ N. S. after July } & \multirow{2}{*}{$\begin{array}{l}\text { Type } \\
\text { of } \\
\text { spatio- } \\
\text { tem- } \\
\text { poral } \\
\text { distri- } \\
\text { bution }\end{array}$} & \multicolumn{3}{|c|}{$\begin{array}{l}\text { Ecological } \\
\text { characteristics }\end{array}$} & \multirow{2}{*}{$\begin{array}{l}\text { Adap- } \\
\text { tation } \\
\text { to inun- } \\
\text { dation }\end{array}$} \\
\hline & $\mathrm{H}$ & M & $\mathrm{L}$ & $\mathrm{H}$ & M & $\mathrm{L}$ & $\mathrm{H}$ & M & $\mathrm{L}$ & $\mathrm{H}$ & M & $\mathrm{L}$ & & Ow & Fl & Нp & \\
\hline $\begin{array}{l}\text { Poecilus } \\
\text { versicolor } \\
\text { Pterostichus }\end{array}$ & 20 & 0 & 31 & 0 & 0 & 0 & 4 & 1 & 2 & 4 & 0.2 & 0.7 & C & ad & conf & hy & $1 \& 2$ \\
\hline $\begin{array}{l}\text { anthracinus } \\
\text { Amara }\end{array}$ & 8 & 12 & 2 & 2 & 10 & 0 & 8 & 45 & 1 & 0.9 & 18 & 2 & $\mathbf{C}$ & $\mathrm{ad}$ & conf & hy & 2 \\
\hline $\begin{array}{l}\text { plebeja } \\
\text { Calathus }\end{array}$ & 0 & 0 & 0 & 0 & 0 & 0 & 0 & 0 & 0 & 1 & 0 & 0 & D & juv & conf & eu & 2 \\
\hline $\begin{array}{l}\text { fuscipes } \\
\text { Calathus }\end{array}$ & 0 & 0 & 0 & 0 & 0 & 0 & 0 & 0 & 0 & 2 & 0 & 0 & D & juv & unli & xe & 2 \\
\hline $\begin{array}{l}\text { melanocephalus } \\
\text { Patrobus }\end{array}$ & 0 & 0 & 0 & 0 & 0 & 0 & 0 & 0 & 0 & 2 & 0 & 0.2 & D & juv & conf & xe & 2 \\
\hline $\begin{array}{l}\text { atrorufus } \\
\text { Pterostichus }\end{array}$ & 0 & 0 & 0 & 0 & 0 & 0 & 0 & 0 & 0 & 0 & 0.7 & 0 & D & juv & unli & hy & 1 \\
\hline $\begin{array}{l}\text { niger } \\
\text { Trechus }\end{array}$ & 0 & 0 & 0 & 0 & 0 & 0 & 0 & 0 & 0 & 0.7 & 0 & 0.3 & D & d.s. & conf & hy & 2 \\
\hline obtusus & 0 & 0 & 0 & 0 & 0 & 0 & 0 & 0 & 0 & 0 & 0 & 0.7 & D & juv & conf & hy & 2 \\
\hline
\end{tabular}

Sampling sites

$\mathrm{Co}=$ Control plots

$\mathrm{Ex}=$ Exclosure tents

N.S. $=$ Nearby sites

Flooding impact

$\mathrm{H}=$ High

$\mathrm{M}=$ Medium

$\mathrm{L}=$ Low

Type of spatiotemporal distribution

$\mathrm{A}=$ Exclosure tents July (but not sampled in May)

$\mathrm{B}=$ Control plots July (but not May nor exclosure tents in July)

$\mathrm{C}=$ Control plots and nearby sites in May

$\mathrm{D}=$ Nearby sites later than July

\section{Ecological characteristics}

$\mathrm{Ow}=$ Overwintering stage

$$
\begin{aligned}
& \text { Egg = egg } \\
& \text { juv = juvenile } / \text { larvae } \\
& \text { ad = adult } \\
& \text { d.s. = different stages } \\
& \text { unce = uncertain }
\end{aligned}
$$

$\mathrm{Fl}=$ Capability of flight or ballooning

Conf $=$ confirmed

unli $=$ unlikely

unce $=$ uncertain

$\mathrm{Hp}=$ Habitat preference

$$
\begin{aligned}
& \text { Hy }=\text { hygrophilous species of open habitats } \\
& \text { eu }=\text { euryhygric species of open habitats } \\
& \text { xe }=\text { xerophilous species of open habitats } \\
& \text { fo }=\text { forest species } \\
& \text { unce = uncertain }
\end{aligned}
$$

Adaptation to inundation

$1=$ Submersion tolerance (may additionally include immigration to an unknown extent)

$2=$ Immigration

unce $=$ uncertain 


\section{Appendix 4}

\section{Impact of mowing on the suitability of grassland as habitat of corncrakes (Crex crex) in the Lower Oder Valley National Park}

(Data from and written by Peter Just, Institute of Geography, Landscape Ecology Group, Goldschmidtstr. 5, 37077 Göttingen)

\section{Introduction}

The corncrake (Crex crex L.) is a bird species, a rail (Gruiformes: Rallidae), that is considered under threat of global extinction (Groombridge 1994). The birds return in late April and early May from the south and southeast of Africa and start breeding on the ground of marshland, hay and silage meadows and other tall vegetation in Central Europe in the middle of May (Glutz von Blotzheim et al. 1973). The world-wide population has been estimated as 1.5 million individuals in 1997 (Green et al. 1997). Losses of nests, chicks and adults occur during the mowing of meadows. Former studies indicate that the mechanisation of agriculture, mowing earlier in the year and loss of habitats with tall vegetation are causes of the decline (Green 1996). With the process of mechanisation in agriculture, especially in western Europe, the corncrake population has been decreasing for more than a century (Cadbury 1980). The bird has its centre of distribution in Europe. In Germany the population consists of less than 3000 individuals (Green et al. 1997) having its greatest population with 100-300 individuals in the Lower Oder Valley National Park. As the species is categorised as critically endangered in the Red List of Germany (Witt et al. 1998) as well as in the Red List of Brandenburg (Dürr et al. 1997), Germany has a certain responsibility for the conservation of this species. Hence, it is necessary to investigate corncrake's habitat requirements to enable successful conservation programs. The bird species comply in a special way with the criterions for target species, proposed by Mühlenberg and Hovestadt (1992) and Vogel et al. (1996):

- the species is threatened with global, nationwide and local extinction (Schäffer and Münch 1993, Fischer et al. 1999).

- the threat of extinction is founded in changing landscapes, not in direct persecution by humans (Green and Stowe 1993).

- the species has its main breeding area in Europe (Glutz von Blotzheim et al. 1973).

- corncrakes are habitat specialists, who are bound by special environmental conditions (Schaefer 2002, personal notification).

- corncrakes have a great home range (Stowe and Hudson 1991, Schäffer and Münch 1993, Helmecke 2000), so they may be considered as an umbrella species. 
The hypothesis of this study is that the non use of grassland, as proposed for wide areas in the national park, will have negative impact on the suitability of grassland as corncrakes' habitat. The impact of land use changes in floodplain grassland on the suitability of the corncrakes' habitat was investigated. Additionally, two further questions have to be answered:

- What are the main factors for the colonisation of meadows by corncrakes in May ?

- What are the main factors for the establishment of corncrakes in June ?

\section{Methods}

The places of singing corncrakes in the national park have been counted and marked in maps since 1994 by regional ornithologists. In May 2002, the structure of vegetation was determined in 58 plots $\left(1 \mathrm{~m}^{2}\right)$ in 36 territories of corncrakes, and in 45 plots $\left(1 \mathrm{~m}^{2}\right)$ in the dominant grassland associations of the national park, five in each vegetation unit. In the middle of June, the same variables were estimated in 58 plots in 53 territories of corncrakes and 50 plots in 10 plant associations. The 15 variables were:

- height of vegetation

- total cover

- height and cover of the upper, middle and lower strata of grassland

- height and cover of dead phytomass

- proportion of grass and herbs in the upper, middle and lower strata

- penetrability

- land use

Height of vegetation was defined as the height of a line on a table $\left(1 \times 1.5 \mathrm{~m}^{2}\right)$, upstanding in the grassland, which was more than $1 / 3$ covered by plants, seen from a distance of $5 \mathrm{~m}$ and a height of $1.75 \mathrm{~m}$. Cover was estimated as a percentage. The height of strata was defined as the centre of strata in $\mathrm{cm}$ above ground.

Penetrability was acquired by the resistance the vegetation offered to an effortless swinging foot in a 6 - ary ordinary scale, by the author. Land use has been mapped since the strictly protected areas in the national park were founded in 1996, in three categories: meadow, fallow and willow.

The data were analysed by stepwise multiple logistic regression. Logistic regression methods are useful in the analysis of relationships between a response variable and one or more explanatory variables and allows the use of metric and categorical scaled variables (Hosmer and Lemeshow 2000, Kleyer et al. 1999/2000). Binary logistic regression predicts the probability of occurrence of a dichotomy response variable as a function of one or more independent variables. Thus, it can be used to predict the probability of occurrence of a species as a function of environmental variables. The probability of occurrence of a species can be interpreted as the suitability of defined areas as a habitat (Schröder 2000). The comparison of regression coefficient of significant standardised variables gives insight into the relative importance of environmental variables as habitat 
parameters (Peeters and Gardeniers 1998). The backstep variation of logistic regression takes stepwise variables out, as long as there is no more significant debasement of the model (Schröder 2000). In statistical modelling of the species-habitat relationship, the binary response variable ( 1 or 0 ) is based on presence and absence observations of species in the field. In this study absence was defined as plots where there was no singing male within a range of $200 \mathrm{~m}$. Presence and absence can be defined as a species-specific parameter, so that additionally the abundance of small species can be defined as a dependent variable (Kleyer et al. 1999/2000).

\section{Results}

Figure 45 shows the development of the number of corncrakes within the polder including the highest density of corncrakes, in comparison to the number of individuals within the core zone.

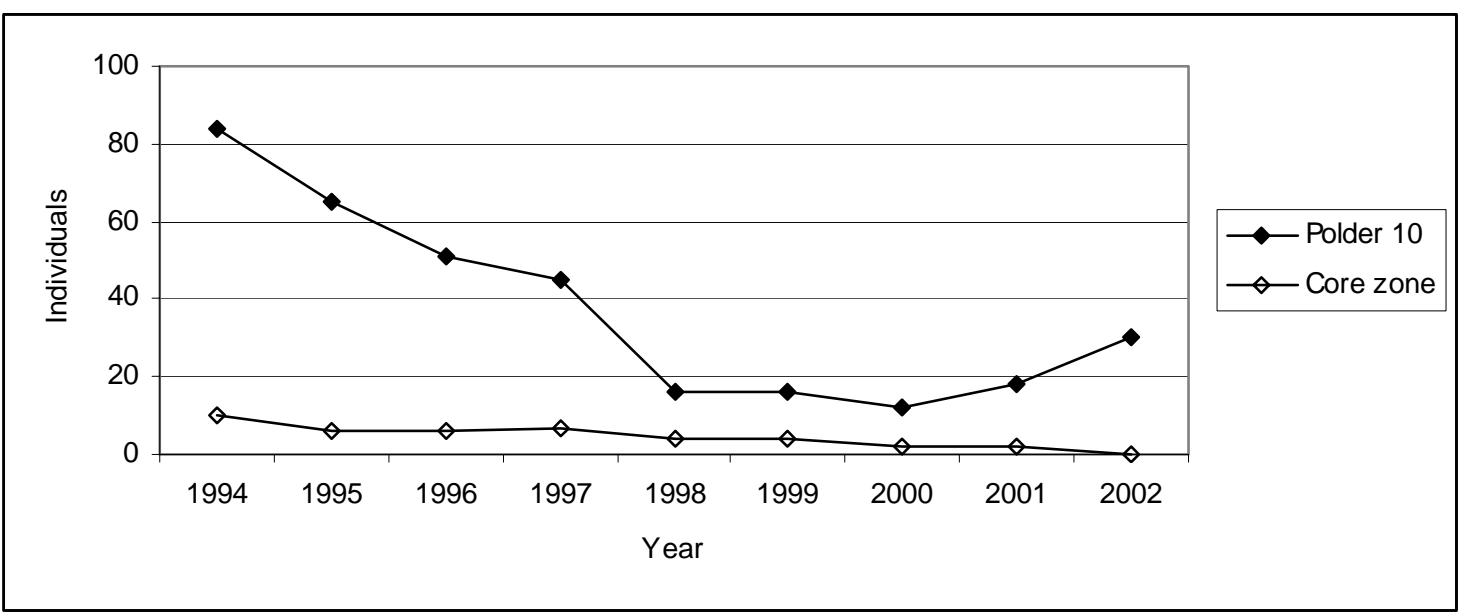

Fig. 45: Number of singing males in polder 10 and in the core zone

The core zone, untouched since 1995, has a range of 200 ha within the polder with a range of 1800 ha in total. It is shown that the number of corncrakes in the core zone has decreased since 1997. Since 2000, there were scarcely any, and in 2002 there were no more corncrakes, whereas the number of birds in polder 10 in-creased after a long period of depression in the last three years from 12 to 30 individuals. In sum, there is great variability in the number of individuals of corncrakes in the national park.

What are the main factors for the colonisation of grassland in the study area by corncrakes?

The significant $(\mathrm{p}=0.05)$ of the 15 standardised variables acquired in the middle of May, analysed by binary logistic regression: "cover of upper strata" and "height of upper strata". These two variables were analysed by backstep multiple logistic regression (Table 23). 
Table 23: Variables in equation after backstep logistic multiple regression including the standardised significant variables acquired in mid May $(\mathrm{p}=0.10)$

\begin{tabular}{lccc}
\hline Variables & Regression coefficient (ß) & Standard deviation & Significance \\
\hline Height of upper strata & 3.729 & 0.793 & 0.000 \\
Cover of upper strata & 1.150 & 0.342 & 0.001 \\
Constant & 0.177 & 0.304 & 0.560 \\
\hline
\end{tabular}

Table 23 shows that the variable "height of the upper strata" affects the strongest impact on the distribution of corncrakes in the middle of May. Additionally, the variable "cover of the upper strata" significantly separates between the presence and absence. A regression model with these two variables predicts $86.1 \%$ of presence and absence. The regression model reaches a Nagelkerkes $\mathrm{R}^{2}$, of 0.643 and a -2 Log Likelihood of 78.448 .

These two variables, i.e. height and cover of the upper strata of grassland, were the most impacting variables in the structure of vegetation for the establishment of singing males in May, when they try to attract females with their loud and buzzing shouting at night.

In the middle of June the same statistical method containing the same variables, leads to very different results: Nine variables significantly $(\mathrm{p}=0.05)$ separate between the presence and absence of corncrakes in the study area:

- height of vegetation

- total cover

- cover of the lower strata

- height of dead phytomass

- cover of dead phytomass

- proportion of herbs in total

- proportion of herbs in the middle strata

- proportion of herbs in the lower strata

- land use

The backstep multiple logistic regression leads to a more complex regression model (Table 24). Three variables: "cover of the lower strata", "proportion of herbs in total" and "land use" were let out, in three steps. 
Table 24: Variables in equation after backstep logistic multiple regression including variables acquired in the middle of June $(p=0.10)$

\begin{tabular}{|c|c|c|c|}
\hline Variables & $\begin{array}{c}\text { Regression } \\
\text { coefficient }(ß)\end{array}$ & $\begin{array}{l}\text { Standard } \\
\text { deviation }\end{array}$ & Significance \\
\hline Total cover & 0.689 & 0.333 & 0.039 \\
\hline $\begin{array}{l}\text { Height of dead } \\
\text { phytomass }\end{array}$ & 0.654 & 0.437 & 0.134 \\
\hline $\begin{array}{l}\text { Cover of dead } \\
\text { phytomass }\end{array}$ & -1.557 & 0.461 & 0.001 \\
\hline $\begin{array}{l}\text { Proportion of herbs } \\
\text { in the middle strata }\end{array}$ & -0.789 & 0.291 & 0.007 \\
\hline $\begin{array}{l}\text { Proportion of herbs } \\
\text { in the lower strata }\end{array}$ & 1.060 & 0.335 & 0.002 \\
\hline Height of vegetation & -0.528 & 0.277 & 0.056 \\
\hline Constant & 0.168 & 0.254 & 0.507 \\
\hline
\end{tabular}

In the middle of June the variable "cover of dead phytomass" $(\beta=-1.557)$ has the strongest impact on the distribution of corncrakes in June. Additionally, the variables "proportion of herbs in the lower strata" $(\beta=1.060)$, "proportion of herbs in the middle strata" ( $(=-0.789)$, "total cover" $(\beta=0.689)$, "height of dead phytomass" $(\beta=0.654)$ and "height of vegetation" $(\beta=-0.528)$ affects the distribution of corncrakes in the Lower Oder Valley in June. The regression model with these six variables predicts $69.9 \%$ of the corncrakes and Nagelkerkes $\mathrm{R}^{2}$ amounts to 0.473 , the $-2 \log$ Likelihood a value of 98.676 .

\section{Discussion}

In May the height and the cover of the upper strata were the significant variables separating between the presence and absence of corncrakes. Another backstep logistic regression analysis, only using metric scaled independent variables (not the categorial scaled variable "land use") confirms this result. The significant variables with the highest regression coefficient were "height of the upper strata" $(\beta=4.743)$, "cover of the upper strata" $(\beta=1.873)$, "total cover" $(\beta=1.729)$ and "height of the lower strata" $(\beta=$ 1.019). So the height and the cover of grassland were the main variables in the structure of vegetation for the habitat selection of corncrakes in the study area, after the return of the birds. The higher the meadows grow in the national park and the higher the cover of the meadows, the higher the probability of occurrence of corncrakes in May. The results of this study comply with the results of Schäffer (1997), who studied habitat selection of corncrakes in the Biebrza National Park in Eastern Poland. He found that in May the height and the cover of grassland vegetation are the determining factors for singing corncrakes. He detected a minimum height of grassland of $20 \mathrm{~cm}$ and a total cover of more than $50 \%$ to be suitable as habitat (Schäffer 1997). "An important feature of selected habitat, is that they are tall enough to provide cover" (Tyler 1996). In the northern part of the breeding range in western Scotland, corncrakes select stands of tall herbs like Urtica dioica or marsh vegetation Iris pseudacorus, Phragmites australis and 
Phalaris arundinacea as habitat in May and early June, because hay and silage meadows provide too little cover. Only when the height of grass exceeds about $20 \mathrm{~cm}$ in mid June, are the meadows used by corncrakes (Cadbury 1980).

Most parts of grassland within the national park exceed much more than $20 \mathrm{~cm}$ in height in mid May, so in particular, the dominant plant association Phalaridetum arundinaceae and Caricetum gracilis are suitable for the corncrakes. In mid May there are no indications in regression analysis that fallows in the core zone are less suitable for singing males than used meadows.

In mid June, there is the highest correlation between the variable "cover of dead phytomass" and the distribution of corncrakes $(\beta=-1.557)$. The lower the cover of dead phytomass, the higher the probability of the occurrence of corncrakes. The variable "total cover" $(\beta=0.689)$ indicates that certainly the grassland has to offer a high cover in June. For the other highly significant variables in the regression model: "proportion of herbs in the lower strata" ( $(=1.060)$ and "proportion of herbs in the middle strata" $(\beta=$ $-0.789)$ there are no indications in the literature on the ecology of corncrakes. Perhaps herbs in the lower strata offer less resistance to the birds than closely spaced blades of grass. Green et al. (1997) found that in most selected habitats of corncrakes, the annual production of plants is removed by mowing, grazing or winter floods. "Stands of dead grasses from previous years tend to be avoided" (Green et al 1997). Additionally, meadows where the grass is pushed to the ground by wind and rain are avoided because they are too difficult to penetrate (Schäffer 1997). In the Biebrza National Park, he observed no corncrakes in grassland where the meadows were too dense to be penetrated by an effortless swinging foot and where the resistance of grassland near the ground was higher than 20 Newton. The findings of Tyler (1996) confirm these results. "Another important feature of selected habitats is, that they are not so dense that they are difficult for the birds to walk through" (Tyler 1996). Schäffer (1997) presumes that closely spaced grasses in fertilised meadows may also be too dense to be penetrated by corncrakes.

With the growths of meadows in June, they become more dense and less penetrable. The cover of dead phytomass, as an indicator for fallow grassland, is the most correlated variable on the distribution of corncrakes in mid June. The higher the cover of dead phytomass, the lower the suitability of grassland as corncrakes' habitat. So, there is a great impact of mowing on the suitability of grassland of corncrakes in the Lower Oder Valley. The results shown in figure 1 presume that only after non use for more than four years does the cover of dead phytomass finally become too dense to be penetrated by corncrakes at all, and the fallows become totally unsuitable to be colonised by the species.

In a nutshell, in the study area we find a preference of used meadows adverse to fallows in June. Thus, nature conservation management on corncrakes as a target species has to include the mowing of the meadows. They have to be mown to inhibit the accumulation of dead phytomass (Green and Stowe 1993) and the date of mowing has to be considered. Corncrakes start to breed in mid May after the last egg is laid. The breeding takes 15-18 days. It takes until the end of July, until the chicks are able to fly, when the 
meadows are mown by fast and heavy machines. There will be almost no reproduction of the species if the meadows are mown earlier than the end of July. In Britain and Ireland the species was absent if the average date of mowing of hay meadows was earlier than late July (Green et al. 1997). In summary, in the parts of the floodplain where process conservation in form of fallows takes place, in a few years time there will be no suitable habitats for corncrakes.

One aim of the national park's development plan is that by $201050 \%$ of the national park's area will be declared as core zone. The core zone will be predominantly situated in the northern parts of the national park. Unfortunately, most corncrakes occur at present in the area of the future core zone. It is assumed that by creating new appropriate habitats by the help of management, the national park's corncrake population will accept and colonise the new suitable habitats. However, this raises the following questions: In the last few years, in these parts of the national park there were scarcely any corncrakes. Which parts of these areas are the most suitable and how are these areas to be managed to offer corncrakes optimal habitats and provide for the reproduction of the species? These questions will be answered in future by the development, application and validation of spatial explicit statistical habitat models (Kleyer et al.1999/2000, Schröder 2000) including further parameters like i.e. plant associations, soil moisture or the exact point in time when the meadows are used. 


\section{Appendix 5}

\section{Impact of flooding on the amphibian community}

(Data from and written by Kai Bentlage, Centre for Nature Conservation, Von-Siebold-Str. 2, 37075 Göttingen)

\section{Introduction}

The Lower Oder Valley National Park is one of the last remaining floodplains in Central Europe. With its numerous collections of different waterbodies in form of old river arms, ditches, ponds, pools and puddles, it represents suitable habitats for many amphibian species present in Germany. The different requirements of the fourteen species of Anura resident in Germany, are given in the different natural landscape structures in the more than 10,000 hectare large area. As already mentioned in the description of the study area, there are two different polder systems in the national park which are different with regard to the regulation of the flooding taking place. One is exposed to flooding until the middle of April, the other is excluded from flooding the whole year. The aim of the work was to investigate the occurrence of amphibians and their dominance structures in the polder area of the national park. A special interest applied here for the comparative view between waterbodies in the "dry" and the "wet polder". The work was mainly based on the following hypothesis: The different management measures in the polder system, which lead to different flooding conditions, affect the community of the amphibians which are highly dependent on water regimes. This takes place in a specific way corresponding to the preferences of each amphibian species. In order to be able to represent the differences between the "dry" and the "wet polder" on the basis of the occurrence of amphibians, a defined number of waterbodies was examined in two areas of the national park and the frequency of amphibians occurring there, was determined. On this basis, statements about the effects of flooding, concerning amphibians could be made. Future planning, which concern the flooding and the water management in the polder system, can be judged on the basis of the investigations in an amphibianspecific manner.

\section{Materials and Methods}

\section{Study area}

The area of investigation, with a total of 24 examined waterbodies, is limited to two ranges of the national park. The investigation area "A", the so-called "dry polder" (Lunow-Stolper Polder), lies in the southern part of the Lower Oder Valley. The investigation area "B", the so-called "wet polder" (Criewener Polder - Polder A), is subjected to an artificial flooding regime. Gates, which are opened between the middle of November and the middle of April, lead to a direct contact with the river Oder and the high level water in the flooded polder. When closed in April, the polder area becomes drained. 


\section{Selection of the waterbodies}

Twelve waterbodies in the "wet" and twelve waterbodies in the "dry polder" were selected. In each case, five were permanent waterbodies, four were temporary waterbodies and three were ditch-sections of $100 \mathrm{~m}$ length. The selection of waterbodies took place on the basis of coincidental criteria and a comparability of the study areas in "wet" and "dry polder" was given.

\section{Times of data acquisition}

Each of the 24 waterbodies was examined nine times in total between May and September 2002. The investigation of all waterbodies took place in regular time blocks fourteen days apart. Each one was examined at different times during the day and night.

\section{Mapping of adults and juveniles}

To take stock of the amphibians existing in the study area, each waterbody was orbited for 30 minutes by foot and all adult and juvenile amphibians were caught and determined. Searching took place water-near, within a radius of 25 meters distance to the edge of the water. Moreover the calling activities of adult male frogs in the water were examined. On the basis of the calling males, the place of residence of the frogs in the water was determined and registered. Both male and female frogs were registered and visually estimated. The registered individual numbers referred therefore not to the calling males, but to the visually detectable frogs. The occurrence of juvenile froglets was taken up and rated as reproduction proof at the specific waterbody. Only freshly metamorphosed froglets were regarded and defined as juveniles.

\section{Mapping of larvae}

The occurrence of larvae (tadpoles) of different amphibian species and their frequencies were determined on the basis of dipnetting. Four catches were performed at four different places in each waterbody. Generally, the selection of the catching-places took place on the basis of five selected vegetation structure zones. The catching took place both at the edge and within the waterbody and also near the surface and in up to $1 \mathrm{~m}$ depth. The determination of the amphibian larvae was made directly after the catch in the field. The determination of the larvae of Rana temporaria L. and R. arvalis Nilss. was made on the basis of the different morphology of their mouthparts. A distinction of the larvae of $R$. ridibunda Pall. and $R$. kl. esculenta L. was not possible in the field, so all larvae of these species were taken up as larvae of the water frog complex.

\section{Water frog complex}

The so-called water frog complex consists of three species of Central European green frogs. Berger (1967) discovered that Rana kl. esculenta is a hybrid form, which appears after the crossing of two other species of water frogs, $R$. ridibunda and $R$. lessonae Cam. (Eikhorst and Rahmel 1986). Nearly all water frog populations occurring in Germany consist of mixed populations of $R$. kl. esculenta and R. ridibunda or of $R$. kl. es- 
culenta and R. lessonae. An occurrence of all three species of water frogs together is rare (Günther 1990, Plötner 2001). Due to the morphological similarity of water frogs, which can be differentiated only with difficulty (Eikhorst 1984), they were not separately regarded, but designated as the water frog complex (RID/ESC). The composition of the water frog complex in different parts of the national park, was investigated in a separate study (Ogielska personal notification): a large sample of frogs was caught over a two night period and identified.

\section{Results}

In the study area, the polder system of the Lower Oder Valley National Park, a total of eight species of amphibians could be found as adults, juveniles or tadpoles. Three of these species were found in the area of the "wet polder" and seven were found in the area of the "dry polder". From the adult frogs found in the "dry polder", only individuals of $R$. ridibunda (lake frog), $R$. kl. esculenta (edible frog), $R$. arvalis (moorfrog) and Bufo bufo (L.) (common toad) could be found in larger individual amounts. Bombina bombina (L.) (fire-bellied toad) and Hyla aborea (L.) (European tree frog) could only be found as isolated adults or, in case of the R. temporaria (common frog) only as tadpoles. Juvenile froglets of the following species could be proven: the common toad, the moorfrog, the common frog and the frogs of the water frog complex (Table 25).

Table 25: The occurrence of amphibian species in the polder system of the Lower Oder Valley National Park and the frequency of adult and (in brackets) larval individuals; $x$ : occurrence of juveniles. The numbers shown refer to the total number of individuals found during the eight or nine (larvae) investigations.

\begin{tabular}{lll}
\hline Species & Wet polder & Dry polder \\
\hline $\begin{array}{l}\text { R. ridibunda and } R . k l . \\
\text { esculenta }\end{array}$ & $2663(970) \mathrm{x}$ & $1917(304) \mathrm{x}$ \\
R. arvalis & $0(0)$ & $209(403) \mathrm{x}$ \\
R. temporaria & $0(0)$ & $0(47) \mathrm{x}$ \\
B. bufo & $0(0)$ & $27(167) \mathrm{x}$ \\
B. bombina & $0(0)$ & $3(0)$ \\
H. aborea & $0(0)$ & $1(0)$ \\
$P$. fuscus & $1(0)$ & $0(0)$ \\
Number of species & 3 & 7 \\
\hline
\end{tabular}

The frogs of the water frog complex, both adults and tadpoles, were the only ones in the "wet polder" to be found in larger amounts. Together with one caught individual of Pelobates fuscus (Laur.) (common spadefoot) only these three species could be proven. Compared with the result of the caught adults and tadpoles, only juveniles of the water frog complex could be found. 
The dominance conditions of the seized adult frogs in the "wet" and "dry polder" are shown in Figures 46 and 47.

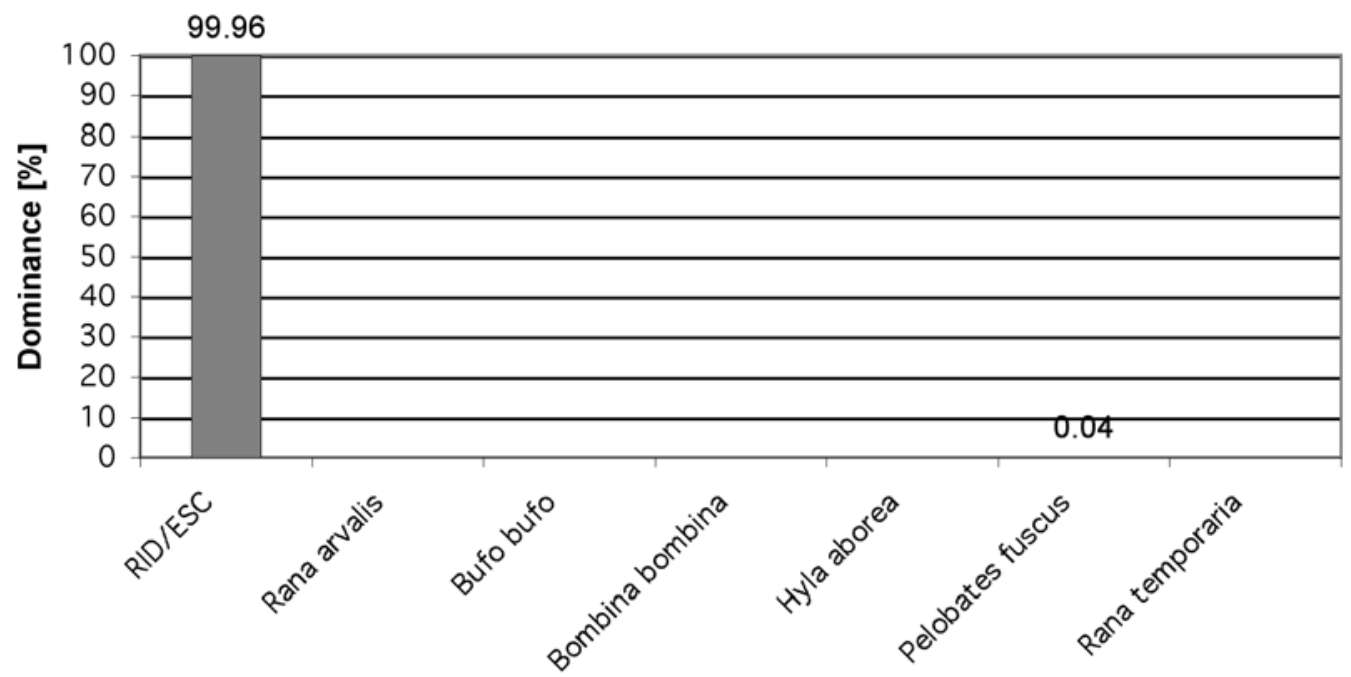

Fig 46: Dominance structure of adult amphibians found in the investigated waterbodies of the "wet polder" in the Lower Oder Valley National Park

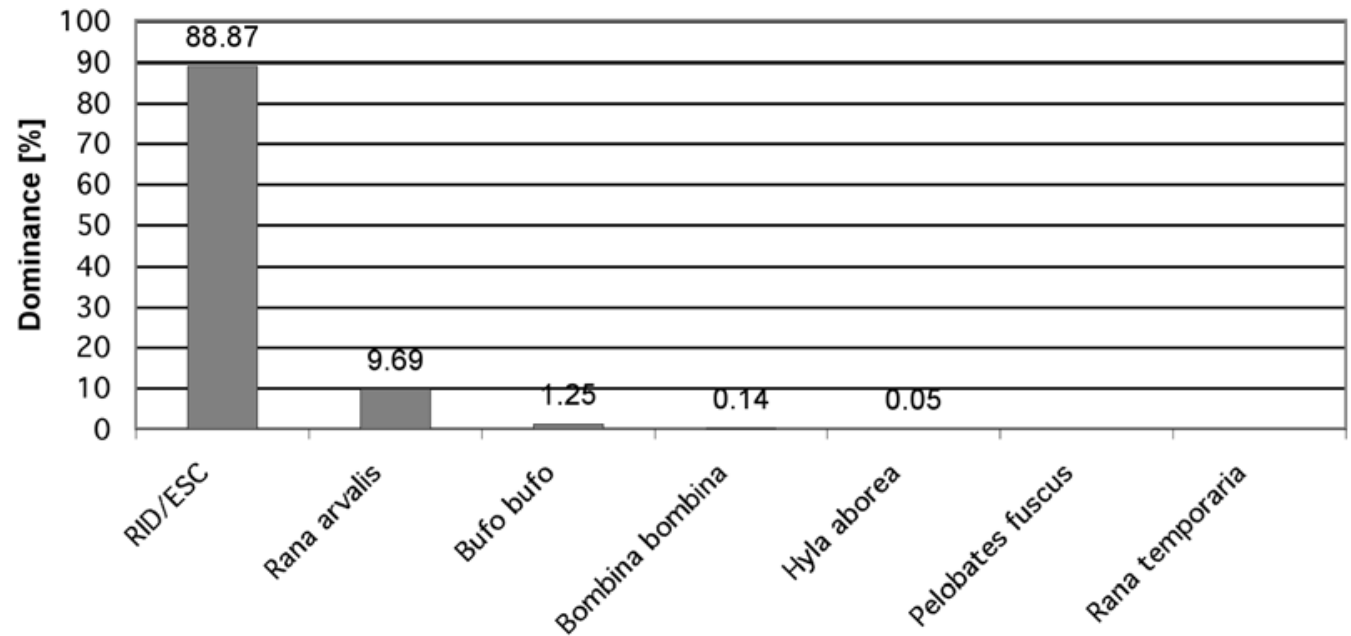

Fig. 47: Dominance structure of adult amphibians found in the investigated waterbodies of the "dry polder" in the Lower Oder Valley National Park.

In the "wet polder", the frogs of the water frog complex (RID/ESC) are the almost exclusively occurring species. With six species proven in the "dry polder", it exhibits a larger diversity of species than the "wet-polder". The species of the water frog complex and $R$ arvalis are called "dominant species" and thus "main species", while the other occurring species are classified as "recedent" and "sporadically" species (Engelmann 1978). 
In the case of the "wet polder", the occurrence of tadpoles is limited to the larvae of the water frog complex (RID/ESC). Other species cannot be proven in the waterbodies (Fig. 48 and 49). In the "dry polder", tadpoles of the species RID/ESC, R. arvalis, R. temporaria and $B$. bufo can be registered. $R$. arvalis is the "dominating" species, followed by the frogs of the water frog complex which are called "eudominant" and the species B. bufo and R. temporaria which are classified as dominant and subdominant (Engelmann 1978).

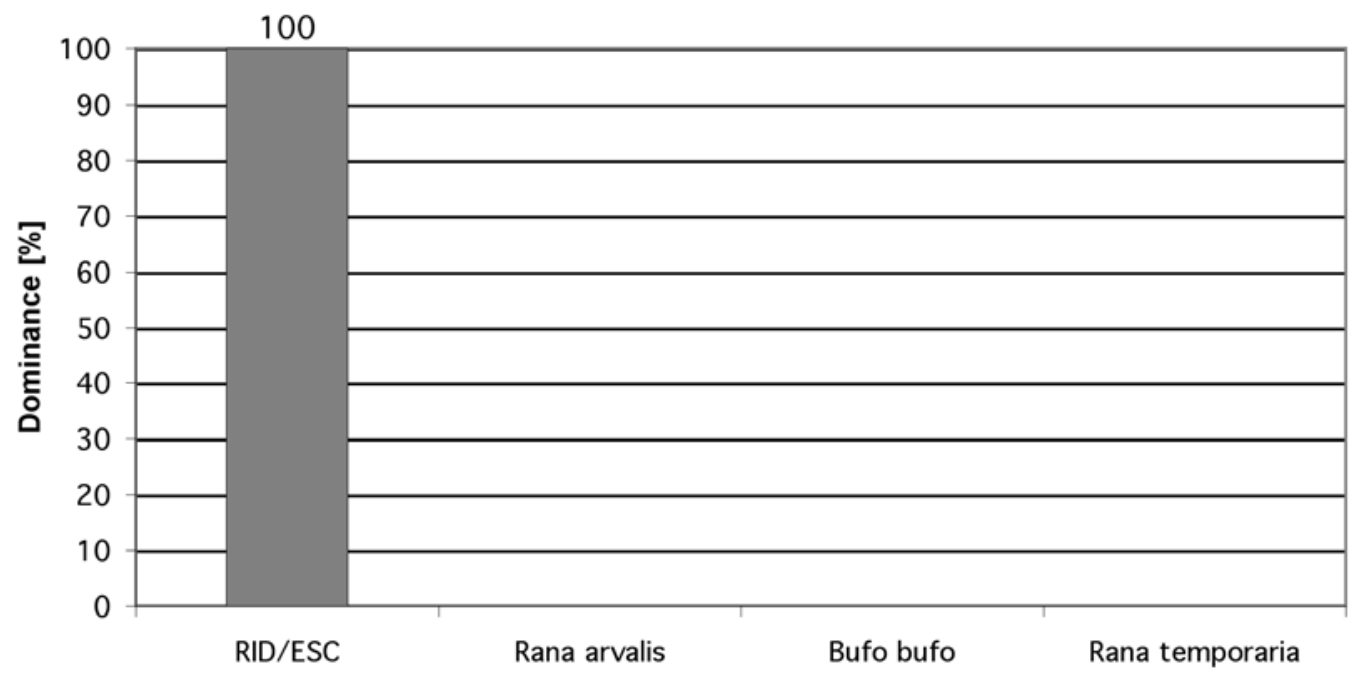

Fig. 48: Dominance structure of amphibian larvae in the waterbodies of the "wet polder" in the Lower Oder Valley National Park.

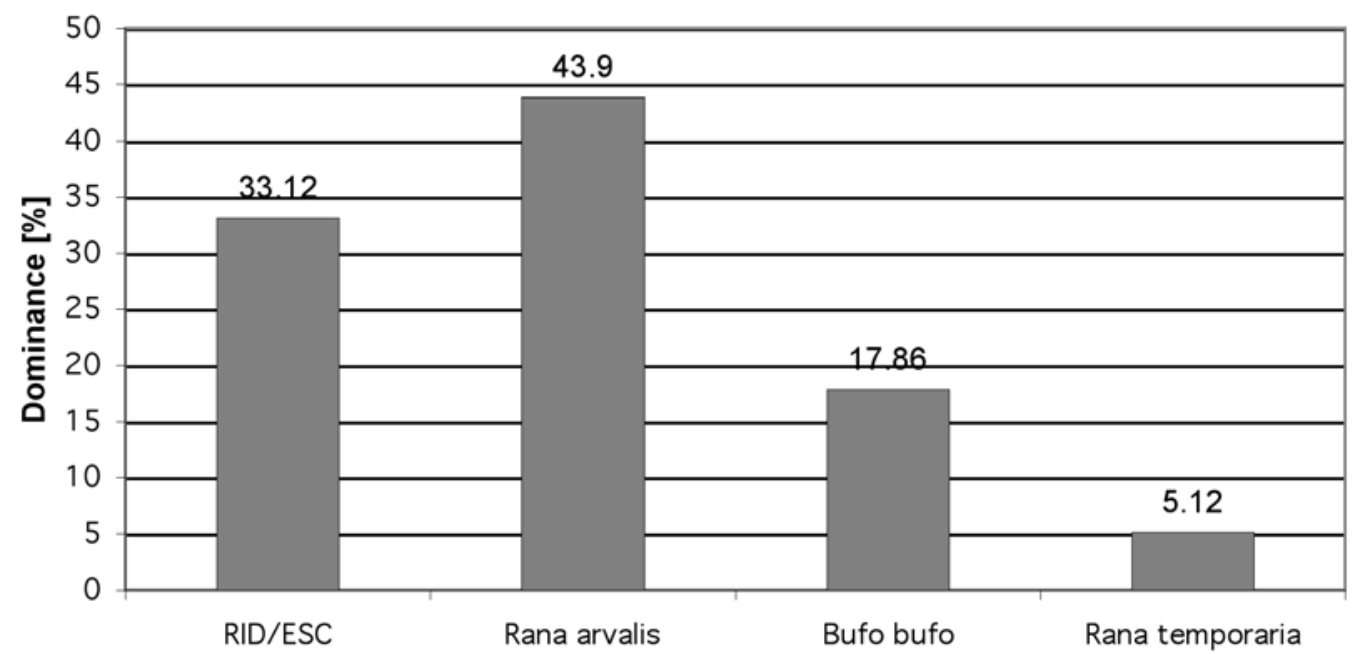

Fig. 49: Dominance structure of amphibian larvae in the waterbodies of the "dry polder" in the Lower Oder Valley National Park. 
The water frog complex population in the Lower Oder Valley consists of the lake frog $R$. ridibunda and the edible frog $R$. kl. esculenta. With a portion of $70 \%$ in the "dry polder" and $90 \%$ in the "wet polder", $R$. ridibunda is the dominant species in each area (Ogielska personal notification) (Fig. 50 and 51).

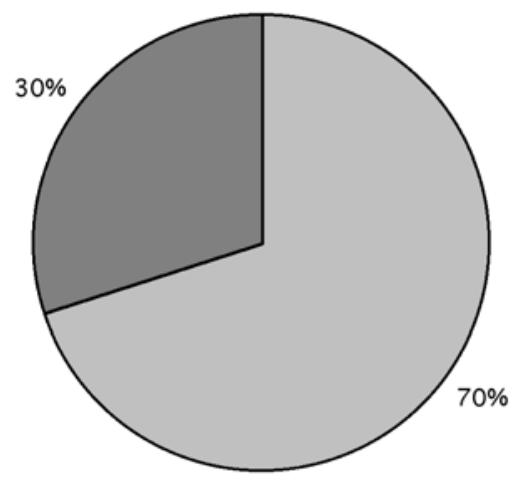

Rana ridibunda

Rana kl. esculenta

Fig. 50: Composition of the water frog complex of the "dry polder" in the Lower Oder Valley National Park $(n=20)$.

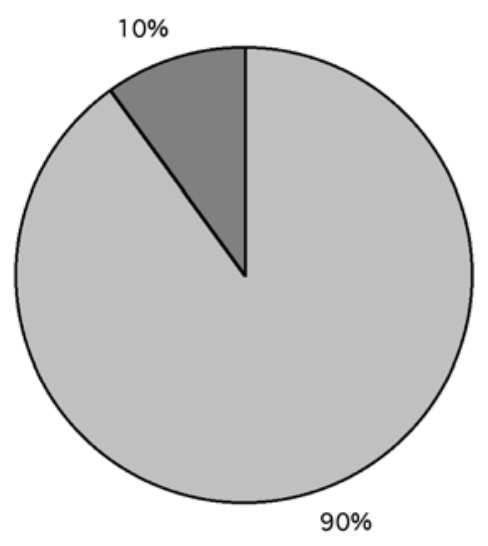

$\square$ Rana ridibunda

$\square$ Rana kl. esculenta

Fig. 51: Composition of the water frog complex of the "wet polder" in the Lower Oder Valley National Park $(n=39)$.

\section{Discussion}

With eight anuran species occurring in the polder system of the Lower Oder Valley, the national park represents a suitable habitat and reproduction area for many species of amphibians occurring in Germany (Blab 1986). Following further studies about this area, it can be assumed that there are still four further species of amphibians within parts of the national park and its direct environment. The following species could be found: B. viridis Laur., R. lessonae, Triturus vulgaris (L.) and T. cristatus (Laur.) 
(Mädlow and Adam 1998, Wilke 1995). This diversity of amphibian species in a closely limited area is rarely observed in Germany (Schmidtler and Gruber 1980).

Looking at the distribution of the amphibian species in the different areas of the national park, it becomes clear that the majority of the proven amphibians occur only within the smaller part of the "dry polder". Within the area of the national park which is affected by flooding (and constitutes its largest part), only the frogs of the water frog complex seem to appear.

After the flooding of the "wet polder", during which it appears in a sea-similar condition lasting until the middle of April, it is not possible for other species of amphibians (except the water frog complex) to find suitable places for hibernation in winter and waterbodies for reproduction in spring. While the frogs of the water frog complex have the possibility to hibernate under water (Günther 1996a, 1996b), the other occurring species of amphibians search for accommodation ashore (Nöllert and Nöllert 1992). These are underground, under stones or under leaves and wood structures (Blab 1986). Only the common frog is known to be able to hibernate under water as well (Schlüpmann and Günther 1996). The second reason for the absence of amphibian species in the "wet polder" is the absence of suitable waterbodies for breeding. They are firstly formed after the drainage of the flooded polder at the beginning of May. At this time, most of the amphibians have already begun to migrate to their breeding places. $R$. arvalis, R. temporaria, B. bufo have already passed the breeding period (Blab 1986). Thus, a possible hibernation in the dyke of the "wet polder" would not make the use of waterbodies as breeding places possible because the right time conditions are not met. For later breeding species like B. bombina and P. fuscus, a migration to the waterbodies would still lie in the phase of water running off the polder, which would lead to suboptimal conditions (Grosse 1994, Schneeweiß 1996). Water frogs start their mating period in May and mating can take place until July. In contrast to other amphibian species, they do not have the problem of a long distance migration and thus can find suitable waterbodies for breeding in the "wet polder" in their specified time period (Blab 1986, Günther 1996a, 1996b).

In the "dry polder" there are a lot of different types of waterbodies with a different structure and vegetation. In principle, the whole area offers the possibility for all proven amphibians to use it as a suitable habitat and for reproduction (Lindeiner 1994). The human influences, in form of the artificial lowering of the ground-water level and agricultural use, make it harder for some of the proven amphibians to develop larger populations. This concerns, above all, the two species B. bombina and $H$. aborea which are both threatened by extinction (Borgula 1995, Schneeweiß 1996). 


\section{Acknowledgements}

I would like to thank everyone who made this work possible.

I am particularly grateful to:

my academic teacher Prof. Dr. Matthias Schaefer, who offered a laboratory as well as scientific, logistic and financial support,

Prof. Dr. Ulrich Ehlers for writing the second expertise,

the administrational staff of the Lower Oder Valley National Park for permission to work on their sites and their manifold support,

the German Science Foundation (DFG) for making this study possible by supporting it with a grant,

Dr. Herbert Nickel for the invaluable information on Auchenorrhyncha, help in identifying plant- and leafhoppers, the many stimulating discussions, helpful comments on the manuscript, for good company in the office and in the field and for regularly providing me with tasty bread and "Apfelzimtbrötchen",

Dr. Sonja Migge for helpful discussions, for her support in solving miraculous statistical problems, her help in the field and numerous enjoyable chats,

Dr. Jürgen Schauermann, Christel Fischer, Ingrid Kleinhans and Dieter Nünchert who provided logistical or technical support,

Dr. Christian Platner and Axel Rothländer who answered a number of statistic related questions and confused me sometimes as well,

Klaus Dornieden for identifying the ground beetles and Alexander Sührig for checking spiders that were difficult to identify,

Ines Vollhard for reading and commenting on the manuscript,

Kai Bentlage, Peter Just, Dorota Kowalczyk, Hedje Lüssow and Katja Dietrich for the good company in the flat in Schwedt and their support in the field,

the colleagues from the graduate training program "Valuation and Conservation of Biodiversity" for helpful discussions throughout the working process and the numerous social events,

Tobias Hellenbroich, Johannes Klose, Petra Maass, Astrid Pelka and Swen Renner for relaxing hours in the "Mensa am Turm",

Monika Körner for sharing a room with me while we attended several congresses and for some great days at the sea,

Stephanie Kronenberg and Eva Stiemerling for moral support during endless hours on the phone,

the "Wegners" for offering hospitality during many relaxing weekends at the pool,

my brother Tobias Rothenbücher for compiling the maps, linguistic help and his patience,

Tom Wegner for stimulating discussions, helpful comments on the manuscript and his patience and manifold support.

Especially I want to thank my parents, Hans and Gisela Rothenbücher, who supported me in various ways throughout my studies. 


\section{Lebenslauf}

Persönliche Daten

Name

Geburtsdatum

Geburtsort

Nationalität

Familienstand

Schulbildung

$1981-1985$

1985-1994

Hochschulbildung

10/1994-07/2000

$09 / 1997-06 / 1998$

$10 / 2000-12 / 2004$
Judith Rothenbücher

20.01 .1975

Lahnstein

deutsch

ledig
Goetheschule (Grundschule) Lahnstein

Staatliches Gymnasium Lahnstein, Abschluss: Abitur

Studium der Biologie an der Friedrich-Wilhelms-Universität Bonn, Abschluss: Diplom

Thema der Diplomarbeit: Vergleichende Untersuchung der Carabidenfauna auf vegetationsarmen Insel- und Uferflächen am Mittelrhein

Auslandsaufenthalt, University of Aberdeen, Schottland

Doktorarbeit an der Georg-August-Universität, Göttingen bei Prof. Dr.

Matthias Schaefer

Thema: The impact of mowing and flooding on the diversity of arthropods in grassland habitats of the Lower Oder Valley National Park, Germany

Berufliche Tätigkeiten/

wissenschaftlicher

Werdegang

$10 / 2000-09 / 2003$

Stipendiatin im interdisziplinären DFG-Graduiertenkolleg „Wertschätzung und Erhaltung von Biodiversität"“

$04 / 2001-04 / 2004$

Arbeit als wissenschaftliche Hilfskraft am Institut für Zoologie, Anthropologie und Entwicklungsbiologie, Universität Göttingen

seit $05 / 2004$

wissenschaftliche Mitarbeiterin am Institut für Zoologie, Anthropologie und Entwicklungsbiologie, Universität Göttingen

z.Zt. angestellt im BMBF-Projekt „Förderschwerpunkt ,Zukunftsorientierte

Waldwirtschaft" - Verbundvorhaben einer integrierenden Ergebnissynthese " 